\title{
A History of the Welsh English Dialect in Fiction
}

\author{
Jones, Benjamin A.
}

How to cite:

Jones, Benjamin A. (2018) A History of the Welsh English Dialect in Fiction. Doctoral thesis, Swansea University. http://cronfa.swan.ac.uk/Record/cronfa44723

Use policy:

This item is brought to you by Swansea University. Any person downloading material is agreeing to abide by the terms of the repository licence: copies of full text items may be used or reproduced in any format or medium, without prior permission for personal research or study, educational or non-commercial purposes only. The copyright for any work remains with the original author unless otherwise specified. The full-text must not be sold in any format or medium without the formal permission of the copyright holder. Permission for multiple reproductions should be obtained from the original author.

Authors are personally responsible for adhering to copyright and publisher restrictions when uploading content to the repository.

Please link to the metadata record in the Swansea University repository, Cronfa (link given in the citation reference above.)

http://www.swansea.ac.uk/library/researchsupport/ris-support/ 


\section{A history of the Welsh English dialect in fiction Benjamin Alexander Jones}

Submitted to Swansea University in fulfilment of the requirements for the Degree of Doctor of Philosophy

Swansea University

2018 



\section{Summary}

The systematic study of language varieties in fictional texts have primarily focused upon written material. Recently, linguists have also added audio-visual genres to the analytic framework of literary dialect studies. Studies have traditionally examined writers' lexical, phonological, and grammatical output; contemporarily, research has begun examining metalinguistic commentaries and linguistic indexing of character stereotypes to this repertoire (Hodson, 2014).

Except for minor analysis of early texts (German, 2009), there has been no largescale investigation of any Welsh English dialect in fiction. This thesis addresses this gap, asking the fundamental question: throughout history, how has Welsh English been represented in fiction? The thesis surveys a large chronological scope covering material from the $12^{\text {th }}$ century until the present day across four narrative-genres: early writings and theatrical writing, novels, films, and, new to literary dialect studies, videogames. In doing so, a historical discussion forms that covers Welsh English's fictolinguistic output, cross-referencing its linguistic forms with recorded data, identifying forms hitherto unknown to dialectological surveys, and addressing metalinguistic and attitudinal stereotypes in fiction.

Key findings include that phonology was an early representational linguistic domain in the literary dialect, whilst lexical and grammatical domains became common from $19^{\text {th }}$ century literature onwards. The commonest phonological and lexical features were glottal fricative drops and tapped $/ \mathrm{r} /$; and the endearment terms ' $\mathrm{bach} / \mathrm{fach}$ ' and 'mam' respectively. Grammatically, 'Focus Fronting' and 'Demonstrative There' regularly occurred. Regarding linguistic evidence, several authors and filmmakers were prolific lay surveyors of the variety, adding to the historical dialectological record. Concerning dialectal attitudes, Elizabethan playwrights used linguistic stereotyping to create character stereotypes of Welsh people as 'comical'. By the $19^{\text {th }}$ century, fictive Welsh English representation was the dominion of native-users in literature, film, and videogames; however today, the Comic stereotype, and an emerging stereotype of Welsh English users being Fantastical, appears embedded within the dialect's representation. 



\section{DECLARATION}

This work has not previously been accepted in substance for any degree and is not being concurrently submitted in candidature for any degree.

Signed (candidate)

Date

\section{STATEMENT 1}

This thesis is the result of my own investigations, except where otherwise stated. Where correction services have been used, the extent and nature of the correction is clearly marked in a footnote(s).

Other sources are acknowledged by footnotes giving explicit references. A bibliography is appended.

Signed (candidate)

Date

\section{STATEMENT 2}

I hereby give consent for my thesis, if accepted, to be available for photocopying and for inter-library loan, and for the title and summary to be made available to outside organisations.

Signed (candidate)

Date

NB: Candidates on whose behalf a bar on access has been approved by the University (see Note 7), should use the following version of Statement 2 :

I hereby give consent for my thesis, if accepted, to be available for photocopying and for inter-library loans after expiry of a bar on access approved by the Swansea University.

Signed (candidate)

Date 



\section{Contents}

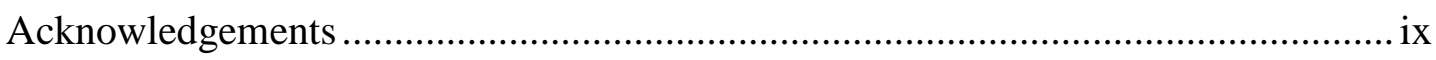

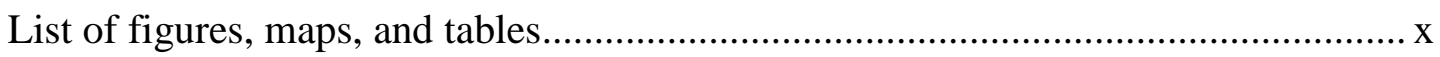

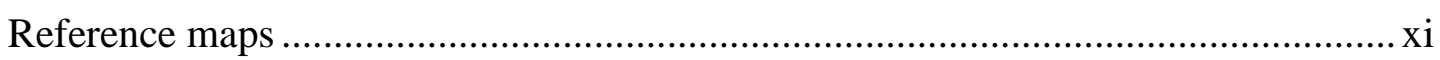

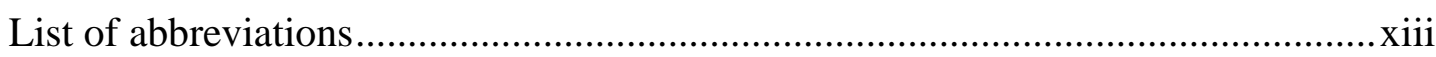

Broad transcription as used in text: Welsh English (WE) and Received Pronunciation

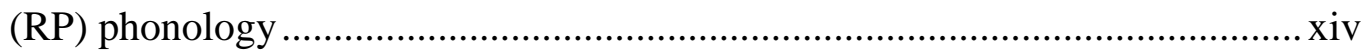

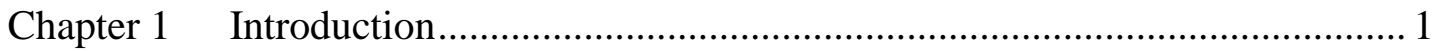

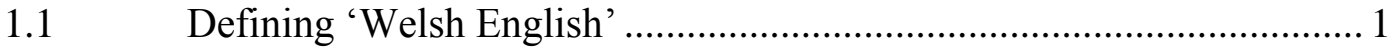

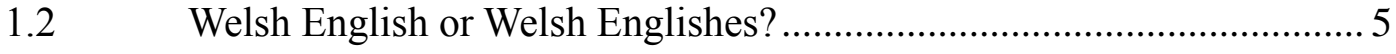

1.3 Studying Welsh English and thesis structure ........................................ 8

Chapter 2 A brief history of systematic Welsh English study ............................. 11

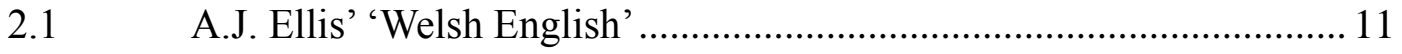

2.2 David Parry's Survey of Anglo-Welsh Dialects.................................. 15

2.3 Layman and non-specialist glossaries........................................... 17

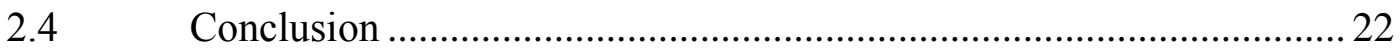

Chapter 3 The study of dialect in fictive texts................................................. 24

3.1 The linguistic field of Dialect in Literature/Film................................ 24

3.2 Literary dialect as linguistic evidence ........................................... 25

3.3 Authors' methods for representing dialect.......................................... 32

3.3.1 Representation of linguistic domains (lexis, grammar, phonology) ..... 32

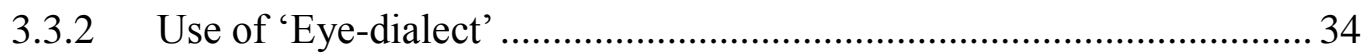

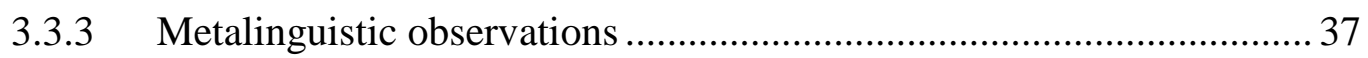

3.4 Example case studies: previous scholars' literary dialect studies......... 38

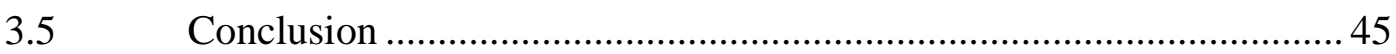

Chapter 4 Perceptions and attitudes towards language varieties, the Welsh English variety, and the Welsh cultural sphere ............................................................ 47

4.1 Dialectal discrimination and language ideologies ............................ 47

4.2 Dominance and subordinance of dialectal speakers in live-action and

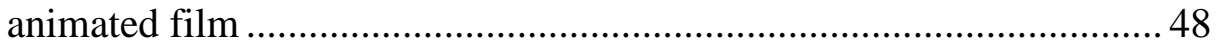

4.3 Insights from language attitude studies ......................................... 51

4.4 Analyses of Welsh English attitudes and perceptions - historic ........... 54

4.5 Analyses of Welsh English attitudes and perceptions - recent ..............56

4.6 Attitudes, perceptions, and stereotypes of Wales and the Welsh people

4.6.1 The Welsh as barbarians and uncultured ...........................................5 59

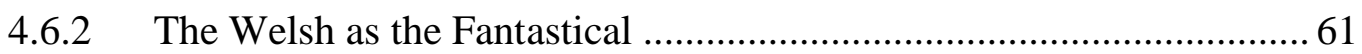




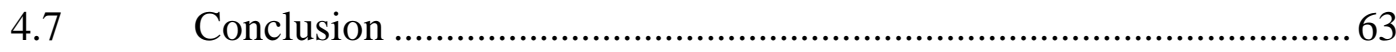

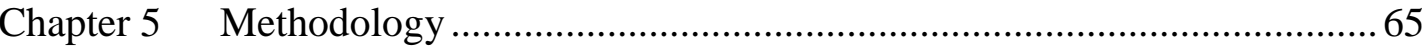

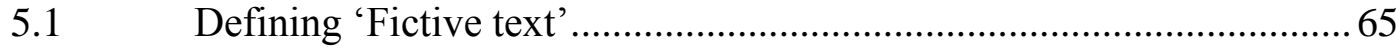

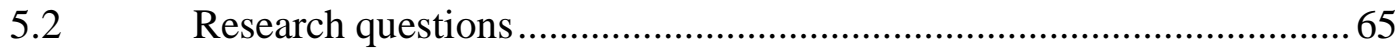

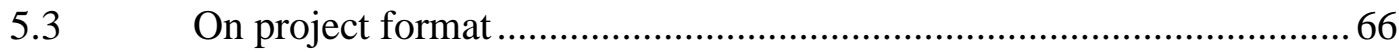

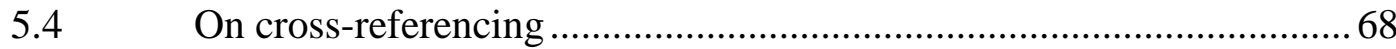

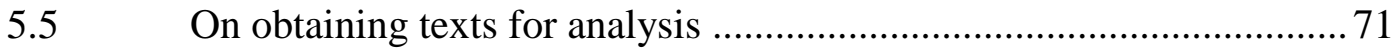

5.5.1 Obtaining early texts and theatrical Welsh English samples ............... 71

5.5.2 Obtaining Literary Welsh English samples ....................................... 72

5.5.3 Obtaining Filmic Welsh English samples ......................................... 72

5.5.4 Obtaining Videoludic Welsh English samples ................................. 73

Chapter 6 Representation of early Welsh English in Late Medieval texts,

Elizabethan plays, and early Anglo-Welsh poetry .......................................... 75

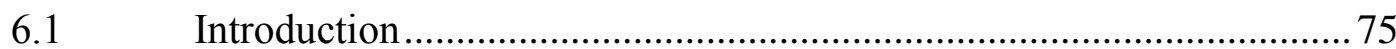

6.2 Early texts featuring Welsh English dialect ....................................... 76

6.2.1 Welsh and English within Marcher communities (1100s-1400s) ......... 76

6.2.2 Acknowledgement of Welsh English speakers (1480s-1550).............. 79

6.3 The Welsh English speaker in Early Modern Stage (1550-1618)......... 82

6.3.1 Shakespeare's Henry V (1599) and Merry Wives of Windsor (1597).... 84

6.3.2 Dekker's The Welsh Embassador (1597) and Patient Grissill (1600).. 89

6.3.3 Anonymous' Sir John Oldcastle (1600) .............................................. 91

6.3.4 Armin's Two Maids of More-Clacke (1609) ......................................... 92

6.3.5 Middleton's A Chaste maid in Cheap-side (1613) ............................... 93

6.3.6 Jonson's For the Honor of Wales (1618) ............................................. 95

6.4 Welsh English in Later theatrical plays................................................ 96

6.4.1 Later theatrical plays: Mid 1600s -1759 ........................................... 98

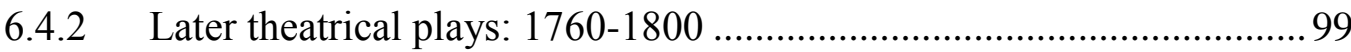

6.5 Welsh English in $19^{\text {th }}$ century Anglo-Welsh poetry ............................ 100

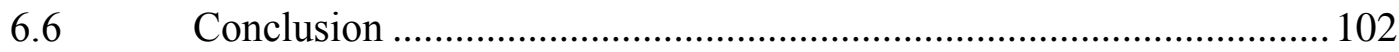

Chapter 7 Representation of Welsh English in $19^{\text {th }}, 20^{\text {th }} \& 21^{\text {st }}$ century novels.. 105

7.1 Introduction to 'Welsh writing in English' ....................................... 105

7.2 $19^{\text {th }}$ century novels and the 'Contact Story' ..................................... 109

7.2.1 Thomas J.L. Prichard's The Adventures and Vagaries of Twm Shon

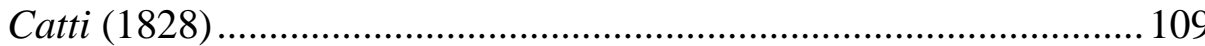

7.2.2 Owen Parry's (a.k.a. Ceredig) Among the Mountains (1870)............. 117

7.2.3 Amy Dillwyn's The Rebecca Rioter (1880) ..................................... 119

7.2.4 Allen Raine's Queen of the Rushes (1906) ........................................ 123 


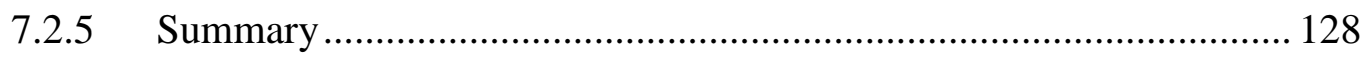

7.3 Early $20^{\text {th }}$ century novels and 'The First Flowering' .......................... 129

7.3.1 Caradoc Evans's My People (1915).................................................... 129

7.3.2 Margiad Evans's Country Dance (1932) ............................................ 136

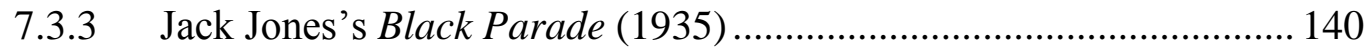

7.3.4 Geraint Goodwin's The Heyday in the Blood (1936) ......................... 143

7.3.5 Lewis Jones's Cwmardy (1937)....................................................... 151

7.3.6 Lynette Roberts's Village Dialect with Seven Stories (1944)............. 155

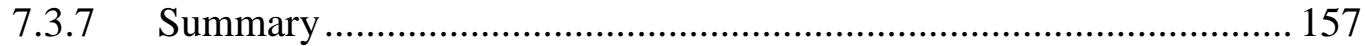

7.4 Late $20^{\text {th }}$ and early $21^{\text {st }}$ century novels and 'The Second Movement' 157

7.4.1 Dylan Thomas's Under Milk Wood (1954) ........................................ 158

7.4.2 Glyn Jones's Island of Apples (1965) .................................................. 161

7.4.3 Ron Berry's So Long Hector Bebb (1970)......................................... 169

7.4.4 Joe Dunthorne's Submarine (2008) .................................................. 174

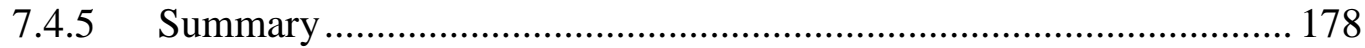

7.5 The use of Welsh English in late 20 $0^{\text {th }}$ century fantasy novels ............ 179

7.5.1 Alan Garner's The Owl Service (1967).............................................. 179

7.5.2 Dianna Wynne Jones's Howl's Moving Castle (1986) ........................ 181

7.5.3 Terry Pratchett's Soul Music (1995) ................................................... 182

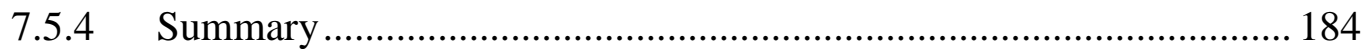

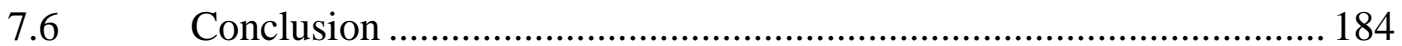

Chapter 8 Representation of Welsh English in $20^{\text {th }}$ century film......................... 188

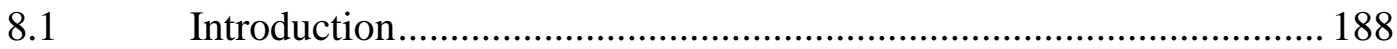

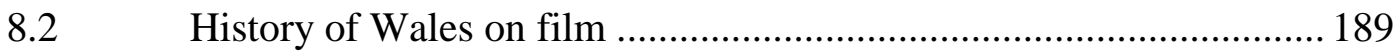

8.3 Welsh film around the early $20^{\text {th }}$ century: 1938-1949 …..................... 193

8.3.1 The Citadel (1938), Dir. King Vidor .................................................. 194

8.3.2 The Proud Valley (1940). Dir. Pen Tennyson. .................................... 197

8.3.3 How Green Was My Valley (1941). Dir. John Ford.............................. 200

8.3.4 Halfway House (1944). Dir. Basil Dearden.......................................... 203

8.3.5 A Run for Your Money (1949) Dir. Charles Frend............................... 205

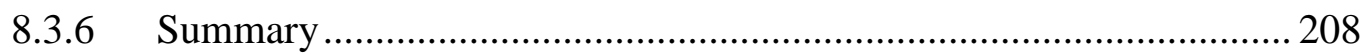

8.4 Welsh film around the mid-20 ${ }^{\text {th }}$ century: 1959-1967 ......................... 209

8.4.1 Tiger Bay (1959), Dir. J. Lee Thompson ........................................... 209

8.4.2 Only Two Can Play (1962), Dir. Sidney Gilliat ................................ 212

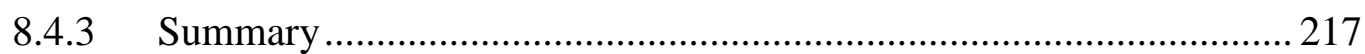

8.5 Welsh film around the late-20 ${ }^{\text {th }}$ century: $1987-1999 \ldots \ldots \ldots \ldots \ldots \ldots \ldots \ldots \ldots . . .217$ 
8.5.1 On the Black Hill (1987). Dir. Andrew Grieve

8.5.2 The Englishman Who Went Up a Hill and Came Down a Mountain (1995). Dir. Christopher Monger 221

8.5.3 Twin Town (1997). Dir. Kevin Allen ...............................................2225

8.5.4 House of America (1997) Dir. Marc Evans ........................................ 230

8.5.5 Human Traffic (1999) Dir. Justin Kerrigan ...................................... 233

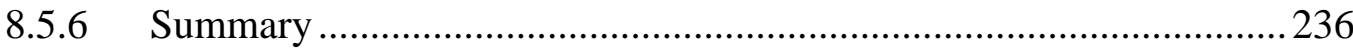

8.6 Welsh film from the millennium until present: 2005-2014 .............. 236

8.6.1 Big Font. Large Spacing (2009) Dir. Paul Howard Allen ................... 237

8.6.2 Hunky Dory (2011) Dir. Marc Evans ................................................... 238

8.6.3 PRIDE (2014) Dir. Matthew Warchus................................................. 241

8.6.4 Peter Jackson's The Hobbit (2014) .................................................... 243

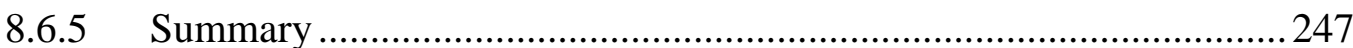

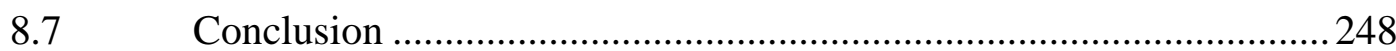

Chapter 9 Representation of Welsh English in $21^{\text {st }}$ century videogames ............ 251

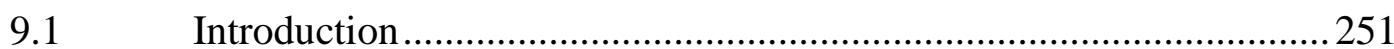

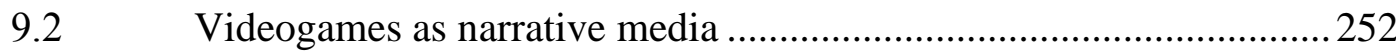

9.3 Welsh English In Fantasy Videogames .......................................... 258

9.3.1 The Elven 'Other': Welsh fairies, and Tolkien's 'Elf' ........................ 258

9.3.2 Fable III (2010), Lionhead studios ................................................... 260

9.3.3 Dragon Age II (2011), Bioware ....................................................... 263

9.3.4 Star Wars: The Old Republic (2011), Bioware................................... 267

9.3.5 Ni No Kuni: Wrath of the White Witch (2013), Level-5 .................... 271

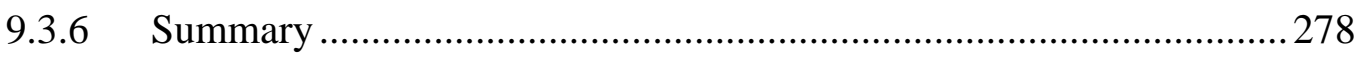

9.4 Welsh English in real-world videogames ......................................... 278

9.4.1 Timesplitters: Future Perfect (2005), Free-Radical-Design ............... 279

9.4.2 Red Dead Redemption (2010), Rockstar Games............................... 281

9.4.3 Assassin's Creed IV: Black Flag (2013), Ubisoft-Montreal............... 284

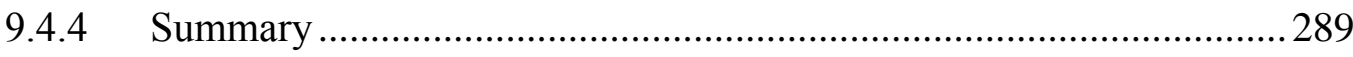

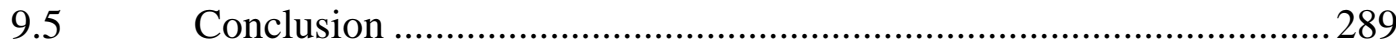

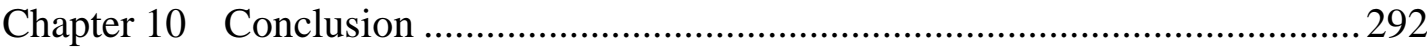

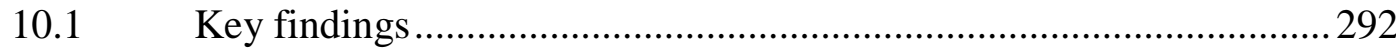

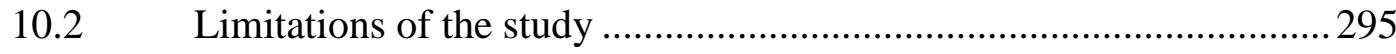

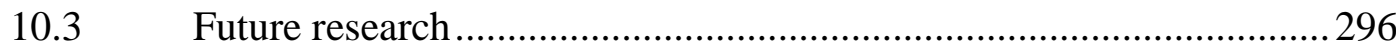

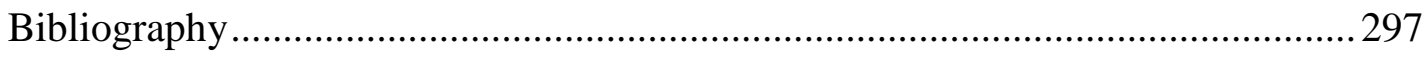




\section{$\underline{\text { Acknowledgements }}$}

It would not have been possible to undertake this thesis without the financial support of the James Pantyfedwen Foundation scholarship and Swansea University Postgraduate Research bursary, to which I am much indebted.

I would like to thank my supervisors, Dr. Rob Penhallurick and Dr. Vivienne Rogers, for not only their expert advice but also their patience in reading drafts and offering support of varying kinds. Many years ago, Rob suggested this very topic of linguistic inquiry, little did I know it would blossom into something so expansive as this thesis! Also, a thank you to everyone in Swansea University Applied Linguistics department who listened to my many linguistic queries surrounding this topic.

I'd also like to thank the scholars who have been kind enough to offer advice from other disciplinary backgrounds, such as literature studies, in particular those studying Welsh writing in English. Thanks to Prof. M Wynn Thomas (Swansea University), Dr. Kirsti Bohata (Swansea University) as well as Prof. Jane Aaron (University of South Wales) for their Welsh writing in English expertise.

A thank you also to all my good friends in the Arts and Humanities postgraduate community; and my parents, siblings and family - all of whom kept my enthusiasm for my research burning strongly throughout.

Finally, I would like to offer my thanks to my loving partner, Sofie. I couldn't have completed this work without you. 


\section{List of figures, maps, and tables}

\section{$\underline{\text { Figures }}$}

Figure 4.1: Enregistered merch: Cwtch (Supplied by author) ….............................58

Figure 8.1: Screenshot of Tiger Bay. Llanwis or Clanwis? ................................... 212

Figure 8.2: Morgan's paralinguistic twp gesture. The Englishman Who Went up a

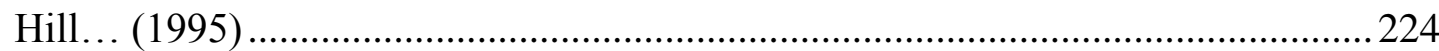

Figure 8.3: Chip's paralinguistic cwtch gesture (Twin Town, 1997) ...................... 228

\section{$\underline{\text { Maps }}$}

Map 1: Welsh counties pre-1974 _.............................................................................

Map 2: Welsh counties 1974-1992 _..........................................................................

Map 3: English border counties adjacent to Wales (Cymru) ....................................xii

Map 4: Approximate division of Welsh Englishes ................................................

Map 5: Map of author birthplaces and/or residences ........................................... 108

\section{$\underline{\text { Tables }}$}

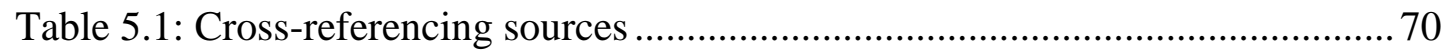

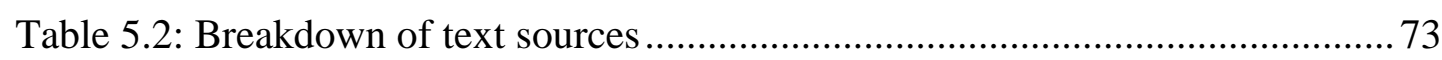

Table 6.1: List of late medieval, Elizabethan, and early Anglo-Welsh poetic texts .. 75

Table 6.2: Shakespeare's phonetic respellings in Henry V ....................................... 86

Table 6.3: Summary of Elizabethan era Welsh English phonetic respelling ........... 102

Table 7.1: Welsh writing in English period descriptors......................................... 106

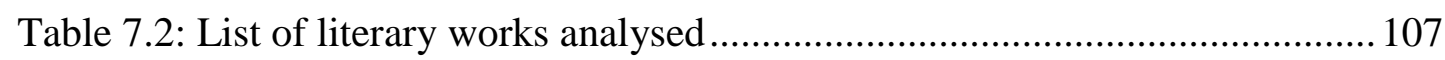

Table 7.3: Bidding terms of rural Wales from Prichard (1828) .............................. 112

Table 7.4: Reproduction of Raine's paratext (edited) (Queen of the Rushes, 1906)124

Table 7.5: List of phonetic respellings in Raine $(1880,1998)$............................... 127

Table 7.6: Mock translations for 'to say' in My People (1915) .............................. 133

Table 7.7: Instances of Demonstrative There + adj/NP in My People (1915) ......... 135

Table 7.8: Reproduction of Glyn Jones's paratext (Jones, 1992:xxxiii-xxxiv) ....... 163

Table 8.1: Welsh film period descriptors ................................................................ 190

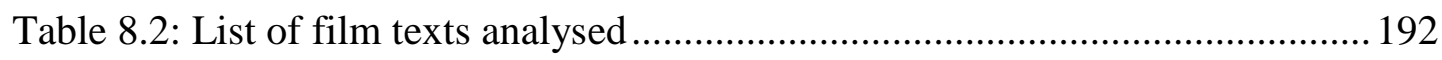

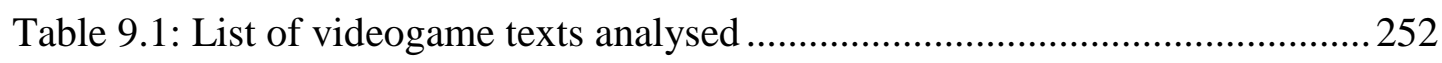

Table 9.2: List of videogame characters, their character type/roles \& voice-actors 255 


\section{$\underline{\text { Reference maps }}$}

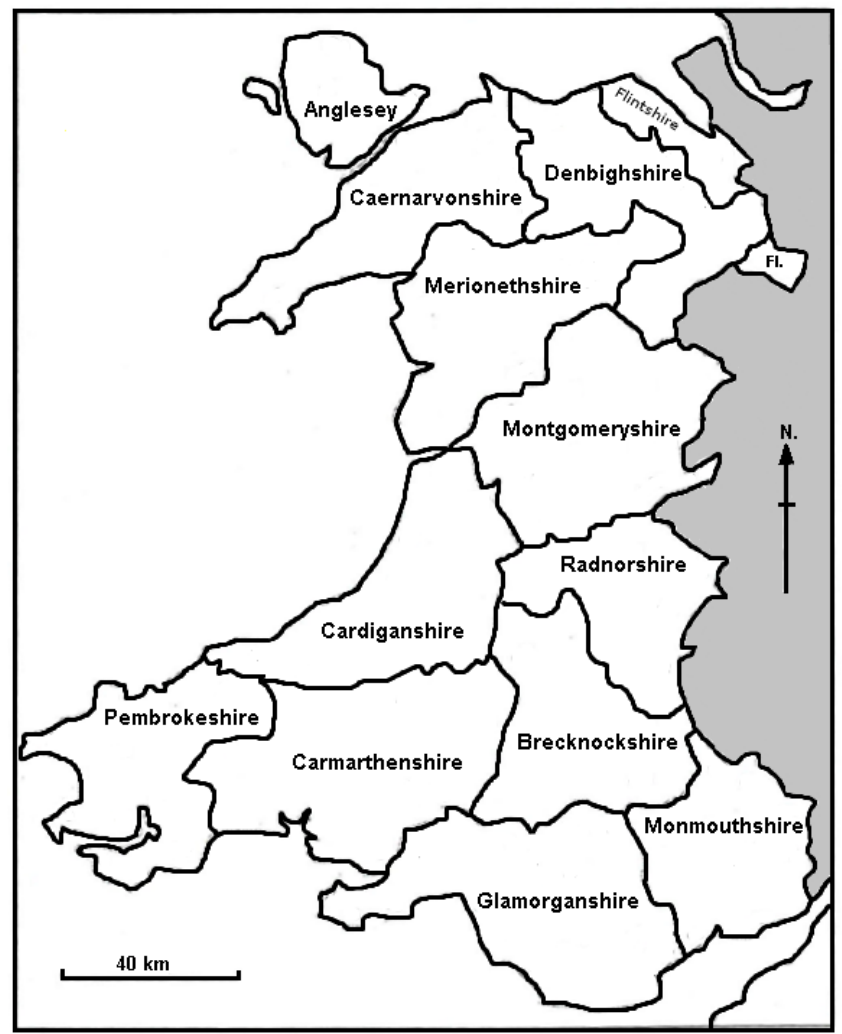

Map 1: Welsh counties pre-1974

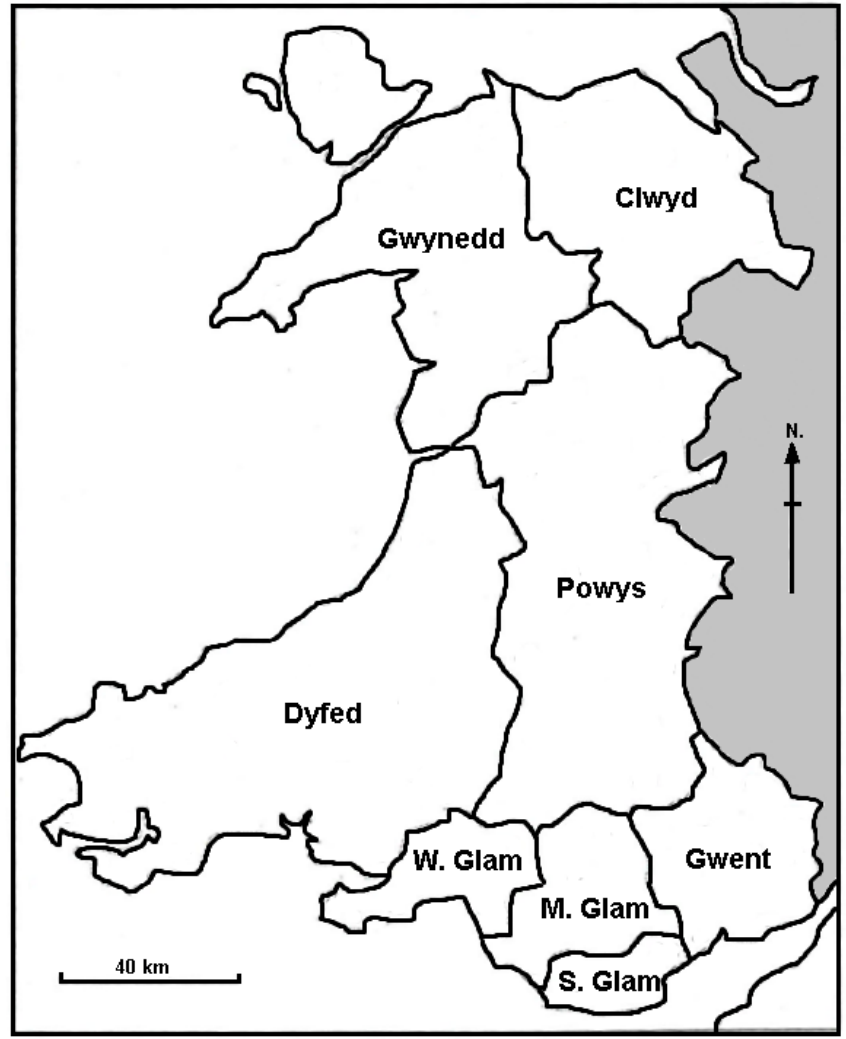

Map 2: Welsh counties 1974-1992 


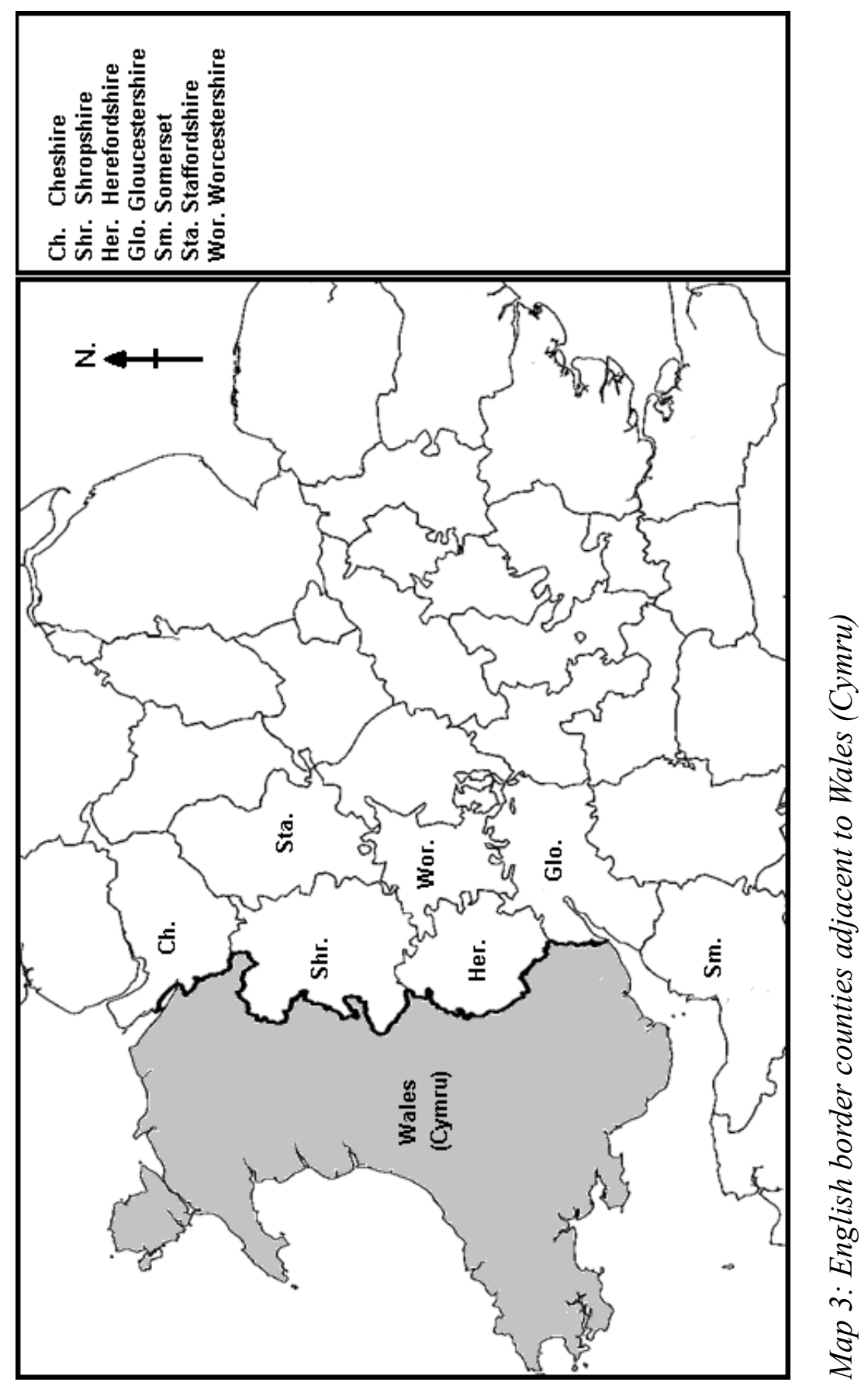




\section{$\underline{\text { List of abbreviations }}$}

EDD - English Dialect Dictionary (Joseph Wright, 1898-1905)

eWAVE - electronic World Atlas of Varieties of English

GPC-Geiriadur Prifysgol Cymru [University of Wales Dictionary] (2017 online edition)

OED - Oxford English dictionary (2017 online edition)

RP - Received Pronunciation [variety/accent]

SAWD - Survey of Anglo Welsh Dialects (D. Parry, material taken from the Grammar and Glossary 1999)

SED - Survey of English Dialects (Harold Orton, material taken from The Dictionary and Grammar 1993)

TT - Talk Tidy (1985), a laymen's glossary by J. Edwards

WE - Welsh English [variety/dialect]

Weng. - Wenglish (2008), a layman's glossary by R. Lewis, 2008

$\underline{\text { Pre-1974 Welsh counties }}$

Mon. - Monmouthshire

Glam. - Glamorganshire

Bre. - Brecknockshire

Crm. - Carmarthenshire

Pem. - Pembrokeshire

Rad. - Radnorshire

Crd. - Cardiganshire

Mtg. - Montgomeryshire

Mer. - Merionethshire

Den. - Denbighshire

Fli. - Flintshire

Crn. - Caernarvonshire

Ang. - Anglesey

\section{$\underline{\text { Post-1974 Welsh counties }}$}

Gw. - Gwent

MG. - Mid Glamorgan

SG. - South Glamorgan

WG. - West Glamorgan

Dy. - Dyfed

P. - Powys

Cl. - Clwyd

Gn. - Gwynedd

$\underline{\text { English counties }}$

Her. - Herefordshire

Glo. - Gloucestershire

Shr. - Shropshire

Ch. - Cheshire

Sta. - Staffordshire

Wor. - Worcestershire 
Broad transcription as used in text: Welsh English (WE) and Received Pronunciation (RP) phonology

\begin{tabular}{lll}
$\begin{array}{lll}\text { Vowels } \\
\text { Vowel } \\
\text { (IPA) }\end{array}$ & Phoneme name & Example \\
\hline $3:$ & Open-mid central unrounded & RP: Burn \\
& & WE: Year \\
o: & Open-mid back rounded & Law \\
$\mathrm{e}$ & Closed-mid front unrounded & Pet \\
I & Near-closed near-front unrounded & Pit \\
v & Open back rounded & RP: John \\
& & WE: Jones \\
$\mho$ & Near-closed near-back rounded & Could \\
$\Lambda$ & Open-mid back unrounded & Putty \\
i: & Closed front unrounded & Bean \\
u: & Closed back rounded & Boon \\
a: & Open back rounded & Barn \\
$æ$ & Near-open front unrounded & Pat \\
$\partial$ & Mid central unrounded (schwa) & Infant \\
\hline
\end{tabular}

\section{Diphthongs}

\begin{tabular}{|c|c|c|}
\hline $\begin{array}{l}\text { Diphthong } \\
\text { (IPA) }\end{array}$ & Phoneme name & Example \\
\hline eI & $\begin{array}{l}\text { Open front to near-closed near-front (falling, } \\
\text { narrow, closing) }\end{array}$ & Bay \\
\hline aI & $\begin{array}{l}\text { Open front to closed front } \\
\text { (falling, wide, closing) }\end{array}$ & Buy \\
\hline गI & $\begin{array}{l}\text { Open (mid)-back to closed front (falling, wide, } \\
\text { closing)? }\end{array}$ & Boy \\
\hline$\partial \mho$ & Central to near-closed near-back & RP: No \\
\hline av & $\begin{array}{l}\text { Open back/front to near-closed near-back (falling, } \\
\text { wide, closing) }\end{array}$ & Brow \\
\hline Iə & $\begin{array}{l}\text { Near-closed near-front to centre (unstressed, } \\
\text { medium, centring) }\end{array}$ & Peer \\
\hline eə & $\begin{array}{l}\text { Closed-mid front to centre } \\
\text { (unstressed, narrow, centring) }\end{array}$ & Pair \\
\hline ৩ə & $\begin{array}{l}\text { Near-closed near-back to centre (unstressed, } \\
\text { medium, centring) }\end{array}$ & RP: Lure \\
\hline $\mathrm{IU}$ & Near-closed front to closed back & WE: You \\
\hline
\end{tabular}




\section{Consonants}

\begin{tabular}{lll}
$\begin{array}{l}\text { Consonant } \\
\text { (IPA) }\end{array}$ & Phoneme name & Example \\
\hline d & Voiced dental fricative & Then \\
$\mathrm{t} \int$ & Voiceless palato-alveolar affricate & Cheap \\
$\mathrm{y}$ & Voiced velar nasal & Bang \\
$\int$ & Voiceless palato-alveolar fricative & Sheep \\
$\theta$ & Voiceless dental fricative & Thin \\
3 & Voiced palato-alveolar fricative & Measure \\
$\mathrm{b}$ & Voiced bilabial plosive & Bad \\
$\mathrm{d}$ & Voiced alveolar plosive & Dad \\
$\mathrm{f}$ & Voiceless labiodental fricative & Fat \\
$\mathrm{g}$ & Voiced velar plosive & Game \\
$\mathrm{h}$ & Voiceless glottal fricative & Had \\
$\mathrm{j}$ & Voiceless palatal approximant & Yank \\
$\mathrm{k}$ & Voiceless velar plosive & Cool \\
$\mathrm{l}$ & Voiceless alveolar approximant & Lad \\
$\mathrm{m}$ & Voiced bilabial nasal & Mad \\
$\mathrm{n}$ & Voiced alveolar nasal & Nat \\
$\mathrm{p}$ & Voiceless bilabial plosive & Pat \\
$\mathrm{r}$ & Voiceless post-alveolar approximant & Rat \\
$\mathrm{s}$ & Voiceless alveolar fricative & Sap \\
$\mathrm{t}$ & Voiceless alveolar plosive & Tap \\
$\mathrm{v}$ & Voiced labiodental fricative & Vat \\
$\mathrm{w}$ & Voiceless bilabial approximant & Woman \\
$\mathrm{z}$ & Voiced alveolar fricative & Zap \\
$\mathrm{d} 3$ & Voiced palato-alveolar affricate & Jeep \\
$\mathrm{f}$ & Voiced alveolar tap & WE: Right \\
$\mathrm{t}$ & Voiceless alveolar fricative & WE: Llanelli \\
$\mathrm{x}$ & Voiceless velar fricative & WE: bach \\
\hline
\end{tabular}




\section{Chapter 1 Introduction}

\subsection{Defining 'Welsh English'}

Wales (or Cymru in the Welsh language: Cymraeg) is one of four countries within the United Kingdom, alongside England, Scotland and Northern Ireland. The most recent statistics for the nation detail that Wales has a total area of 20,782 square kilometers (or 8024 square miles) (Facts About Wales, n.d.) with a population estimate of 3,092,036 as of mid-year 2014 (StatsWales, 2015a) and an estimate population density of 149.1 as of mid-year 2014 (StatsWales, 2015b). Cardiff, the capital, has a population of 354,294 (StatsWales, 2015c), and as of 2015, Cardiff's southeastern conurbation is home to around $60 \%$ of the Welsh population. Both the English and the Welsh languages have equal language status within the country (see Welsh Language Act, 1993), and are now 'official languages' (See Welsh Language Measure, 2011).

Welsh English is a British variety of English. It can be classified simply as: the English language as spoken in Wales. The interactive morphosyntactic online database - eWAVE (current release: eWAVE 2.0 November 2013), which maps over 250 grammatical features across over 50 English varieties, classifies Welsh English as a 'high-contact L1 variety' rather than a 'traditional L1 variety'. High-contact L1 varieties are varieties which, although used in a L1 (first language) capacity, are a result of contact between an original language and a secondary language; in Wales' case this is between the Brittonic Celtic language - Cymraeg ${ }^{1}$ and the WestGermanic language - English. For comparison, eWAVE groups other British Isles English varieties such as Irish English (Irish Gaelic / English), Manx English (Manx / British English) and Channel Islands English (Norman French / British English) under this classification. Selections of similar examples from further afield are: Maltese English (Maltese / English), Philippines English (Filipino / American English) and Aboriginal English (New South Wales pidgins and creoles / Standard Australian English). It is due to this, that Welsh English (hereafter WE) could be

\footnotetext{
${ }^{1}$ To avoid confusion, the thesis uses the term 'Cymraeg' for the Celtic language (otherwise known as 'Welsh'), whilst using adjectivial 'Welsh' to denote cultural qualities of Welsh people overall (Cymraeg and English users alike).
} 
classified alongside particular 'World' or 'Colonially' established varieties of English, distinct from its neighbouring English varieties in the U.K., the U.S., Australia, New Zealand, and South Africa.

Llamzon (1983) lists four essential features that incorporate the many 'New [world] varieties of English' that are emerging in traditionally Non-Anglic territories.

1. Ecological features: has there been, or are there still presently, a polyglossic (multiple languages) linguistic environment in the variety? i.e. is there a history of code-switching, code-mixing and lexical shifts (lexical borrowing from a region's native language into the replacement language).

2. Historical features: has there been a comparatively brief historical development for the new variety from the parent language/variety (e.g. WE from Cymraeg)?

3. Sociolinguistic features: are there sociolectal tiers within the new variety? Do speakers of this new variety alter their variety's speech depending on situational environments? i.e. are there differences between formal and informal meetings; at home and with friends?

4. Cultural features: Is there a body of literature that features the new variety? e.g. literary dialect created by novelists, poets and playwrights? (Llamzon suggests this final criterion 'signals that the transplanted tree has finally reached maturity, and is now beginning to blossom and fructify' (Llamzon, 1983:104)).

It can be argued that WE meets all these criteria: it continues to receive loanwords from Cymraeg and the dialect is still informed by its syntax; WE has largely developed in the last 100 years due to a cultural-economic shift; there exists formal and informal examples of the variety (e.g. WE newsreaders' speech on television has 'formality'), and its vaguely understood that WE has appeared in some creative works. In many ways, the uncertainty surrounding this last criterion in fact informs much of this thesis' discussion. Welsh English has many characteristics of a 'World English' or 'Transplanted English' but is there a literary tradition? Llamzon (1983:106) notes that Commonwealth and postcolonial writers, some of which have included their transplanted varieties of English, have won acclaim within the literary 
world since the 1980s. For example, The Man Booker Prize nominees and prizewinners include Hong Kong born Timothy Mo, Sri Lankan born Michael Ondaatje, Nigerian English user Ben Okri, Trinidadian English user Derek Walcott, and Indian English user Vikram Seth. McCrum (cited in Iyer, 1993:53) sums the situation up adequately:

[T]here is not one English language anymore, but there are many English languages ... each of these Englishes is creating its own very special literature, which, because it doesn't feel oppressed by the immensely influential literary tradition in England, is somehow freer.

Butler (1997) lists a similar five criteria for a variety's inclusion as a 'World variety' of English:

1. A standard and recognizable pattern of pronunciation 'handed down from one generation to another';

2. A set of lexis unique to the variety's physical and social environment;

3. A historical sense amongst speakers that the variety is the way it is because of the language community's contact situation;

4. 'A literature written without apology in that variety of English' (emphasis mine)

5. Existence of dictionaries and style guides 'which show that people in that language community look to themselves, not some outside authority, to decide what is right and wrong in terms of how they speak and write their English' (emphasis mine).

Emphasis should be placed on these last two points: writing in the variety without apology, and having the social confidence to construct dictionaries and style guides. With reference to the latter, glossaries for WE have recently emerged, one example addressed in chapter 2.3 is John Edwards' Talk Tidy (1985-1986) series.

We can go one step further in identifying where WE exists within the family of Englishes by consulting Mesthrie's continuum of the English language family (2002:112-113). Mesthrie splits the family up into nine divisions. The first three concern the English language as it's largely spoken in culturally 'English' countries: Colonial Standard Englishes (U.K., U.S., Aus., N.Z., Canada, S.Afr.), Regional 
Dialect Englishes (the 'nonstandard' varieties of the above locales), and Social English Dialects (sociolects within these regions, such as Cockney in London). The next two positions concern Pidgin Englishes (arisen from interaction between users who do not share a common language) and Creole Englishes (when aforementioned Pidgin is used as an L1). The following two categories concern Englishes used as an alternative language. First, ESL Englishes, where English is used as a secondary language, these varieties emerged during the colonial period (e.g. Kenyan English, Nigerian English); and second, EFL Englishes, which are Englishes used as a foreign language, where the influence from the language has been external not internal (such as settlers) and is used in international contexts (e.g. French accented English, Bhutanese English). The final two concern what may be called 'Adoption Englishes' for they have adoptive characteristics. First, Immigrant Englishes develop from peoples immigrating to English speaking countries and adopting the local variety (often Colonial Standard) (e.g. Chiacano English developed from Mexican Spanish and U.S. Englishes); and Language-shift Englishes, which are varieties arisen when English replaces the 'erstwhile primary language of a community'. Mesthrie (2002:113) notes that 'frequently the linguistic properties of ESL become stabilized' as an L1 with the language/variety 'retaining distinctiveness and a sense of continuity with the ancestral languages and cultures' (e.g. many groups of native Americans' Englishes, the Irish speakers of English, and South Africans of Indian heritage).

Of the many options provided by Mesthrie (2002), WE fits the category of a language-shift variety best. There were several factors contributing to this shift from Cymraeg to English in Wales. First, when Wales annexed fully into the kingdom of England under the Acts of Union of 1536-1543, English became the language of government and law. Thereafter, similar language policies enforced by England, as well as a large English-speaking immigrant population working in the south Welsh coalfield during the Industrial revolution, saw English speakers gradually increase (Penhallurick, 2013).

Because of this contact and generations of codeswitching, the WE across Wales bears a resemblance to the morphosyntax and phonology of the country's original Welsh language. A characteristic feature of Welsh English on a lexical level is the borrowed loanwords from Cymraeg. Some words are anglicised, whilst others retain 
Cymraeg's ortho-phonologic forms, and may be recognized as legitimate loanwords by speakers of Standard Englishes (for example, the Cymraeg word 'eisteddfod' [arts festival]). Others would be treated as 'foreignisms' to English speakers outside Wales. It is important to also note that the neighbouring non-standard border dialects of rural and urban England also influence the variety's form too (Penhallurick, 2013).

\subsection{Welsh English or Welsh Englishes?}

Such a simple definition for Welsh English being 'English spoken in Wales' does not wholly suffice under scrutiny. This is because by naming this language variety simply as 'Welsh English' creates a somewhat paradoxical entity. This can be demonstrated in two opposing qualities: namely that WE (if defined in the aforementioned manner) can then boast a reputation as being both one of the earliest varieties of English (and perhaps the first 'Colonial' variety of English) and also one of the more recently formed varieties of English, dating back to approximately a century ago. It is both old and new. Confusing, but not without explanation.

When we speak about the Welsh variety of English, it should be stressed that we are in fact speaking not of the singular, but the plural: we are speaking of the Welsh varieties of English. Welsh English is a convenient umbrella under which falls several Englishes. The regional variety's current appellation (in modern academic literature) - Welsh English - is used to denote the various dialects of this Anglophone region. How many distinct varieties of English there are in Wales remains uncertain, although tentatively it may appear that the speech throughout Welsh speech communities can broadly be divided into a handful of vague linguistic regions. Furthermore, it is these populations' distinct histories that identify why it is these regions' 'Welsh Englishes' understandably differ.

Broadly speaking, eight English-speaking regions can be recognised in Wales (see Garrett, Coupland \& Williams, 1999:325-237). The following areas are sorted by an approximate chronology that notes when the English language first began usage within each region, and in doing so creating the impetus for that region's variety of WE (see Map 4). South-West Coastal Welsh English is commonly associated with speech communities below the 'Landsker Line': a delimited, historic linguistic division between English speaking South-West Wales and Cymraeg speaking SouthWest Wales (i.e. areas such as southern Pembrokeshire and southern 
Carmarthenshire, and the Gower peninsula); Borders Welsh English, covering Monmouthshire, Brecknockshire and Radnorshire; 'Welsh Valleys' English, covering much of historic Glamorganshire, likely to be the most recognized variety of Welsh English and arguably the variety with the most speakers; Western Welsh English, covering historical Cardiganshire, Northern Carmarthenshire and Northern Pembrokeshire and finally Northern Welsh English, covering historical Gwynedd (itself: Anglesey, Caernarvonshire, and Merionethshire) and parts of historical Clwyd (consisting of Denbighshire and Flintshire). It should be noted that each of the southern Severn Estuary cities could additionally be defined into dialectal 'zones' of their own, therefore creating traditions in the vein of a Cardiff Conurbation English (Cardiff and Newport) and Swansea English (Swansea Valley). Furthermore, the north-eastern city of Wrexham is also distinct within north-eastern Clwyd with such a Wrexham English said to contain qualities of Merseyside English from across the English border. Although little study has been carried out to purport that such dialect 
regions definitively exist (let alone owning names ${ }^{2}$ ), and although a mapping activity such as this could be insignificant (a relic of sociolinguistics of yesteryear as such regions are fluid entities without boundaries), it must be emphasised that there is a need to illustrate, at least to the layman, that there is significant variety within the amalgamic label of "Welsh English". WE is not a singular entity.

The issue of defining and naming the varieties is muddied partly because the variety's collective name (this 'umbrella' under which the WE varieties lie) has not been christened in any conclusive way, thus leading regularly to inconsistent reference. Amongst both the literature of academics and layman, four separate names have found usage: 'Cambrian English', 'Anglo-Welsh', 'Wenglish', and the last, and most-recently accepted, 'Welsh English' (occasionally stylized hyphenated: WelshEnglish). Conveniently, each of these labels coincide with various time periods in which English in Wales has been investigated. The first was a brief dialectal survey

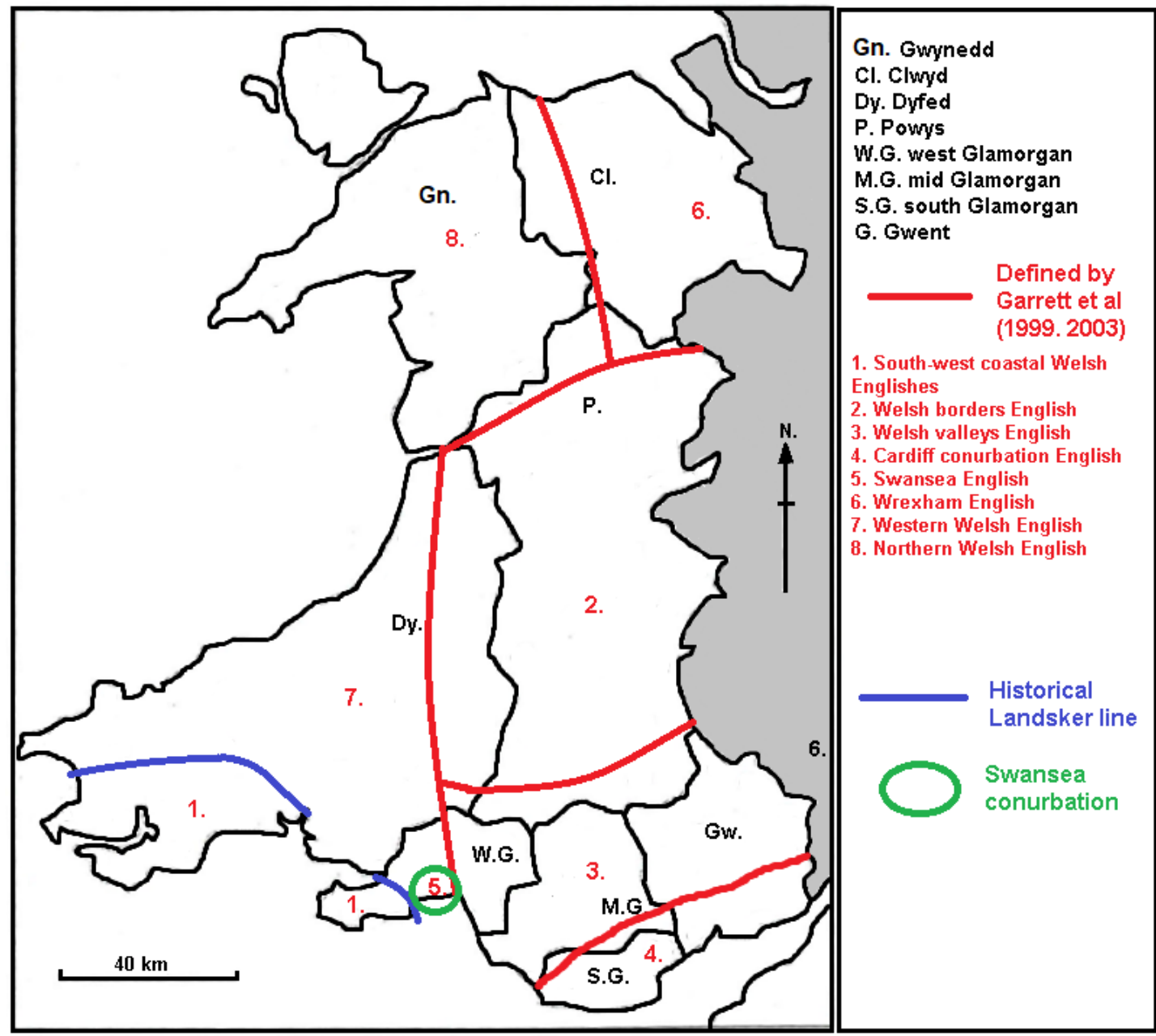

Map 4: Approximate division of Welsh Englishes

\footnotetext{
${ }^{2}$ These names were chosen loosely by the current author for illustration.
} 
by A.J. Ellis in the $1870-80 \mathrm{~s}^{3}$, the second being an in-depth academic survey in the traditional dialectology method initially conducted from 1968 to 1982; the third was a trend in layman glossaries (often catering to a humorous writing style) beginning with Edwards (1985) who effectively coined the blended term 'Wenglish' (its usage prior to this popular glossary is scant if not non-existent); and the fourth being further academic work within the sociolinguistic method of the language variety studies (English In Wales by Coupland (1990) is a seminal collection). Currently, it is not uncommon to see Welsh English referred to by any one of these titles.

\subsection{Studying Welsh English and thesis structure}

Although the language variety has been given various labels during the last halfcentury of research by layman and scholars, it should be emphasized that its lack of 'title' has not deterred investigation into the variety. WE has already been investigated by philologists, dialectologists, and sociolinguists (chapter 2 and chapter 4). The variety has also been depicted within numerous fictional narratives for centuries, from poetry to plays, and across literary, filmic, and videoludic media. Ieuan ap Hywel Swrdwal's ambitious 1470 English-written poem, Hymn to the Virgin, is often cited as the catalyst for lay observance of the language variety in writing; the poet desiring to write a piece that phonetically represented his own use of English, rather than his English contemporaries.

With the exception of German (2009)'s study of WE in Shakespeare's Henry $V$ (1599) and Hywel Swrdwal's aforementioned poem, hitherto, no work has been carried out on connecting these fictive/creative depictions to the larger body of sociolinguistic research into WE. There has been no consolidatory compilation that draws together the material of writers' attempts, whether faithful or disingenuous, at recording and representing the WE they were familiar with. There is no record of the linguistic conventions (e.g. lexical, grammatical, or phonological representations) that fictive writers used; no attempt to compare these forms to what we know of WE from modern surveys; and no assessment of what writers 'perceived' to be markers of 'good' WE dialect (i.e. most common forms). This thesis's chief aim is to complete such a compilation, not only to act as a resource for those with an interest

\footnotetext{
${ }^{3}$ Ellis also used the term Welsh English, although it referred to Welsh usage influence in English-speaking Shropshire.
} 
in WE in fiction, but also to create a template for how future studies into the historical representation of language varieties, across eras and narrative media, might look. Compiling a record of fictive WE is just one goal, however. This thesis will also draw upon the dialectal perceptions and attitudes associated with the variety within fiction, by way of addressing linguistic and character stereotypes that may be embedded in its representation, asking: how does the concept of 'authenticity' play a role in what may be described as 'Welsh fictive English'?

This first chapter has introduced the concept of WE as a language variety in the larger context of English varieties and within the context of British Englishes, being one of the only British Englishes to be a 'contact variety' or 'language shift variety', formed through the interaction between the Celtic language Cymraeg/Welsh and the Germanic language English. The chapter has also highlighted that WE itself is not necessarily one variety of English, but one made up of several distinct varieties, divided regionally between rural or urban locations. The second chapter reviews the history behind the study of WE by linguists and laymen, focusing upon the works of A.J. Ellis, David Parry, and John Edwards. The third chapter reviews the field of language varieties in fiction, touching upon the history of literary linguistics and dialect literature. This thesis' methodological framework will derive from the literature reviewed here. The fourth chapter reviews the literature that focuses upon language attitude studies, addressing perceptions held on dialects, the linguistic field that studies them, the way in which these perceptions can be utilised in fiction for stereotyping and the known stereotypes and perceptions held of WE in particular. Chapter five concerns the methodological framework. It addresses what constitutes a 'fictive text' in a WE context, and details the thesis' research questions. It then discusses the format of analysis of key texts; the dialectal sources that were used to cross-reference the lexical, phonological, and grammatical forms; and how texts were obtained for analysis.

Four analysis chapters then address the ficto-linguistic form of WE across a historical period starting with the $12^{\text {th }}$ century up until 2014. Chapter six analyses the WE representation in literary and theatrical dialect of the late medieval, Tudor, and Stuart periods of British history, largely focusing upon the Elizabethan plays. Chapter seven analyses the WE variety in novels from the early $19^{\text {th }}$ century until 2008. Chapter eight analyses the dialect within film beginning in 1938 and concluding in 
2014. Finally, chapter nine breaks new ground for ficto-linguistic analysis, for it addresses a variety (WE) in the narrative form of the modern videogame. 


\section{Chapter 2 A brief history of systematic Welsh English study}

\section{$2.1 \quad$ A.J. Ellis' 'Welsh English'}

It is important to begin by illustrating the works of previous investigations into the language variety. In doing so, a character of Welsh English shall emerge. The genesis of systematic research into Welsh English likely falls to the renowned English philologist, A.J. Ellis (see Ellis, 1882; Ellis 1889). Ellis spent about twelve years surveying the pronunciation of numerous British Isles Englishes, describing the project as being both 'laborious and difficult' (Ellis, 1882:5*4). Acknowledging that 'a large portion of Scotland speaks Gaelic, and most of the principality of Wales still speaks Welsh', Ellis' inquiry sought to answer to what extent the English language extended into these westerly regions (p.5*). His investigations of Wales were chiefly concerned with three discussions. Firstly, the speech of Gower and southern Pembrokeshire (below the 'Landsker Line'); secondly, the westerly influence of English dialects upon East Wales; and finally, the idea that where this influence was strongest was a linguistic confluence: a 'Celtic Border' that linguistically divided the British isles in two.

Furthermore, the dialectal label 'Welsh English' that we today use to refer to the English of Wales, may be first attributed to Ellis: '[the] southern part of Shropshire was a Welsh [Cymraeg] speaking country, on which English was forced hundreds of years ago. It is therefore an old English speaking region, but the English was always a Welsh English. (emphasis mine)' (Ellis, 1882: 18*). Although it seems, Ellis' preferred term for the dialect was Cambrian English.

In the first of Ellis' Welsh English discussions, he describes southern Pembrokeshire and the Gower Peninsula as being two very early cases where Cymraeg had been 'driven out'; where 'West-Saxon dialect[s], certainly much worn out under the influence of education', have gained prominence since the $12^{\text {th }}$ century CE and were currently (as of 1882) 'without any [Cymraeg] influence' (p. 7*). Ellis goes as far to associate these regions as a 'part of England' and that any presence of Welsh persons in these regions are 'accident[s] of immigration, as insignificant in respect to

\footnotetext{
${ }^{4}$ The use of asterixis after page numbers parallels Ellis's own usage; his work's page numbering restarts again after a set of initial asterixed pages.
} 
nationality as the presence of Welsh people in London' (p.10*).

Ellis (1882) provides historical commentary for the settling of these areas and their following cultural changes. First, that Flemish citizens under Henry I (according to Fenton's History of Pembrokeshire) were removed from North of England and supplanted in Pembrokeshire, followed by a new colony 50 years later by Henry II to 'supply his new garrisons raised and fortified by Strongbow, Haverfordwest and Tenby' (p.10*). A common name for this region was: 'Little England Beyond Wales', a name still found today (p.12-13*). For Gower, Ellis notes that by the $16^{\text {th }}$ and $17^{\text {th }}$ century the expressions of Gower Wallica and Gower Anglica were used to denote the division of the Welshry (Welsh-speaking inhabitants) and the Englishry (English-speaking inhabitants) in the Gower peninsula (p.11*). In Ellis' eyes, he did not consider the Pembrokeshire and Gower regions of the contemporary Welsh nation to be 'Welsh' in any respect: not linguistically, and not culturally.

The linguistic claims that these regions contained distinct varieties of English were backed-up through Ellis' surveying. Ellis (1882) relied heavily on phonetic transcriptions of Gower and South Pembrokeshire English speech provided by informants. According to one Reverend J.D. Davies, there were 'no printed specimens of [the Gower] dialect' (to which we might suppose Davies was referring to dialect glossaries and/or dialect literature), and therefore provided the following transcriptions: 'zo' (so), ‘zay' (say), 'ze' (see) etc., 'gwain' (going), 'drough' (through [rhymes plough]), 'beant' (isn't) and 'know-n' (know him) (p.11*). Of these samples, Ellis states: 'Of these, the use of initial $z$ for $s$ [..] and of initial $d r$ for $t h r$ [..], the use of gwain for going, of beant for isn't and especially of $-n$ in know- $n$ for know him, are distinctive marks of the strongest Southern English, which is situated on the other side of the [Bristol] Channel'. Ellis concludes that Gower English of 1882 was: 'ancient and not acquired in modern times' (p.11*). For Pembrokeshire, Ellis provides a phonetic transcription given to him from the meeting of the Cambrian Archaeological Society in 1861: 'I'ze a gwaaing to zell zum vish to buy zum vlesh vor that blezzed day Zoonday' (p.14*). Although Ellis believed the z/s distinction was genuine, he had doubts whether the $<$ ze $>$ in 'I'ze', $<$ oo $>$ in Zoonday and $<$ ng $>$ in 'gwaaing', were genuine and cast the remainder off as merely 'picturesque' (i.e. contrived) (p.14*). These early insights suggest from WE's early scholarly analysis was framed by questions of 'authenticity' of what 'good' WE was. 
Ellis proceeded to describe how 'greater England [excluding 'Little England' and Gower]' had an 'immediate pressure on Wales from the East' (p.15*). Ellis makes a distinction between how English might put such 'immediate pressure' on Wales by distinguishing between influence by other dialects and influence by 'Book English'. Ellis states:

It is necessary to divide these places into at least two classes - those in which a more or less dialectal form of English is used, and those where 'book' English [...] is spoken, that is, those in which English has been learned by instruction and not by communication. (p.20*).

Ellis defines dialectal influence as that which is 'real natural English, hereditarily transmitted from father to son' and is 'simple local speech, learned without book, essentially a spoken and not a written dialect' (p.16*). Of the neighbouring dialectal influence along the English/Welsh borderland, Ellis identifies the English counties of Shropshire, Herefordshire and (arguably) Monmouthshire as influencing the English speech of this Welsh region distinguishing 'this region linguistically as Cambrian' (p.20*) and divides it into North Cambrian (north of Shropshire), Mid-Cambrian (south-western Shropshire) and South Cambrian (below Shropshire) (p.20*).

Of ‘Book English', Ellis (1882:16*) says:

Foreigners, $[\ldots]$ persons who by birth speak a different language, and not give it any invidious political signification - foreigners who learn a language by book and by orthoepical instruction, naturally acquire the book language, tinctured, however, essentially by their own nationality. We have numerous instances of such English speech in Wales.

We can then assume that by 'Book English', Ellis is referring to the acquisition of English through learning a language Standard, originating from England. Ellis is right to consider that both of these dimensions influenced the speech of English in Wales. Regarding the large class of Cymraeg-users of English, Ellis could 'no more reckon these as English speakers, than [he] [could] call educated English people who can read, write, and speak French, French speakers. They are merely foreign speakers of English and French respectively' (p.22*).

Effectively, Ellis viewed WE that was influenced by neighbouring English dialect regions as a genuine variety, whilst English learned by book (as a second language) 
to not be genuine. It should be noted that Ellis' work was carried out during mass anglicisation of Wales' Cymraeg-speaking population; in decades following Ellis' observations, it would be difficult to claim that such a contact variety, like the one that emerged from the interplay between English and Cymraeg, to not be a legitimate variety of English in its own right.

Ellis' research into these speech communities, which involved a postal questionnaire sent to informants such as clergymen asking whether their speech communities spoke chiefly one language or the other (p.25), enabled him to map and draw a line of delimitation, dividing the region between the English dialects (which included his 'Cambrian Englishes') and areas where Cymraeg was considered the primary language (regardless of how much 'Book English' its speakers knew). A line where, in his own words, 'purely English native speech ceases and bilingual speech commences' (p.24).This was discussed more in Ellis (1898) where he titled the line the 'Celtic Border'.

Reverend John Griffith from Merthyr Tydfil disagreed to some extent with Ellis' approach to surveying where Cymraeg ended and English began contesting: 'it is difficult to answer your questions, as they do not apply to a district like this' (p.37*). Griffith noted that the community's speech was '[Cymraeg] principally, but there is English intermixed [...] [throughout] Pontypool and Newport'. Griffith also noted that 'most, or a very large portion, speak both languages' and that Ellis would 'find it very difficult to trace a boundary in towns. The English is peculiarly 'Welsh [Cymraeg] English', neither like Hereford nor Gloucester, in fact English in a Welsh [i.e. Cymraeg] idiom'. Griffith's comments herald in a sociolinguistic factor that Ellis had not considered, one that Ellis simply ignored in his paper: that there was a genuine new variety of English forming in the south Welsh valleys from the contact between Cymraeg and English. Another informant, Reverend J. Powell Jones alluded to the English-speaking immigrant work force even being a factor in the formation of this new variety: '[Cymraeg] is generally spoken by the natives, but on account of the large influx of English people [for work], English is much spoken in the town and its vicinity'. Clearly it was not as simple a delimitation as Ellis concluded. 


\subsection{David Parry's Survey of Anglo-Welsh Dialects}

It was the pioneering effort of David Parry in 1968 that saw the first wave of dialectology research into Welsh English. Parry carried out a large-scale survey of the character of English within Wales, and used the term Anglo-Welsh to describe the variety. The study was consequently titled The Survey of Anglo-Welsh Dialects (hereafter $S A W D$ ). Three volumes of the results have been published. The first two by Parry focused on South Wales; Vol. 1 was south-east (Parry, 1978), and Vol. 2 was south-west (Parry, 1979). The final north Wales volume was published by Rob Penhallurick (Penhallurick, 1991). A later volume, titled: A Grammar and Glossary of the Conservative Anglo-Welsh dialects of Rural Wales (Parry, 1999), compiled previous material, and has been a seminal resource for examining WE.

This later volume provided an analysis of data collected by the SAWD from 1968 until 1982. Prior to initiating the $S A W D$, Parry had completed linguistic research with dialectologist, Professor Harold Orton of the University of Leeds (Parry, 1999:1). Orton developed the Dieth-Orton dialect questionnaire for the Survey of English Dialects (hereafter SED) that was carried out between 1948 and 1960; it is this questionnaire that was modified for usage in Wales by Parry (1999:1). The aim was to have two comparable databases for English dialects throughout England and Wales.

Informants for the survey were chosen if they met the following criteria. They had to be over 60 years old; had to have knowledge of agricultural life; were not formally educated above 15 years old; were a resident of the area without significant interruption; and were without speech impediments (p.1). Localities were chosen for their rurally remote geographic positions (i.e. minimal external influences), small population figures, and their local occupations. In Parry's words:

A population figure of 500 to 1000 would suggest a place large enough to have an established local dialect but small enough to preclude the development of significant linguistic sub-divisions, especially of course if this small isolated population were a relatively stable one. (p.1)

For data-collection, Parry's survey divided Wales into three regions: The North consisting of Gwynedd, Clwyd and the Montgomeryshire, the South-west 'conterminous with Dyfed', and the South-east consisting of Radnorshire, 
Breconshire, Glamorgan and Gwent (Parry, 1999:2). Each locality produced a corpus of data consisting of questionnaire responses and 'incidental material', which Parry describes as 'significant items occurring in the informants' conversation that, although not specifically asked for in the [q]uestionnaire, did appear to bear upon the linguistic matters under investigation' (p.1).

The results are divided into four sections: phonology, morphology and syntax, glossary, and maps. Phonology (Parry, 1999:8-104) addresses the phonology of WE through 144 chosen words by fieldworkers who aimed to outline the sound-systems and reflexes of the sounds of Middle English. The words were then divided into distinct sets (e.g. the BRIDGE set) that can be used to 'facilitate making references to all members of the group collectively' (p.8). Rather than detailing the 'phonemes' of Anglo-Welsh, Parry and contributors chose to distinguish them as 'Anglo-Welsh sound units' which are distinct from phonemes, thus their transcription is not into IPA (international phonetic alphabet), but rather an offshoot of the system (p.10). The morphology and syntax section (p.105-120) addresses differences in Welsh English in contrast to Standard English. The next section, Glossary (p.121-201), lists lexical items of both the $S A W D$ questionnaire and the incidental material (p.121). The glossary lists word-class, pronunciation, its Anglo-Welsh distribution, and definition. As this survey is an extension of the $S E D$, lexical items could be cross-referenced with that database. Usages and word etymologies were also cross-referenced with Joseph Wright's English Dialect Dictionary (hereafter EDD), Oxford English Dictionary (hereafter OED), Onion's Oxford Dictionary of English Etymology or the Cymraeg dictionary Y Geiriadur Mawr (p.121). The final section, Maps, plots material from the Phonology, Morpho-syntax and Glossary sections and are marked out by isoglosses. Some of the maps denote Wales alone, and others, where material aligns with neighbouring England, detail Wales and England (p.202).

Whereas Ellis noted a 'Welsh English' quality to certain dialects in Shropshire, choosing rather to use the term Cambrian English to refer to English varieties in Wales, Parry chose to use 'Anglo-Welsh'. It seems likely that Parry chose AngloWelsh to reflect or complement the then-contemporary usage within English literature circles. Scholarly research into English-written literature from a Welsh background was once termed: 'Anglo-Welsh', an attempt possibly to connect the Anglo- prefix to Welsh culture and therefore denote an Anglicised quality. The 
cultural attitudes towards the term had changed by the closure of the $20^{\text {th }}$ century, with the body of literature now commonly referred to as 'Welsh writing in English'. Knight (2004) illuminates the situation: 'Anglo-Welsh is found unacceptable by most authors, and indeed many others, on the grounds that it refuses Welsh status to Welsh people who, not speaking Cymraeg, nevertheless do not feel at all English' (p.xv).

Systematic work on WE continued after the $S A W D$. One seminal collection of late $20^{\text {th }}$ century work is Coupland's edited volume English in Wales (1990). It features 'descriptive sketches' (grammar, phonology, lexis) of Cardiff English, Glamorgan English, Port Talbot English, and Abercrave. Only recently have dialectologists also begun investigating the unique 'sing-song' intonation of WE (e.g. Quaino, 2011, Arashiro, 2014).

\subsection{Layman and non-specialist glossaries}

The growth in English language dialect lexicography that began in the $18^{\text {th }}$ century, encouraged numerous laymen, especially in England, to create non-specialist glossaries for publication (Penhallurick, forthcoming: chapter 1.3). Unlike treatments for English Englishes, attempts to record the Welsh variety of English by those with little linguistic training (i.e. laymen), have been few. This is likely due to English's relatively recent foothold within the region (see 1.1).

Understandably, there have been many Welsh English glossaries and wordlists for the speech of the Gower and Pembrokeshire dialects, which is expected considering their lengthy tenure within the region. Many items from these glossaries were compiled in Rob Penhallurick's Gowerland and its language (1994). Early examples include, Isaac Hamon's The Old English of West Gower, which is now out of use (1697), that included 54 words many of which were archaic (Penhallurick, 1994:121); Rev. J. Collins' A List of Words from the Gower Dialect of Glamorganshire (1849), part of the Philological Society Proceedings, contained a list of 71 words (p.122); J.D. Davies' A History of West Gower, Glamorganshire Parts I-IV (1877-94) contained small numbers of dialectal material, also noting there was some Cymraeg element in the Gower dialect (p.123); and C.D. Morgan's Wanderings in the Gower: A perfect Guide to the Tourist, with all the Lays, Legends, and Customs, and Glossary of the Dialect (1886) contained a wealth of 159 words, and acted as an early guidebook to 
the area. In regards to Morgan's tone, Penhallurick states: '[it] is elegiac, suggesting that we must assume that its glossary refers to a vocabulary passing away' (p.125).

$20^{\text {th }}$ century glossaries include, T. Witton Davies' Gowerland: Its People, Speech and Some of its Ways (1920), who was concerned with highlighting the supposed Flemish influence in Gower (p.126); Clarence A. Seyler's 'Stedwordlango' A study of the Free of Penmaen in Gower (1920) (p.127); and finally Horatio Tucker's research work on Gower dialect, that was published in three separate pieces. The first was The Dialect Speech of Gower (1950), published in the Journal of the Gower Society, the second was Gower Gleanings (1951), a book published by the Gower Society, and finally My Gower (1957), a further book published by Rowlands \& Company. The first article included 42 words, 19 line phonetic transcriptions (p.129). Tucker was aware of the connection between the speech of Gower and south Pembrokeshire stating that the two regions' commonality 'are due, either to their common origin or to their mutual contact with the [Cymraeg]-speaking peoples. The differences, which are most obvious, are the result of centuries of isolation from each other and from their parent West Country [of England] dialect' (Tucker, 1950:27; cited in Penhallurick, 1994:130). The 1951 glossary contains 160 words, phrases and pronunciations, and his 1957 volume covers similar ground (p.131). Regarding dialect glossaries from other regions within Wales, like aforementioned - there are few. One in particular that covers the north-eastern area within Flintshire is Dennis Griffiths' Talk of My Town (1969) which covers the English speech of Buckley which comprises a glossary of hundreds of words and expressions and features a reproductions of literary texts 'in dialect' (p.48).

The most-recognised layman glossaries of the past thirty years have been John Edwards' Talk Tidy series $(1985 ; 1986)$ and Robert Lewis' Wenglish: The Dialect of the South Wales Valleys (2008). The two texts have many similarities. Both glossaries solely treat the speech of the southern Glamorgan valleys as it was/is spoken throughout the $20^{\text {th }}$ and $21^{\text {st }}$ centuries as the definitive 'Welsh' variety of English, excluding English material from elsewhere in Wales. They also both use the blended coinage 'Wenglish' for the name of the Welsh English dialect, and approach the language variety with an air of jest. It seems likely that John Edwards coined the term; however, its blended coinage mirrors other layman coinages around the world that are often used for contact varieties. For example, researchers Bae (2014), 
Hadikin (2014), and Henry (2010) identify examples such as 'Singlish' (Singaporean English), 'Konglish' (Korean English), and 'Chinglish' (Chinese English). The blending of such compounds and their subsequence usage by the public (sometimes those who are not users of the variety) are not viewed approvingly within sociolinguistic circles, this is often because the blends are created to index negative linguistic perceptual qualities. Hadikin (2014) notes these can be 'disparaging' terms that present speakers of these varieties as comical or unable to master a Standard 'global' English, although Bae (2013: 644) reports that users of 'Singlish' have begun using the term as a cultural marker of identity. Regarding 'Wenglish', though developed for jest, today is often seen in a similar light.

Edwards (1985) describes the dialect of the valleys as being 'a unique blend of residual [Cymraeg] and the distinctive patterns of spoken English' which is spoken in Gwent and Mid/West Glamorgan (p.1). Acknowledging the contact situation and Wales' two opposing languages of Cymraeg and English, Edwards states: the [Welsh] dragon has not merely two tongues, but three. The third is "Wenglish" (p.1). Edwards identifies the dialect as being 'an oral badge of identity', an identifier which is muchneeded when one considers the language situation: "with all the attention which, rightly, is given to the place of [Cymraeg] in Wales, it is not surprising that the monoglot native of South Wales suffers at regular intervals from the symptoms of 'identity crisis' (p.1). Edwards' purpose for the glossary is attached to this ideal of celebrating the local language and giving identity to the identity-less through his coinage of 'Wenglish'; this is highlighted in three derivational terms: 'Wenglishman' and 'Wenglishwoman' (p.2) and 'Wenglishfolk' (p.3). Rather than choosing 'AngloWelsh' identity, there is an argument that Edwards' attempts at coining 'Wenglish' could be an attempt to simply put the Welsh linguistic-cultural identity before its base English language identity.

Edwards' glossary and introduction shows sufficient knowledge of aspects of the Welsh variety, such as its forms and its history, even if somewhat naïve in some of his linguistic terminology:

[Wenglish] retains the rhythms, refrains, cadences and inflections of [Cymraeg], but one which shows, also, the major influence of the one-time alien language - English which was brought to South Wales from many areas in Britain and elsewhere, when the onward march of the industrial revolution turned the region into a British 'Klondyke' (p.1) 
He notes how certain Cymraeg loan words have, in his own words - 'mutated', for example 'gibbons' from 'sibwns' (Spring-onions), and acknowledges the stereotypes associated with the dialect, especially the 'stage-welsh' of Shakespeare's Henry $V$ (more of which will be discussed in chapter 6). Following his glossary, he provides a few stories written in-dialect, although acknowledges that with 'Wenglish [being] essentially a spoken language [,] [it] causes very real problems when attempts are made to write down some of the distinctive, often-spoken rarely-written words in cold print' (p.4). He notes that some of his words are not unique to 'Wenglishspeaking areas'.

Unfortunately, there is little reference to the work that had already been done on WE (Parry's SAWD, for example), nor to the writers who have used dialectal writing (other than Shakespeare). Granted, the $S A W D$ 's focus on rural communities excludes polities like Cardiff and Swansea - two urban areas associated with 'Wenglish', yet there is no mention of other dialectal investigation. Edwards' perception of linguists and prior linguistic investigation is also unfounded. He states: 'To the purists and scholars of linguistics of the classical school, much of Wenglish is slovenly and unacceptable in a world where individuality and regional identification are not always encouraged' (p.3). What Edwards meant by the 'classical school' of linguistics is unclear, but there is a hint that he conflates the field of linguistics with Standard English language policies used in school teaching curricula.

Furthermore, other than presenting his thoughts regarding Wenglish at 'after-dinner parties', there is little to suggest Edwards conducted any sort of sound methodology to obtain words for his glossary; suggesting most of the words came from his own personal observation of language-users. We can measure the 'authenticity' of Edward's wordlist by comparing it to Parry's academic survey. On the whole, Edwards provides at least 80 words that can be verified with the SAWD. However, the speculative quality of the glossary is still evident; there are several words of uncertain origin, which might be features of a small sociolects, or possibly even idiolects. Then there are the phonological renderings of 'Wenglish' words, e.g. 'wossname' for 'whatshisname', 'frages' for 'ages', 'agen' for 'again'. These add little to the glossary, for they are simply common features of rapid English speech 
(contractions or allegro speech) and are likely features of many varieties of English. In the case of 'agen', such an alternative spelling is not dissimilar to usages by authors of the phonetic respelling of literary eye-dialect (more of which will be discussed in chapter 3). It seems that Edwards perceived the difference in pronunciation, however was unable to display this within the limited orthography of the Latin alphabet.

Edwards also produced a follow-up volume titled More Talk Tidy (1986) which addressed further lexical items that were not included in his initial work. For this volume, material used was that that had been sent to him by his enthusiastic readership (Edwards, 1986: p.1). It is therefore debatable to what extent such items' usages can be verified as being in widespread use. Based on aforementioned enthusiasm from readers, Edwards also attempted to devise a phonetic script, although the efforts were largely confusing as Edwards based his phonetic system off of Standard English. As Lewis later mentions in his Wenglish volume: 'it presupposes a knowledge of how the 'Standard English' words and sounds should be pronounced and is prone to inconsistency (Lewis, 2008:40).

Unlike Talk Tidy books which were short pamphlet-sized books, Robert Lewis' Wenglish: The Dialect of the South Wales Valleys is the first large glossary of the Valleys varieties of English. The format of Wenglish parallels the Talk Tidy series in several ways. It includes an introduction (p.9-38) highlighting the contact history and dialect formation and concludes with a section on pronunciation. A section titled 'Wenglish in Action' (p. 39-45) displays brief stories told using 'Wenglish' lexis, pronunciation and grammar, bearing similarity to Edwards dialectal tales in Talk Tidy. The large glossary follows this (p.46-229), which is considered in the author's own words to be 'the largest and most complete listing in existence' (p.10). Much, if not all, of Edwards' Talk Tidy material appears to be replicated here. Lewis provides a greater wealth of Cymraeg loan words and syntactic phrases than Edwards, in part possibly because he also speaks the south-eastern Cymraeg dialect: Gwenhwyseg. A section on grammar of Wenglish (p.230-319) follows the glossary for 'the more serious student' (p.10). The way in which the grammar is presented bears a striking resemblance to Standard English grammar books with its numerous exercises for 'students' to complete. 
Lewis makes a point that his Wenglish volume is 'not an academic paper on sociolinguistics or dialectology', being for 'the general reader' (p.10), one example stylistic choice being to leave out phonetic script. It is difficult to place Lewis within the framework of the layman, especially considering he acknowledges both dialectology and sociolinguistics; in the blurb it does indeed state he was a student of Modern and Medievaal languages at Cambridge University. The lack of any mention of Parry's $S A W D$ is strange considering the length at which Lewis has gone to obtain his material. Much like Edwards (1985; 1986), Lewis does not provide a methodology for obtaining his dialectal material. Following, Wenglish (2008), Lewis obtained a $\mathrm{PhD}$ in linguistics on the topic of the cultural phenomenon of 'Wenglish' (this is discussed below in Methodology).

The question remains: should we trust layman glossary collections of Welsh English? To quote Nikolas Coupland (who was commenting upon Edwards' Talk Tidy series): 'although sociolinguists will rightly doubt the reliability of such collections as constituting 'evidence', it would be quite wrong, and indeed naïve to dismiss them as irrelevant or valueless' (Coupland, 1990:11). Popular lay glossaries, although taking a lighthearted approach, not only give us 'sensitively observed catalogues of local usages', but also demonstrate a 'significant sociolinguistic phenomenon', a phenomenon that champions variation in language (p.11). It is for this reason that some of these texts will be vital in cross-referencing of fictive WE dialect.

\subsection{Conclusion}

This chapter has highlighted prior researchers' efforts in collecting WE material. We have seen that systematic research into the variety began with A.J. Ellis and his investigation into Britain's many English varieties' in the late $19^{\text {th }}$ century. Ellis not only coined the term 'Welsh English', but gave a detailed overview of how English first began its usage in Wales within the S.W. Coastal region, and how as the English language encroached upon easterly border region of Wales, it formed a 'Cambrian English', whilst in other regions of Wales, Welshmen displaced Cymraeg with 'Book English', or the English English standard. The chapter has identified David Parry's Survey of Anglo-Welsh dialect (SAWD), as the pioneering mid-20 $0^{\text {th }}$ century project that systematically surveyed Welsh English (or 'Anglo-Welsh') throughout Wales for the first time. Inspired by Orton's Survey of English dialects, Parry developed a 
mirror survey of Wales' rural English varieties by interviewing elderly male inhabitants with a questionnaire. Results have appeared in numerous publications in the form of lists of phonological, grammatical, and lexical features. Finally, the chapter addressed attempts by casual 'laymen' to document their speech communities. Starting with historic glossaries from Gower, and following onto late $20^{\text {th }}$ century attempts such as John Edwards' Talk Tidy series and Robert Lewis' Wenglish that address the Valleys variety, we have seen that many writers have passionately recorded their speech communities' vocabulary.

Although lay glossaries often contain misinformation for some linguistic concepts (e.g. believing allegro speech like 'frages'/'for ages' being solely characteristic of WE), laymen's endeavors are to be commended. Lay glossaries may contain items that dialectological systematic surveying did not record. Lewis (2008) is correct to presume that material in his volume will 'certainly merit the attention of the relevant departments at our schools, colleges and universities' (Lewis, 2008:10). Yes, the $S A W D$ is a key WE database, but it should not be assumed that the material in lay glossaries are in any way false, though, caution regarding certain items' claims to widespread usage should be noted - especially because the methods of obtaining items are not defined. 


\section{Chapter 3 The study of dialect in fictive texts}

\subsection{The linguistic field of Dialect in Literature/Film}

Writing in 1990, Coupland \& Thomas (1990) suggested that future research on the Welsh variety of English should address 'popular cultural phenomena [that] might include the Welsh English dialect performances' (p.14) (emphasis mine). The authors listed comedians, singers, television and popular radio broadcasters as example texts, and suggested that studies could address how stereotyped portrayals of Welsh characters exist in such media. Although the authors excluded mention of dialect representation in plays, novels, and television, it is to be assumed the 'invitation' surely is extended to these genres as well. However, we cannot disregard the possibility that such genres were omitted from the list due to historic animosity between linguistics and literary dialect studies.

Dialect speakers have been represented in fictional texts for centuries, although serious academic study of the phenomenon blossomed in the $20^{\text {th }}$ century. Shorrocks (1996) outlines two important stylistic distinctions in the study of dialect in fictional texts: two modes in which authors produce dialectal works. The first body of work we can analyse are authors who produce works known as "literary dialect", the second concerns authors who produce "dialect literature". Literary dialect is the 'representation of non-standard speech in literature that is otherwise written in Standard English' (Shorrocks, 1996: 387). It is also often 'aimed at general readership' (p.387) and for this reason is a frequent and popular mode of writing, appearing notably in Victorian works of George Eliot, Charles Dickens and Thomas Hardy. Dialect Literature, on the other hand, are 'works composed wholly (sometimes partly) in a non-standard dialect, and aimed essentially, though not exclusively, at a non-standard-dialect-speaking readership' (p.387). Examples can be found in the poetic works of Victorian writers such as Robert Burns (who used Lowland Scots dialect), Alfred Tennyson's (used Lincolnshire dialect), and William Barnes (a Dorset dialect speaker).

Where a writer places their dialect can vary. A simple framework provided by Short (1996) and modified by Hodson (2014) suggests three core positions in which dialectal speech might appear: in direct speech and thought, within the narrative, and via 'free indirect discourse'. Direct speech is typically punctuated with speech 
marks and will be introduced by a reporting clause (Short, 1996:289), within the narrative is typically a 'narrative representation of speech acts' (p.297) occurring if the narrator is a named character in the story (Hodson, 2014:86), whilst free indirect speech/discourse (Short,1996:306; Hodson, 2014:87) involves the blending of narrative voice and speech of a character.

\subsection{Literary dialect as linguistic evidence}

Using literary dialect for linguistic evidence has received mixed receptions from linguists in the past, the subject usually being dismissed on the grounds that creative fiction should not 'merit serious linguistic consideration' (Sullivan, 1980: 195). Shorrocks (2000) comments that throughout English dialectology's history, investigation of literary dialect and dialect literature are often neglected (p.97-98). However, Shorrocks (1996) believes it curiously ironic that those studying dialect within the sociolinguistics field have also neglected the study of dialect literature, especially when 'non-standard dialect literature is itself a phenomenon of considerable social import' (p.385). Shorrocks's $(2000,1996)$ view suggests that the study of both literary dialect and dialect literature can be beneficial in piecing together linguistic information about historic speech communities' varieties.

Sullivan (1980) was an early pioneer in approaching literary dialect from a sociolinguistic perspective, asking whether laymen's dialect observations and renderings in fictive dialogue coincided with what sociolinguists knew from dialect surveying. Sullivan's study of Hiberno-English representation in theatrical portrayals unearthed qualities that have been noted in sociolinguistic studies. Sullivan (1980) believed that rather than examine whether or not dialect $X$ has an 'authenticity' we might ascribe to it, it is as important to investigate other dimensions of a linguistic variety in a fictive text. To quote Sullivan:

The utilization of different linguistic varieties is dependent upon situational and/or demographic variables, and linguistic variation is no longer considered a random phenomenon, either at the individual or community level, but is now viewed as a social phenomenon correlated with either demographic or contextual factors, or both. Sullivan (1980: 205).

Consequently, Sullivan discovered four unique usages and variations of the HibernoEnglish by playwrights: demographic variation, contextual-situational variation, individual inconsistencies, and diachronic shifts (1980:205). For demographic 
variation, Sullivan noticed that different characters displayed varying gradations of Hiberno-English forms, with footmen and domestics speaking dialect, while those in higher positions using Standard English. For contextual-situation variation (where one might expect to see a character's dialect 'shift' depending on the receiving character's status), Sullivan discovered little other than occasional shifts to Irish Gaelic (rather than a Standard English), theorising that literary dialects may not be 'optimal devices' to execute the phenomenon because as it might confuse an readership already 'attuned' to a specific dialect (Sullivan, 1980:208). Individual inconsistencies were discovered, though they were often not uniform, with characters using both standard and nonstandard features in a single utterance. Sullivan (1980) suggests that these might be artistic choices rather than linguistic, actual variation in the patterns themselves, or a combination of both. Finally, Sullivan noted diachronic shifts from dialect representations focusing on phonological variation being the 'marker' of dialect to one emphasising syntactic changes, with phonological forms becoming less popular through time (Sullivan, 1980:210).

From constructing a chronology for Hiberno-English in plays and subsequently analysing not only form but function by author, Sullivan concludes that even though authors' literary dialect were not 'linguistically complete reproductions', the portrayals of the variety have 'reflected certain aspects of the dialect rather accurately' (Sullivan, 1980:212). Ultimately, 'features of a literary variety are, in at least some cases, based on actual dialect phenomena and ought not be considered as fictitious as linguistic critics have often alleged them to be' (Sullivan, 1980:212). Sullivan warns, however, that literary dialect is an inadequate substitute for actual fieldwork, although, may serve the function of supplying missing language forms absent from the historical record (p.212).

Ellis (1994) also asserts that linguists should not dismiss the valuable data embedded in literary dialectal representations. To Ellis, a sociolinguist needs to assess the reliability of both individual authors and their individual works, primarily because the execution of literary dialect is a question of style, to quote Ellis: 'for many authors the accurate and objective rendering of regional speech was not a primary concern' (p.128). Rather than completely dismissing literary dialect, Ellis advocates sociolinguists acknowledge literary dialect's pros and cons. The advantages are clear: firstly, unlike surveying data, linguistic evidence in literary dialect can be both 
abundant and often accessible (especially if editions have been reprinted). Secondly, we must acknowledge authors' purposes for rendering dialect; Ellis (1994) argues that many authors want to represent dialectal features in fictional literature to act as record, fearing that lexical or phonological features could otherwise be lost because of the encompassing influence of written standards (p.128). That in mind, a sociolinguist investigator should be wary of the disadvantages. In order to emphasise dialectal features, authors can be easily exaggerate features of regional or socially divergent characters (Ellis, 1994: p.128). Ellis forewarns that analysts must also be aware that although no two authors of literary dialect are identical, authors will draw from common pools of features regardless of whether features correspond with a specific dialect and time period. For example, in American Englishes, authors may draw from 'General Low Colloquial': an extensive data-set of spellingpronunciations and nonstandard grammatical features often used to represent 'rustic speech'.

Recently, Hickey's edited volume Varieties of English in writing the written word as linguistic evidence highlights how the written form (both non-fictional and fictional) may be of linguistic value providing us historical linguistic evidence of varieties' histories (see Hickey 2010a). In Hickey’s volume (Hickey, 2010), several contributors use this approach to assess how examples of written linguistic varieties from the past can inform us of present day composition of particular varieties. For example, Katie Wales (2010) investigates Northern English [English] in writing, Gunnel Melchers (2010) investigates Southern English [English] in writing. And, within this volume, Hickey investigates how the representation of Irish English in early modern drama birthed particular linguistic stereotypes Hickey (2010b).

Dialectal scholars of the earlier $20^{\text {th }}$ century have taken literary representations at face-value, particularly if authors were long-time residents of an area. Ellis (1994) stresses that modern sociolinguistic analysis of literary dialect should not be so callous: 'residency alone is no guarantee that a literary representation is authentic (p. 129). Should authenticity of dialect be sought, Ellis remarks that a sociolinguist need only refer and compare material to the 'wealth of detailed linguistic evidence generated over the last fifty years' (p.129), such as dialectal surveys. Citing Ives (1950), Ellis suggests literary dialect will be authentic if 'a significant number of features used [...] are also found in the corresponding present-day dialect' (Ellis, 
1994:129). Ellis notes that although this method should be the basis for a comparative approach, an important limitation is that 'overreliance on more recent evidence may lead to a tendency to ignore the fact of language change - a literary dialect might contain authentic features which have since become uncommon or disappeared altogether' (p.129). Ellis' final caveat concerns exaggeration to suit ulterior, subjective purposes (rather than objectively highlighting dialect). Ellis states that usage of exaggerated dialect in literature can be used for 'comic, thematic, and [...] political purposes', for example the comic mispronunciations and malapropisms in $19^{\text {th }}$ century dialect literature indicates 'intentional exaggeration on the part of authors' (p.139-40). This therefore 'creates perhaps the greatest single complication for a linguistic investigation' especially if an analyst wants to use literary dialect for linguistic evidence (Ellis, 1994:139-40).

Regardless of whether or not the author is using dialectal depiction within fiction for an ulterior motive, Ives (1950) makes a clear point that all sociolinguists seeking 'linguistic evidence' from texts should take heed of the fact that authors are first and foremost artists (Krapp (1926:525) insisted we refer to dialect writers as: 'dialect artists'), not trained linguists; and that the reader is a casual consumer, again - not somebody with linguistic training and interest. To cite, Ives:

Nearly all examples of literary dialect are deliberately incomplete; the author is an artist, not a linguist or a sociologist, and his purpose is literary rather than scientific. In working out his compromise between art and linguistics, each author has made his own decision as to how many of the peculiarities in his character's speech he can profitably represent. (Ives, 1950; cited in Sternglass, 1975: 201.)

Wherever an author's rendition of dialect is upon a linguistic-artistic scale, it should be emphasised that their usage of such literary dialect is not necessarily static either, an author may change their opinions and usage of literary dialect over time. McCafferty (2005) reports that William Carleton did this for his representations of Hiberno-English, where he moved from linguistic stereotyping to an aim of authenticity: "early in his career, the intention was to stereotype characters of whom he disapproved. Later dialect was intended to further his claim to have provided authentic portrayals of the peasantry' (McCafferty, 2005:341). For example, Carleton depicted Irish Catholics speaking Hiberno-English, whilst he rendered the speech of Protestants with Standard English; two discrepancies which probably were not present in these speech communities (p.345). McCafferty (2005)'s study of 
Carleton's work also revealed that Carleton would later use a distinct literary dialect device in which he would specifically use a Hiberno-English as substitution for a character who was realistically speaking Irish Gaelic (p.343).

Azevedo (2002) argues that linguists should question how literary dialect has been used by the author, suggesting that authors can use literary dialect as a powerful tool to question normative language conventions, especially in static written orthography. By using socially stigmatized speech and subverting grammatical norms and 'proper usage', an author of literary dialect 'implicitly questions the purism that lies at the foundation of linguistic normativism' (Azevedo, 2002:510). A commentator (whether linguist or not) should avoid superficial readings of literary dialect as simply 'flavouring' the narrative, or that it solely acts as 'inconsequential comical device[s]'; Azevedo argues that there is more to its representation on page than 'binary oppositions' such as 'standard' vs 'nonstandard' or 'correct' vs 'incorrect' that in many cases literary dialect operates as a 'marked code', with contrastive values and 'complex relationships among linguistic modes' (p.511). Through defamiliarizing language, an author's work demands interpretation, 'not only for its denotative meaning, but also for crucial sociolinguistic connotations': the features a standard language (or orthography) possibly hides (p.511). Azevedo (2002) concludes that 'literary dialect challenges us to interpret not only semantic meaning, but also the significance of specific language norms' (p.511).

Azevedo (2002)'s approach is in-line with Susan Ferguson's philosophy that as linguists investigating dialect in literature we should move beyond simply rating texts on their real-world accuracy, authenticity, or consistency, and to instead view them as central components of the fictional worlds in which they appear (Ferguson, 1998:3). This method of linguistic analysis, that Ferguson dubbed 'ficto-linguistics', is distinct from methods of carrying out a purely sociolinguistic textual reading, for it treats a text's and characters' language varieties as isolated and unique, albeit derived from real-world varieties.

Indeed, this concept of authenticity, both within sociolinguistics and within literary dialect studies, have been thoroughly interrogated in recent years. Eckert (2003) argues that the value that sociolinguists and dialectologists have traditionally placed the concept of 'the authentic speaker' has been misguided in that what has been 
judged as 'authentic' of a speech community has been the language user who does not leave it. Eckert (2003) elaborates: 'neither social locations and identities, nor language, are static. Is the person who remains centrally located in what is viewed as prototypical practice more authentic than the person who is pushing the envelope?' (p.393).

It is perhaps better to view authenticity less as a neutral quality and more like subjective judgements made by those within speech communities. Coupland (2007: 180-2) set out five qualities of 'authenticity' within social networks, i.e. for things to be authentic speakers will believe them to have: ontology, historicity, systematic coherence, consensus, and value. In relation to 'authentic' dialect: ontology purports a dialect should exist in the real world, historicity means it has not been 'made to order' thereby having established longevity, systematic coherence refers to how it would be 'properly' constituted within their the social groups that use it, consensus details how its speakers authoritatively judge it to exist, and value means it has worth to its speakers (or analysts). In relation to stylistics of literary dialect, Hodson (2014:226-227) argues literary dialect fails many of these tests. They do not have ontological existence beyond page or screen; they lack both well-established historicity and systematic coherence 'within society as a whole'; there is little consensus regarding a literary dialect's authenticity; and finally whilst a novel may have value, rarely does the dialect used by characters have a sense of value for readers.

Hodson (2014) argues that 'where claims are made about authenticity of a specific literary dialect, this is always achieved by demonstrating that the features of the literary dialect correspond to the features of the real-world' (p.227). This is already problematic if the benchmark of 'authentic' dialect features in sociolinguistics are already suspect (Eckert 2003). Nevertheless, say we are to take the systematic work of dialectology as a 'level' of authenticity, literary dialect is always deriving its authenticity at one remove from real-world varieties. In this way, literary dialect is an 'authenticity parasite' (Hodson, 2014: 227). Here, any real-world dialect used in fiction is recontextualised: whatever original set of meanings the variety had, having a new fictive context gives it new social meanings. For this thesis: there is Welsh English, and then there is its fictive dialectal parasite: a sort of 'Welsh Fictive English'. 
Coupland (2007) argues that 'instead of glorifying authenticity or dismissing it out of hand, we can approach it in other ways' (p.25). We can, for example, observe how authenticity is often 'earned discursively rather than automatically credited' (Coupland, 2007:184). There is great worth in analysing commentaries by dialect writers and/or readers who comment on authenticity. Indeed, Leigh (2011) in their $\mathrm{PhD}$ thesis, notes that for many literary dialects in the nineteenth century, 'authenticity' was always the product of 'extra-textual transactions between writers and readers'.

Such an approach is useful when looking at dialectal authenticity in film (Hodson, 2014). With film, sociolinguists are rarely looking to recover linguistic forms in the same way they are within historic written texts (although we can of course compare film accents to 'real world' equivalents). For viewers, however, the focus is often placed upon actors' performances of accent (Hodson, 2014:231), rather than a screenwriter's script. Each viewer may rate accent performance independently; a well-performed accent might rate poorly if the viewer is familiar with the actor in question. Hodson (2014) writes:

the audience accepts the illusion that a 'good' accent is being performed and does not think about it further unless something (such as personal familiarity with the variety, or knowledge of the actor's natural accent) triggers more careful attention. (p. 231).

What is of interest for filmic dialect's 'authenticity' is often the discourses that surround film texts. This can be marketing, interviews with actors, or film reviews. Much like literary commentary, these discourses help sociolinguist analysts to 'recognise that dialect is frequently part of a much broader construction of authenticity' than just textual representation (Hodson, 2014:234). Ultimately, as Hakala (2010) comments, "we should not [...] discount the importance of the idea of authenticity in identity formation' (p.14). Simply: it matters because readers, viewers, reviewers, directors and writers believe that it does.

To summarise, using a literary dialect for linguistic evidence can prove beneficial, especially when used alongside dialectal surveying (Ellis, 1994; McCafferty, 2005). Although, it must be stressed that not all authors aim to present authentic dialectal 
speech and even authors who believed they were presenting authentic dialect may have been mistaken. Therefore, linguistic evidence we take from literary dialectal texts can certainly be more than attested linguistic features, all texts have other dimensions of ficto-linguistic analysis (Sullivan, 1980; Ferguson, 1998), some of which can inform of us of how readers and writers perceive the notion of 'authentic' dialect on page or screen (Leigh, 2011; Hodson 2014; Hakala, 2010).

\subsection{Authors' methods for representing dialect}

\subsubsection{Representation of linguistic domains (lexis, grammar, phonology)}

The three core linguistic areas that authors of literary dialect focus upon when representing dialect align with observances from dialectology: vocabulary, grammar, and phonology. Regarding vocabulary representation, words provided can range from dialect words (i.e. geographically-associated words), sociolectal, and even colloquial registers. Some words provided may even be respelled to emphasise their 'nonstandardness' (Blake, 1981:17). Hodson (2014:101) notes that 'paratextual' dialect glossaries may also accompany texts at the front or rear of a text.

Grammatical representation in literary dialect tends to be less common than lexis and phonology. Standard English speaking characters might be portrayed with perfected grammar, despite, as Hodson (2014) notes, the fact spoken language will not mirror the type of grammatical forms found in writing (p.102). Dialect speakers will be represented speaking stereotypical forms typically eschewed by prescriptivist grammarians, some of the most common being double negatives and lack of agreement between verbs and nouns.

An area of much interest in literary dialect studies is the representation of a variety's phonology upon the page. 'Semi-phonetic respelling' is the respelling of words in an 'endeavour to communicate something about [a character]'s accent to the reader' (Hodson, 2014:90). Some respellings are 'phonetically transparent' and will allow many users of other varieties to understand the idiosyncrasies of the variety on page, for example TH-fronting in London English being represented with a $\langle f\rangle: / \theta /$ becomes /f/. Meanwhile, others are 'phonetically opaque' and would require a reader to be familiar with the accent to understand the difference, for example, rendering $\langle\mathrm{dog}>$ as $\langle\mathrm{dorg}>$ suggests a long vowel to an RP speaker, but to a rhotic 
speaker of American English might suggest medial rhoticity /r/. This can be detrimental to the reader, as their 'ability to identify the intended pronunciation depends upon their own accent' (Hodson, 2014). Ultimately, without knowledge of the accent, semi-phonetic respelling is risky, and can frustrate the reader - creating a puzzle out of the narrative flow.

Toolan (1992:34) referred to this frustration or adversity as 'reader resistance'. Readerships will feel that their reading will be 'a spirit of enforced labour'; resulting in reading speeds decreases, the loss of important plot information (if a reader misunderstands speech), and the decision by the reader to skip texts' dialogues. Regardless whether a dialect author overtly acknowledges the phenomenon, Hodson (2014:110) reports that they may still combat reader resistance through using several literary devices. First, they may be deliberately inconsistent in the dialect representation, using marked forms at the beginning of the text, and less as the narrative continues (e.g. Arthur from Alan Sillitoe's Saturday Night and Sunday Mornings). Second, an author might choose to voice a protagonist or central character in a Standard, even if logically they would be speaking a nonstandard variety alongside peers (e.g. Charles Dickens' Oliver Twist). Finally, dialect speakers may simply be treated with less respect: the speech gets less representation, their speech is less intelligent, or it's used for laughs.

Similarly, in film measures are often taken by the production to tailor the dialectal speech of characters. There may be genuine restraints regarding how 'authentic' a film's dialectal speech can be (see Hodson, 2014:61-65). The first limitation concerns production restraints. Filmmaking is expensive and investors often want to make profit, which often leads to 'star' actors in roles. This approach often requires the expertise of dialect coaches who can train actors to tailor their accent, however, even this is limited by time and money; furthermore, actors' aptitudes for acquiring accents, much like Second Languages Acquisition, will vary unpredictably. A second limitation concerns reception restraints. There is the risk that real-world portrayals of accent on-screen may do more to alienate audiences, and therefore balances may be struck between a mixture of familiar Standard forms and nonstandard forms (this applies lexically and grammatically too). It should also be noted that script-tidying also occurs. Because actors work by memorising written 
scripts, the idiosyncrasies we find in spoken discourse (e.g. hesitations like 'err', and pauses) are often omitted.

\subsubsection{Use of 'Eye-dialect'}

Another key word common to the literature is 'eye-dialect', a contested practice that has been observed throughout the history of literary dialect study. Its commonality with literary dialect practices is that eye-dialect also uses respelling conventions, however, it is the purpose of the author's respelling that is different.

The Oxford English Dictionary (hereafter $O E D$ ) defines eye-dialect as 'unusual spelling intended to represent dialectal or colloquial idiosyncrasies of speech' (emphasis mine). Krapp (1925:228), an early observer of this phenomenon and coiner of the term, notes that 'impression of popular speech [i.e. spoken discourse represented by orthographic illustration] is often assisted by what may be termed 'eye-dialect', in which the convention violated is one of the eye, not of the ear.' For example, Krapp gives the examples 'frunt' for 'front' and 'pictsher' for 'picture' as examples of eye-dialect and states that a writer does so not to indicate 'genuine difference of pronunciation', but to give a 'friendly nudge to the reader', that the speaker speaks 'in dialect' (or what today we would identify as a non-standard variety). Another name for this phenomenon, which is attributed to John S. Kenyon, is 'pseudo-dialectal' spelling (Bolinger, 1946:337). Cook (2016) groups together three common eye-dialect tendencies. The first is that writers utilising eye-dialect may render unstressed weak forms of English words in new phonetic respellings, e.g. 'fer' for 'for' or 'yer' for 'your'. The second is 'alternative eye-dialect spellings for the same sound', e.g. 'wot' for 'what', 'bludy' for 'bloody'. A final characteristic Cook identifies is 'sundry exclamations', in which the exclamation mark is overly present for dialectal speakers. Macaulay (1991) contributes an additional characteristic within the punctuation category. Although punctuation can be used to show tempo or rhythm by using hyphens, eye-dialect discourse may also use apostrophes to note elision and thus given the text 'the appearance of colloquial language' (emphasis theirs) for the dialect speaker (Macaulay, 1991: 281). Such features are odd because vowel reduction, elision and consonant cluster simplification are very common features of most spoken language regardless, 'Standard' or otherwise. 
However, according to Levenston (1992), deviating from conventional spelling is often done to indicate deviation from conventional pronunciation and examples of this in English are found as early as the Reeve's Tale in Chaucer's Canterbury Tales (p.45), authors sometimes choose to deviate the spelling and grammar to denote the speaker is uneducated (p.54). In which case, eye-dialect will be used to mark sociolectal difference. Levenston explains that the phenomenon of eye-dialect can make 'the eye perceive [the eye-dialect] as nonstandard forms, though the ear recognizes the normality [in its pronunciation]' (Levenston, 1992:55). Bolinger (1946) believes that the misspelling component of eye-dialect usage provides a 'substitute for mispronunciation' that 'suggest[s] [...] the speaker is at the level of ignorance', for if 'one misspells in this fashion, hence [they] mispronounce as well' (p.337).

Deliberate misspellings are common, as is the use of apostrophes denoting absent phonemes. In an analysis of Stephen Crane's Red Badge of Courage, Walpole (1974) discovers that Crane's usage of eye-dialect is spread liberally, but illogically, for instance 'them' is rendered as both ' 'em' and ' $\mathrm{m}$ '. Walpole's conclusion for such inconsistency is that:

[For the writer] it's impossible to show all speech variations by using the standard alphabet and an apostrophe. [...] Hence only a few selected words are misspelled just enough to indicate ignorance and locality - while the remainder of the 'dialect' dialogue is properly spelled. (p.193)

Walpole (1974) touches upon a psychological explanation for the reader encountering eye-dialect in text, believing that a reader's 'inner ear' supplies the dialect based upon the reader's mental 'acoustic image', upon memories of discourse and upon the reader's knowledge of language varieties (p.195), effectively: 'as he reads dialogue, he transmutes orthography into recollected sound' (Walpole, 1974:195). Therefore, it will echo their own imagined version of each character's voice, no two readers will render it the same in segmental and suprasegmental phonemic features, yet ultimately, the reader will be satisfied. Walpole concludes that 'like standard orthography, eye-dialect is merely a typographical convention, an arbitrary cue to the reader and not an accurate written reproduction of speech (Walpole, 1974:195). In all, during analysis of dialect in fiction, one might conclude from this that encountering a writer's usage of eye-dialect in-text should raise 
warning flags: not only showing their unwillingness to complete their own dialectal inquiries, but also disrespect to the dialect character they are portraying and their real-world speech community.

Preston (1983) goes further and makes a clear distinction between two types of eyedialect: liberal eye-dialect and Strict/True eye-dialect. We can use Preston's example of a written dialectal variation for the word skeleton: 'skellipin', to illustrate the difference. In this example, respelling the second $\langle\mathrm{e}\rangle$ as $\langle\mathrm{i}\rangle$ and the $\langle\mathrm{o}\rangle$ as $\langle\mathrm{i}\rangle$ are examples of liberal eye-dialect: they are unnecessary alterations because common speech would dictate that both these sounds would be reduced to schwa; they are ordinary phonological processes that needn't be differentiated, although the attempt to bring them into the same phonetic script of $\langle\mathrm{i}\rangle=/ \mathrm{I} /$ is arguably admirable. The inclusion of second $<1>$, however, has no purpose other than to make the word look more dialectal and 'othered' compared to the standard written form. The alteration of the grapheme $\langle\mathrm{t}\rangle$ to $\langle\mathrm{p}\rangle$ is the only genuine mark in the transcription, and has been used to illustrate the change of a interdental plosive to a bilabial plosive. Preston argues the only 'justifiable' respelling would therefore be <skelepon> (Preston, 1983: 320).

It is evident that usage of English eye-dialect is intertwined with utilising a new orthography, but in a 'twisted' manner that offers little linguistic value - just suggestive, perceptual value. It could be suggested that the only reason eye-dialect can exist so wholeheartedly in English dialect texts is due to the English orthography being a system that allows a wide variety of realisations for the same set of sounds. It should also be noted that eye-dialect is not an exclusive English trait, but is found in other languages too: for example Spanish eye-dialect has also been used in Hispanic fiction (See Nuessel, 1982).

It should be noted that a writer's application of eye-dialect may be beneath their conscious awareness. For the writer, eye-dialect may be part of their phoneticrespelling repertoire alongside the rendering of genuine phonological differences. This is illustrated well in a notorious scholarly debate that erupted between dialectologist Dennis Preston and folklorist Elizabeth Fine (See Preston, 1982; Fine, 1983; \& Preston, 1983). When Preston criticised folklorists for relying too heavily on eye-dialect tactics in their notations instead of phonetic transcription, Fine, a 
folklorist, misunderstood, thinking that Preston was attacking all usage of literary dialect. Fine was unable to understand that many eye-dialectal forms (like 'wanna' and 'gonna) used by folklorists are indeed features of all English rapid speech and do little for giving additional linguistic evidence on a particular dialect. What is poignantly apparent from the debate is that the use of eye-dialect may be invisible and unconscious to the user of eye-dialect (whether a fictive writer or not).

In recent years the literature within the literary dialect field has begun to use 'allegro speech' to refer to this subset of eye-dialect, a subset that asserts a nonstandard difference, however is in fact simply reminiscent of rapid speech of most language users: e.g. vowel reduction (e.g. 'want to'/wanna) and phoneme omission (e.g. 'aven't) (Hodson, 2014:95-99).

\subsubsection{Metalinguistic observations}

One final consideration when analysing the representation of dialects in fiction, is an author's, and by extension: characters', own overt commentary about the dialect. In other words, their metalanguage (talk about talk). Hodson (2014) explains that 'writers can $[\ldots]$ make use of metalanguage to define dialect words, describe speech styles and explain why dialect is being represented in a particular way' (p.148). Hodson (2014) provides a linguistic framework for analysts assessing metalinguistic placement in-text in four placements (Hodson, 2014:151-159).

1. Paratextual placement (PP): descriptive and authoritative and originates from the text's implied author and exists outside of the text-proper. Although written exclusively from the text, it can still contain subjectivity bias. Examples include prefaces, glossaries, footnotes, etc.

2. Third-person narration placement (3PN): descriptive and authoritative and originates from the text's omniscient narrator and implied author of text. Readers are not invited to reflect upon the omniscient author's opinions about their linguistic commentary, nor whether they may not be accurate. E.g. The man spoke with a coarse brogue

3. First-person narration placement (1PN): Not an omniscient observer, but participatory within story, offering subjective thoughts into the mind of the 
character. 1PNs rarely acknowledge their thoughts on a dialect are subjective. E.g. I didn't like the way he pronounced his Rs

4. Character speech and thought (CST): The speech and thoughts of characters as they judge one another's language usage. Provides readers with insights into the sociolinguistic work the speaker is trying to accomplish, e.g. distance themselves, or accommodate.

Regarding film, metalanguage is less frequently used and less overt largely because there is less opportunity for it to occur with just CST and occasionally 1PN being the options (Hodson, 2014:164).

To summarise, dialect authors may use both semi-phonetic spellings and/or eyedialect to represent something of a phonetic difference to the reader from the Standard. They may use vocabulary that is non-standard, although transparent to the readers. And, although less common, an author may use nonstandard grammar to tweak grammar of dialect speakers. Authors will also 'metalinguistically' discuss dialect in multiple ways, either paratextually, or via narrative placement and character placement.

\subsection{Example case studies: previous scholars' literary dialect studies}

Literary dialect has been studied extensively for the last century. The following section acts as a sampling of previous methods and results, many are from scholars studying literary dialect, although not all were linguists like Sullivan (1980). Both literary dialect, dialect literature and the phenomenon of eye-dialect are considered by many of these scholars. From these scholars' work, frameworks were constructed for the current project on literary dialect representations of the WE dialect.

One of the earliest examples is Randolph's 1927 study of the 'Missouri Ozark dialect' within a range of fictional texts. Although Randolph is to be commended in his construction of an early 'corpus' of texts, his ruthlessly judgemental analysis earmarks Randolph as an early analyser of dialect - obeying few objectively linguistic norms. For example, Randolph states: 'I have read [fifteen] Ozark stories, and the dialect in every one of them is very bad indeed. One could write volumes on the subject' (Randolph, 1927: 283). Randolph's aim seemed to have been to question 
authenticity of dialectal representations and to illustrate how poorly authors had depicted it thus far. However, the benchmark that Randolph uses to judge authenticity is simply his own experience of having lived in the area. For example, for a text by a preacher Monteith, he states: 'the Ozark natives that I know do not pronounce afore and nigger in the Monteith fashion at all' (p.283). Nevertheless, Randolph was intrigued by new lexical items from Alice French's text, although had issues with the orthographic representations of particular pronunciations, offering his own alternatives: "Mucher is new to me, and ketched for taken would be better than cotched' (p.284). Randolph's early analysis took notice of inconsistencies. In J.N. Baskett's text, he questioned the use of pronunciation changes for the determiner $<\mathrm{a}>$ : 'It is difficult to see why the article $a$, which is unchanged before whopper and foot, becomes uh before lot, and er before fish-worm and string' (p.284). He also questions eye-dialect in C.E. Tuck's text: 'when one turns been into bin he is simply changing the appearance of the printed word, not altering the sound of it' and concludes: 'Tuck's work is full of this meaningless eye-dialect--he says plumb for plum, $u v$ for of, cum for come' (p.286). In all, Randolph's approach was concerned with quantifiable objectivity, 'I do not presume to discuss the literary merits of these Ozark stories, being concerned only with the dialect' (p.289), and although there is merit in this search for 'authenticity', in having done so he has not addressed authors' motivations and aims for representing the Ozark dialect.

Walser (1955) approached the topic of literary dialect by using the format of a chronological window choosing to study the 'Negro dialect' in a distinct period, between 1767 and 1789. Like Randolph (1927), Walser utilised a corpus of texts (10 plays). For Walser, although it was known that early forms of written African American Vernacular was within dramatized performances, Walser was surprised to find no researcher had attempted to investigate the dialect 'play by play'. In the 10 plays, Walser noticed that just one playwright was consistent in their usage of dialect, and that for many playwrights the spelling was 'capricious' and the grammar inconsistently variable (Walser, 1955:271). Similar to Randolph's (1927) observation of the Ozark dialect, Walser picked up on usage of the pronunciation differences for the determiner $\langle\mathrm{a}\rangle$ : '[Character $\mathrm{X}]$ 's [speech] is characterized mainly by the unaccented a', although speculates that this characteristic might 'possibly [be] intended as a personal trait rather than a general dialect practice' (p.275). This builds upon sterilely analyzing mere dialect in text (i.e. Randolph, 1927) by acknowledging 
potential idiolectal differences within a dialect's representation in-text. Furthermore, Walser (1955) strongly believed through his analysis that 'all the Negro characters, [with one exception], were used for comic purposes in greater or less degree; and playwrights would thus be prone to overcolor the language in order to provide humor' (p.276), a conclusion that suggests that dialect stereotypes are fundamental to particular examples of literary dialect.

Randall (1960) also studied a Midland American English within literary dialect (much like Randolph (1927)'s Ozark treatment), examining in particular the Hoosier dialect utilised by James Whitcomb Riley. Randall wanted to analyse the literary dialect in the following three modes: to examine an author's 'modus operandi' (way in which a method is conducted); what an author's own comments surrounding their representation were; and, like other scholars, address the dialect's representation on page. Randall's analysis demonstrated that Riley 'suggested [Hoosier dialect] well' in fictive verse (p.50). Through examining personal letters that highlighted Riley's methods and opinions on the dialect, Randall discovered that Riley often reiterated a claim that his dialect speech was very accurate. Although this, when analysed, is an infallible claim to make, it gives us an idea of how dialect writers perceived their own work. For Riley's sake, however, Randall suggests that for the most part Riley was indeed accurate, with his accuracy being supported not only by local men and women of the time, as well as letters of $19^{\text {th }}$ century Indianaians, but also by dialect wordlists and more recent academic dialect surveys. In representing this, Randall (1960) does well in introducing a format of tables to illustrate Riley's representations of the dialect, dividing the tables into sections such as: Pronunciation (using International Phonetic Alphabet phonetic script), 'Morphology and Syntax', 'Vocabulary', and instances of 'eye-dialect'. Methodologically, Randall's format is a sound and clear approach to analysing a specific author's usage of dialect, identifying not only on its merits but also its weaknesses (see Randall, 1960:41-44 for example of this method).

Malin (1965) approached literary dialect from analyzing a medium other than textual verse by studying the use of eye-dialect in the Li'l Abner satirical comic book strips drawn by Al Capp. Acknowledging that eye-dialect is not only a 'particularly common feature among American authors' (p.229), but has been appropriately analysed by scholars in the past. Malin's question was: why had there been no 
treatment of comic strips, which also contained heavy usages of phonetic respelling? In analyzing the Li'l Abner strips Malin found that Capp utilized Standard Orthography for most city-dwellers, however exceptions were made for speakers from Brooklyn, New York as well as underdeveloped outskirts, which Capp coined with the derogatory term: 'Lower Slobbovia' (p.230), playing on both the informal English word 'slob' for somebody lazy, and the -ovia Eastern European toponymistic suffix. For the 'Dogpatcher' characters, who were rural, Capp used eye-dialect of an inconsistent variety to mark their comical attitudes (p.231). On technique, Malin (1965:231) states that it is rarely difficult to read Capp's phonetic respelling, as the unaccustomed spelling is etched out in heavy block letters, and embedded within the syntax in such a manner that words of Standard spelling 'cushion' the eye-dialectal word. Other features included hyphenating the eye-dialect to indicate potentially attesed polysyllabic stress, for example 'pree-dick-shun' and 'Yew-nited states'.

A study of Mark Twain's relationship with literary dialect by Carkeet (1979) highlighted the variation of dialects that can occur within a single text (e.g. The Adventures of Huckleberry Finn). The dialects in particular were the 'Missouri negro dialect' and the 'Pike-county' dialect (which itself contained at least five modified varieties). Metalinguistic commentary by Twain in the preface suggests that he included a variety of dialects in his work, however identifying them has long been a task for critics and scholars alike, Carkeet states that: 'some have given up the fight and concluded that the preface is a joke. Others have taken the preface seriously but have still failed to decode it' (p.315). After analyzing the text, Carkeet concluded that there were in fact 9 distinct entities that could be classified as a variety of English, three more than Twain suggests (p.321). Carkeet, however, notes that Twain's representation of speech for Huck had its own inconsistencies. Carkeet provides a valid reason for such inconsistency; by drawing upon journalistic notes left behind by Twain he discovered that the author had written two fifths of the novel in the summer of 1882, and three fifths in the summer of 1883. Carkeet thus speculates that despite dialect being written on the page in front of him, Twain had an imperfect recollection of all the details of the dialects he had [previously] written' (emphasis mine) (p.328). Carkeet argues that although more varieties were discovered in-text (possibly due to above inconsistencies), there were in fact seven distinct varieties that Twain had in mind when writing Huckleberry Finn, and that 
the preface should not wholly be read as a joke because there is sufficient evidence within the author's commentaries that suggested he had an 'abiding interest in folk speech' (p.331). Indeed, the original manuscripts are coated with marginalia showing adjustments to the speech of characters; such amendments demonstrated that Twain had an 'earnestness in the representation of dialects' (Carkeet, 1979:331).

Analyses of sociolects within literary dialect have also be conducted with Smith (1987) analysing the social prestige of Yorkshire Englishes represented within Charlotte Bronte's text: Shirley. Smith notes that Bronte realized that language acted as 'a central marker of the acute division separating these [working] groups' (p.637). Hiram Yorke is presented as a 'bi-dialectal' character, who could speak with an 'educated Middle-Class accent [sic] and a 'Yorkshire Burr' (p.638), the function of his sociolectal variation acting as a literary device to bridge the gap between the classes. In another instance, Smith reports that the character Caroline 'adopts [the character] Martin's vocabulary in order to minimize the difference between herself and him' (emphasis mine) and understands that 'dialect and accent are social markers' (p.642). Sociolinguistically, today we would read Caroline's 'adoption of vocabulary' to 'minimize difference' as an example of 'accommodation theory' (See Giles \& Powesland, 1975: 155-180). What is ultimately missing from Smith (1987)'s analysis is a true sociolinguistic reading of the text, although her literary reading serves its purpose to present Bronte as a literary dialect writer eager to represent the continuum of speech in Yorkshire during her time of writing. Smith concludes that the bi-dialectal characters serve the function of being 'subtle reminders that the social system is not fixed and unchanging [and] bi-dialectal characters undermine those underlying assumptions and subvert the system through their control of language' (p.643).

Much like Carkeet (1979)'s investigation of Mark Twain (see above), Tamasi (2001) also studied Twain's various dialects in The Adventures of Tom Sawyer and The Adventures of Huckleberry Finn, notably the aforementioned 'Missouri negro dialect' and 'Pike-county' dialect. Tamasi's chief aim was in analysing how 'consistent' the character of Huck Finn was between these two novels: what was the relationship between a character's development and the representation's development of that character's speech? (Tamasi, 2001:130). Tamasi (2001) concluded that Twain was consistent in some dialect features (e.g. use of 
contractions, g-dropping), though variation did occur in Huck's speech in later novels with eye-dialectal features such as 'becuz', 'bout' and 'nuther' changing to standard forms. Tamasi's theory is that Twain 'consciously changed how he represented dialect between books' as a means to reveal 'the personalities and complexities of [...] characters' and suggest that due to Huck's social changes, his speech was altered to reflect a change to his personality (p.141). In all, Twain's inconsistency was designed especially to reflect sociolinguistic style shifts.

More recently, there have been several treatises of literary dialect across larger chronological periods and across various modes of representation. In scope, it is these examples which parallel the work that has been completed on WE in fictional narratives in the present thesis. One of the key examples is Hodson \& Broadhead (2013). Choosing a tight chronological window (much like Walser, 1955) of 1800 to 1836, the authors investigated the literary dialect representation throughout several British Englishes: Scots, Irish English, WE, London English and the Regional England Englishes, from a variety of authors. The aim was to describe changes in the representation of dialect during the latter half of the Romantic Period, a time when the stereotyped 'Stage' dialect characters were being replaced by characters that were more in-line with the target dialect in question. The authors insist that rather solely looking for authenticity when analysing literary dialect, they focused upon means in which dialect is both executed and perceived by 'ordinary speakers'. In conclusion, they noticed an overall increase in dialectal representation, with earlier novels acting as satire that depicted dialect-speakers with 'broad brush strokes' and narrow ranges of stereotyped features (p.321). They also noticed that it was during this period both Scots and Irish English representations became widespread (p.323). Perhaps the most interesting observation in regards to this thesis' research was that unlike the above Celtic Englishes, WE representations in the period, which were 'already infrequent', completely dried up in the later period to a point of non-existence (p.326). Although the authors chose texts that potentially promised WE (e.g. Griffith ap Griffith's The Sons of St. David, 1816; Anonymous' The Mortimers, or the Vale of Machynllaeth, 1828), no texts alluded to a WE in any form (p.327).

Hodson \& Broadhead (2013) note one occasion of WE in Thomas Love Peacock's Headlong Hall (1816). For example, Peacock writes a WE dialectal character thus: 'Cot pless your honour! I should n't have thought of meeting any pody here at this 
time of the morning, except, look you, it was the tevil' (Peacock, 1816: 128-129, cited in Hodson \& Broadhead, 2013: 327) (emphasis mine). The authors observe that Peacock, 'draws on a repertoire that dated back to at least Shakespeare's day,' (p.327) (my emphases highlight: devoicing of plosives, stereotyped discourse markers); ultimately concluding: 'there is no evidence of any author in the database attempting to expand the representation of [WE] (p.327). Though the authors do not provide explanation for the lack of WE in Victorian literature, they do speculate. Although the dominance of both Cymraeg and its literary tradition during this period likely demoted the importance of any Welsh English portrayals (p.327), there was overall little interest in Wales during this period quite possibly because unlike Ireland and Scotland, Wales had political stability: 'there was little motivation to develop less stereotypical representations of Welsh English' (p.326). Of all three Celtic Englishes, it was the Scots' lengthy linguistic history and literary tradition that ensured that that particular dialect developed a range of literary dialectal functions, this was less the case for Irish English (though see Zingg (2013) below), whilst WE served little to no function other than Shakespearean comical stereotyping (p.328).

Zingg (2013)'s Hiberno-English in Modern Irish literature: The Use of Dialect in Joyce, O'Brien, Shaw and Friel investigates a selection of texts from four key authors who used Hiberno-English within their writing as a literary device: James Joyce, Flann O'Brien, George Bernard Shaw and Brian Friel. Altogether the period covers 80 years, and incorporates several texts per author. Zingg writes that authors of the period were challenged to create a new literature, one independent of English literary tradition in Britain; the purpose of the monograph is to act as a large corpus and resource to record the abundance of the use of Hiberno-English as a literary device. In conclusion, Zingg (2013:307) suggests that the variety is chiefly used to raise the question of Irishness as a concept, although authors' motives vary in how this is performed. For example, Joyce uses the dialect for comical purposes and for satirising types of Irish people, notably the 'Citizen' archetype. O'Brien (the sole bilingual writer analysed) also uses the dialect for comedic and satiric ends, and even his translations from Irish Gaelic into Hiberno-English are represented through crude exaggerations; similar to Joyce he uses Hiberno-English for the archetype of the urban 'Dubliner' (p.309). In contrast, Shaw uses the variety to 'expose the stereotypes of the "typical Irishmen" by using mocking performances by speakers of 
other English varieties, whilst in the main accurately portraying Hiberno-English elsewhere (p.309), thus demonstrating how an author's metalinguistic awareness can be represented through use of literary dialect. Finally, Friel, the most contemporary dialect author analysed, represents a linguistic situation that encompasses Irish Gaelic, Hiberno-English, and several other varieties and language (such as Latin and Standard English) to create a more 'authentic' Irish speech community.

\subsection{Conclusion}

This chapter has addressed the linguistic field of literary dialect studies, summing up not only concepts and methods researchers have used to analyse dialect in fictive narratives, but has also illustrated influential key case studies useful to this thesis' methodological framework.

The chapter has identified Shorrock (1996)'s key distinction between literary dialect, where dialect appears sporadically in-narrative, and dialect literature, where the narrative is constructed solely of dialect; for literary dialect, its presence can vary between direct speech and thought, or indirect speech. We have also assessed whether it is feasible to use literary dialect as linguistic evidence, a subject of contention within sociolinguistics. Although dialect forms can be lifted from literature as examples of a period's speech (Ellis,1994), we must take into consideration that they are fictive lects written by 'dialect artists' (Krapp, 1926), and that sociolinguistic rules that govern real lects, for simplicity's sake, may not apply to a literary dialect (Sullivan, 1980). We should ask 'how' a literary dialect has been represented by an author (Azvedo, 2002, Ferguson, 1998), however, should 'authenticity' be sought, the wealth of dialectological data is always available for comparison.

The chapter was also concerned with authors' methods for representing dialect. We saw that authors will chiefly use a combination of lexical, grammatical, and phonological approaches to represent dialect and that representation of phonology permeates literary dialect studies, with analysts observing that phonetic respelling can be both phonetically transparent or opaque - more opaque examples then leading to 'reader resistance'. Also, authors may only want to create the 'appearance' of dialect by misspelling words using 'eye-dialect'. Metalinguistic commentary is also 
important as authors may define dialectal terms by using paratext, or through third or first person narration and character speech and thought.

Finally, the chapter has reviewed several linguistic studies on literary dialect. For example, Randolph's (1927) early corpus of the Missouri Ozark dialect; Walser's (1955) study that utilises a chronological window of $18^{\text {th }}$ century for study of 'Negro dialect'; Randall's (1960) study of 'Hoosier' Midland American English, which interrogates a dialect writer's metalinguistic commentary; Malin's (1965) study of 'eye-dialect' in comic books; Carkeet's (1979) investigation of texts where multiple literary dialects are present; Smith's study (1987) of social prestige in literary Yorkshire English, and Tamasi's (2001) investigation of an author's consistency in literary dialect representation. More recently, large-scale projects catering to British Isles Englishes have been constructed by Hodson \& Broadhead (2013) who studied British Englishes in $19^{\text {th }}$ century, and Zingg (2013) who studied Irish literary dialect.

Ultimately, there are many means of analysing literary dialect. Shorrocks (2000:98) best sums this up in saying literary dialect can be reviewed as 'aesthetic' or 'social phenomenon[s]', or as sources of 'linguistic evidence'; they can be analysed in terms of 'geographical [or] chronological setting', of 'social standing of characters', or their 'psychological states', and provide insights into how an author may 'critique established values'. So where does Welsh English fit in? Have there been any analyses of Welsh English within literary dialect? In a word: no. Hodson \& Broadhead (2013) clearly note that in Blake's 1981 survey of Non-Standard Language in English literature, he was unable to find any WE representation in the Victorian period. Indeed, little has been surveyed and documented elsewhere. The aim of this thesis is certainly to turn this notion on its head. 


\section{Chapter 4 Perceptions and attitudes towards language varieties, the Welsh English variety, and the Welsh cultural sphere}

It is essential that when we analyse a literary dialect, we must take into account the wider representation. Not only can we check a representation's form against what we know of the dialect from academic surveys, but we can also analyse its usage and purpose for what we know of the time it was written, and the stereotypes associated with those who spoke it. This chapter reviews previous work on language variety stereotyping, the attitudinal dialectal research conducted on the WE dialect, as well as cultural stereotypes associated with Welsh people - traits that form a basis for WE character/linguistic stereotyping.

\subsection{Dialectal discrimination and language ideologies}

There is a consistent pattern throughout the world's language communities regarding social evaluation of standard and non-standard speakers (Hodson, 2014). The Standard is often associated with high socioeconomic status, power and media usage. Personas such as these are created through, Hodson argues, 'historical influence, rather than intrinsic value' [and] 'because of [their] extrinsic associations [the standard] is typically evaluated more favourably on traits relating to competence (such as intelligence, confidence and ambition) in comparison with other (regionally marked, non-standard, urban, and minority ethnic) varieties' (p.26). Speakers of nonstandard varieties may even 'downgrade' themselves in comparison to the Standard, and will internalise 'judgements about their own language variety' made by others, especially those speaking the Standard (Hodson, 2014:26). They genuinely, psychologically believe that they speak poorly, despite often having no control over the myriad of processes that result in their language usage.

However, linguistic prejudice occurs even amongst neighbouring nonstandard varieties. Canon (2009) posits that attitudes are complex and loyalties to one's region connect with their dialect, and larger identity; simplistically, one speaker may view another in terms such as: "People who sound like me are a part of my home, my local identity, and that is good. People who don't sound like me are not part of my 
home - their home is elsewhere and the characteristics of that home place, including dialect, could threaten the local identity of my home"” (p.2).

Recognition that one is discriminating against a particular person's accent or dialect is widely unaccounted for by many, something that Lippi-Green (1997) believes is a modern societal anomaly. Historical language ideologies are still used to subordinate particular speech communities so that speakers can be actively marginalised:

What is surprising, even deeply disturbing, is the way that many individuals who consider themselves democratic, even-handed, rational, and free of prejudice, hold on tenaciously to a standard language ideology which attempts to justify restriction of individuality and rejection of the Other. (p.73)

\subsection{Dominance and subordinance of dialectal speakers in live-action and animated film}

Rosina Lippi-Green (1997) has extensively studied the relationship between the inclusion of English accents within animated film, and the attitudinal stereotypes that are attached to them. A collection of observations about film and dialectal portrayal are summed up in chapter 5 of Lipi-Green's 'English with an Accent' and shall be summarised below.

We must consider the processes in which dialects (or language generally) come to be represented in film. Firstly, it should be acknowledged that actors will bring to their role, through varying degrees, aspects of their natural variation of speech (i.e. idiolect and/or sociolect). Common practice is for the director to then request an actor to use a specific lect. This may be the standard, social, regional, or foreign accent of English in their production. If this is the case, then actors are often provided with accent training through the guidance of accent/dialect coaches (LippiGreen, 1997: 82-83).

Authorities on how to execute 'correctly' an accent on-film have existed since the beginning of film. An early guide from 1943 titled: Foreign Dialects: A Manual for Actors, Directors and Writers (Herman \& Herman, 1943) utilised what we perceive today to be pejoratively subjective descriptions of lects, descriptions certainly not grounded in objective research, to teach actors. For actors attempting to speak 
Cockney English, they described Cockneys as 'brash little fellows' who were 'inveterate heckler's' and whose speech was 'usually nasalized', providing the dialect with characteristics of a 'whine' (Herman \& Herman, 1943, 1978: 19). For foreign accented English, they advised that actors attempting to portray a Polish speaker of L2 English should try to sound religious, industrious, hard-working, yet pleasure-loving, and that Polish people are not 'what may be called a thinking man' for 'he is slow to thought, slow to speech, and slow to action' (Herman \& Herman, 1943:351). Descriptions such as these connote what we today see as racial, ethnic and most importantly to this discussion - linguistic stereotypes.

These early descriptions contrast somewhat with how dialect is perceived today, namely in that someone's dialect is not attached to biological advantages or disadvantages, such as intelligence; that they are inherently still able to pursue the same choices in the life (or the story), regardless of their speech. This is certainly the perspective taken up by modern dialect coaching guides. An excerpt from Karshner \& Stern (1990) highlights this view admirably:

Dialect actors must avoid going so far with certain speech traits that they end up creating ethnic or linguistic stereotypes ... language or dialect background does not dictate character actions. Characters with accents must have the same range of choices available to them as characters whose speech is identical to yours. (Karshner \& Stern, 1990:Preface).

Lippi-Green (1997:84) also observes that within film a foreign accent may be used to represent, or index, a foreign language. Lippi-Green (1997) cites Schindler's List (Spielberg, 1993) as a noteworthy example. In the film, British actor Ralph Fiennes plays a Nazi who speaks English with a contrived German accent, to suggest he would in fact be speaking German. Though Lippi-Green does not name this process, tentatively, we might coin the term foreign language accent correspondent, because it corresponds a foreign tongue to a foreign-accented target language. LippiGreen (1997) argues, however, that even here there is subtle linguistic prejudicial conditioning taking place, as the more brutal Nazi guards have thicker accents than the attractive leads, who have weak German English accents (p.103), itself a common practice in film, similar to 'reader resistance' (see 3.3.1).

Lippi-Green's core argument concerns the way in which accent/dialect is represented in animated film. More so than live-action film, language in animation is used as a 
'quick way to build character and reaffirm stereotype' (p.85) - in other words it can be used as a tool for quick, often stereotyped, characterisation: an 'Othering accent tool'. People rarely notice the blatant stereotyping (in our case, linguistic/dialectal) enacted in animation often because of animated film's 'assumed innocence and innocuousness' (Burton, 1992:23-4). Furthermore, due to animation's tendency to subvert realistic representation through simplification, analysts may use this animatic mode to study how a dominant culture constructs and perceives a subordinate culture. Often, negative characters in animations use contrived accents that parallel national fears of 'the Other'. For example, in the $20^{\text {th }}$ century both German English and Russian English accents were used to index 'badness' during the World and Cold War periods, and more recently, Middle-Eastern accented English has been used to denote the 'bad guy'.

Lippi-Green (1997) questions what people take away from these experiences; do they associate 'bad people' in films with 'bad accents'? Do animations play a role in teaching young people to discriminate based on language variation's attachments to race, ethnicity and place? Consequently, she conducted a study that assessed the sociolinguistic aspects of systematic construction of dominance and subordinance in a specific set of children's animated films (Walt Disney productions) to assess how they could teach children to associate specific characteristics and lifestyles with specific groups through variation of English speech (whether regional or social). Lippi-Green's (1997) study comprised of 371 Disney characters from 24 featurelength films. At the time of the study, Disney were the largest producer of animated films and were most heavily marketed and advertised, and therefore were seen most by children and adults (p.86). Lippi-Green (1997) analysed the variety of language and the attached characterization variables to determine whether there were dimensions of stereotyping present.

The results indicated that $43 \%$ characters used a variety of US English with no stigmatization in social or regional terms; meanwhile, $15 \%$ spoke US Englishes that were attached to regional, social, racial/ethnic or economic traits, for example Southern American English or African American Vernacular English. For foreign Englishes (at least from an American perspective), 33\% spoke a British English variety. 
Interestingly, in a manner similar to the foreign language accent correspondence in Schindler's List, 91 out of 371 characters were not logically speaking English. An example of this was The Lion King (1994), as the cast were animated African animals, though it is acknowledged that other languages would have been spoken here via characters' names: Pumbaa, one of the protagonist's companions, means 'simpleton' in Swahili. However, the only character with Swahili accented English was Rafiki ('friend'), a sagely character in the film. Lippi-Green (1997) also acknowledged that although $93 \%$ speak with a Native English variety, only $60 \%$ take place in the Anglophone world (i.e. US, UK, Australasia), the other $40 \%$ took place in countries within continental Europe and the Middle East; mythical kingdoms; and uncertain settings. All of which suggest English was being used in circumstances in which it would be hard to justify its presence and use.

Motivations (both positive and negative) behind the accented characters' actions are interesting. Due to Disney's focus on themes such as good vs. evil, this was easy to accomplish. When taking away the minor characters from the sample, Lippi-Green notes that $20 \%$ main 'evil' characters were accented with US English, 30\% were British accented, and $41 \%$ were non-native. The fact there are twice as many 'bad guys' with non-native Englishes to US English portrays an especially prejudiced and unequal representation to English speaking children (p.90-92).

In these productions, Lippi-Green (1997) noticed more in the usage of accent than a simple good/bad paradigm. The link between Disney's casting of voice-actors with African American vernacular English and Southern American English to characters that were animals. Of the 161 characters, $43 \%$ were humanoid, $54 \%$ were animal and 2.5\% were objects; however, of those that spoke AAVE or Southern English, all were animals. One example, African American actress Whoopi Goldberg's character Shenzi in Lion King, although generally speaks with a standardised American English, does vary to AAVE cadence and lexis for comical effect.

\subsection{Insights from language attitude studies}

It is worthwhile to now address some of the language attitudinal research that has been conducted. Some of the earliest academic insights into linguistic perceptions were made by William Labov, Wallace Lambert, and Howard Giles. In Labov's classic New York City study, he identified language prestige phenomena 
sociolinguists now term: 'overt and covert prestige' (see Labov 1972). Whilst overt prestige is often the social prestige of using linguistic features associated with a language standard, covert prestige is the unannounced social prestige of in-groups using nonstandard features and driving features from beneath conscious acknowledgement. Other scholars' interests in speakers' coverted perceptions about language variation included sociolinguists like Wallace Lambert (Lambert et al, 1960), who developed the matched-guise test (MGT) to test language attitudes. It saw respondents listen to a singular speaker utilising several varieties under the 'guise' they were different speakers to assess respondents' language perceptions. In the 1970s, Howard Giles then developed speech accommodation theory (Giles \& Powesland, 1975), which posits that language-users will shift their speech to suit their social needs depending on the perceptions of the person they are conversing with; they may choose to converge for social solidarity or diverge to socially distance themselves.

One of the more recent theories of linguistic perception to arise out of dialectology and sociolinguistics is the framework of enregisterment, first proposed by Asif Agha around 2003. Agha (2007) defines the process as the "processes and practices whereby performable signs become recognized (and regrouped) as belonging to distinct, differentially valorized semiotic registers by a population' (Agha, 2007, p. 81). Johnstone, Andrus \& Danielson (2006) both reworked and expanded the notions of indexicality and enregisterment when they studied the phenomenon of "Pittsburghese". Expanding upon previous frameworks such as Silverstein's "orders of indexicality" (Silverstein, 2003) and Labov's "sociolinguistic stereotypes" (Labov, 1972), the authors posit that there are four levels of indexing that occur along an indexicality scale (p.82-83). In the first order, a relationship exists between a linguistic feature (or features) and a geographic locale, however, nobody within the group acknowledges it. This might be because of a lack of ability to compare the feature to features of other groups due to lack of mobility. In the second order, speakers acknowledge the feature(s) that make their variety unique, and associate a value of 'correctness' with this paradigm. In the third order, the subset of linguistic features is widely associated as markers of the dialect in question; and, the community may begin to produce dialect glossaries, with people referencing the dialect through specifying features from the dialect (e.g. vocabulary, phonology, grammar). The features become 'enregistered'; they are enshrined and have a looser 
geographic association. People that identify as users of the dialect may state they use the features, even if upon close-inspection, they do not. Dialect speakers will also overtly choose particular features to construct culturally an identity of the idealised dialect speaker. In turn, this can lead to small sets of enregistered features being tied to characterological figures or stereotypical personae.

More recently, Joan Beal and Paul Cooper have applied enregisterment theory to literary dialect studies. Beal (2009) investigated $19^{\text {th }}$ century texts (chiefly dialect dictionaries and songs) from the Northern English cities of Newcastle and Sheffield to see how features had become enregistered and commodified, whilst Cooper (2015, 2017) investigated enregisterment of Yorkshire dialect terms and their eventual 'deregisterment'.

Beal found that locally-produced dialect dictionaries played an important role in enregistering forms. Both cities in the $19^{\text {th }}$ century used them, and though were often scholarly philological publications to begin with, by the $20^{\text {th }}$ century they had been superseded with 'folk' dictionaries often portraying stereotyped characters alongside 'stereotyped' (i.e. enregistered) dialect words (much like John Edwards' Talk Tidy, see Chapter 2.3 above). Regarding the enregistered items, vocabulary like mardy and its variants were enregistered for Sheffield dialect, whilst phonological respellings seemed enregistered for Newcastle's 'Geordie' dialect. Despite both cities having had similar industrial beginnings, she concludes that the Sheffield dialect is 'lagging behind' in terms of its process of enregisterment compared to Newcastle's 'Geordie' dialect due to several factors. Not only is Newcastle a larger urban area, but its social network patterns have differed from Sheffield. Furthermore, whereas speakers are more inclined to see Sheffield as part of Yorkshire regional dialect, Newcastle's 'Geordie' is its own enregistered entity, one that is managed in part by its expatriate community's dialectal marketing and touristic trade. Beal lists that enregisterment can therefore lead to commodification, with words and respellings appearing on anything from folk-dictionaries to mugs and tea-towels (Beal, 2009:155).

Cooper's $(2015,2017)$ research similarly argues that we can use fictive data from historical periods to observe discursively constructive practices, i.e. the social agreement on what forms are 'authentic' dialect (see Chapter 3.2) that may lead to enregisterment. Because the $19^{\text {th }}$ century saw huge growth of dialect representation 
in northern England, Cooper constructed a corpus of $19^{\text {th }}$ century texts (18 paratexts and 27 fictive text samples) to identify forms that historically enregistered 'Yorkshire'. He compared this to a modern corpus of texts, and then conducted a survey to gauge native and non-native reactions to the forms. For the historical data, Cooper observed that 'enregistered' forms were those that were consistently discussed in paratexts, were quantitatively numerous and consistently represented, and were found both in texts written by natives and non-natives suggesting salience (p.8). Cooper found that some forms retained levels of enregisterment in the modern corpus and were positively received in the survey (like theeltha for you, and Definite article reduction), although some forms were not. From these results, Cooper (2017) posited the idea of 'deregisterment ${ }^{5}$, suggesting that previously enregistered linguistic forms might lose their enregistered status, becoming linguistically 'fossilised' and unknown. For example, it was clear mun 'must' and gan 'go' were frequently represented in the historical corpus, but became less associated with the variety to the point where modern speakers do not associate it with the region; thereby: deregistered (Cooper, 2017:8).

\subsection{Analyses of Welsh English attitudes and perceptions - historic}

Research investigating public attitudes and stereotypes towards WE speakers date back to 1970 when Giles analysed the prestige and perceived pleasantness associated with South WE through using matched-guise test mentioned above (Giles \& Powesland, 1975:27). Thirteen accents were presented to 177 local-accented South-Welsh and Somerset children between 12 and 17 years old. Results indicated that amongst Somerset schoolchildren WE had an intermediate level of prestige, schoolchildren preferring the accents of Standard English, Foreign Englishes and Non-native speakers of English (Received Pronunciation, North American English, and French English \& German English respectively). That being said, the surveyed children believed WE to be more prestigious than particular other regional varieties in the U.K. (lower prestige associations were: Northern English English, Cockney English and Birmingham English).

\footnotetext{
${ }^{5}$ Originally suggested by Williams (2012) in relation to a set of linguistic values (i.e. a whole language or language variety) falling out of favour. E.g. preference for South African musicians rapping in Kaapse Afrikaans rather than SA English in Hip-Hop)
} 
A similar study was constructed by Giles in 1971 that analysed the perceived personality of various accented speakers (RP, Welsh, and Somerset) (Giles \& Powesland, 1975:68). This study concluded that participants had formed beliefs that RP speakers were more ambitious, intelligent, self-confident, determined and industrious than regional counterparts (note: the survey included Somerset English and WE speakers). Meanwhile, the qualities associated with regional speech were that WE and Somerset speakers were less serious, more talkative, more humourous and more entertaining than RP speakers. It should be noted that many of these qualities in themselves could be subjectively viewed either positively or negatively depending on context. Giles and Powesland (1975) speculate that:

\begin{abstract}
Regional accented speakers, precisely because they maintain their nonstandard speech patterns, may be perceived by both groups (i.e. Listeners from both the standard and the nonstandard accent groups) as being not at all concerned with a determination to improve their socioeconomic position. Accordingly, they may be seen as more community-oriented, and more concerned with the development of interpersonal relations, personal integrity and social attractiveness. One might speculate further that to a nonstandard-accented regional listener, RP speech implies that the speaker has a need to camouflage his origins and perhaps even his true personality. (p.69)
\end{abstract}

Writing in 1990, Nikolas Coupland expressed desires for future research on WE to focus upon which varieties of WE are discriminated against by both those living inside and outside of Wales (Coupland, 1990:8). In doing so, researchers would explore the social functioning of stereotyped portrayals of uniformed perception that there is just a singular 'Welsh English'.

Coupland (1990) suggested using a range of material in analyses, providing example texts such as advertising, humour, and mimicry (p.8), and 'other relevant popular cultural phenomena' that include 'Welsh English dialect performances of comedians, singers and popular radio and television broadcasters, as well as stereotyped portrayals of Welsh characters in media (p.14).

Garrett, Coupland \& Williams (1999) constructed a quantitative perceptual dialectological study that, for the first time, inwardly assessed the perceptions and attitudes of speakers from several Welsh Englishes. School students' native English varieties from around six regions of Wales were perceptually assessed by another group of students and teachers from within Wales. They rated them on affiliation, 
status, and Welshness. Some attitudinal results indicated that WE student speakers on average did not favour RP accents and associated Borders Welsh English and North East (Wrexham) WE with English English varieties, though were attracted to Cardiff English speakers; speakers who sounded 'most Welsh' were those from West Wales and the Valleys. On the other hand, Welsh teachers found West Wales WE accent most attractive, however found Valley WE to be least attractive.

\subsection{Analyses of Welsh English attitudes and perceptions - recent}

Attitudes towards WE speakers, as well as nonstandard speakers overall, have shifted in recent years. In November 2014, the global market research and data company YouGov conducted their own perceptual dialectal survey poll. The survey asked 2,018 online voters to rate the attractiveness of eight varieties of British English (Dahlgreen, 2014, YouGov, 2014). The results showed that the most attractive English accent was Southern Irish, followed by RP. In third position (out of eight) was WE. This illustrates that today, almost 45 years after Giles' original investigations, WE likely still holds an intermediate, or arguably higher, prestige. Also, that, from the sample, WE was viewed as the most attractive regional accent of English in Great Britain. However, some caution regarding the study's methodology should be taken. For example, respondents were only asked which dialects they perceived to be attractive with no audio accompaniment, having to rely on preconceived notion of accents' phonologies therefore it is not comparable with Giles' match-guise testing.

A recent study by Durham (2014) used the social-media platform Twitter to assess public attitudes towards Welsh accented English. Durham amassed a corpus of 90,000 tweets between September 2012 and May 2013 that included the keywords 'Welsh' and 'accent' to gauge the "twittersphere"'s discussion of the variety's pronunciation. The attitudes were grouped into three common themes: love for the accent, hatred towards the accent, and discussion of U.K. varieties generally. Durham (2014) states:

There are far more tweets from people who love the accent than any other type. People on Twitter are much more likely to think that the Welsh accent is sexy rather than ugly. This contrasts with earlier research which found that Welsh accents were often judged negatively. 
Hodson (2014:29) importantly notes it is still only WE's accent that is perceived to be linguistically favourable, citing that although today it is acceptable for newsreaders to read the national news with a Welsh accent, one is unlikely to find any hint of WE grammar or lexis being used in broadcasting at national or local level; acceptance of nonstandard varieties has only scraped the surface of accepted on-screen presence.

In a series of interviews with Welsh English speakers from around Wales ${ }^{6}$, Paulasto (2015) qualitatively gauged modern attitudes towards the variety from metalinguistic commentaries. For North Walians, they perceived there to be little variation in their region. They recognised that Wales has many varieties overall, especially the Valleys and Wrexham (a respondent from Wrexham said Wrexham English was 'a mixture', and not very Welsh). Of interest to this thesis is that one respondent stated that what is depicted 'in books' like linguistic stereotype 'look you' may not true of WE. For N. Walians, the Welsh accent today is 'accepted'; although the English used to mock it, it is now perceived as 'cool' to have the accent.

For South-West Walians, Carmarthen's accent was perceived as being different from Swansea's and other rural areas. Respondents had had their accent described as 'nice', that it is 'liked' outside Wales, and have been 'complimented' for using it. One respondent stated that in S. Pembrokeshire (i.e. South-west Coastal WE) they speak 'immaculate' English (likely referring to the influence of RP in the region). Both hatred and love for their accent was reported by younger people. In Cardiff, the S. Welsh accent (i.e. Valleys) was described as 'full-bodied' compared to Cardiff, and that Cardiff English users were nevertheless 'proud' of their accent. It should be noted that some S. Welsh respondents do not necessarily understand the concept of 'Welsh English', but know what a 'Welsh accent [of English]' means.

Although there has been no research on Welsh English enregisterment terms yet, personal observations can be provided. For some lexemes, a social awareness exists, in that they are placed on what could be termed 'Welsh dialect merch', also known as 'dialect commodities' (Beal, 2009). Book covers of layman glossaries like the

\footnotetext{
${ }^{6}$ Localities included: NW. Caernarfon, Wrexham, Pencaenewydd, Llanuwchllyn, Ruthin, WW. Lwyngwril, Carmarthen, Llandybie, SW. Cardiff
} 
Talk Tidy series (see 2.3.) highlight both adverbial 'by there' and noun 'daps' [plimsol] as markers of the dialect, whilst Cymraeg loans such as noun 'cwtch' [cuddle, or cosy space], can be found on t-shirts (see Fig 4.1.), and often used for store fronts. A small survey in which a phonebook was inspected (in my own 'layman-style' general readership glossary Welsh English dialect; Jones, 2016:39), noted 'cwtch' has been used on numerous coffee shops, creches, gift shops, clothing stores, beauty salons, and pet services throughout south Wales.

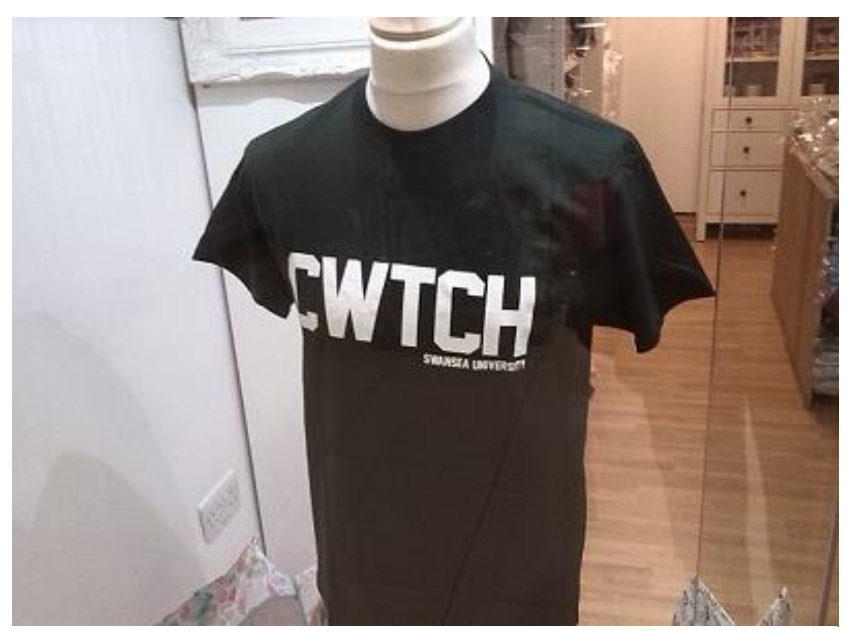

Figure 4.1: Enregistered merch: Cwtch (Supplied by author)

\subsection{Attitudes, perceptions, and stereotypes of Wales and the Welsh people}

It is to be expected that both attitudes towards, and perceptions of, Welsh accented English users will in part coalesce with character stereotypes that have been established surrounding Welsh people. Fictional characters who are depicted to use dialect, may be stereotyped in numerous ways Hodson (2014:114) argues, however, it is important to distinguish between character stereotyping and linguistic stereotyping if we are to analyse characters using literary dialect. Whereas linguistic stereotyping concerns the 'inaccurate rendering of a particular dialect based on a small number of linguistic features', character stereotyping concerns the construction of a character's particular personality/behaviour (often comical, unusual or unintelligent) based 'solely upon their membership [in] a particular social or ethnic group' (p.114). Hodson notes that often both linguistic and character stereotyping go hand in hand, so bearing this in mind, it is important to conclude this chapter on 
attitudes by investigating some of the character stereotypes that underpin Welsh peoples.

\subsubsection{The Welsh as barbarians and uncultured}

Few treatises have explored the stereotypes and cultural attitudes towards the Welsh people as thoroughly as Parker (2007), whose work Neighbours from Hell? English attitudes to the Welsh has opened up discussion surrounding historical English perceptual attitudes towards the Welsh peoples by providing an anthology of viewpoints that range between attitudes towards the Welsh character, the Welsh language, and the Welsh landscape highlighting how prejudiced views towards the Welsh have long been prominent amongst many members of the English establishment.

English perceptions of the Welsh have historically leaned more towards the negative, Parker (2007) arguing that at the time of writing if one were to query English people what were their perceptions of the Welsh character, that: 'the same old qualities [would] keep rearing their tired old heads; the Welsh are sly, cunning, unentrepreneurial, unfriendly, secretive, sentimental and lazy' (p.15). In a unbridled, border-line racist soliloquy from the 1912 text Taffy Was a Welshman, Thomas William Hodgson Crosland (a Yorkshireman known for stereotyping various Celtic ethnic groups in his time) wrote: 'the fact is that Wales is a little land, and the Welsh are a little people with little intellects and little views', and that 'Englishmen were born to rule and not to be ruled, and least of all to be ruled by a bumptious, snuffling, flighty, tiresome, fifth-rate bunch of barbarians like the Welsh' (cited in Parker 2007: 21-22). Crosland's views suggest that the Welsh character should be afforded no agency in British affairs, on the undeniably racist account that the Welsh-born are inherently uncivilised and unintelligent.

Some writers took pity on the stereotype they believed to be true, supposing that such 'misfortunes' such as being born Welsh could be changed. In Arthur Tysilio Johnson's The Perfidious Welshman (1910) he pleads to the Welsh:

Anglicize yourself as speedily as you can. It will never be possible for you to be equal to an Englishman, but you can make him your ideal and you may realise the misfortune of having been born Welsh. Forget your language as quickly as you can. It is vulgar to use it in decent society. Never mention your country or its history 
more often than you can help (cited in Parker (2007:19), from The Perfidious Welshman, 1910)

Here that we have a direct comment towards the perceptions of the language used by the Welsh people. Whether Johnson specifically meant Cymraeg or a WE, it is clear he desired the Welsh to dispense with all Welsh linguistic characteristics and accommodate to an English English centric language usage, for Welsh characteristics were supposedly 'vulgar'.

Despite some journalists' attempts to downplay the disdain for the Welsh, elements of national superiority still seeped through, for example this 1867 excerpt from a national newspaper:

The Welsh are cordially liked and heartily respected by all their fellow-subjects, as a gallant and most gifted race. Year by year, the English know them better, and year by year the English like them more. There really is not a lingering trace of national jealousy. Long ago, we fought our last fight with the Welsh, and luckily for them we won it. (as cited in Parker (2007) from Daily Telegraph, 15 September, 1867).

Perhaps most interesting about this clipping is that it purports that the Welsh were supposedly, as of 1867, only just beginning to acquaint themselves with their neighbouring English, that few English truly knew what the 'Welsh character' was until the lead-up to the $20^{\text {th }}$ century.

Stereotyping the Welsh as 'barbarians', as many historic English dignitaries have done so in the past, has bred further prejudiced assumptions that Welsh people lack all semblance of culture. Below are two scathing statements from novelist Evelyn Waugh and journalist A.N. Wilson who both posited views within the $20^{\text {th }}$ century that the Welsh are wholly uncultured:

The Welsh are the only nation in the world that has produced no graphic or plastic art, no architecture, no drama. They just sing. [...] Sing and blow down wind instruments of plated silver. - (Evelyn Waugh, 1928, as cited in Parker, 2007:42).

and

The Welsh have never made any significant contribution to any branch of knowledge, culture or entertainment. They have no architecture, no gastronomic tradition, no literature worthy of the name. - (A.N. Wilson, as cited in Parker, 2007:43)

Parker (2007) comments that the literary remark in particular is 'startling in its audacity' (p.43) for not only does Welsh literature predate English literature, but 
unlike England, Wales has a well-attested tradition for '[holding] its writers and artists firmly centre stage in the national action', by which Parker alludes most likely to the tradition of eisteddfodau, prestigious arts festivals dating back to the High medieval ages.

\subsubsection{The Welsh as the Fantastical}

The stereotypical association that the Welsh are connected with the pagan world, that they act in a godless manner, and that they are acquainted with mythical creatures, goes back centuries. Remarkably, one of the first instances of this perception is in 1159 when the archbishop of Canterbury accused that: 'the Welsh are Christian in name only, [for] they are barbarians' (Parker, 2007:29). Later, an English MP in the 1600s declared the Welsh were 'Devil worshippers, living like thieves and robbers in the mountains, the most base, peasantly, perfidious people in the World' (Parker, 2007:29). And, more recently, English economist John Maynard Keynes had no qualms with associating David Lloyd George, the Caernarvonshire-born British primeminister between 1916 and 1918, with ancient mythologies, the Christian Devil, witchcraft, and Celtic fantasy when he wrote:

How can I convey to the reader, who does not know him, any just impression of this extraordinary figure of our time, this siren, this goat-footed bard, this half-human visitor to our age from a hag-ridden magic and enchanted woods of Celtic antiquity? - (John Maynard Keynes, as cited in Parker, 2007:32)

This fantastical associative stereotype works, however, on an axis: balancing between negative connotative associations as seen above, and positive connotations (albeit still generalised). Initial English reactions to the Welsh landscape in the 1600s were pessimistic. William Richards in his book Wallography (1682) decried that Wales' mountainous landscape was 'an excellent place to breed famine in', and the Archbishop Thomas Herring described Wales as 'the rubbish of creation' in 1740 (as cited in Parker, 2007:76-77). However, sentiment improved with the arrival of landscape artists and casual tourists and the advent of 'the picturesque' art movement; finding beauty in Welsh mountains, waterfalls and coasts. Parker (2007:81) notes that between 1770 and 1815 there were over eighty books published on touring Wales, and that 'Wales of the Picturesque' was encompassed in artists' fascination with the Hafod estate in Ceredigion from the 1780s on. George Borrow 
when visiting in 1854 found the house to be 'a truly fairy place... beautiful but Fantastic [of fantasy]' (as cited in Parker, 2007:81) (emphasis mine). William Wordsworth, who spent much time in Wales, spoke favourably of the Monmouthshire countryside and the River Wye, directly portraying Wales as a place of mythic nymph enchantment, when he wrote: 'How oft, in spirit, have I turned to thee / O sylvan Wye! Thou wanderer thro' the woods / How often has my spirit turned to thee!' (as cited in Parker, 2007:87, emphasis mine).

Literary commentators during the $19^{\text {th }}$ century, such as Albert Schulz, began to recognise the integral part that Welsh myths and folklore had had in the construction of the Arthurian myth, a mythology largely considered Pan-British rather than British Celtic beforehand. Recognitions such as this, Sullivan (1989) argues, began to reinvigorate Wales as a place of fantasy, one tied to beneficent fairies, miraculous trees, dragons and more (p.7). Indeed, this sense of Welsh Celtic 'natural magic' can, according to Sullivan (1989) be traced throughout the works of $19^{\text {th }}$ and $20^{\text {th }}$ century writers such as William Blake, Lord Alfred Tennyson, James Joyce and T.S. Eliot.

Sullivan's (1989) monograph: Welsh Celtic Myth in Modern Fantasy (1989) provides a thorough record of the methods in which contemporary authors, several of whom are High Fantasy writers, have utilised the classical Welsh myths (Y Mabinogi). Sullivan shows how the Mabinogi's stories have been 'expanded' upon by some authors, had their elements and segments 'interweaved' into new stories, and had themes and characters borrowed for the 'invention' of new fantasy worlds. Sullivan concludes that this utilisation from Celtic myths, legends, and folklore has helped create 'a sense of wonder in High Fantasy' (Sullivan, 1989:150, emphasis mine) and that Wales connotes 'a place of magic and mystery, music, song and poetry' (p.146).

One final English writer who has, in a significant way, contributed to the construction of this fantastical Welsh stereotype is J.R.R. Tolkien, who in part used Welsh mythology and Cymraeg to create his The Lord of the Rings legendarium. In particular, Tolkien used Cymraeg to construct the language of the Elves, Sindarin. Tolkien has been quoted as saying that he chose Welsh not only because he believed it a 'very attractive' language, but also because 'it seemed to fit the rather "Celtic" type of legends and stories told of [his] [Elven] speakers (Phelpstead, 2011:42). Doing so, it appears he was attaching the Welsh linguistic sphere (arguably both 
Cymraeg and Welsh accented English) with the fantastical; the "Celtic" type of legends Tolkien was referring to were The Mabinogion, the Welsh mythological canon. Further discussion of Tolkien's development of the 'Tolkien Elf', its connection to the Welsh world and Welsh English dialect will be discussed in Chapter 9, and will elaborate upon the formation of 'the Welsh elf/fairy' trope and its usage in recent Welsh accented characters.

Parker (2007) believes that much of the tourist industry today plays on this mythic stereotype, stating: 'tourism in Wales is increasingly peddling [a] fantasy version of the country, $[\ldots]$ whether it's the 'Living Medieval', [or] some dewy cod-Celtic nonsense, $[\ldots]$ there's the gnawing feeling that it's the past which matters most' (p.123).

\subsection{Conclusion}

This chapter has addressed the perception and attitudes towards WE speech. It has reviewed both approaches in literary dialect studies, as well as perceptual dialectology, language attitudes, and the stereotypes that are attached to WE, Wales, and the Welsh people.

First, we examined how discrimination against nonstandard speakers can lead to the formation of language ideologies, where dialectal prejudice can become normalized (4.1.). Accent stereotypes are especially used in filmic fiction to index stereotypical concepts about a speech community; in subordinating particular accents, producers can use accents as an 'Othering tool' to quickly index stereotypes (4.2).

The chapter then addressed the linguistic field of perceptual dialectology (4.3). Starting with Labov's idea of covert and overt prestige, noting that particular linguistic features have prestigious qualities amongst speech groups; then Giles' developments in the Matched Guise test and the formation of accommodation theory, that demonstrates how users may shift their variety and linguistic features upwards or downwards to better suit their social needs. Finally, the topic of enregisterment was addressed, that observes the tendency for a linguistic feature to be enshrined by its dialect users as a marker of 'good dialect'. 
The remainder of the chapter focused upon Welsh perceptions. Key case studies were reviewed of the perceived qualities of the Welsh variety of English, both historically (e.g. Giles \& Powesland, 1975) (4.4), and contemporarily (e.g. Paulasto, 2015) (4.5). The Welsh accent has moved in prestige considerably since the 1970s, with recent studies indicate an increase in its social attractiveness. The review then discusses perceptions of Welsh ethnicity at a sociologically macro level, where we saw that two prominent Welsh perceptions have centred upon the Welsh being stereotyped as 'uncultured', and stereotyped as being 'Fantastical' or having mythic 'Celtic' qualities.

Ultimately, when addressing the role that dialect has within WE fictive texts, we must bear in mind not just representation of lexical, phonological, and grammatical features, but also contextual weight borne from any stereotypical or perceptual attitudes associated with both the variety and wider the Welsh community. 


\section{Chapter 5 Methodology}

\subsection{Defining 'Fictive text'}

For the purposes of this historical project, it should be made clear that the working definition of a 'fictional text' are media that are not non-fictional: poetry, theatrical scripts, novels, films, and narrative-videogames. What has not received treatment is non-fictional material of a nature such as English language newspapers, local travelogues, personal diaries or biographic writing, personal letters or verbatim transcripts (like court trial records).

Granted, there is likely a wealth of dialectal material to be attained from examining non-fictional English material from Wales, and although such a focus was initially part of this project's scope it was soon established that analyzing fictional material alone had become a significant task of its own ${ }^{7}$. Also consider that the methodology for data-collection of fictional prose and verse material contrasts with that of gathering governmental and personal non-fictional material. Gathering material for the latter would involve extended time spent in each region within Wales seeking collaborators who may wish to share historical writing and consulting local town archives. The current project has benefited greatly from examining the texts and materials currently present at Swansea University ${ }^{8}$.

\subsection{Research questions}

The core research question of the thesis can be put simply. To what extent can a historical account of the Welsh English dialect in fictive narratives be established? How has WE been represented throughout fiction, and, is it methodologically feasible to create a linguistic history of a language variety across multiple time periods and several narrative types?

\footnotetext{
${ }^{7}$ Preliminary pilot work between October 2013 and January 2014 was conducted in Monmouthshire. Libraries, museums and archives were consulted to assess the feasibility of utilising non-fictional material. Sample copies of the papers from Feb $17^{\text {th }} 1872$, Feb $23^{\text {rd }}$ 1882 and Feb $19^{\text {th }} 1892$ were examined using services at the Abergavenny Library, and an inquiry was made into diaries at the Gwent Archives.

${ }^{8}$ Swansea University is arguably one of the key centres for the study of Welsh writing in English.
} 
From this central question, four further questions may be interrogated.

1. By conducting a qualitative analysis of fictive texts over time, can we diachronically trace the usage of particular linguistic features across multiple time periods and several narrative types? Which features do writers use most frequently in fictive writing, and to what extent may we say that these features were enregistered for these dialect writers (Beal, 2009; Cooper, 2015)?

2. What lexical, phonological and grammatical forms are present in these narrative genres that were not recorded in dialectological surveys? Also, what metalinguistic commentary about the variety is given by authors? To what extent can this be considered 'linguistic evidence'? (Shorrocks, 1996, 2000; Sullivan, 1980, Hickey, 2010)

3. Is there a salient linguistic representational difference between WE written by /acted by native producers of WE, and non-Welsh writers/actors of WE?

4. Finally, within the fictive works, what linguistic and character stereotypes are attached to WE representation, and do these stereotyped representations change over time? (Lippi-Green, 1997).

Ultimately, the focus of the research has been to create a fictolinguistic resource of WE; in this manner, it will complement previous work carried out by dialectologists on the variety, acting as a companion piece to databases such as the $S A W D$, and, given time may be used as a starting point from which further work could be created.

\subsection{On project format}

There have been several prior studies that have influenced the current methodology. Many previous studies on literary dialect are reviewed in chapter 3, (key studies: 3.4). Here, mention of specific formatting is addressed. Hickey's (2010) edited volume approaches several varieties historically by dividing results of several fictive/non-fictive texts into sections such as phonology, lexis, and grammar. Zingg (2013)'s monograph Is there Hiberno English on them? demonstrated a clear method in which a historical dialectal analysis of fictive texts could be presented by dividing the work into authors, thereby creating a close diachronic reading that investigates a select historical period. In doing so, Zingg was able to detail many of the linguistic 
features that these authors included within their creative works, with Zingg's work largely concerned with authenticity of dialect represented.

One project that is somewhat similar to that of the current study is that of Lewis (2010). Lewis investigates how 'Wenglish' as a popular linguistic trope manifests itself in a variety of genres such as literary texts, formal performance, and everyday performance. Lewis' scope is not as wide as this thesis', for the present research covers all WE representations, not just the 'Wenglish' of Valley communities. Unlike the current research that aims to trace a history of Welsh English usage, the diachronic range for Lewis is short (situated in the mid to late 20th century). It also doesn't interrogate analysis from the linguistic field of literary linguistics (e.g. eye dialect, dialect literature, metalinguistic perspectives, linguistic stereotyping and discrimination) - its methods being grounded largely in discourse analysis.

Lewis' methodology, however, was of some importance in the construction of this study's own list of texts to analyse. For their project, Lewis mentions that it was: 'necessary to compile a 'canon' or reference list of texts containing Wenglish. This by-product of the research could be a useful as a resource for researchers. It could also be developed and expanded in further research' (p.367-368). Indeed, several of the texts that Lewis chose to include in his canon are texts that this thesis has investigated; this affirms perhaps the sociolinguistic importance of texts such as Twin Town (Allen, 1997) and Island of Apples (Jones, 1965).

Some of the texts that Lewis had dismissed as being irrelevant to WE of the valleys, have been analysed in this research, on the account that they have been sociolinguistically interesting in some way Lewis has not perceived; usually this is a text outside of Lewis' 'Wenglish' geographic scope, or a text that he believes is not authentic 'Wenglish'. In fact, insistence upon authenticity of 'Wenglish dialect' to create a 'Wenglish index' of the 'most authentic' texts is perhaps Lewis' greatest weakness: if one is to create a canon of WE from creative sources, from an objective sociolinguistic viewpoint it is of little importance as to how authentic a text is, for even if an author conveys a misrepresentation of the dialect, the decision to include a linguistic variety within their fictive work demonstrates an author's metalinguistic awareness that the variety is of worth to them, and therefore their work is of worth to us scholars studying literary dialect. 
The following work on fictional depictions of the WE dialect is divided into analysis chapters. Each deals with the treatment of Welsh English within a particular fictional narrative and stylistic form. The chapters progress through an approximate chronology, with older narrative forms being the earliest chapters, and modern narrative forms towards the end of the thesis. Each chapter begins with an introduction (in a vein similar to a literature review) of that narrative genre's history and cultural importance. The decision to include these within the analysis chapters situates the linguistic analysis within the scope of that genre, a purpose that would feel weakened if these sections were included with the beginning literature review chapters. Chapter 6 addresses the usage and treatment of the WE dialect within the Tudor period and within the Elizabethan era of English playwrights corresponding with the period between $15^{\text {th }}-17^{\text {th }}$ centuries. Chapter 7 , addresses the usage of WE in novels and prose between the $19^{\text {th }}$ and $20^{\text {th }}$ centuries. Chapter 8 discusses filmic narrative of the $20^{\text {th }}$ and $21^{\text {st }}$ century. And, finally, chapter 9 addresses the recent incorporation of WE in the modern ludonarrative form of the videogame.

Considering that this research is in many ways acting to complement the Survey of Anglo-Welsh dialects, the descriptive format of the texts will follow a framework that will be useful for informative retrieval. Therefore, many entries have been analysed to address three parts:

1. Situational background of the author/creator and its text.

2. Discussion of linguistic WE features that have been found in the text: lexis, phonology, grammar.

3. and, finally, if necessary, commentary about the text's larger metalinguistic awareness of language usage (this may include discussion of stereotypes, and commentaries about the dialect by the narrative-creator).

\subsection{On cross-referencing}

Material that has been gathered and verified through systematic sociolinguistic research has been the primary resource for consultation (see Table 5.1.). David Parry's comprehensive 1999 volume developed from the SAWD research, A Grammar and Glossary of the Conservative Anglo-Welsh dialects of Rural Wales, has 
acted as the primary database for comparison and cross-referencing of WE linguistic features in texts. Parry's grammar and glossary details the phonology, morpho-syntax and lexical glossary of rural WE and provides detailed maps for areas in which specific phonological and lexical traits were recorded. Penhallurick's Gowerland (1994) then provides an in-depth glossary and grammar for the Gower peninsula. The Electronic World Atlas of Varieties of English (eWAVE) database has also been instrumental for cross-referencing the morpho-syntax qualities of WE within written texts.

Research data from both philologist/dialectologist surveying and layman glossaries have been consulted where appropriate, especially to cross-reference lexical forms that were not recorded by the SAWD. For example, Wright's English Dialect Dictionary (EDD) (1898-1905) and Orton's SED (using the Survey of English dialects: the Dictionary and Grammar, 1992), as well as Edwards' Talk Tidy (hereafter TT) series $(1985,1986)$ and Lewis' Wenglish (2008) (hereafter Weng.)

The value of this kind of cross-referencing should be taken with caution. Whereas it can confirm attestation of particular forms, absence of a feature within a text does not render a dialectal representation within that text any less significant or accurate. The cross-referencing's chief aim is to address what forms might have been used by literary dialect writers prior to systematic surveying or thereafter. Nevertheless, bear in mind that access to large databases of WE have only recently been made publically available. It should be noted too that the usefulness of this method works best for texts that match the era in which data (SAWD or EDD) was collected. In other words, Parry's decision to use elderly rural-speakers in the 1960s meant that the data corresponds well with WE speakers who were alive during the earlier part of the $20^{\text {th }}$ century, thus matching up with the era in which many Welsh written English novels were first produced and the beginnings of Wales' filmic era. For earlier texts (such as Elizabethan era plays), the cross-referencing is understandably less appropriate, however, not altogether ineffectual - as will be seen, several texts contain linguistic features that match up with those still present in the speech communities observed by Parry. Finally, features that are present in texts from such earlier eras which are then not present in the cross-referencing sources, ultimately do provide us with some possible 'linguistic evidence' of the WE usage of its era. 
Linguistic features that are identified are introduced within the analysis-discussion. The first text in that particular genre to introduce an item receives the most linguistic description, with later texts referencing the earlier form. In this regard, although each chapter may be read individually, chapters themselves are to be treated as one continuous analysis that chronicles the representation of the Welsh variety of English through genre and time.

Table 5.1: Cross-referencing sources

\begin{tabular}{|c|c|c|c|}
\hline Source & $\begin{array}{l}\text { Year } \\
\text { Abbr. }\end{array}$ & Type & Notes \\
\hline $\begin{array}{l}\text { Grammar \& } \\
\text { Glossary of the } \\
\text { conservative } \\
\text { Anglo-Welsh } \\
\text { dialects of rural } \\
\text { Wales } \\
\text { David Parry }\end{array}$ & $\begin{array}{l}1999 \\
\text { SAWD }\end{array}$ & $\begin{array}{l}\text { Dialect survey glossary } \\
\text { of Lexical, grammatical, } \\
\& \text { phonological features }\end{array}$ & $\begin{array}{l}\text { Survey of Anglo-Welsh } \\
\text { dialects (SAWD), } \\
\text { conducted between } 1968 \\
\text { and } 1991 \\
\text { First published in } 2 \\
\text { volumes in } 1977 \text { and } \\
1979 .\end{array}$ \\
\hline $\begin{array}{l}\text { Gowerland } \\
\text { Rob Penhallurick }\end{array}$ & $\begin{array}{l}1994 \\
G O W\end{array}$ & $\begin{array}{l}\text { Dialect survey glossary } \\
\text { of Lexical, grammatical, } \\
\& \text { phonological features }\end{array}$ & $\begin{array}{l}\text { Gower peninsula, } \\
\text { history of English usage }\end{array}$ \\
\hline $\begin{array}{l}\text { Oxford English } \\
\text { Dictionary }\end{array}$ & $\begin{array}{l}\mathrm{N} / \mathrm{A} \\
O E D\end{array}$ & $\begin{array}{l}\text { Lexicography of varieties } \\
\text { of English, chiefly } \\
\text { Standards, and other lects }\end{array}$ & $\begin{array}{l}\text { The OED is regularly } \\
\text { updated }\end{array}$ \\
\hline $\begin{array}{l}\text { Geriadur Prifysgol } \\
\text { Cymru }\end{array}$ & $\begin{array}{l}\mathrm{N} / \mathrm{A} \\
G P C\end{array}$ & $\begin{array}{l}\text { Lexicography of varieties } \\
\text { of Cymraeg. All dialects }\end{array}$ & $\begin{array}{l}\text { The GPC is regularly } \\
\text { updated }\end{array}$ \\
\hline $\begin{array}{l}\text { Survey of English } \\
\text { dialects : the } \\
\text { dictionary and } \\
\text { grammar }\end{array}$ & $\begin{array}{l}1993 \\
S E D\end{array}$ & $\begin{array}{l}\text { Dialect survey glossary } \\
\text { of lexical, grammatical, } \\
\& \text { phonological features }\end{array}$ & $\begin{array}{l}\text { Survey of English } \\
(S E D), \text { conducted } \\
\text { between } 1950 \text { and } 1961\end{array}$ \\
\hline $\begin{array}{l}\text { English Dialect } \\
\text { Dictionary }\end{array}$ & $\begin{array}{l}1905 \\
E D D\end{array}$ & $\begin{array}{l}\text { Dialect survey glossary } \\
\text { of lexical, grammatical, } \\
\& \text { phonological features }\end{array}$ & $\begin{array}{l}\text { Earliest dialect } \\
\text { dictionary } \\
\text { Methodology criticized } \\
\text { by some. }\end{array}$ \\
\hline $\begin{array}{l}\text { Talk Tidy series } \\
\text { John Edwards }\end{array}$ & $\begin{array}{l}1984 \\
T T\end{array}$ & $\begin{array}{l}\text { Laymen's dialect } \\
\text { dictionary }\end{array}$ & $\begin{array}{l}\text { Little mention of project } \\
\text { methodology }\end{array}$ \\
\hline $\begin{array}{l}\text { Wenglish } \\
\text { Robert Lewis }\end{array}$ & $\begin{array}{l}2008 \\
\text { Weng. }\end{array}$ & $\begin{array}{l}\text { Laymen's dialect } \\
\text { dictionary }\end{array}$ & $\begin{array}{l}\text { Little mention of project } \\
\text { methodology }\end{array}$ \\
\hline
\end{tabular}




\subsection{On obtaining texts for analysis}

One of the caveats of the research lies in the fact that there was no unequivocal method of assessing whether a particular text contained notable usage of WE dialect other than to obtain the text and then read, view, or play the text in question. Understandably, this was a time-consuming work. Similarly, in Sullivan's study of Irish English in theatrical drama (Sullivan, 1980), their methodology consisted of locating lists of the target genre's texts. Sullivan (1980) located a comprehensive list of works likely to be relevant from an earlier source (Duggan, 1969), however, though discovered after analysis that they contained no features of Irish English. Further titles were then added through random sampling through categories of Irish drama (p.196). Sullivan's work demonstrates that an unavoidable degree of trial of error is often required when long lists of historic texts for linguistic analyses.

The term 'literary dialect', which is derived from the associated field of linguistics (Chapter 3), is a good placeholder name when interrogating analysis on fictive representation of $\mathrm{WE}$, however, descriptors related to individual narrative media may also be used. For example, fictive dialect that occurs in early plays may be referred to as 'theatrical dialect', WE occurring in film may be called 'filmic dialect', and dialect occurring in videogames may be named 'videoludic dialect'. See Table 5.2 for a list of sources for each of the fictive dialect types.

\subsubsection{Obtaining early texts and theatrical Welsh English samples}

A large part of the first analysis chapter comprises a historical editorial that collates together largely what other medievalists, literary critics, and linguistic historians have unearthed regarding the early use of English in Wales in a creative writing context. Publications from several scholars of Welsh medieval studies (e.g. Meecham-Jones, 2010; Dobson, 1976; Roberts, 2010; Davenport, 2010) have been useful for reproductions of medieval texts. Also, scholars of historical WE like Rob Penhallurick and German (2009) were instrumental for providing possible early texts. Where possible, Elizabethan theatrical texts have been accessed to assess how their fictive writing incorporates WE. Databases such as archive.org and Project Gutenberg have both been instrumental in locating early works. 


\subsubsection{Obtaining Literary Welsh English samples}

A selection of fictional texts was provided by conducting independent research into the Welsh writing in English literary movement. Some academics within this field of literary study were also contacted. Both Professor M. Wynn Thomas and Dr. Kirsti Bohata provided speculative lists of authors that might have utilised a literary WE in their novels or short stories. What followed was a large reconnaissance project where authors' texts that were readily available were diligently studied for examples of WE dialect. Due to not only restraints on time but also project scope (bear in mind other narrative media were to be consulted), where a principal text showed promise, it was chosen for analysis. This provided a total of seventeen authors and seventeen texts to create what can be considered the first linguistic chronological surveying of WE 'literary dialect'. Texts were then analysed comprehensively for the features of lexis, phonology, grammar, and metalanguage. Texts were first scoured objectively from cover to cover, before then being read as the author intended: as narrative prose, to assess the variety in its story context. During these processes, lists were created detailing the findings, and texts' linguistic features were cross-referenced with known dialectological databases. Lexis, phonology, and grammar for this chapter were cross-referenced with dialectological databases.

\subsubsection{Obtaining Filmic Welsh English samples}

The chapter does not address all potential uses of Welsh English in film, the methodology omits one-off instances where the variety might only briefly cameo. Not only would it be a gargantuan task to identify all small instances of WE; but for sampling reasons, usage of WE in small roles is less likely to tell us more about its representation within a certain filmic-era than a film in which the variety is used extensively. Most texts analysed in this section are texts that are situated in Wales or the British Isles. This is not to say that this range has been chosen because it is the 'most authentic', but because methodologically, these accounts were those in which WE characters were likely to occur more frequently.

To find primary sources with WE variety present, several databases have been examined. Scholarly resources such as Steve Blandford's edited volume Wales on Screen (2000) and Dave Berry's monograph Wales \& Cinema: The First Hundred Years (1994), have been useful, if not somewhat outdated currently (no Welsh film 
scholarly work has been written since 2000). One caveat, however, is the limited availability of many of these films for they are not currently in wide market circulation.

Similar to novels, filmic texts were watched first objectively, pausing the narrative to take note of linguistic features as they arose, before then rewatching the texts to assess the variety in its narrative context. Again, lists were created detailing the findings and cross-referenced with known dialectological databases.

\subsubsection{Obtaining Videoludic Welsh English samples}

Not only are there no videogames in which Welsh English is exclusively used, but narrative videogames, as a fictive genre, are in their infancy (Chapter 9 includes an introduction to videogame studies). Therefore, it was more difficult to search for texts for analysis. Many of the texts obtained were either from the researcher's familiarity with the text, from newspaper articles promoting WE in a videogame, or the result of web searches using key terms such as 'Welsh' and 'videogame'.

Where available, videogame texts were acquired and played on the appropriate consoles in order to sample WE dialect. A caveat, however, was that unlike film and novels, many narrative videogames do not allow for rewinding the game's narrative. Conveniently for the videoludic dialect analyst, because of the presence of popular videogaming, there are YouTube channels that feature 'longplays' (or LPs) of users playing and recording game narratives. This is a boon for videoludic dialect analysis.

Table 5.2: Breakdown of text sources

\begin{tabular}{|c|c|c|c|}
\hline Chapter & Narrative text genre & Sources & Notes \\
\hline \multirow[t]{2}{*}{ Chapter 6} & $\begin{array}{l}\text { Literary } \\
\text { dialect/theatrical } \\
\text { dialect }\end{array}$ & $\begin{array}{l}\text { - Dr. Penhallurick } \\
\text { (personal } \\
\text { communication, } \\
\text { October 2013) }\end{array}$ & $\begin{array}{l}\text { - Scholar of Welsh } \\
\text { English studies }\end{array}$ \\
\hline & & $\begin{array}{l}\text { - Meecham-Jones, } 2010 \\
\text { - Dobson, } 1976 \\
\text { - Roberts, } 2010 \\
\text { - Davenport, } 2010\end{array}$ & $\begin{array}{l}\text { - Scholars of Welsh } \\
\text { medieval studies }\end{array}$ \\
\hline Chapter 7 & Literary dialect & $\begin{array}{l}\text { - Dr. Kirsti Bohata } \\
\text { (personal } \\
\text { communication, March } \\
4 \text { 2014) } \\
\text { - Dr. M. Wynn Thomas }\end{array}$ & $\begin{array}{l}\text { - Scholar of Welsh- } \\
\text { written English } \\
\text { language literature } \\
\text { - Leading scholar }\end{array}$ \\
\hline
\end{tabular}


(June $4^{\text {th }}$ 2014)

of Welsh-written English language literature

\begin{tabular}{|c|c|c|c|}
\hline Chapter 8 & Filmic dialect & $\begin{array}{l}\text { - Wales on Screen } \\
\text { (Blandford, 1999) } \\
\text { - Wales \& Cinema: the } \\
\text { First } 100 \text { Years } \\
\text { (Berry, 1994) }\end{array}$ & $\begin{array}{l}\text { - Comprehensive } \\
\text { list of all films } \\
\text { produced in Wales } \\
\text { between 1896-1994 } \\
\text { (p.447-468) } \\
\text { - List comprised of } \\
\text { Blandford (1999) } \\
\text { \& Berry (1994). }\end{array}$ \\
\hline
\end{tabular}




\section{Chapter 6 Representation of early Welsh English in Late Medieval texts, Elizabethan plays, and early Anglo- Welsh poetry}

\subsection{Introduction}

The development of the Welsh English dialect has a long history. What makes the dialects of English speakers in Wales distinct, however, is that that history dates back to the $12^{\text {th }}$ or early $13^{\text {th }}$ centuries CE, far further than many other varieties of English, especially varieties outside of England proper. These early centuries were times when English as we know and speak it today was not present. It is often believed that WE as a variant of the English language can be traced back into the last half-millennium, placing the first examples at the end of the Elizabethan period (1558-1603). A text commonly referenced is William Shakespeare's play Henry $V$ (1599); which saw a Welsh military captain, Fluellen, speak an approximate WE of his day. This chapter will go further than this notable portrayal, by analysing nine core theatrical texts, in addition to twenty minor texts that briefly use WE, to detail not only the largely unexplored early origins within the late Medieval era, but also document further examples of WE usages within other playwrights' scripts from Tudor and Stuart Britain up until the emergence of the popular novel.

Table 6.1: List of late medieval, Elizabethan, and early Anglo-Welsh poetic texts

\begin{tabular}{|c|c|c|}
\hline Author & Year & Text \\
\hline Anonymous & $12^{\text {th }} C-13^{\text {th }} C$ & Ancrene Wisse \\
\hline Anonymous & $1182-1198$ & Hali Meiðhad \\
\hline Anonymous & $12^{\text {th }} C-13^{\text {th }} C$ & Ste Margarete \\
\hline Anonymous & $12^{\text {th }} C-13^{\text {th }} C$ & Sawles Warde \\
\hline Anonymous & Late $14^{\text {th }} \mathrm{C}$ & Sir Gawain and the Green Knight \\
\hline Anonymous & $15^{\text {th }} \mathrm{C}$ & Sir Cleges \\
\hline $\begin{array}{l}\text { Ieuan ap Hywel } \\
\text { Swrdwal }\end{array}$ & 1480 & Hymn to the Virgin \\
\hline Anonymous & 1526 & Hundred Merry Tales \\
\hline Andrew Borde & 1547 & $\begin{array}{l}\text { Fyrst Boke of the Introduction of } \\
\text { Knowledge }\end{array}$ \\
\hline William Salesbury & 1547 & A dictionary in Englyshe and Welshe \\
\hline William Salesbury & 1550 & $\begin{array}{l}\text { A Brief and a Playne Introduction ... } \\
\text { [to] the Brytysh Tongue }\end{array}$ \\
\hline
\end{tabular}




\begin{tabular}{lll}
\hline William Shakespeare & 1597 & The Merry Wives of Windsor \\
Thomas Dekker & 1597 & The Welsh Embassador \\
William Shakespeare & 1599 & Henry V \\
Anonymous & 1600 & Sir John Oldcastle \\
Thomas Dekker & 1600 & The Patient Grissill \\
Robert Armin & 1606 & Two Maids of More-Clacke \\
Thomas Middleton & 1613 & A Chaste Maid in Cheapside \\
Ben Jonson & 1618 & For the Honor of Wales \\
\hline Anonymous & 1660 & Goldsmith Hall performance \\
Edward Ravenscroft & 1683 & Dame Dobson \\
Thomas D'Urfey & 1693 & The Richmond Heiress \\
John Hippisley & 1730 & Journey to Bristol \\
Anonymous & 1751 & Theatrical Manager \\
Richard Cumberland & 1772 & The Fashionable Lover \\
Charles Dibdin & 1785 & Liberty Hall \\
\hline Ieuan Ddu & $1795-1871$ & Harry Vaughan \\
Thomas Hughes & $1818-1865$ & A Cheese for the Archdeacon \\
Richard hall & $1817-1866$ & Crickhowel \\
\hline
\end{tabular}

n.b. Italised texts are brief mentions taken from secondary sources, unitalised are core primary source theatrical WE texts.

\subsection{Early texts featuring Welsh English dialect}

\subsubsection{Welsh and English within Marcher communities (1100s-1400s)}

It is possible that the earliest contact that the English language had with another language in a foreign region was with the Celtic language of Cymraeg in neighbouring Wales. Rees Davies states that Wales held a special place in British imperialism's history, for it was essentially the first 'colony' that England, and by later extension - the British Empire, acquired (Davies 2000). With English being transplanted to the area, the English of Wales could well be the first foreign variety of English within the Anglophone world. Ultimately, Middle English made contact with Cymraeg and as a result, a new contact variety of English was formed - WE.

To date, there has been strikingly little study of Welsh people in medieval English literature (Meecham-Jones, 2010:4). Of course, the further back we go, the harder it is to locate any reputable sources that a WE variety was forming. However, although 
sources are scarce, they do exist. To understand how the languages of English and Cymraeg made first contact, we require a summary of the political situation of the 1100s-1200s.

During the early 1100s, the area now known as Wales was undergoing considerable changes, especially amongst its border regions with England and southern coastline. After the Norman invasion of Britain in 1066, Marcher Lordships were set up by the Norman invaders to repel the Welsh from gaining control outside their Welsh peninsula, these regions were controlled by Marcher Barons and comprised of regions which would later become the Welsh counties of Monmouthshire, Glamorgan, Brecknockshire, Flintshire, Carmarthenshire and Pembrokeshire.

Often, the Anglo-Norman rulers of these Lordships subjugated much of Welsh culture, leaving us with little record of the life the Welsh had under Anglo-Norman authority (Meecham-Jones, 2010:3). The anglicised Marcher Lordships communities were not, however, devoid of Welsh culture and language. Although these Welsh Marches were frontier regions that housed both Welsh and English armies, they were also shared with working classes, and consequently were areas of rich linguistic diversity (Meecham-Jones, 2010:30). Along with the native Cymraeg and English speakers of the border, immigrants arrived from both the French possessions of England, Norman-controlled France, and Flanders, bringing the French, AngloNorman and Flemish languages into the Marches (p.31). Over a long period of time, English began gaining footholds in the region, and gradually Cymraeg was whittled away from those in the language community (German, 2009:27). Nevertheless, for the time-being, the source language remained as a central language, Meecham-Jones states that: "the pattern of conquest and appropriation in the March ensured that [Cymraeg] functioned as a crucial linguistic and cultural substrate in the development of Marcher culture' (Meecham-Jones,2010:31).

This can be evidenced within the ancient British kingdom of Ergyng which lies within present day Herefordshire and Monmouthshire (Meecham-Jones, 2010:31). Before Marcher conquest it was often shifted between the Welsh royal houses, being joined to Gwent, Glywysing or Morgannwg; and afterwards it remained a prominently Cymraeg-speaking area. Although few examples demonstrate that Cymraeg was spoken in this region, a collection of Middle English texts known as 
the 'Katherine Group' demonstrate that Cymraeg lexical items clearly influenced the English written texts of the region. Both Ancrene Wisse and Sir Gawain and the Green Knight contain Cymraeg lexical qualities, in fact it is these features that helped locate the texts' origins to Herefordshire (p.32). The English dialect of Herefordshire circa 1200 contained at least three Cymraeg words. The first, 'cader' ('candle'), featured in both the Ancrene Wisse and Hali Meithad; 'genow', the Cymraeg word used for 'mouth' was used in Ste Margarete; and 'keis' was used for both 'satellites' and 'henchmen' in Sawles Warde (Dobson, 1976:115-16).

Although Welsh law was different from English law, Welsh law still influenced the Marcher system. This can be evidenced in the Cymraeg law words 'galanas' (a word associated with homicide) and 'anghyfarch' (a word associated with thievery), which were often left untranslated in English and Latin textual translations within the territory, as the concept could not be directly translated (Roberts, 2010:89). As is to be expected, it was not a one-way system; English loanwords found their way into the territory's Cymraeg as well. One notable example was the Cymraeg 'edling', a direct loan from Old English's 'aetheling' meaning 'male heir' (p.89). Though the words detailed by Roberts are not strictly examples of early WE, what this tells us is that the languages were malleable - willing to trade lexical items with one another, and in essence represent the foundations for WE to begin developing into a variety of its own.

During the $15^{\text {th }}$ century, Wales featured as a backdrop for a few Middle English romance stories, one notable example is the tale of Sir Cleges, a once wealthy knight residing outside King Arthur's court "by Cardyff Syde", whose generosity had rendered him poor (Davenport, 2010: 141-2). The anonymously written text features Welsh characters engaging in English language discourse; whereas one could interpret this simply as translation from what may have been Cymraeg speakers in Cardiff for the sake of narrative, it could equally be a representation of English that was spoken in the Cardiff March at the time.

The story tells of Cleges finding a mystical cherry tree, with fruit he would like to present to King Arthur. Cleges exclaims: 'tomorrow to Cardyff, I will go'. This syntactic structure, that emphatically places focus on the subject predicate first, is common in Cymraeg; here this syntax has possibly been borrowed as a marker of 
Clege's 'Welsh' English speech. In modern WE this is a common feature 'focus fronting' (see Chapter 7 especially), this usage may be its first literary usage. Cleges reaches the gates, and demands entry for his find, where a porter tests him. Cleges suffers much humiliation by the porter, though is eventually let in.

Davenport believes Clege's humiliation at the gate could be read as a contrast between Welsh and English manners, however, whether the Welshmen was Cleges and the Englishman the porter is unclear (p.144). The tale was written long after the Welsh royal families' defeat by the English with history pointing towards a reading of Cleges as an English marcher lord rather than a native of Cardiff looking for revenge (p.144). Whatever the matter, the written English used in the text could be viewed as having a WE character distinctive of the Marches.

\subsubsection{Acknowledgement of Welsh English speakers (1480s-1550)}

Few examples of Welsh people writing in English exist from this period, although one Welsh scholar and translator was prolific with his translation work - William Salesbury. Born in 1520 in Denbighshire, Salesbury may have received education in both Wales and Oxford (Evans, 2010:255). He was first active in London during King Edward VI's reign, a period where Cymraeg works were welcome to be printed in London - in fact, at the time, London's Welsh population was far greater than any settlement in Wales (pp.250-1). He wrote four works in Cymraeg and four in English. Two works were notable, A Dictionary of Englyshe and Welshe (1547) and A Brief and a Playne Introduction ... [to] the Brytysh Tongue (1550), which were written to help non-Welsh clergy practising in Wales (p.253). Whether Salesbury's native Cymraeg grammar and pronunciation impacted his English orthography is debatable; the following example is a short extract from a translation of his own work into English:

A certaine case extracte / out of the auncient Law of Hoel da, kyng of Wales / in the yere of oure Lorde, nyne hundred and fourtene / passed: whereby it maye gathered that priestes had lawfully married wyves / at that tyme.- MS STC21612 (Davies, 1902: 4).

Fortunately, there is record of one Welshman who aimed to write English in the way that his fellow countrymen pronounced it - Ieuan ap Hywel Swrdwal. Little is known about Hywel Swrdwal's life other than he grew up in an aristocratic family and that 
he was trained in Cymraeg bardic poetry (German, 2009: 28). His poem, Hymn to the Virgin (1480), was composed whilst studying at Oxford in retaliation to his English classmates, who claimed the Welsh had no culture (Dobson, 1953:112).

The poem was written using Cymraeg orthography, and due to the conservatism of written Cymraeg, we are able to view a precise picture of the phonetic values of English phonemes as perceived by native Cymraeg speakers from 1480 (German, 2009: 28). German discovered that fricative phonemes such as $/ \mathrm{z} /, / 3 /$, and $/ \mathrm{J} /$ and affricate phonemes $/ \mathrm{t} /$, and $/ \mathrm{d} 3 /$ were not present in the poem, even though they do exist in Cymraeg and most WE dialects of today (p.29). Examples include: 'dazzle'

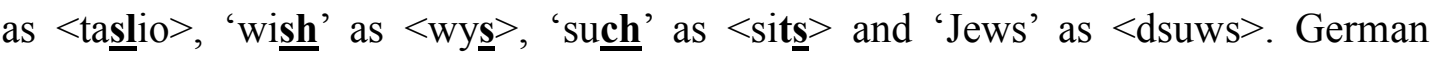
believes many of these phonemes would have entered Cymraeg due to contact with the English and Anglo-French (p.30). The text also illustrates issues with English glides. / $\mathrm{j}$ / is often rendered as a vowel, for example: 'win your love and your loving'

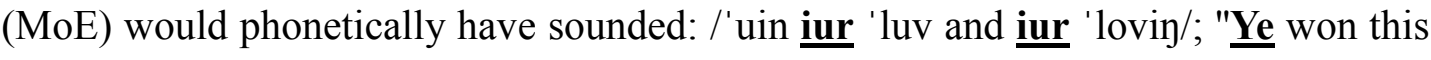
with bliss" sounded /i: 'uan ðis ui $\theta$ 'plis/. Bilabial glide /w/ was often a full vowel /u/ or /u:/: 'I would as old as I sing' sounds /[ẹi uld as ould as ẹi sig/ ; whilst 'to wone

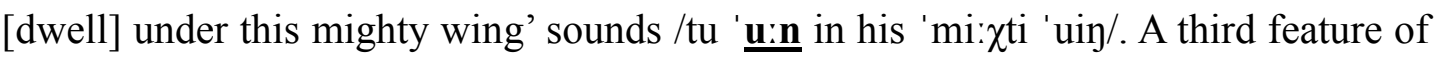
WE of 1480 is the devoicing of voiced plosive consonants in the final position: $<$ bant $>$ ['band'], <went $>$ ['wend'], <ant $>$ ['and'] and <off $>$ ['of'] (p.31). Devoicing such as this can still be found today in WE accents (see SAWD; Penhallurick, 1991; Thomas, 1984); and because of this, German (2009) believes Swrdwal may have been unaware of his own consonantal devoicing (p.32). The final feature of this early WE is the use of provection, which although common in Middle Cymraeg, no longer exists in Cymraeg or WE (p.32). Adjacent phonemes such as /-d/ followed by/t-/ will see the former also become a /t/; take for example: 'a god-made throne' being pronounced /a 'go:d mat 'tru:n/ and 'rood tree' being /'ru:t tri/. Likewise, /d/ + /ð-/ alters both to $/ \mathrm{t} /+/ \mathrm{T} /$, as in "to abide the boon" being /ta'bẹid te 'bu:n/; and "Christ that" being /'kreist tat/. German (2009) rightfully states that this text is of "utmost sociolinguistic significance' for it may be the first text in which Cymraeg-influenced English is used by a Welshman to highlight Welsh national identity (p.33); furthermore it demonstrates the dialect's historical language changes, for many salient features discussed above are now absent half a millennium later (p.23). 
It was not long before Swrdwal's efforts were put to less academic, and more performative uses through character stereotyping. Taking Swrdwal's template for the WE dialect, texts began to appear that played jest to England's Welsh cousins. Welshman serve as stock characters in a collection of jests called A Hundred Merry Tales (Anonymous, 1526). The tales were highly discriminatory, for example one told that Welshmen were not wanted in the Christian heaven for they babbled nonsense and ate 'cause bob' [Cymraeg: roasted cheese] (tale 78, in Zall, 1963:131); another told of a Welsh speaker of English who, when told to hunt deer, returns with a man's wallet made of deer hide (tale 31 ). His dialogue follows, and demonstrates several key phonetic identifiers such as devoicing of plosives, in this case $/ \mathrm{g} /$ to $/ \mathrm{k} /$ and /d/ to /t/: 'Master, by Cot's bloot [God's Blood] and her [his] nail I have stand yonder this two hours and I could see never a male [deer] but a little male that a man had hanging at his saddle bow'. (in Zall, 1963: 93-94). Also, the object pronoun 'her' is used in the subject position. This feature is unlikely to have been used in this manner by WE speakers, the misconception of its usage may stem from English writers mishearing Welshmen use feminine pronouns in particular contexts such as describing the weather, where 'mae hi'n bwrw glaw' literally translates as 'she [The weather] is raining'. This misconception resulted in English poets and playwrights applying the expression to situations in which it did not belong (Blank, 1996: 134; Bartley, 1954:73).

Similar to Salesbury's Welsh to English dictionary, Andrew Borde (b.1490), a traveller and writer, aimed to provide guidance for Englishmen travelling in Wales; the difference in his English work was that it was not written by the hand of a Welshman, but an Englishman from Sussex (Evans, 2008:89). Borde's Fyrst Boke of the Introduction of Knowledge (1547) aimed to be a linguistic guide for merchants travelling in Europe and Asia-Minor and items were rendered as they might sound to English English ears (p.90). The Welsh chapter contains 164 lines and is the longest in the book; Borde is to be praised for including Cymraeg in his guide, for previously the language had only seen print by Salesbury. Twenty-four lines are poetry, but forms an antithesis to what Swrdwal was hoping to convey about the WE speakers of the time (p.90). The poem is written in the first-person perspective, and groups together lists of popular Welsh linguistic markers of identity and stereotype, from roasted cheese to walking barefoot. The rhyming verse of the poem somewhat 
renders any Cymraeg influenced syntax obsolete, though attempts to render a WE dialect do occur lexically. Two lines regarding foods eaten features the Cymraeg word for cheese amongst the English words: 'I do loue cawse boby', and a revered Welsh mead - metheglin (Warner, 1897), 'And swyshe swashe metheglyn'. 'Swishswash' as an adjective may too be a lexical feature Borde was hinting toward, though seems more likely a fictional or poetic usage. Unlike both earlier and later works that tried incorporating Cymraeg phonological transfer into WE representations, Borde did not include them in his English poem, though was familiar, to a limited extent, with Cymraeg phonetics as he attempted to render them in his guide. Unfortunately, Borde's orthography for certain phonemes was often inconsistent, especially for sounds which did not exist in Middle English (Evans, 2008:92). For example, the voiceless lateral fricative / 1 / occurs as $<\mathrm{cl}>$ in "llety" and "lletywraig" and $<\mathrm{Kl}>$ in "Llundain". He did pick up on the spoken Cymraeg final consonants [d] reverting to $/ \mathrm{t} /$ and $/ \mathrm{g} /$ moving to $/ \mathrm{k} /$.

In summary, since Middle English's contact with Cymraeg speakers along the Welsh Marches, several writers have attempted to depict WE in writing. Early texts like Ancrene Wisse and Sir Cleges used borrowed Cymraeg lexis, whilst later texts like Hymn to the Virgin began experimenting with phonology. These texts laid down literary dialect foundations that would go on to form linguistic and character stereotypes within Elizabethan plays.

\subsection{The Welsh English speaker in Early Modern Stage (1550-1618)}

The profitable venture of London continued to entice Welshmen during the Tudor period; Welshmen went to universities in England, studied law and many became tradesmen (Lloyd, 2010:59). In fact, Geraint Dyfnallt Owen believes that 'there was hardly one sphere of [trading] activity into which Welshmen did not penetrate' (Owen, 1962:68). They became an integrated part of the community, perhaps distinguishable only by their accented English (p.68). How removed these Welshmen were from Cymraeg cannot be determined, though some sources indicate that Cymraeg and WE speakers were self-conscious about their speech, and often regretted it, with some viewing it as a disability (p.60). For example, Captain Thomas Madryn comments about his 'false [accented] English' to the Earl of Essex: 
'If I have in anywise offended you, either in speaking false English or otherwise in my simple manner of speech, I beseech you to consider that I am a Welshman' 1598 (Williams, 1987:464). This kind of remark by a Welshman may have been spurred on by cultural attitudes. One anonymous English writer associated accented WE with mental disabilities caused by cultural and even racial differences (Blank, 1996:130); whilst a $17^{\text {th }}$ century source said Welshmen in Abergavenny could not speak English 'without corruption from [their] mother tongue', stating the accent was full of 'vicious pronunciation [and] idiotisms' and was an 'infection' upon England (cited in Williams, 1987:465). On the other hand, the Welsh in London, were critical of Welshmen who chose to not speak Cymraeg, or accented English, in favour of prestige, preferment or power. Welshman Gruffydd Robert believed, for example: 'you will find some people, who as soon as they see the Severn, or the bell-towers of Shrewsbury, and once hear an Englishman say "Good Morrow", they begin to let their Welsh fall away" (cited in Morgan, 1966:14).

Nevertheless, some scholars believe the Welsh language had a widespread 'smattering' within London, with Londoners even recognizing the odd Cymraeg lexical item (Bartley \& Richards, 1947:40, cited in Lloyd, 2010:60). To consolidate a more exact 'King's English', levelling dialectal differences in writing and speech was the goal for early language purists, seeking WE speakers as easy targets; by 1603, Welshmen in the Marches and London had come into contact with this form of anglicisation (Blank, 1996:128). Writers like Alexander Gill promoted ideas that all peoples should be unified in a single language and stated: 'were human ingenuity to attempt this, certainly no more suitable language than English could be found' (Gill, 1619; cited in Blank, 1996:126). Although, efforts were made to ensure political and legal written representation were denied to Cymraeg speakers, forcing many to outwardly seek education in English writing, Cymraeg speech remained dominant in most Welsh areas, creating a community of Welshmen who wrote in English, yet spoke in Welsh (Blank, 1996: 131). Factors like these contributed to the creation of more WE speakers due to language transfer, and though English intentions may have been to convert Cymraeg language users to English language users, or to eradicate dialectal features of WE, the presence of the WE dialect undeniably increased catapulting it into the mainstream entertainment of the time - that of the early modern theatre. 
Regardless of the little worth that some Welshmen saw in their speech, the English playwrights of the day put it to use for comedic effect in their works (Lloyd, 2010:61). Recording dialect speakers was common practice in the early modern stage, with playwrights often transcribing approximations of French and Dutch accents for London audiences (Griffiths, 2010:111). Including accented speech served purposes such as providing local colour, and consideration about the emergence of different national contiguities of early modern Britain (Griffiths, 2010:113). Due to this, Celtic characters were quite common, J.O. Bartley's survey of Celtic types in the early modern stage found that Welsh characters far exceeded Irish and Scottish characters; and had become incredibly popular in the 1620s, partly due to their superstitions and cheese affinity, and partly due to their problems with English pronunciation (Lloyd, 2010:61). Griffiths (2010) believes the Welsh were 'singled out' by the English playwrights for having amusing and 'musical' accents. Such were not accurate representations, but cultural impositions; and by continuing to render Cymraeg or Cymraeg-accented English as 'nonsense', the theatre were, in a sense, contributing to a mandate of what speech was, and was not, acceptable 'English' (Griffiths, 2010:116). This is debatable, as we shall see: although some playwrights mocked the accents for comedy, others aimed to represent them more faithfully.

\subsubsection{Shakespeare's Henry V (1599) and Merry Wives of Windsor (1597)}

Shakespeare's relationship with Wales and thus WE, was notably different to his contemporary playwrights. Although there is no evidence he visited the country, Wales was the closest foreign land to his Warwickshire birthplace, and therefore it comes as no surprise that it was closest to his imagination (Maley \& Schwyzer, 2010:1,2). In fact, Shakespeare wrote about Wales more frequently than he did about contemporary Italy, penning at least eight plays that prominently featured Welsh locales or characters (p.2) ${ }^{9}$. In two of these, the historic play Henry $V$ and comedic play Merry Wives of Windsor, Shakespeare experimented with rendering a literary WE variety.

\footnotetext{
${ }^{9}$ These were: Richard III (1592), Richard II (1595), Henry IV part 1 \& 2 (1597), Merry Wives of Windsor (1597), Henry V (1599), Cymbeline (1611) and Henry VIII (1613).
} 
Whereas his peers often used the Welsh character and their voice (whether English or Cymraeg) as comical stock, the characterisation and personalities of Shakespeare's Welsh characters were subtly more detailed. Similar to the Welsh masquers of Jonson, Shakespeare strove to give the Welsh a voice, or presence, amongst authority. Shakespeare understood the power of Cymraeg words in London, and rather than use them for comedy (Lloyd, 2010:59), put them to use in Henry IV to convey a strong female presence in the character of Lady Mortimer (p.62). Lady Mortimer speaks and sings entirely in Cymraeg, Lloyd (2010) describes her presence as a: 'forceful reminder of Welsh resistance' (p.62) who was not a 'meek, shy lady', yet one who spoke Welsh for her family and her nation, something the titular character desired to extinguish (p.63). Shakespeare honours her message in providing an English Cymricphilic husband, Mortimer, whose desire it is to learn Cymraeg to please his wife; together they form a powerful pro-Welsh couple (Lloyd, 2010:70). Shakespeare renders Cymraeg speakers 'not as cheese-loving mountain dwellers, but well-read, generous [and] friendly' (p.70).

But does Shakespeare's Welsh appeal translate to his WE characters: Hugh Evans (from Merry Wives) and Fluellen (from Henry V)? There are certainly similarities in positive connotation; both demonstrate scholarly, humanitarian pursuits. Fluellen is both a captain in the English army and a military historian, whilst Evans is both a clergyman and multilingual tutor (Griffiths, 2010:114). Nevertheless, they too often come under fire for their stereotyped performance of the WE dialect (p.115). Shakespeare's respect for Cymraeg may not have extended to Welshmen's production of English.

\section{Pronunciation}

Shakespeare's abilities to represent WE of the Elizabethan era are mixed. The fact that Fluellen, his WE user, is rendered thus, suggests that Shakespeare was mishearing the Welsh name Llewellyn. Shakespeare was phonologically unequipped, and therefore unable, to hear the Cymraeg lateral fricative phoneme / $1 /$, a phoneme which is absent from most Englishes. Instead the playwright heard a combination of labiodental fricative and lateral alveolar approximant: /fl/ (German, 2009:33). Nevertheless, Shakespeare was the progenitor of WE phonetic respelling in 
Elizabethan plays, and is credited with many of their conventions; his contemporaries would go on to add to this repertoire.

Similar to Merry Wives, in Henry $V$, Shakespeare's most common phonetic respelling is the devoicing the bilabial plosive (/b/ to /p/) (see table 6.3. for a full list of Henry $V$ 's WE respellings), e.g. 'plue [blue]' and 'pridge [bridge]. Also devoiced were: Fluellen's alveolar plosives (/d/ to /t/) in 'digt [digged]' (e.g. 'digt himself four yard under'); his alveolar fricatives (/z/ to /s/) in 'ass [as]' (e.g. 'I will tell you ass my friend'); his palato-alveolar affricates $\left(/ \mathrm{d}_{3} /\right.$ to $\left./ \mathrm{t} / /\right)$ in 'By Cheshu [Jesu]'; and his labiodental fricatives (/v/ to /f/) in 'aggriefed' and 'falorous'. There are also examples of palato-alveolar sibilant fricatives being 'depalatised' (/S/ to /s/) in 'silling [shilling]'. Shakespeare omits Fluellen's final voiced alveolar plosive (/d/) in 'an [and]' (possibly eye-dialectal), and omits the initial bilabial approximant (or glide) in 'orld [world]'. Finally, Shakespeare attempts to represent a change in diphthong with his spelling of 'ancient' as 'aunchient', possibly a shift to a back vowel?

However, Shakespeare is not consistent in his usages; 'Cheshu' is later spelt 'Jesu' and later again 'Jeshu', whilst 'orld' is rendered with its initial bilabial approximant.

Table 6.2: Shakespeare's phonetic respellings in Henry $V$

\begin{tabular}{|c|c|c|}
\hline Phonetic respelling & StE & Phonemic process \\
\hline Aggriefed & Aggrieved & Labiodental fricative devoicing \\
\hline An & And & $\begin{array}{l}\text { Omission of final voiced alveolar } \\
\text { plosive }\end{array}$ \\
\hline Ass & As & Alveolar fricative devoicing \\
\hline Aunchient & Ancient & Diphthong shift to back vowel \\
\hline Cheshu & Jesu & Palato-alveolar affricate devoicing \\
\hline Falorous & Valorous & Labiodental fricative devoicing \\
\hline 'Orld & World & $\begin{array}{l}\text { Omission of initial bilabial } \\
\text { approximant }\end{array}$ \\
\hline Pashful & Bashful & Bilabial plosive devoicing \\
\hline Pear & Bear & Bilabial plosive devoicing \\
\hline Peat & Beat & Bilabial plosive devoicing \\
\hline Peseech & Beseech & Bilabial plosive devoicing \\
\hline Petter & Better & Bilabial plosive devoicing \\
\hline Plack & Black & Bilabial plosive devoicing \\
\hline Pless & Bless & Bilabial plosive devoicing \\
\hline Plod & Blood & Bilabial plosive devoicing \\
\hline Plue & Blue & Bilabial plosive devoicing \\
\hline
\end{tabular}




\begin{tabular}{lll} 
Porn & Born & Bilabial plosive devoicing \\
Poys & Boys & Bilabial plosive devoicing \\
Pragging & Bragging & Bilabial plosive devoicing \\
Prave & Brave & Bilabial plosive devoicing \\
Prawl & Brawl & Bilabial plosive devoicing \\
Pread & Bread & Bilabial plosive devoicing \\
Prerogatifes & Prerogatives & Bilabial fricative devoicing \\
Pridge & Bridge & Bilabial plosive devoicing \\
Silling & Shilling & Palato-alveolar sibilant fricative \\
& & depalatisation \\
Tavy & Davy & Alveolar plosive devoicing \\
\hline Grammar & &
\end{tabular}

It is with Shakespeare's Henry $V$ that the stereotyped discourse marker, 'look you' became associated with WE. Perhaps most interesting is that it is likely that 'look you' is a marker of Fluellen's idiolect rather than his dialect, for the first usages in the play are in fact by King Henry and the King of France, Fluellen likely imitating this structure. If so, Shakespeare's contemporaries (who thoroughly used this hereafter) were grandly misappropriating a non-feature of WE. That said, Fluellen's usage does occur 21 times, alongside modifications like 'hark you' and 'mark you'.

\section{Metalanguage and linguistic/character stereotyping}

Powers (1994) believes that in Henry $V$, Shakespeare solely 'relies on ethnic humour', such as dialect jokes and 'comic stereotyping' (p.120). 'In Merry Wives the principal butts of humour are the Welsh and French accents', whilst 'much of [Henry V] can be seen as an elaborate Welsh joke' (p.120). Blank (1996:135,136) too makes a point that in Merry Wives, Evans is the consistent running joke, and that Shakespeare uses dialect as a device to expose his pretensions as a scholar and teacher. For example, Blank notes that Evans' recitation of Christopher Marlowe's pastoral lyric 'Come Live With Me', could be devalued by his accent: 'there will we make our peds [beds] of roses'. Furthermore, upon instructing a young character, William Page, in his Latin, Evans unwittingly creates humour for Mistress Quickly, who evidently believes the Latin teacher's credibility is lessened by the fact he still has yet to perfect his secondary language, English. Hugh Evans demonstrates an inability to pronounce both fricative / $/$ when detailing 'the focative case' and glide /w/ in 'oman' in the following:

Evans: $\quad$ I pray you have your remembrance, child: accusative hing, hang, hog. 
Ms. Quickly: 'hang-hog' is Latin for bacon, I warrant you.

Evans: leave your prabbles, 'oman [woman]. - What is the focative [vocative] case, William?

William:

$$
\mathrm{O}-\text { vocativo }-\mathrm{O}-
$$

Shakespeare may have intended a viewing of this as comedy, and audiences may well have laughed at it, but it is hard to deny that here Shakespeare demonstrates the linguistic discrimination of the era. Evans' WE is attacked on at least two other occasions. When Evans enters a quarrel with French doctor Caius, an English host asks for them to be disarmed, stating: 'Let them keep their limbs whole, and hack our English'. This scene suggests that the existence of a language ideology was in place: that WE was the result of 'hacking' at 'good' English. Another Englishman who takes offence to Welsh accented English is Falstaff, who quotes and mocks Evans' pronunciation of 'cheese' and 'butter' as 'seese' and 'putter', crying: 'Have I liv' d to stand at the taunt of one that makes fritters of English?'

Some linguists such as German (2009) argue that Shakespeare's representation of WE was remarkably close to other works by WE speakers, and to ridicule it as 'unrealistic', or dismiss it as 'stage Welsh', is not wholly justified (p.34). German goes on to say that Shakespeare 'was a much better dialectologist than most people might believe today'. That said, Shakespeare did directly address the dialect for the purpose of comedy. A key scene is in Henry $V$, when Fluellen directly translates 'Alexander the Great' from the Cymraeg 'Alexander Fawr' to 'Alexander the Pig [Big]' (Blank, 1996:138). When corrected, he responds: 'Why, I pray you, is not pig great? The pig, or the great, or the mighty, or the huge, or the magnanimous, are all one reckonings, save the phrase there is a little variations.' The underlying humour here is that Fluellen understands synonymy, yet does not realise the discrepancies of meaning creating by his WE pronunciation

However, there is more to Fluellen's Welsh character than simplistic character stereotyping. Although Henry $V$ features three speakers of English varieties (Jamy a Scotsman, MacMorris - an Irishman, and Fluellen - a Welshman), it is Fluellen, that professes a greater awareness and understanding of worldliness (Blank, 1996:136). In Fluellen's conversation with Gower, an English captain who reports 
that Henry is putting prisoners of war to death for their rebellion, that is of interest. Fluellen continues past the 'pig' speech and makes parallels between their Henry and Alexander. Fluellen asserts (in dialect), that if Gower had studied the 'orld' (glidal omission) that he 'sall' (affricate silibantisation) find that Alexander knew when to execute his unreliable friends. Gower retorts that Henry would never kill any of his friends, to which Fluellen makes the parallel that he will turn away those who cannot be trusted, referring directly to the arrogant Falstaff. For Blank (1996) this scene demonstrates that Fluellen is scholarly, placing Henry's killing of prisoners under moral scrutiny. Shakespeare's Fluellen is not simple comical stock. Although his accented English evidently holds him back within his 'workplace', and would have certainly drawn laughter from the audience, he transcends some of the stereotyping. Shakespeare thus demonstrated that a Welshman, and therefore any dialectal speaker, could indeed surpass their stereotyped inferiority. It is through Henry's words that Shakepeare truly epitomises this perspective: 'Though it appears a little out of fashion, there is much care and valour in this Welshman.'

How sympathetic Shakespeare was to the Welsh is somewhat clouded. Shakespeare may have had to tread carefully in his depictions of the Welsh and their language usage, for the political climate saw Celtic sympathiser Elizabeth I upon the throne (German, 2009). If anything, there is the possibility that Shakespeare's fictive WE may have been discursively constructed amongst his peers and indeed the London Welsh to be as 'authentic' as possible, as not to offend certain sensibilities.

\subsubsection{Dekker's The Welsh Embassador (1597) and Patient Grissill (1600)}

Following Shakespeare, Thomas Dekker wrote two plays with Welsh characters, The Welsh Embassador (1597) and Patient Grissill (1600). The Welsh Embassador, a comedy in which an Englishman must take the supposed 'comical' disguise of a Welshman, provides us with the kind of WE that comedy troupes were presenting to audiences. Two lines stand out, for they illustrate both linguistic stereotyping and phonetic respelling of the era in remarkably few words:

1. Welse tongue I can tell you is lofty tongue / And prave sentill men [brave gentlemen] as are in the urld [world] tawge [talk] it.

2. In Wales...wee have noe universities to tawge [talk] in uplandish greekes and 
lattins, wee are not so full of our rethoriques as you are heere, and therefore your greate and masesticall eares was not to looke for fyled oratories [valid oratories??] and pig [big] high stiles.

The first excerpt sees palato-alveolar fricatives and palato-alveolar affricates

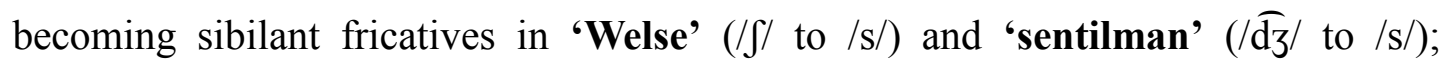
bilabial plosive devoicing in 'prave' (/b/ to /p/) and velar plosive voicing in 'tawge' (/k/ to /g/), as well as glide omission /w/ in ''urld'. Dekker linguistically stereotypes the Welsh language and its speakers as using 'lofty tongue'. The second excerpt elaborates on this discrimination, and features devoicing of labiodental fricatives $(/ \mathrm{v} /$ to /f/) in 'fyled [valid]'.

The Patient Grissill (1600) is Dekker's second comedy to feature Welsh characters, and like its predecessor contained WE that featured devoicing and alteration of affricates. Unlike his first play, Dekker creates characters who are Welsh born: Sir Owen, a Welsh Knight, is the chief user of dialect. His squire Rice, however, does not, though the character Gwenthyan also does. Act 2, scene 1 captures most of the phonetic respelling. Many conventions are similar, such as devoicing velar plosives ('cod [god]') yet voicing other velar plosives ('knog [knock]'), whilst devoicing labiodental fricatives ('faliant [valiant]'). Differences include changing voiced and voiceless palato-alveolar affricates $(/ \mathrm{t} /$ and $/ \mathrm{d} z /)$ into palato-alveolar fricatives $/ \mathrm{J} /$ 'shallenge [challenge]' and 'shentelman [gentleman]'; whilst voicing final bilabial plosives ('keeb [keep]') and medial palato-alveolar affricates ('fedge [fetch]').

Although there is a large amount of phonetic respelling in the play, suggesting that Dekker went to a great extent to render his WE dialect, his inconsistency with his own rules (especially compared to The Welsh Embassador, but also within the Patient Grissill) suggest Dekker was probably just providing approximant respellings simply to 'other' the Welsh characters.

The play also contained a repetitive twin-phrase structure: 'pribles and prables', which were supposedly commonly markers of WE speakers during Elizabethan England (Blank, 1996:135; Griffiths, 2010:115). A final feature is the grammatical use of object pronoun 'her' in the position of the subject (e.g. 'her [he] thinke the 
prittish shentelman'), which though previously used in A Hundred Merry Tales (1526), is the first usage in an Elizabethan play.

\subsubsection{Anonymous' Sir John Oldcastle (1600)}

Sir John Oldcastle was a production that was published for print around 1600, and like similar plays of its era, also exhibits some Welsh characterisation (Griffiths 2010:113) with the use of WE to index a sense of 'Welshness' to the production. The play concerns John Oldcastle, a real-life figure who was a late medieval rebellious Lollard. Little is known about who wrote the play, although penmanship has been attributed to Shakespeare in some editions of the text. That being said, it can be argued that the reproduction of WE dialect does match what we know of Shakespeare's own methods of rendering the Welsh variety above.

Several characters are depicted using a Welsh accent. The first is Owen, one of Lord Powis's soldiers, and the second is Davy, another of Powis's men. A class-divide in relation to accent is defined, for although Owen and Davy speak in dialect, their master Lord Powis and his wife Lady Powis are both of the gentry and exhibit no WE speech.

\section{Pronunciation}

Owen uses some bilabial devoicing and velar plosive voicing in utterances such as 'cosson pe puse' [cousin be busy]' and 'haw, no pill [bill] nor wells hoog [hook]?'. Also, the text uses an example of a palato-alveolar affricate $/ \widehat{d} /$ becoming a sibilant palato-alveolar fricative $/ \mathrm{J} /$ in 'pray you do shustice [justice]'. And, both allegro and eye-dialectal features are used: 'down i' [in] tha [the] knave's name, down!' Furthermore, 'busy' is rendered 'puse', possibly indicating a shorter final vowel than a close front vowel /i:/. Davy uses similar bilabial and alveolar plosive devoicing in 'pye [bye]', 'pud [pud]', 'pale [bail]', and 'tie [die]'. He similarly devoices the sibilant fricative /z/ in 'resson [reason]', voices velar plosive in 'harg [hark] you', and whilst Davy turns the initial palato-alveolar affricate into a palato-alveolar fricative in 'Lord shudge [judge]', does not repeat the structure for the final palatoalveolar. However, for vowels, Davy differs from Owen in that he renders a close front vowel in 'will' as a close back vowel, thus: 'wool' (e.g. 'I wool give you'), and 
the respelling of 'Powis' as 'Pawesse' (e.g. 'Lord Pawesse in prison?') also phonetically suggests a more closed vowel such as /e/. 'Cousin', and its shortening 'cous', are respelled various ways for both Owen and Davy. Owen uses 'cosson', whilst Davy uses 'cosse', 'cossonne', and 'coozin'. Finally, the play highlights the misspelling of 'knave' by Owen as 'kanave'. Owen pronounces the 'silent' velar plosive, thereby highlighting his poor education; and for audiences, likely a source of humour.

\section{Lexis and grammar}

The playwright experiments in using some lexical and grammatical forms that may have been used by $17^{\text {th }}$ century speakers of WE. Both 'pray you' and 'hear you' seems to be variants of the 'look you' discourse marker that Shakespeare used and characteristic of a WE speaker during the time (Blank, 1996:134). Also, Ise, (e.g. 'Ise live and [die] in good quarrell') is likely a Cymraeg loan of 'Iesu', the language's term for Jesus. Finally, grammatically, Owen uses object pronoun 'her' in place of subject pronoun 'she' in 'Has her nothing to say but O Yes?'

In all, unlike Shakespeare's work, that used phonetically transparent examples of WE, the phonetic respelling in Sir John Oldcastle is more difficult in places to decipher, leading to a level of phonetic opaqueness for scholars today. Indeed, because of the literary dialect's inconsistency with Henry $V$ and Merry Wives, there is a strong case that the writer was not Shakespeare.

\subsubsection{Armin's Two Maids of More-Clacke (1609)}

Robert Armin's Two Maids of More-Clacke (1609) features a similar plot to Dekker's Embassador, in that a servant character, Tutch, disguises himself as a Welsh Knight to help his master, Filbon in courtship. Filbon then assumes the role of Tutch's servant. Griffiths (2010) says of the play: '[Armin] lays [the accent] on thick and [it], as recorded in the printed text, is ridiculously and gloriously overdone' (p. 115). Armin, who was chiefly an actor, was associated with both the comedy troupe Lord Chamberlain's Men, as well as William Shakespeare.

\section{Pronunciation}


In the following segment Armin also makes plosives of the affricates ('dudge'), devoices the initial plosives ('pad'), whilst voices final plosives ('knog').

Tutch. Where is Tailer? dudge [judge] me, will knog [knock] his pad [bed?/bad?], What is chirken with cold button done, say you.

Filbon. Excellent, this is welch indeede, O my honest Tutch.

Tutch later uses 'ples me' for 'bless me', devoicing again the bilabial plosive. Filbon is pleased with his servant's rendering of WE (or 'Welche'), and the courtship proceeds.

\section{Grammar}

Tutch also uses numerous tag phrases. He uses both 'say you' and 'marg you', rendering voicing of devoiced consonants. These are reminiscent of the stereotyped 'look you', which he also uses, e.g. 'giue a ducket, looke you'.

Ultimately, Armin renders a WE variety by devoicing voiced consonants. He also employs numerous voicing of devoiced consonants. There is no record of this latter characteristic surviving into later varieties of WE. Perhaps it was used; but speculatively, it is likely that Armin (and the author of Oldcastle), altered the devoicing stereotype to voicing to simply elaborate upon the theatrical WE and to further enforce an 'Othered' language variety.

\subsubsection{Middleton's A Chaste maid in Cheap-side (1613)}

Thomas Middleton's A Chaste Maid in Cheapside (1613) focused largely upon a Welsh Gentlewoman. Regarding her characterisation, Woodbridge (2007) argues that Middleton 'avoids the city-bashing of pastoral writers to whom the countryside is a repository of simplicity and virtue', arguing that the Welsh Gentlewoman is 'as corrupt and street-wise as the canniest Londoners' (p.907). In fact, many of the women portrayed in Middleton's Maid in Cheapside are some of the most successful tricksters in the play (Woodbridge, 2007:910). That said, in the main the Welsh Gentlewoman fulfils the role of another Elizabethan period stock Welshman in fulfilling both the stereotype of the Welsh being 'comic', and here 'promiscuous'. The Welshwoman is in fact not a 'gentle' niece of Sir Walter Whorehound, as is first 
presumed, but a crafty prostitute that Walter is looking to marry to the Yellowhammer family's Tim.

Upon the Welsh gentlewoman entering the scene (replicated below), we observe an exchange in which Sir Walter commands the Welsh Gentlewoman to use the English language rather than Cymraeg. The Welsh gentlewoman, like many Welsh people from her historical era, uses Cymraeg as her native language (L1) and uses English as an L2 variety, and is content in switching between the two.

\section{Act 1 , Scene 1}

Sir Walter Now, wench, thou art welcome to the heart of the city of London.

Welsh Gentlewoman Dugat a whee [modern Welsh: Duw cato chwi; i.e. God be with you $]^{10}$

Sir Walter You can thank me in English, if you list.

Welsh gentlewoman I can, sir, simply.

The unnamed Welsh Gentlewoman's chief characterisation and her comedy comes from her linguistic capabilities. She fulfils the purpose of an exotic speaker of a foreign tongue (i.e. Cymraeg), however, unlike some other plays of this era, this Cymric asset is not wholly mocked by Middleton but finds an advantageous superiority in the comedy. Indeed, it is Tim's naïve assumption upon meeting the Gentlewoman that she is a speaker of Latin that drives the comedy, Tim being totally inexperienced in Cymraeg.

There is little to suggest that Middleton had any intention to render a 'stock' WE for his gentlewoman, and, for his Welsh character, does not conform to the dialectal template his contemporaries were using, although does fall back on the character stereotype that Welsh people eat lots of cheese in: 'Rhegosin a whiggin harle ron corid ambre. [modern Cymraeg: i.e. Rhyw gosyn a chwigyn ar ôl bod yn; i.e. some cheese and whey after taking a walk]'. An adverb that lacks the typical -ly suffix ('He mocks me sure'), could hint towards the Welsh gentlewoman's nonstandard L2 variety, although this does not match anything on record at this point (see Chapter 7).

\footnotetext{
${ }^{10}$ In later editions of the play, like Gary Taylor's 2009 collection, Woodbridge (2009) has translated many of the Cymraeg phrases into standardised modern Welsh. The original orthographic representations give us some indication of the approximated phonology of the speakers in Middleton's time.
} 
The play also features a character who serves as Sir Walter's manservant Davy Duhamma, whose surname Woodbridge (2007) glosses as a phonetic respelling on the Cymraeg 'dewch yma' (come here) (p.914). There is little to suggest Davy is Welsh, or at least Welsh in the same way the Welsh gentlewoman is - that is a second language speaker of English, the Duhamma surname potentially acting as another element to lure the Yellowhammers into believing in Sir Walter's Welsh connections.

\subsubsection{Jonson's For the Honor of Wales (1618)}

Ben Jonson's masque, For the Honor of Wales (1618) was a reworking of his own Pleasure Reconciled to Virtue for James I, which, when performed to Charles I, had received criticism for being too tedious (Blank, 1996:142). The reworking featured comical Welshmen, who light-heartedly took the role of Jonson's critics, before then reforming the original 'for the honor of Wales', by incorporating Welsh characters and places instead (p.142). Cymraeg was used when performers were in masque, whilst a rendering of WE was used when addressing the audience (Blank, 1996:140).

The performance begins in heated argument about who should speak for the group between Griffith, Jenkin and Welsh attorney, Evans. Griffiths asks to be 'pold [bold] to advise' and for everyone to not be 'too byssy [busy]', as Jenkins makes note of 'the king of Gread Prittain [Great Britain]'s presence; in response to the quarrels, Evans pleads: 'do not [...] pyt wrong upon us all by your rassness [rashness]'. Evans is eventually nominated by his countrymen but upon speaking to his king exclaims: 'I know not a oord [word] or a syllable of what I say (113)'. In response to the previous incarnation's lacklustre performance he adds that all of Wales agrees it was too poor for royalty: 'your ursip [worship] would suffer our young master Sarles [Charles], your ursip's son and heir'. Regarding the plays reformatting, he states that: '[It] is done without any manner of sharshes [charges] to your madesty [majesty], onely shanging [changing] his [the hill's] name" (140-1).' Following the excitement by the Welshmen for the King to visit their nation, the Welshmen tell the King of '[Welsh] provisions for the belly'. They pronounce 'udder' as 'uther', 'English sheep' as 'Englis seep', followed by 'and then for your fiss [fish], sall [shall] shoose [choose] it your diss [dish].' 
The phonological tropes here are as evident and numerous as in other contemporaries' works; from experimenting with voicing and devoicing ('pold', 'Gread Prittain'), to combining features such as 'ursip's' glide omission and sibilantising affricates. Jonson's most prolific phonetic feature was evidentially the replacing of affricates with sibilant fricatives: 'rassness', 'Sarles', 'englis', 'seep', 'fiss', 'sall', 'shoose', 'diss'. Jonson also shows affricate /dz/ revert to a plosive /d/ in "madesty" (also seen in Armin's work above), as well as altering a palato-alveolar affricate $(/ \mathrm{t} /)$ to a palato-alveolar fricative phoneme $(/ \mathrm{g} /)$ in 'shanging'; as well as 'sharshes' which features two affricate-fricative transformations from $/ \widehat{\mathrm{t}} \mathrm{f} /$ to $/ \mathrm{g} /$ and $/ \widehat{d} /$ to $/ \mathrm{J} /$.

Towards the end of the masque, Griffith denies that the Welsh nation had been conquered by the English, despite the union occurring 100 years prior, showing his resilient facets of Welsh culture and spirit (Blank, 1996:143). Blank (1996) argues that although the masque's humour was undoubtedly focused upon Welshmen addressing King James in what was considered poor English; the Welshman managed to make their point that they could speak to the King about what they wanted in whatever English variety they deemed necessary (p.141). The fact that Jonson gave the fictional Welshmen a voice in front of their King marks a turnaround in the power of WE representation, providing them with a semblance of respect and authority, similar to Shakespeare's Fluellen.

The Elizabethan plays of the late Tudor period had profound impact upon representations of early WE dialect. Shakespeare formed the initial interest in representing WE theatrical dialect, conducting his own inquiry into the variety. Many of Shakespeare's phonetic respellings matched ap Hywel Swrdwal's earlier dialect poem. So popular was the representation of Shakespeare's comical Fluellen, that many other playwrights such as Thomas Dekker, Robert Armin and Ben Jonson chose to use linguistic stereotypes such as consonant devoicing and discourse markers such as 'look you', in turn forming a stereotype of the 'comic Welshman'.

\subsection{Welsh English in Later theatrical plays}

The dialectal representation of WE between the Elizabethan period and the advent of 
the Welsh writing novelist period is scant because of a lack of an Anglophone writing culture within Wales. However, that is not to say that there were no representations, as will be seen below (documented by Bartley (1954)). During this era, English playwrights relied on the previous established popular WE linguistic stereotypes that had been popularised by playwrights such as Shakespeare.

There are several culturo-political reasons why popularity of the Stage Welshman and his stereotyped English waned during this period. The centuries that followed Shakespeare's era saw the nation of Wales legally assimilated into England. As a result this significantly quelled notions of rebellion. Unlike their Celtic cousins, the Irish and the Scottish, the Welsh cared little for nationalism or English affairs and in return England had no strong feelings towards Wales either (Bartley, 1954: 135). The rural Welshmen were left alone in the mountainous regions where Cymraeg in fact flourished, and England's focus fell upon the other border nations.

This lack of interest can surely be evidenced in the sheer decrease of Welsh-themed plays when compared to other Celtic-focused plays written by Englishmen during this period. Bartley states: 'the number of plays with Irish characters is more than double what it was in [1600s], and the Scots increase a third below the preRestoration figure' (Bartley, 1954: 136). This marks a significant change from the earlier period, where the Welsh were once the most represented national character. Portrayals of WE speakers had become unpopular, primarily as they were no longer considered an exoticism to English audiences.

Despite the Welsh upper classes becoming anglicised (Bartley, 1954: 135) (which in turn would have given their English a regional quality), few WE plays demonstrated anything of the sort. Shakespeare's plays continued to be popular throughout the 1700s with Captain Fluellen remaining a very popular character (p.145). It is likely that their popularity took precedence over realism, because new plays which were produced during this era continued to write a Shakespearean Stage Welshman, refusing to add any new associations with the stock character or dialect; if anything, characteristics of WE were reduced to a minimum (p.142). Bartley states that this may have either been due to the hardening of the conventional, standardised speech within writing, or the lack of interest in capturing a Welsh user of English; as a result, 
'a decline in realism [was] evident' (p.144). One of the few remaining tropes was the devoicing of initial plosive consonants, according to Bartley's survey this occurred within all plays of this era (p.145).

\subsubsection{Later theatrical plays: Mid 1600s -1759}

Linguistic stereotypes were still being strongly represented in 1660 , as a brief 'performance' was enacted at Goldsmith's Hall on April $11^{\text {th }}$. The script provides us with a WE portrayal that used the trademarked devoicing of plosive consonants $/ b /$ to $/ \mathrm{p} /, / \mathrm{g} /$ to $/ \mathrm{k} /$ and $/ \mathrm{v} /$ to $/ \mathrm{f} /$, as well as creating fricatives of affricate sounds, and misuse of the 'her' pronoun:

Her pe shentleman of Wallis, and her lost her creat fortune for her creat loofe to her creat land lord, Sir Thomas Middleton; but her have cot it acain, her thank her coot Sheneral. (Bartley, 1954: 138)

Towards the end of the $17^{\text {th }}$ century two comical portrayals, one titled Dame Dobson (1683) by Edward Ravenscroft and the other The Richmond Heiress (1693) by Thomas D'urfey featured Welshmen called Jinkin and Rice ap Shinkin. Ravenscroft's Welshman used grammatical tropes such as a subject female pronoun usage 'her', as well as a variant of the Shakespearean 'look you' phrase - 'mark you' (p.138). D'urfey also used devoicing of $/ \mathrm{v} /$ to $/ \mathrm{f} /$ and $/ \mathrm{g} /$ to $/ \mathrm{k} /$ to identify his Stage Welshman (p.139). However, D’urfey also used a Cymraeg lexical item in his discourse: 'methgelin', the Welsh word for mead (p.142), which was first recorded as a WE word in Borde's Introduction of Knowledge (1547).

According to Bartley's (1954) survey the presence of Cymraeg to denote Welsh identity alongside the English usage was a feature of Lacy Ryan's Cobler's Opera (1730) in his character, Ap Leek. The year 1730 also saw the publication of Journey to Bristol: The Honest Welshman (1730) by John Hippisley; the Welshman of the play, David Shenkin was played by Hippisley and was a comic part. Bartley comments that the dialect is 'neither interestingly conventional nor has it any special claims to realism' being 'slight and carelessly indicated' (p.141). For example, use of 'her' as a subject pronoun: 'hur [she] was gone ten or eleven months with child by hur [him?]'. Interestingly, Hippisley wrote, and thus recited, Cymraeg to convey his bicultural WE character, within the phrase: 'duhoma' (modern Cymraeg for 'come 
here': dewch yma) (p.145), similar to Middleton's A Chaste Maid in Cheapside. Following this, the phrase saw usage in a play titled Prison Breaker, however was incorrectly rendered as an oath (p.145). Many of the previous forms (devoicing of $/ \mathrm{b} /, / \mathrm{d} /$ and $/ \mathrm{v} /$, the pronoun misuse, and altering affricates) are utilised in this snippet from Theatrical Manager (1751) which featured a Welsh servant Ap Meagre: 'By Cheshu [Jesu], her [his] treatments is no petter [better] than is a Puppy Togs [dogs], for tho' hur is famished, if I crafe [crave] any meats, peradventure her is kicked for hur desires' (p.42).

\subsubsection{Later theatrical plays: $1760-1800$}

Of the sixteen plays that featured Welsh characters between 1760 and 1800, Bartley records only seven containing traces of the regional variety, of these there are none that include new associations within the dialect's representation (Bartley, 1954: 212, 214). Bartley comments that the personal names of characters attract some focus, being divided equally between what could be genuine Welsh names and fabricated, humorous names (p.215). As for the usage of the variety in this period, playwrights were careless in their depiction, with inconsistent speech indications scattered throughout texts, giving the impression that they were most derived from literary dialect rather than life (p.215). Two examples of this era follow.

Richard Cumberland's Fashionable Lover (1772) featured Dr. Druid, 'a gentleman of very antient family in North Wales' whose interests included genealogy; Bartley comments that Druid's comedy as a WE speaker is secondary to his scientific pursuits. A sample of the text provided illustrates: devoicing of $/ b /$ in 'pats [bats], peetles [beetles]', and omission of initial /w/ in ''ooman'. Finally, one of the last texts from the $18^{\text {th }}$ century, Charles Dibdin's Liberty-Hall (1785) demonstrates an unremarkable Ap-Hugh devoicing his /d/ to /t/ in 'tisputes' [disputes], /v/ to /f/ in 'ferry' [very] and /b/ to /p/ in 'peseech' (Bartley, 1954: 213).

In summary, after prominence of Elizabethan era plays, the representation of WE in fiction stagnated: Bartley wrote: 'in every way there is a considerable further decline in the fullness with which dialect is represented' (p.215). Playwrights active during this era used the known linguistic conventions (and linguistic stereotypes) that 
Shakespeare and company had transcribed, and continued their usage. This is evidenced in the fact no new forms were attested in this two-century period: at this point WE theatrical dialect was little more than outdated, stage dialect. Ultimately the WE dialect was not 'popular' enough for English playwrights to warrant further dialectological inquiry; the dialectological inquiry Elizabethan playwrights had done had become fossilized.

\subsection{Welsh English in $19^{\text {th }}$ century Anglo-Welsh poetry}

This chapter's final section shifts the focus from plays written by Englishmen who had had little connection with the WE dialect, to Welsh poets of the early AngloWelsh movement. Raymond Garlick \& Roland Mathias poem anthology - AngloWelsh Poetry: 1480-1990 (1982) provides a sampling of English poetry written by genuine speakers of WE throughout the $19^{\text {th }}$ century and up until the emergence of the popular novel. Except for ap Hywel Swrdwal's earliest work, there were few poets, or writers, following his creative footsteps; there are no renderings of WE pronunciation, grammar or vocabulary until the beginning of the $19^{\text {th }}$ century. Much of the poetry takes on a standardised English form, Garlick \& Mathias (1982:36) themselves comment upon this, that the use of nonstandard speech within the poetry was largely omitted, leaving scholars with a Standard rather than the regional voice, or 'the English of the Welsh professional class'. The comfort in retaining the Standard rather than a displaying a variety's forms reflects what Bartley stated (1954:141): that the hardening of written conventions was more important. ${ }^{11}$

Of the forty-two poets detailed in the poem anthology (up until 1900), more than half were Cymraeg speakers and at least one third wrote in the language (Garlick \& Mathias: 1982). This bilingualism affected many poets' linguistic identities. For example, Ieuan Ddu (John L. Thomas, b.1795-1871), a schoolmaster from Carmarthen and writer of both English and Cymraeg, remarked in 1867 that English was a language of Wales, that Wales was supported by both Cymraeg and English (p.35). Acknowledging that the English language was of equal value is reflected in Ddu's poetry. Ddu was content in using Cymraeg loaned lexis amongst his English

\footnotetext{
${ }^{11}$ This will forever remain a caveat for those studying written dialectal forms of the past, whether in fiction or non-fiction.
} 
verse. This is evidenced in his poem Harry Vaughan (1867) where Ddu wrote following rhythmic coupling that rhymed English 'history', with 'Llyfr du', a couplet that only works if the English speaker also knows Cymraeg colour adjectives:

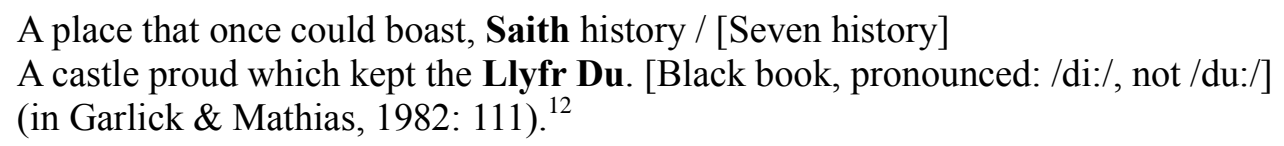

Thomas Hughes (1818-1865) also used Cymraeg lexis within his English poetry. A rector from Ruthin, North Wales, Hughes was learned in Cymraeg, English and Latin. Hughes published a volume of poetry written by himself and his father, with $A$ Cheese for the Archdeacon $(1865)^{13}$ being the poem of importance. Within it, Hughes uses two Cymraeg phrases, perhaps demonstrating the lexical borrowing of his speech community. He uses the word for bread and cheese in 'nor suppose I deem wanting in bara a chaws' and 'a chroesaw - the cloisters, a liberal house', a phonetic respelling of 'croeso' - Cymraeg for welcome.

Although the usage of Cymraeg loans as markers to denote WE were common, and most likely accurate of the region's English speech, dialectal English vocabulary from across the border was also written by Anglo-Welsh poets. Richard Hall (18171866), a pharmacist from Brecon used dialectal vocabulary in his poem Crickhowel $(1850)^{14}$ in the line: 'in green-leaved groves the cushat tells its tale' (Garlick \& Mathias, 1982:117). The paratexual notes provided by Garlick \& Mathias (1982) define a 'cushat' as a wood-pigeon. Interestingly, when cross-referencing the term with the $O E D$, the lexis's origin is of 'chiefly Scottish English and Northern English', a far cry from the Welsh borders.

Ultimately, the emergence of Welsh people using literary dialect in poetry, rather than English playwrights, handed WE depiction back to the Welsh. Unlike ap Swrdwal's $15^{\text {th }}$ century dialect poem that likely inspired English playwrights to use WE dialect

\footnotetext{
${ }^{12}$ This is from Ddu's original collection titled: Cambria Upon Two Sticks (1867)

${ }^{13}$ This is from Hughes' original collection titled: Poems by Hughes (1865). Unknown publisher.

${ }^{14}$ This is from Hall's original collection titled: A Tale of the Past and Other Poems (1850)
} 
for their stage Welsh, $19^{\text {th }}$ century poets like Ieuan Ddu, Thomas Hughes, and Richard Hall set the foundations for the genre of Welsh-written English literature to develop in the late $19^{\text {th }}$ and early $20^{\text {th }}$ centuries. Indeed, Garlick \& Mathias (1982) remark that although there are few 'distinctive words and phrases recorded by the [SAWD]' (p.35) within Anglo-Welsh poetry, this changes with the emergence of the Anglo-Welsh novel. This era of literary dialect study of great significance as shall be shown in the next chapter.

\subsection{Conclusion}

This chapter has addressed the representation of WE in fiction from the $12^{\text {th }}$ century until the $18^{\text {th }}$ century, and briefly looked at the beginnings of Anglo-Welsh writing in the $19^{\text {th }}$. The chapter has traced the emergence and continuation of several prominent linguistic features. Regarding lexis, early writers of the $12^{\text {th }}-13^{\text {th }}$ centuries depicted several Cymraeg loans that were used in the contact variety, though few of these were continually used. A chief grammatical feature was the use of 'her' as a subject pronoun, emerging in the $15^{\text {th }}$ century, and found continued usage well into the $17^{\text {th }} \mathrm{C}$ (6 texts). The tag 'look you' ( 3 texts) also became a linguistic stereotype during the $17^{\text {th }}$ century. However, the key linguistic domain in rendering a WE dialect was phonology. A number of phonemes appear to have become enregistered in English playwrights' perceptions as markers of WE dialect of the Elizabethan era and were used for indexing the character stereotype of the comic Welshman. For example, devoicing (and alternatively voicing) of bilabial, alveolar, and velar plosives, devoicing of alveolar fricatives and labiodental fricatives were very common; as were depalatising palato-alveolar fricatives to alveolar fricatives, and rendering affricates as fricatives and omitting initial glidal phonemes (Table 6.3. summarises these features).

Table 6.3: Summary of Elizabethan era Welsh English phonetic respelling

\begin{tabular}{llll}
\hline $\begin{array}{l}\text { Phonological } \\
\text { feature }\end{array}$ & English English phonemes & $\begin{array}{l}\text { Theatrical Welsh } \\
\text { English phonetic } \\
\text { respelling }\end{array}$ & $\begin{array}{l}\text { Example } \\
\text { quotation }\end{array}$ \\
\hline $\begin{array}{l}\text { Bilabial, } \\
\begin{array}{l}\text { alveolar, and } \\
\text { velar }\end{array}\end{array}$ & Initial $/ \mathrm{b} /, / \mathrm{d} /$, and $/ \mathrm{g} /$ & $\mathrm{p} /, / \mathrm{t} /, / \mathrm{k} /$ & $\begin{array}{l}\text { Prave } \\
\text { (brave) }\end{array}$ \\
& Medial or final $/ \mathrm{p} /, / \mathrm{t} /$, and $/ \mathrm{k} /$ & $\mathrm{b} /, / \mathrm{d} /$, and $/ \mathrm{g} /$ & Tawge (talk)
\end{tabular}


plosives

\begin{tabular}{|c|c|c|c|}
\hline $\begin{array}{l}\text { Labiodental } \\
\text { Fricative }\end{array}$ & Initial and medial /v/ & $/ \mathbf{f} /$ & $\begin{array}{l}\text { Falorous } \\
\text { (valorous) }\end{array}$ \\
\hline $\begin{array}{l}\text { Sibilant } \\
\text { alveolar } \\
\text { fricative }\end{array}$ & Medial \& final /z/ & /s/ & Asse (as) \\
\hline $\begin{array}{l}\text { Sibilant } \\
\text { palato- } \\
\text { alveolar } \\
\text { fricative }\end{array}$ & $/ \int /<\mathrm{Sh}>$ & $/ \mathrm{s} /$ & $\begin{array}{l}\text { Welse } \\
\text { (Welsh) }\end{array}$ \\
\hline Affricate 1 & $\begin{array}{l}\mid \mathrm{t} \mathrm{g} /<\mathrm{ch}> \\
\widehat{\mathrm{d} 3} /<\mathrm{j}>\end{array}$ & $/ \mathrm{s} /$ & $\begin{array}{l}\text { Sarles } \\
\text { (Charles) } \\
\text { Sentilman } \\
\text { (gentleman) }\end{array}$ \\
\hline Affricate 2 & $\begin{array}{l}\mid \widehat{\mathrm{t} f} /<\mathrm{ch}> \\
/ \widehat{\mathrm{d} J} /<\mathrm{j}>\end{array}$ & $\mid \int /<\operatorname{sh}>$ & $\begin{array}{l}\text { Shallenge } \\
\text { (challenge) } \\
\text { Sheshu } \\
\text { (Jesus)[replac } \\
\text { e] }\end{array}$ \\
\hline Glides & Initial /w/ & Omitted & Urld (world) \\
\hline
\end{tabular}

Because several of these features were present in Hywel Swrdwal's dialect poem Hymn to the Virgin (1470), and because, according to the $S A W D$, some are still in use in the $20^{\text {th }}$ century, this suggests the English playwrights were transcribing WE somewhat accurately; however, treating all English playwrights' phonetic respellings as linguistic evidence should be done with some caution, as, not only were they instigators of particular character/linguistic stereotypes, but also because, on a technical level, several had difficulties hearing particular Cymraeg phonemes (i.e. Fluellen/Llewelyn). Of more interest for 'linguistic evidence' are lexical forms from earlier $12^{\text {th }}-13^{\text {th }}$ century texts in the Katherine Group that showed early border WE used Cymraeg loans like 'cader' for candle and 'genow' for mouth. Also of interest are early Anglo-Welsh poems that used loans such as 'bara a chaws' (bread and cheese) and English English dialect words such as 'cushat' (wood-pigeon).

Throughout these early centuries, there is an important difference between the way in which the dialect is represented by those familiar with it, such as poets Hywel Swrdwal, Ieuan Ddu and Thomas Hughes, and playwrights such as Shakespeare, 
Dekker, and Jonson. Yes, there are similarities in phonetic respelling, but the motive behind WE depiction usage differs. Whilst the Welsh-born poets aimed to provide readers insight into the variety of English in Wales, the playwrights, who likely only heard the accent in passing, rendered WE for comedic effect. The continued use of the set of linguistic stereotypes worked in parallel with the Welshman as Clown; although portrayals became archaic and faded after the Elizabethan era, the stereotype that the Welsh are humorous is rooted into the speech and casting of Welsh characters, as we shall see, into the modern era, not only in novels in the next chapter, but also the films and videogames media that followed. 


\section{Chapter 7 Representation of Welsh English in $19^{\text {th }}, 20^{\text {th }} \& 21^{\text {st }}$ century novels}

\subsection{Introduction to 'Welsh writing in English'}

M. Wynn Thomas suggests that Wales may have not only one of the oldest literature traditions in Europe, in that of Cymraeg literature, but also one of the youngest literatures in Europe, that of the more recent postcolonial 'Welsh writing in English' tradition (Thomas, 2003:1). The catalyst for the advent of English language writing in Wales depended on several social factors. Until the $19^{\text {th }}$ century, English was spoken and written scarcely in Wales, very much being the language of the Welsh gentry, clergy, professional classes and urban bourgeoisie. Examples include, Morgan Llwyd, a $17^{\text {th }}$ century puritan who wrote doggerel verse, and $18^{\text {th }}$ century William Williams, a methodist that wrote English hymns (Thomas, 2003:1). Richard Llwyd wrote about coastal trade in the early 1800s, and some English language poetry and political works of Welsh origin were written by the bourgeoisie poets such as George Thomas, e.g. The Otter Hunt and the Death of Roman (1817) and History of the Chartists and the Bloodless Wars of Montgomeryshire (1840) (Mathias, 1987:40, 44)

In many ways, English-speaking was associated with class and profession, but also social status, education and success in industry and commerce (Mathias, 1987:15); other writers of English from Wales may have been evangelists, or exiles in London (p.31). Although Henry Vaughan and John Dyer were some of the first Anglophone Welsh poets, the majority of writing pre- $20^{\text {th }}$ century offered what Thomas (2003) describes as an 'inferior, provincial version of the mainstream English literature of the day' (p.1). Indeed, this 'mainstream English' equates to Standardness; neither Vaughan nor Dyer were interested in representing regional English speech.

With Wales' large-scale industrialisation in the second half of the $19^{\text {th }}$ century, the mass migration and English language educational reforms that followed saw a cultural anglicisation in Wales (Thomas, 2003:2). At first, there was a contrasting poverty of Anglophone Welsh works, especially when compared to works about Wales by English authors (Mathias, 1987:65). It took several decades until this newly Anglophone Welsh society would begin to accumulate a distinct body of English 
literature. When it did, south Wales, the heart of the coalfield, featured prominently (Thomas, 2003:2). Map 5 plots birthplaces and/or residences of the writers analysed in this chapter. It demonstrates how Welsh writing in English and the depiction of WE literary dialect is chiefly a south-Walian phenomenon.

From the $19^{\text {th }}$ century onwards, there were profound social and educational changes in Wales. With the English-speaking English immigrant families moving to the South-East to work in mines and steelworks, the requirement for speakers to use Cymraeg diminished, with many Welshmen discouraging it (Mathias, 1987:71). In accordance with this, the Welsh Intermediate Education Act of 1889 created new secondary schooling for all, however its mode of curriculum was taught solely in English (p.71). Very quickly, whole speech communities in South Wales had shifted their everyday mode of communication from Cymraeg to English. Mathias (1987) writes that despite such a societal shift, this change was 'a deepening well of so-faruntapped talent in the English language' (p.71). Some of the earliest writers of English in Wales had the merit of being bilingual and bicultural, and, unlike prior gentry writers who were excluded from 'Welshness' by their class, could write about the old way of rural Welsh life for the first time in English (Mathias, 1987:72). Novelist Caradoc Evans spearheaded Welsh writing in English with the satirical, controversial My People in 1915, though, it would take till 1937 for the literary movement to reach substantial recognition (known today as the 'First Flowering') (p.73). Indeed, Mathias (1987) writes: '[The First Flowering] was the product of the new linguistic, social and educational situation' (p.80). Authors such as Margiad Evans, Jack Jones, Geraint Goodwin, Lewis Jones, and Dylan Thomas were all active during this period, and wrote often of the working-class life they lived in, from mines to rural farms and seaside ports, presenting a realist, grounded perspective of Anglophone Wales.

Table 7.1: Welsh writing in English period descriptors

\begin{tabular}{llll}
\hline Time period & $\begin{array}{l}\text { Title used by Welsh } \\
\text { writing in English } \\
\text { critics (e.g. } \\
\text { Thomas, 2003) }\end{array}$ & $\begin{array}{l}\text { Title used by Knight } \\
(2004)\end{array}$ & $\begin{array}{l}\text { WE Literary dialect } \\
\text { period }\end{array}$ \\
\hline 1800 s-1906 & Contact stories & Contact romances & $\begin{array}{l}\text { 'Re-emergence of } \\
\text { use' period }\end{array}$ \\
& & &
\end{tabular}




\begin{tabular}{llll} 
1915-1944 & The First Flowering & $\begin{array}{l}\text { Industrial settlement } \\
\text { writing }\end{array}$ & Ascendency period \\
1954-present & $\begin{array}{l}\text { The Second } \\
\text { Movement }\end{array}$ & $\begin{array}{l}\text { Integration and } \\
\text { independence era }\end{array}$ & Declination period \\
\hline
\end{tabular}

Confidence in the literary movement and a desire for literature about Wales written in English grew over the decades (Mathias, 1987:89). In an era dubbed the 'Second Movement' by literary critics, authors such as Glyn Jones, Ron Berry, Charlotte Williams, and Joe Dunthorne shift the thematic emphasis from Welsh working class life to themes of the fantasy and ancientness of the nation's myths (Mathias, 1987:98), as well as hybridised Welsh identity, that of multicultural and technological Wales.

That said, a public awareness that there existed an English language literary movement in Wales was low. Regarding this, Mathias (1987) writes:

The English-reading public of Wales, largely dependent on London newspapers, followed the wider readership of England in believing that there never had been any Anglo-Welsh writing of importance except from the pen of Dylan Thomas, and he was dead. (p.106)

Indeed, such views could be one of the reasons why scholars have not investigated the WE dialect within English-written Welsh novels. Table 7.2. lists the 17 texts analysed in this chapter.

Table 7.2: List of literary works analysed

\begin{tabular}{lcl}
\hline Author & Year & Text \\
\hline $\begin{array}{l}\text { TJ Llewelyn } \\
\text { Prichard }\end{array}$ & 1828 & The Adventures and Vagaries of Twm Shon Catti \\
$\begin{array}{l}\text { Ceredig (Owen } \\
\text { Parry) }\end{array}$ & 1870 & Among the Mountains, or Life in Wales \\
Amy Dillwyn & 1880 & The Rebecca Rioter \\
Allen Raine & 1906 & Queen of the Rushes \\
Caradoc Evans & 1915 & My People \\
Margiad Evans & 1932 & Country Dance \\
Jack Jones & 1935 & Black Parade \\
Geraint Goodwin & 1936 & The Heyday In the Blood
\end{tabular}




\begin{tabular}{lll} 
Lewis Jones & 1937 & Cwmardy \\
Lynette Roberts & 1944 & An Introduction to Village Dialect with Seven Stories \\
\hline Dylan Thomas & 1954 & Under Milk Wood \\
Glyn Jones & 1965 & The Island of Apples \\
Ron Berry & 1970 & So Long Hector Bebb \\
Joe Dunthorne & 2008 & Submarine \\
\hline Various & $1967-$ & Owl Service \\
A. Garner, D.W. & 1995 & Howl's Moving Castle \\
Jones, T. Pratchett & & Soul Music \\
\hline
\end{tabular}

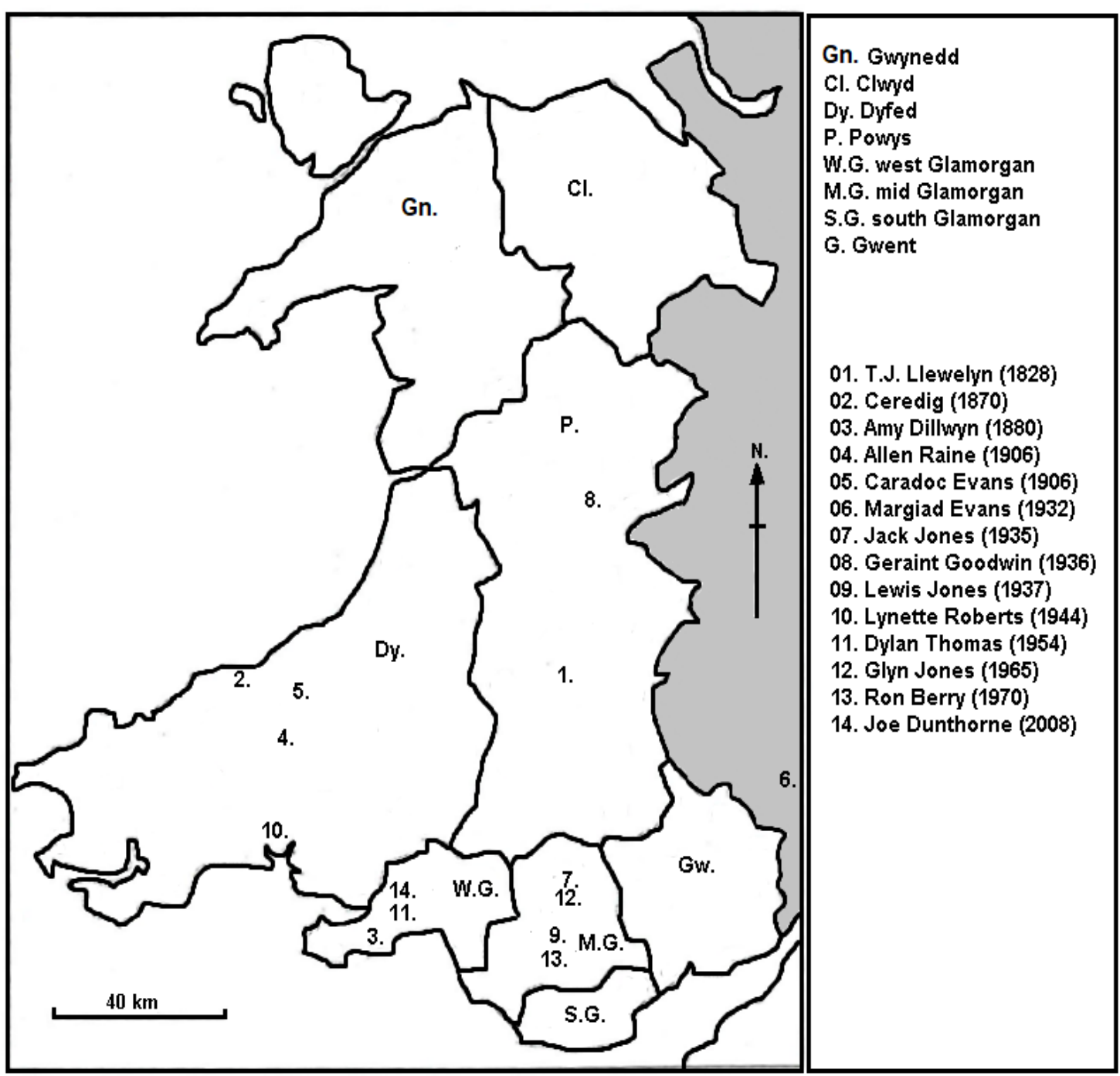

Map 5: Map of author birthplaces and/or residences 


\section{$7.219^{\text {th }}$ century novels and the 'Contact Story'}

The earliest novels that feature a WE variety were published during the $19^{\text {th }}$ century. The methodology conducted has ascertained four authors who constructed literary dialect within their texts: T.J.L. Prichard, Ceredig (a.k.a. Owen Parry), Amy Dillwyn, and Allen Raine. During this era within Welsh writing in English's history, many novels catered to 'contact romance' sensibilities; this genre focused upon Wales and Welsh subject matter as romantic and exotic, often being written for an English audience.

\subsubsection{Thomas J.L. Prichard's The Adventures and Vagaries of Twm Shon Catti} $\underline{(1828)}$

The first novelist to start using aspects of the WE dialect to fulfil the purpose of literary dialect was T.J.L. Prichard in his novel The Adventures and Vagaries of Twm Shon Catti (1828). Not only was it the first to feature WE, but Prichard's Twm Shon Catti, is often alleged as also being the first English language novel of Welsh origin (Mathias, 1987:65; Knight, 2004:8). Prichard (b. 1789) grew up along the borders of Wales, but left his native Builth Wells for London to pursue a career in acting, eventually finding the writing of poetry and plays to be more enjoyable (Evans \& Knight, 2011:93). The English outlaw folk tradition fascinated Prichard, and, having never rejected his 'Welshness' despite speaking little Cymraeg and often spelling Welsh names 'with an English ear', Prichard took it upon himself to write a novel that developed a Welsh outlaw analogue (p.93). Prichard focussed on the Welsh folk tales depicting the Welsh highwayman Twm Shon Catty who lived in the $16^{\text {th }}$ century and romanced a lady of the gentry.

At the time of publication, the text met little fanfare. It was not edited particularly well, and critics did not take the lighthearted story seriously (Evans \& Knight, 2011:91). Until recently critics still upheld this critique. Mathias (1987) had issue with its stereotyping, describing the novel as 'a ragbag of a book' that produced as much Welsh material as possible: 'from flummery to costume to courting in bed and back again' and that it is both 'full of anti-English feeling and yet directed towards English taste for the grotesquerie' (p.65). Humfrey as recently as 2003 wrote that it was little more than a 'picaresque novel' that was of local west-Wales interest but 'no 
literary merit' (Humfrey, 2003:35). More recently, this view has been challenged by literary critics. Evans and Knight (2011) consider it a 'major text' in the Welsh writing in English canon (p.91); a text that, although chronologically distinct from the canon's later works, predicted the incoming potency of the Wales's Anglophone culture. Evans and Knight (2011) stress that Prichard's Twm Sion Catti 'deserves contemporary analysis' (p.91). One such area in which this can be done is in examining Prichard's use of language and literary dialect.

Prichard's preface indicates his awareness of both linguistic inquiry, helping us to understand the method behind Prichard's writing technique. His chief concerns were that non-Welsh writers mispronounced and mistranscribed phonemic inventory used in Welsh speech communities (whether Cymraeg or English). Prichard notes that London playwrights were mispronouncing the eponymous Welsh highwayman, and that it was his duty to make amends (Prichard, 1828:3). Prichard uses semi-phonetic writing to illustrate this point: 'The [Welsh] English pronunciation of Twm Shon Catti, is Toom Shone Katty, instead of which the Londoners called it Twim John Katty, which seemed doubly ludicrous as the name of a tragedy hero.' Here, Prichard renders the Cymraeg long vowel $<\mathrm{W}>$ as $<\mathrm{oO}>(/ \mathrm{u}: /)$ and uses $<\mathrm{Sh}>$ to indicate a voiceless palato-alveolar fricative $(/ \mathrm{J} /)$, suggesting that English English users first mistake the Cymraeg $<\mathrm{w}>$ as a glide $(/ \mathrm{w} /)$, therefore adding a following vowel, and second, often use a voiced palato-alveolar affricate $\left(/ \mathrm{d}_{3} /\right)$ rather than the voiceless palato-alveolar fricative.

\section{Lexis}

It should be noted that for Twm, Prichard writes the character to speak both Cymraeg and English, although it is assumed much of the dialogue between Twm and his countrymen would likely be Cymraeg, it is translated in English for Prichard's readership. Within Prichard's literary dialect, the lexical items he chose likely set a precedent. Prichard chose not only Cymraeg loans, but also English language lexis that may have been common throughout the British Englishes of his time.

Regarding the Cymraeg loanwords, Prichard uses both vach ('Gwenny Vach', p.16) and bach ('for your sake John bach!', p.27) for the female and male terms of endearment. Note that Prichard chooses $a<_{v}>$ to orthographically represent the 
Cymraeg voiced labiodental fricative rather than $\langle\mathrm{f}\rangle$, a pattern he repeated with several other words such as ystavell (p.60) and Eisteddvod (p.236). Prichard does not italicse these endearments, a tactic he does for the following Cymraeg loans, maybe suggesting that London readers would be familiar with this 'Welshism'. In the statement: "“I come from Newcastle Emlyn, the country of good beer, the very home where the Cwrw da of Hen Gymru is bred and born!"' we find both cwrw da (i.e. good beer) and Hen Cymru (Old Wales) (p.51). Both are terms used by a Welsh maid, Cardy, whilst in conversation with her English-speaking non-Cymraegspeaking squire (one of the Welsh gentry). Twm Shon Catti also features bwlch ('observing a bwlch, a gap, parting the mountains in the distance', p.154), a term for 'gap' and one that was recorded in Parry's SAWD survey in Mid-Wales and Dyfed (the setting for Prichard's Twm's adventures). When recorded in the SAWD, the term had semantically narrowed to 'a sheep-hole in a hedge. Literally 'a gap" (Parry, 1997:138). The term chrochon is also used, and is defined as a 'large three-legged iron pot used for cooking' (p.62), a figurative Cymraeg term for crock or pot.

The section of the novel that uses the largest collection of Cymraeg loanwords is chapter 7's wedding of Twm's mother and his step-father. Here, Prichard details specific Cymraeg loans that would have been well-known amongst Cymraegspeakers, and potentially English speakers in Wales too. Because the wedding guests would realistically be using Cymraeg in Twm's $16^{\text {th }}$ century setting, the reader might get the idea that these are included by Prichard as strict wedding term translations. However, it is important to note that Prichard is describing a unique folk wedding associated with Wales and the Old North (i.e. Cumbria) called the Bidding Wedding, a tradition that, until the $20^{\text {th }}$ century, was still common in English-speaking Gower (see Penhallurick, 1994).

The five Cymraeg words that Prichard uses are gwadhoddwr, ystavell, pwrs a gwregys, pwython and Neithior. These concepts mirror some that were used in Gower English (see table 7.3 below for comparison with terms Penhallurick's). These analogues include beader (gwadhoddwr/bidder); heaving (pwrs a gwregys); and the debts (pwython). The modern Cymraeg for several of these terms does not always match the Bidding meaning, thereby suggesting some specialisation for these terms within $19^{\text {th }}$ century Welsh speech communities. 
Table 7.3: Bidding terms of rural Wales from Prichard (1828)

\begin{tabular}{|c|c|c|c|}
\hline Bidding word & Prichard's definition & $\begin{array}{l}\text { Modern Welsh } \\
\text { (Geriadur.ac.uk) }\end{array}$ & $\begin{array}{c}\text { Gower } \\
\text { analogue } \\
\text { Penhallurick } \\
\text { (1994) }\end{array}$ \\
\hline $\begin{array}{l}\text { Gwadhoddwr } \\
\text { / Bidder }\end{array}$ & $\begin{array}{l}\text { 'a Gwahoddwr, or Bidder, whose } \\
\text { business it is to go from house to } \\
\text { house, bearing a white wand } \\
\text { decorated with ribbons, and his } \\
\text { staff of office; while his hat, and } \\
\text { sometimes the breast of his coat, is } \\
\text { similarly adorned.' (p.56) }\end{array}$ & Host, inviter & Beader \\
\hline Ystavell & $\begin{array}{l}\text { 'The Ystavell, or the woman's } \\
\text { furniture; consisting generally of } \\
\text { an oaken coffer, or chest; } \\
\text { a featherbed and blankets; all the } \\
\text { crockery and pewter; wooden } \\
\text { bowls, piggins, spoons, and } \\
\text { trenchers; with the general } \\
\text { furniture of the shelf' (p.60) }\end{array}$ & Floor, chamber & \\
\hline $\begin{array}{l}\text { Pwrs a } \\
\text { Gwregys }\end{array}$ & $\begin{array}{l}\text { 'On the Friday before the } \\
\text { wedding, [the groom] was busily } \\
\text { employed in receiving money, } \\
\text { cheese, and butter, from [his } \\
\text { friends], while [the bride] was } \\
\text { similarly engaged at her residence, } \\
\text { with her partisans, which were not } \\
\text { a few. This custom in Welsh is } \\
\text { called Pwrs a Gwregys, or purse } \\
\text { and girdle, and is, doubtless, of } \\
\text { very remote origin.' (p.61) }\end{array}$ & Purse and belt & Heaving \\
\hline Pwython & $\begin{array}{l}\text { 'and honorably paid their } \\
\text { Pwython; that is to say returned } \\
\text { the presents which he and his } \\
\text { relatives or friends had made at } \\
\text { different weddings.' (p.61) }\end{array}$ & $\begin{array}{l}\text { Requital, } \\
\text { amends }\end{array}$ & The Debts \\
\hline Neithior & $\begin{array}{l}\text { 'The morning of Sunday after the } \\
\text { wedding, which is called Neithior' } \\
\text { (p.69) }\end{array}$ & Wedding feast & \\
\hline
\end{tabular}

Besides Cymraeg loanwords, Prichard also used a variety of lexical terms derived 
from dialectal English English varieties, many being later recorded in the $E D D$, and then the $S A W D$ and $S E D$. One of the only forms that matched frequency and distribution within other British Englishes, yet also occurred in the SAWD dialects, was 'tump' ('some rising 'tump' that overlooked the field', p.23). Parry's survey would later record this in Mid-Wales and southern Wales, such as Powys and Glamorgan. The SED records the term in Wiltshire and Worcester, and the EDD, conducted closer to Prichard's era of writing, notes that the term was common throughout not only the Welsh borders and West country but also Scotland, Ireland, and Yorkshire.

Terms like 'shifts' for 'chemises' ('throw off their flannel shifts', p.46) and 'sidling' for 'shimmying' ('after sidling so far through a comparatively long passage', italics in original, p.213) both had large distribution (EDD) especially in northern England, with 'shifts' continuing to be used when the $S E D$ was conducted, thus suggesting that although archaic and dialectal during the twentieth century, perhaps was more widespread during Prichard's time. However, the italicised script paratextually suggests Prichard either thought the term 'sidling' was infrequent or unfamiliar to London readers during his era. Prichard also italicised 'historical' words that even in his time of writing would be archaic (bear in mind, Prichard was writing about the 1500s). One example is 'saws' ('uttering wise saws', p.80, italics in original) that the $O E D$ defines as 'a saying or story', having become obsolete around the $17^{\text {th }}$ century, which matches Prichard's narrative. Similarly, Prichard's use of the adjective 'musty' ('a musty rug', p.83), is related to 'must' used for fermenting oats between the 1400s-1800s $(O E D)$, though obsolete and rare today, finding some usage in Cumbria for the sense 'sour-looking' $(E D D)$ and Kent and Sussex for the sense 'rancid' (SED).

'Rusties [drunkards]' is one of the obscurest items Prichard uses ('the jovial alefraught rusties', p.69). The $O E D$ attributes rusties to the temperament of horses with a distribution of Scottish and northern Irish Englishes. The EDD gives us some indication of a related compound form in 'rusty-bum', which was a boisterous game that boys played. Another term that only partially appears in records is 'weazonfaced'. The $O E D$ offers that 'weazon' comes from the Old English 'wásend' meaning 'throat' and chiefly dialectal; this is attested by the SED that notes usage throughout 
the north of England, however the compound is not attested in any record. Finally, 'gruffy' ('replied the old gruffy', p.133) is a term that only the $O E D$ notes as being a nickname for gruff people, obsolete now, but in usage strictly in the very late $18^{\text {th }}$ century, therefore possibly a word known to Prichard's literary social circle.

\section{Grammar}

For grammatical structures, Prichard is the first writer of WE to capture in writing two forms that would become grammatical staples for future writers of WE: Focus Fronting and, what I will term: Demonstrative There's + adj/noun (or, Demonstrative There), both of which are transferred structures from Cymraeg that are inherent in the English varieties of Wales. Firstly, both the SAWD and Weng. note that this syntactic construction arrived in WE via a Cymraeg grammatical borrowing: dyna ('that is', or 'there is') + adj, the 'there' always fulfilling a demonstrative pronoun in English (even if there are adverbial qualities in Cymraeg). Secondly, Parry's $S A W D$ writes that in Cymraeg sentence-initial emphasis can be 'imposed upon a word by placing it at the beginning of the sentence' (Parry, 1999:119), thereby subject complements come first. In the text, Demonstrative There's is used by the lady of Graspacre house: “There's an impious rascal, for you!" (p.50), whilst the focus fronting is used by Cardy, Squire Graspacre's maid: “'Good! was it?” retorts the girl.' "“good was it!'” (p.52).

The maids are also written to use allegro speech features such as t'was (“'Twas better sir!"”, p.53). Unlike the ambiguity in which language is used for other parts of the novel, it is inferred that the conversational exchanges made in the house of the Welsh gentry are in the English language. For example, when the squire receives an invitation poem to attend the Bidding of one of his servants, it is translated from Welsh into English at his request (p.56-7). Then, when he decides to attend the Bidding in disguise, Prichard humorously writes: '[The Squire's] deficiency in the Welsh language had been concealed by alternately feigning deafness and drunkenness' (p.69). These statements make it clear that anybody conversing with Squire Graspacre would be English speaker. Whilst Lady Graspacre's relationship with Welsh English is uncertain, it is specifically noted that the maids all come from various counties of Wales, having learned English and thus in the prose are recorded using Welsh accented Englishes. 


\section{Pronunciation}

Mentioned above was Prichard's usage of orthographic $<\mathrm{v}>$ for the Cymraeg $/ \mathrm{v} /-<\mathrm{f}>$; this is but one way in which he attempted, phonetically, to present his literary dialect. Prichard chooses to write the diphthong /eI/ as an elongated vowel, possibly /e:/, by adding an additional $<\mathrm{a}>$ to 'maid' in "'there's a good maaid!", this corresponds with $S A W D$. For 'skip' Prichard uses 'skipe' (““skipe it, child, skipe it”, p.16) using a footnote to explain it is a substitute for 'skip it', thus rendering a close front vowel /I/ as an open front to closed front diphthong /ai/. Prichard's aim to 'correct' non-Welsh writers mispronouncing or mistranscribing Welsh terms persists in a gloss he provides for 'Cwm du' (p.77), lit. black valley, where he writes: 'pronounced Coom dee', phonetically respelling the Welsh orthography to describe a long, closed back vowel of cwm /u:/ rather than a glide /w/, as well as a long closed front vowel /i:/ rather than a long closed back vowel /u:/.

\section{Metalanguage}

There is a noteworthy passage in the novel devoted to Prichard's phonetic respelling and other linguistic experimentation. In an episode where Twm chooses to fool the magistrate of Breconshire, an upperclass English speaker named Powell, he deliberately shifts his variety of English to that of a lower-class Welsh English speaker: 'Twm answered in broken English, imitating the dialect of the lower class,' (p.218). Although Prichard uses what today linguists would consider an outdated linguistic descriptor, 'broken English', in reference to a nonstandard variety, in doing so he offers his perceptions on the WE dialect and its association with class within Wales - indeed its sociolectal qualities. Furthermore, it suggests that in either Twm's Wales (the 1500s), or perhaps more likely in Prichard's Wales of 1790s-1820s, there was a significant proportion of English speakers within Wales to form a semblance of variation of WE, one distinct from the Welsh gentry's capabilities in using the language. Listed below are four of the sentences that Prichard uses for Twm and below them summaries of their features.

a) "I don't no but it iss, if I can get somebody that iss not wice, look you, somebody that was fools to buy him."

i. Eye dialect: 'no' for 'know' 

ii. Devoiced fricative: 'iss' for 'is', 'wice' for 'wise'
iii. Stereotyped tag: 'look you'
iv. Syllable reduction: 'fools' for 'foolish'

b) "Why indeed to goodness," answered Twm, "I was shame to take him there; for look you, he hass a fault on him, and I do not find in my heart and my conscience to take honest pipple in with a horse that has a fault upon him, for all master did send me here to sell him.";

i. Phrase: 'indeed to goodness'

ii. Syllable reduction: 'shame' for 'ashamed'

iii. Devoicing fricative: 'hass' for 'has'

iv. Verb to be omission: 'for all master did [was] send me here'

c) "I will tell you like an honest cristan man, without more worts about it; I will make my sacraments and bible oaths."

i. Syllable reduction: 'cristan' for 'Christian'

ii. Eye dialect: 'worts' for 'warts'.

d) "Indeed and upon my sole and conscience to boot, I can't say what do ail him."

i. Eye dialect: 'sole' for 'soul'

ii. Verb disagreement: 'what do ail him'

Twm's 'lower class' WE matches, in many ways, the kind of theatrical WE that Prichard would have had experienced with theatrical circles in London. Therefore, considering the satirical nature of Twm's adventures and his disdain for the gentry and Englishmen, Prichard's decision to voice Twm in this manner is likely more of a satire on Shakespeare's WE than an attempt at 'authenticity'. After all, Prichard had every opportunity to use these pronunciations elsewhere in the book for Welsh accented English, although he does not, thus suggesting deliberate inclusion to play off the Englishman's naivety. That being said, there are some forms that do not match the Stage WE, such as omitting the to be verb, and the phrase 'indeed to goodness', a structure that is first recorded here, but as we shall see is increasingly used by authors hereafter (notably Caradoc Evans). Prichard also seems to draw upon eye- 
dialect, a common emerging technique of the $19^{\text {th }}$ century, and respellings that infer to the reader that Twm's English speech has shifted to a perceived 'less educated' register.

In all, Prichard used metalinguistic awareness for lexical and phonemic representation, using both first and third person narration to define the items, often guiding the reader using italics to suggest unfamiliarity (whether Cymraeg loans or English dialectal lexis). Prichard also utilised paratexual definition as well as in-text definition via footnote glosses in 'chochron', 'skipe it' and 'cwm du' for example.

Regarding a sense of 'authenticity', Prichard's literary dialect was likely reminiscent of his native era of WE, rather than the English that was spoken during the historical Twm Shon Catti. In this sense, the literary dialect featured in the text is dated to the early $19^{\text {th }}$ century, although we should not dismiss the fact Prichard choose to include some historical items that may have been known to him throughout Wales and Britain. Furthermore, there is the question of how many of Prichard's English language terms can be attributed to a sense of the WE variety; several words could be more reflective of Prichard's London writing circle contemporaries.

\subsubsection{Owen Parry's (a.k.a. Ceredig) Among the Mountains (1870)}

After Prichard published Twm Shon Catti in 1828, there were no further publications that attempted WE literary dialect for about four decades; in part, this is because there were so few novels that could be considered to belong to the canon of Welsh writing in English.

The second author to choose to use aspects of a WE dialect within a literary work was Owen Parry (also, O. ap Harri), who went under the pen-name Ceredig when he wrote Among the Mountains, or Life in Wales (1870). Very little is known about the life of the author. We know that he spoke and wrote in both English and Cymraeg for, along with this English language book, Parry wrote an essay in Cymraeg titled $Y$ Dosbarth Gweithiol yng Nghymru [The Working Class in Wales]. The essay was entered into the 1865 National Eisteddfod and came second place, an accolade Parry wrote into the foreword of Among the Mountains. 
Parry's Welsh National Library catalogue entry adds that, at this time, he was a resident of Caerodor (i.e. the historical Welsh exonym for Bristol), that he may have been a journalist working at the Western Daily Press, and had been born in Aberporth, Cardiganshire (Parry had also sent letters in Cymraeg to the Seren Cymru [Welsh Star], a periodical of Welsh Baptists in 1865) (J. Aaron, personal communication, May $16^{\text {th }}$ 2014). The rarity of the text indeed suggests it is likely the only edition that was printed; and being outside of copyright has not made the novel any more accessible to contemporary readers either.

The novel focuses on Welsh nonconformity and features Arthur Williams, a Christian man who earnestly desires self-improvement. Much like Prichard's Twm Shon Catti, the literary criticism that the text received was poor. Critic M. Wynn Thomas describes Ceredig's novel as a 'naively constructed and piously sententious narrative' and 'a remorselessly, insufferably 'improving text" (Thomas, 2011:72).

\section{Lexis}

Although the setting is Wales, there is not a great deal of linguistic markers that distinguish the text from non-standard speech which would have been present throughout England and Wales during the period. This can be evidenced in several ways. 'Aye' is used throughout as an affirmative: 'Watch, aye' (p.24). Similarly, the vocative expression 'man' is used frequently: ‘shut up, man' (p.25); 'I am Bill Jones, man, your old schoolmate' (p.55). The OED identifies that the item is a characteristic of the WE dialect, but is also common in varying pronunciations in Northern English, Scottish English, Irish English, S.African English, and more. Here, it is the first recorded usage in a WE literary dialect.

The intransitive verb 'mind' is also used in the text: 'but, mind, do not say it after me' (p.56). The SAWD records usage in Dyfed \& Glamorganshire in the sense 'to remember', whilst the $O E D$ states this usage is a colloquialism used to add emphatic force to a statement, although the $O E D$ does not state whether known to be WE, Weng. notes it is common in the South-Welsh valleys.

Cymraeg transfers in the form of lexis and grammar are markers that index for 
readers a specific Welshness of the text's dialogue. Although they are less frequent in this early text than in Prichard's earlier Twm Shon Catti., Ceredig uses the Welsh endearment term for little/dear, bach', e.g. 'Mr Lloyd, bach' (p.66). Bach is documented as 'bachgen' in the SAWD meaning 'little boys' (p.129); it is also documented in Weng. as well as TT. Also like Prichard, the Cymraeg term for 'good beer' is also used: 'a few glasses of cwrw da' (p.91) suggesting that 'bach' and 'cwrw' were two early enregistered forms of WE.

\section{Grammar}

Finally, regarding grammar, copula formation in Ceredig's work takes on nonstandard forms in many instances. Present tense indicative 'are/is' is often rendered as 'be' as in "Where be ye going to, Bill?' (p.11) and 'what be your trade?' (p.69). The $S A W D$ reports that this is a well-documented, attested feature of mid and south-east WE. The second person singular 'you' is rendered as 'ye' (p.29), although it is not documented in any WE survey, the $O E D$ notes it is now archaic used in varieties in the North of the United Kingdom and Ireland. Other grammatical informalities include the phrase 'how like you that place' (p.56) also omits the doing verb and exchanges the pronoun's position with the verb 'like'.

\subsubsection{Amy Dillwyn's The Rebecca Rioter (1880)}

Amy Dillwyn (1845-1935) was born to a wealthy industrial family. Following her affluent fiancé's death, however, she began fearing for her own health; this hypochondria prompted her to begin a writing career (Painting, 1987:71). Although the bulk of her writing challenged gender conventions, she was also interested in the portrayal of Wales' two languages (Gramich, 2008a). Dillwyn was inspired by George Eliot's Middlemarch (1872) to 'write a real novel about real people', and published The Rebecca Rioter in 1880 (Painting, 1987:72). Desiring to write 'daring' fiction, she wrote taboo plots and used 'racy slang' designed to shock readers (Painting, 1987:75).

Like Ceredig and Prichard, Dillwyn's work contains some of the earliest WE in a fictional text. Her familiarity with both Cymraeg and English presents analysts with a unique condition when investigating the dialogue of this novel. Although some 
characters, such as Evan, speak both English and Cymraeg, it is implied that all speech in the novel is Cymraeg, being translated to the reader through the author (Gramich, 2008a). Dillwyn uses the English language as a tool 'against' the perspectives of the colonial Englishmen, presenting the Cymry [Welshmen] as not like the 'quaint superstitious natives of [...] first-contact texts (Knight, 2004:16). Gramich (2008a) states that 'there is an attempt to indicate this by a manipulation and defamiliarisation of the English language' (p.xvii). Whilst the 'defamiliarisation' certainly validates that a language other than English is being spoken, it is the 'manipulation' that is of interest. What Dillwyn attempts is a translation from Cymraeg into WE; Gramich (2008a) calling the translation a 'striking [...] experiment'. Effectively, Dillwyn, after drafting Cymraeg dialogue, re-wrote it in the manner in which she knew Cymraeg speakers used English - thus representing the qualities of early contact variety of WE around west Wales. Indeed, this 'direct translationism' is similar to William Carleton's usage of Hiberno-English as a substitution for Irish Gaelic (see McCafferty, 2005).

\section{Grammar}

Gramich (2008a) argues that Dillwyn's direct translationism is evidenced strongly within phrases that are likely derived from Cymraeg syntactic influence. One structure being the 'deformation of verb tenses'; where a simple past tense could be used, Dillwyn instead opts for the 'typical imperfect tense of [Cymraeg]'. Gramich's example of this is 'I was want it' for 'I wanted it', derived from the equivalent Cymraeg phrase: 'roeddwn I eisiau ef' (p.33). Other similar examples in the text include 'he was take [took] home' (p.11), 'the thing was jump [jumped] out at my feet' (p.22); and 'you was shoot [shot] the man' (p.115). Although we should not dismiss that this form has been used in WE, this direct translation does not appear in any records, and possibly little more than a literary device for English readers to grasp what a literal translation could sound like.

Contrast the imperfect tense of Cymraeg above with two attested forms that derive from Cymraeg and are recorded in WE. Dillwyn is the second author (of many below) after Prichard to use both Demonstrative There, and Focus Fronting. Dillwyn uses a hybrid of both in: 'there's glad I am' (p.72), and exclusively uses focus fronting with: 'Very sad, they both were' (p.80). There are also grammatical 
features that are not necessarily attributed to Cymraeg influence. Dillwyn is the first to use the first person plural object (i.e. 'us') in the position of the subject, e.g. 'Suppose if us [we] was to take it' (p.33), a feature that eWave notes is pervasive throughout WE. The use of 'as' as a relative pronoun is also introduced, e.g. 'There was a boy here as [that] was very like what you do say' (p.52). The SAWD notes that this usage is largely confined to Mid-Wales, but also southern Wales. Another $S A W D$-recorded feature that Dillwyn uses is the present participle $<\mathrm{a}$ '[verb/prep./adverb] $>$, attributed to Radnorshire and Monmouthshire, in: "'I wonder what be a-going on there?" (p.140) and "II can't abear the very sight of him"” (p.169). In both instances Dillwyn uses the $<\mathrm{a}>$ particle with verbs. Finally, a feature that does not appear in records (and will not appear in any other author's literary dialect) is synonymic duplication. In at least two instances, Dillwyn places synonymic lexis next to one another, for instance: 'You do seem most so fond of Rees Hughes' (p.57) and 'You may be certain sure' (p.62). It is unsure whether this is Cymraeg influence, bordering regional English English influence, or a fabrication by Dillwyn.

\section{Lexis}

Some of the vocabulary that Dillwyn uses derives from Cymraeg, though, it is minimal in contrast to her grammatical translationisms. The Cymraeg word for 'hush', 'eisht' (GPC), is used "'heisht, now"' (p.76); similarly, the phrase 'a crot of the boy' (p.34) derives from the Cymraeg 'crwt' meaning 'boy'. Both variations of this item were recorded by the SAWD in Dyfed and S.Glamorgan, and defined as 'a boy aged 12-13 starting work on a farm'. It was also recorded in the EDD (1905) in Pembrokeshire. The Cymraeg for Welshman, 'cymry' (p.66), is also used (GPC).

Non-Cymraeg lexis that Dillwyn adds are largely familiar and markers of WE of the time for they were used too by Prichard. Dillwyn uses the affirmative 'ay' (p.137); as well as the stereotyped phrase 'indeed to goodness' (p.9) (and its shortening: ''deed to goodness', p.93) and also the stereotyped 'look you' form as well (p.9). Prior to this novel, the phrase was associated with exaggerated feature found in theatrical WE (chapter 6), artificially created by English playwrights and misattributed to WE speakers (even Prichard metalinguistically parodies it above). Its inclusion here could mean one of several things. Either it did become a genuine form in WE in some 
locales, simply because of Shakespeare and Fluellen's popularity (i.e. a sort of 'phantom enregisterment" ${ }^{15}$ ), with Dillwyn, having grown up hearing or using it. Secondly, like Prichard, 'look you' was used by Dillwyn as metalinguistic commentary to critique previous theatrical WE. Or, thirdly, Dillwyn believed the Shakespearean usage to have been authentic, though had not heard it herself. Considering the $S A W D$ did not record 'look you' in any capacity, it is likely to be one of the latter two possibilities.

Dillwyn does add some English words to her literary dialect. In the context of the novel being a translation into English, we may surmise that these were borrowed into the Cymraeg of Dillwyn's world. Dillwyn includes nautical terms, for example: 'smacks' and 'skiffs' (p.135), that the $O E D$ defines as single-mast sailing vessels used for fishing and a small sea-going boat respectively; and shortening for magpies: 'pies' (p.136).

\section{Pronunciation}

Dillwyn did not see fit to incorporate phonetic respellings or approximations of WE into her literary dialect, likely because it was Cymraeg-translated. She did however mark a sense of colloquial speech by using allegro features. For example, initial clippings such as ''nother (p.33) and 'pon' [upon] (p.104); and contractions such as 'd'rectly' (p.34), ''tis' (p.104), ''tain't' (p.137), and 't'will' (p.156).

Ultimately, Dillwyn's translation is not a strict translation from Cymraeg into Standard English, but rather a translation from Cymraeg into a form of WE, essentially providing the English reader with both a sense of the Welsh language, as well as the English regional equivalent.

\footnotetext{
${ }^{15}$ This is a coinage, to which I mean an enregistered form that begins its life in the indexicality process not from within (interior) the speech community, but by an (exterior) outside influence, and/or by misattribution. The speech community may question the form, but the exterior influence may hold precedence, especially if they are a prestigious (e.g. Shakespeare). The end result is the same, in that the form becomes enregistered, however, it is has a delusionary, deceptive or 'phantom' presence.
} 


\subsubsection{Allen Raine's Queen of the Rushes (1906)}

Anne Evans (1836-1908) was a best-selling writer from Newcastle Emlyn, Cardiganshire (Jones, 1979:1-2). Moving to London in 1872 with her husband, she adopted the penname Allen Raine and began writing fiction, before moving back to Wales in 1900 (AllenRaine.com, 2015).

Detailing the 1904 religious revival, Raine's Queen of the Rushes (1906) is a text which utilised the WE dialect in a manner that attempted authenticity, drawing from her own experiences of English and Cymraeg. Raine's dialogue and use of literary dialect has been both criticised and commended by literary critics. Knight (2004:21) believed too much of her writing contained 'linguistic stereotypes', for example arguing that Raine's use of 'caton pawb: God keep us all' was 'overused', whilst Humfrey (2003:38) disregarded Raine's 'scattered' use of Cymraeg phrases believing they only served the purpose of indexing 'Welshness'. Cymraeg-using poet Elfed (a.k.a. Howell Elvet Lewis) scathingly wrote that Raine's knowledge of Cymraeg was 'limited and uncertain' and that the 'dialect she used in her stories - never spoken of any human being' (Jones, 1979:76).

Elfed's view is contested by biographer S. Jones. Jones argues that Raine, who, despite Elfed's comments, had proficiency in Cymraeg, presented an authentic fictive portrayal of a bilingual speech community; one that had two languages, several varieties of English, and social backgrounds present. And that the linguistic picture was 'complicated, to say the least', especially considering interlocuters had 'varying degrees' of bilingualism (Jones, 1979:20). Raine's dialectal complexity is apparent to some critics. Mathias (1987:67), writes that Raine's language usage was 'an advance on the efforts of previous writers brought up [...] in Wales'; and Gramich (1998) comments that Raine '[balances] on that bridging hyphen between a [Cymraeg] Wales which she knew at first hand and an Anglicised or English reading public' (p.7-8). This was accomplished through the inclusion of untranslated Cymraeg words amongst the English; in turn depicting a rural south-west Wales in which Raine grew up. Following in the footsteps of Dillwyn, Raine was an Anglo-Welsh writer who was conscious of the way in which language worked within her community. 


\section{Lexis}

Raine, aware of her audience's most-likely unfamiliarity with Cymraeg and WE terms, does provide a paratextual glossary for readers to consult at the text's rear. Twenty-eight lexical items are provided in the glossary, eleven of which are referenced in Gramich's (1998) Introduction as significant examples of 'accurate renderings of Cardiganshire speech' (p.8). Table 7.4 demonstrates the large volume of lexical depiction within Raine's glossary: Gramich's citations are noted, as is language origin, and whether they are attested to in dialectology surveys.

Table 7.4: Reproduction of Raine's paratext (edited) (Queen of the Rushes, 1906)

\begin{tabular}{|c|c|c|c|c|c|}
\hline Word & Definition & $\begin{array}{l}\text { Cited in } \\
\text { introduction? }\end{array}$ & Cymraeg? & SAWD? & Weng./TT \\
\hline ach-y-fi & $\begin{array}{l}\text { 'exclamation of } \\
\text { disgust.' }\end{array}$ & $\begin{array}{l}\text { Gramich } \\
\text { (1998) }\end{array}$ & Yes & Yes & Yes \\
\hline anwl, anwyl & 'dear’ & $\begin{array}{l}\text { Gramich } \\
\text { (1998) }\end{array}$ & Yes & No & No \\
\hline $\begin{array}{l}\text { bachgen, } \\
\text { 'machgen i }\end{array}$ & 'lad, my lad' & & Yes & Yes & Yes \\
\hline bendigedig & 'blessed' & & Yes & No & No \\
\hline bore da chi & 'good morning' & & Yes & No & Yes \\
\hline b't shwr & 'certainly' & $\begin{array}{l}\text { Gramich } \\
\text { (1998) }\end{array}$ & Yes & No & No \\
\hline Bwthin & 'hut' & $\begin{array}{l}\text { Gramich } \\
\text { (1998) }\end{array}$ & Yes & No & No \\
\hline caton pawb & 'save us all' & $\begin{array}{l}\text { Gramich } \\
\text { (1998) }\end{array}$ & Yes & No & No \\
\hline cawdel & 'muddle' & & Yes & No & No \\
\hline clocs & 'wooden shoes' & & Yes & No & No \\
\hline clôs & 'farmyard' & $\begin{array}{l}\text { Gramich } \\
\text { (1998) }\end{array}$ & Yes & $\begin{array}{l}\text { Partially - } \\
\text { 'Close, a field' }\end{array}$ & No \\
\hline croten & $\begin{array}{l}\text { 'homely name for } \\
\text { lass' }\end{array}$ & & Yes & Yes - 'crwtten' & $\begin{array}{l}\text { Yes - } \\
\text { crotyn, } \\
\text { crwtyn }\end{array}$ \\
\hline crydd & 'cobbler' & $\begin{array}{l}\text { Gramich } \\
\text { (1998) }\end{array}$ & Yes & No & No \\
\hline cwrw & 'ale' & & Yes & No & No \\
\hline diwygiad & $\begin{array}{l}\text { 'reformation, } \\
\text { revival' }\end{array}$ & & Yes & No & No \\
\hline $\begin{array}{l}\text { hen Gymru } \\
\text { wen }\end{array}$ & 'dear old Wales' & & Yes & No & No \\
\hline hiraeth & $\begin{array}{l}\text { 'longing, home- } \\
\text { sickness' }\end{array}$ & & Yes & No & Yes \\
\hline lodes, "los" & 'girl, lass' & Gramich & Yes & No & No \\
\hline
\end{tabular}


(1998)

\begin{tabular}{|c|c|c|c|c|c|}
\hline mishteer & 'master' & & $\begin{array}{l}\text { No; orthography } \\
\text { - phonological. }\end{array}$ & No & No \\
\hline 'merch-i & $\begin{array}{l}\text { 'my daughter, my } \\
\text { dear' }\end{array}$ & $\begin{array}{l}\text { Gramich } \\
\text { (1998) }\end{array}$ & Yes & No & No \\
\hline nos da & 'goodnight' & & Yes & No & No \\
\hline n'wncwl & '(my) uncle’ & & Yes & No & No \\
\hline penstif & 'obstinate' & & Yes & No & $\begin{array}{l}\text { Yes - } \\
\text { penstiff } \\
\text { (stubborn) }\end{array}$ \\
\hline $\begin{array}{l}\text { set vawr, } \\
\text { fawr }\end{array}$ & $\begin{array}{l}\text { 'big seat, deacon's } \\
\text { pew' }\end{array}$ & & Yes & No & No \\
\hline 'stafell & 'bride's possessions' & & Yes & No & No \\
\hline tân & 'fire' & $\begin{array}{l}\text { Gramich } \\
\text { (1998) }\end{array}$ & Yes & No & No \\
\hline vach, fach & 'little or dear' & & Yes & No & Yes \\
\hline whintell & 'willow basket' & $\begin{array}{l}\text { Gramich } \\
\text { (1998) }\end{array}$ & No & $\begin{array}{l}\text { Yes - wyntell } \\
\text { from Welsh: } \\
\text { gwyntell }\end{array}$ & No \\
\hline
\end{tabular}

Most of these words are of Cymraeg origin, and are interspersed with the English in a way which suggests the speakers to be either in the process of Anglicisation, or code-switching between the two languages. Thus, in places it is difficult to discern whether they are loanwords belonging to the west-Wales's English variety, or foreignisms resulting from characters' inability to recall English vocabulary, being used to speaking Cymraeg. That said, several of these loanwords are attested within the dialectological records, therefore are of interest to the current study. The SAWD records 'whintell', defined by Raine as a word for a wooden basket, as 'wyntell': as a basket for horse-feed or clothes, being derived from the Cymraeg 'gwyntell' meaning: 'a round basket without a handle'. 'Croten', 'a homely name for lass', is recorded as 'crwtten' in the $S A W D$, 'bachgen' for 'lad', and 'ach-y-fi', 'an expression of disgust', makes its first appearance of many within Raine's novel (Weng. notes this usage is common in south Wales). 'Clôs', the word for 'farmyard' is associated with the word for farmer's fields in SAWD. One word within the glossary does not translate directly from Cymraeg: 'mishteer', which is most likely a phonetic variation of 'master' (e.g. /mæstə/-/miftiə/).

Although it appears that Raine is thorough in documenting her own novel's dialectal features, Gramich's (1998) Introduction notes eight additional items not included 
within Raine's paratext. Three of these items were recorded as WE in SAWD's investigation. 'Bwcii' is the recorded WE item (containing variations such as 'bwcci', 'bwci', 'bwgi-bo' and 'bug-a-bo') and is a Cymraeg-derived term for the 'bogeyman'; in Weng. an additional meaning of 'ghost' is present. 'Ladiwen' (lit. 'white lady' in Cymraeg) is recorded in the $S A W D$ as bindweed. Finally, 'dakee', a rendering of 'dacu', itself a shortening of 'tadcu/dadcu' (Weng.) is a 'child's term of address to a grandfather' $(S A W D)$. Using the GPC, the other four items can be translated as: 'can diolch' (many thanks), 'cryman' (sickle), 'howyr' (good gracious) and 'hysbys' (well-known).

Despite both Raine and Gramich's input, there are several lexical, grammatical and phonological features that neither recognised which are of interest. 'Dei anwl', an interjection, occurs (Raine, 1998:29), and may be translated as 'dear god', from the Cymraeg 'duw' for God. Other interjections and closed-phrases include: 'och-i' (p.46) [woe to], 'tan-i-marw' (p.43) ('fires of hell'), and 'oh twt' (p.56) ('dinky'). Coupled with these is Cymraeg vocabulary in the form of nouns. Raine uses the word for heath/moor, 'rhos', for example: 'blown over the rhos' (p.67). She also uses the words for 'courtyard' (cwrt) and 'parlour' (parlwr), Cymraeg words which were borrowed from English into Cymraeg, and here reborrowed back into WE; for example: 'no front garden or 'cwrt' separated it from the grassy moor' (p.122) and 'chairs from the 'parlwr" (p.131). Two items of interest are 'cawl' (p.40) and 'plock' (p.267), both of which were recorded in the SAWD as WE. The first, cawl, shares similarities with the previous items in that it is also a recognised item of Cymraeg vocabulary. Cawl, a Welsh term for soup, is first used within Raine's work; and was recorded within the $S A W D$ as a term also for 'soup and gruel'. Although the second item, 'plock', occurs in the $S A W D$ as a term for 'paddock' to mean 'animal enclosure', the usage within the novel differs slightly. For example, 'hang a plock around Seren's neck' (p.40), suggests it is related to the Cymraeg 'plocin' (block of wood).

\section{Grammar}

Raine's attempt to render a WE dialect extends also to grammar. These forms are not included within her appendices. Omission of verbs 'to go', are present in phrases like: 'let's to bed' (p.37). The novel also twice documents the phrase: 'in my deed' 
(p.263,266), inserting the infix-adjective 'my' into what appears to be affirmative 'indeed'; although the affirmative remains, it also alters its sense to demonstrate emphasis. This alteration does not appear in the $S A W D, E D D$ or $O E D$. Perhaps one of the more surprising grammatical traits in Queen of the Rushes is the use of stereotyped discourse marker 'look you' (e.g. 'well, most like, look you, a second wife won't care' (p.42).

Finally, the last noteworthy Welsh English grammatical structure within Raine's work, one which is attested to within the SAWD is the Demonstrative There +adj. \& NP. A speaker uses "there's odd now" (p.117). In another instance a speaker states: "there's a fool I was to call him, Gildas" which in StE may have been something like: "how I am a fool".

\section{Pronunciation}

Like many dialect writers, Raine also uses eye-dialect to give further appearance that the language being spoken is regional, rather than standard. Many of these in the novel take the form of allegro speech (contractions), for example: 'tisn't', 'twill' (p.29), ‘'tis' (p.31), ‘'bout', ‘t'would', ‘twas', 'cap'n' (p.57), 'd'ye' (p.58) and 'lemee see' (p.59). This may have been used to maintain the illusion of regional speech, even if many of these forms occur in all rapid speech of most English varieties. Phonetic respelling is also used by Raine, a technique which will not be seen used again until the work of Jack Jones in 1935. Table 7.5. documents these items within sentences, noting their standardised spelling, followed by phonetic respelling of the standard (by way of RP) and a speculative dialectal representation. Respellings such as 'pwr' and 'fforwel' match their Cymraeg equivalents, and 'dono' and 'oction' render an RP diphthong/ov/ as a half-close back vowel /p/, a sound that matches $S A W D$ records.

Table 7.5: List of phonetic respellings in Raine (1880, 1998)

\begin{tabular}{llll}
\hline Respelling & RP form & RP IPA & $\begin{array}{l}\text { Dialectal } \\
\text { IPA }\end{array}$ \\
\hline 'Well, I dono' (p.29) & Dunno & $/ \mathrm{d} \Lambda$ nəo/ & $/ \mathrm{dpn} /$ \\
'Oction at poor Jinni Owen's to-day' & Auction & $/ \mathrm{o}: \mathrm{k} \int \Lambda \mathrm{n} /$ & $/ \mathrm{pk} \int \Lambda \mathrm{n} /$
\end{tabular}


'Hai' (p.32)

'Oh fforwel!' (p.43)

'Alreit, alreit!' (p.49)

'Pwr fellow' (p.60)

'I told mestress' (p.213)
$\mathrm{Hi}$

Farewell

Alright

Poor

Mistress /hai/

/har:/

/feəwel/ /fo:wel/

/o:Irait/ /o:1reit/

/po:/

/pu:'ə/

/mistris/

/mestris/

or

/mestres/

In all, Raine uses her knowledge of English spoken in Wales to create a picture of the WE dialect within her fiction; much of the vocabulary and grammar paralleling entries in the $S A W D$. It is unfortunate that so few of these features were noted by Raine in her appendices. Whilst it can be assumed that noting grammatical features for readers may have been unnecessary, as unfamiliar sentence structures would be enough for readers to recognise regional dialogue without losing semanticity, it is strange Raine did not include a larger glossary of vocabulary. Additional vocabulary found by Gramich (1999) and the present author totals a substantial 16 usages, tallying almost half of Raine's original account of 28 . There are several reasons why this may have been the case. Perhaps Raine made a technical error in tallying her dialectal usages in the novel; however, we cannot rule out the possibility that Raine left undefined vocabulary to entice, mystify or confuse English readers, or alternatively, she was not aware that words such as 'bwcci', 'ladiwen', 'rhos', 'cwrt', 'parlwr' and 'plock' were regional items, thinking they were well-known outside her Cardiganshire life, therby requiring little explanation.

\subsubsection{Summary}

To summarise this chapter's section, the early period of Welsh writing in English, known as Contact Stories or Romances, saw a 're-emergence' of WE literary dialect. Gone was the archaic literary dialect of earlier Elizabethan plays, as Welsh people such as Prichard, Ceredig, Dillwyn, and Raine began writing their own literary dialect. Prichard made his own dialectological inquiries to correct prior writers' 
inaccuracies, using not only Cymraeg loanwords and loan-syntax, but also used English English dialect vocabulary to create his picture of literary $19^{\text {th }}$ century WE. Dillwyn used a 'direct-translationism' method to translate Cymraeg speakers not into Standard English, but a WE, illustrating the grammatical qualities of the contact variety. And, Raine depicted a community where both English and Cymraeg was spoken; she was the first writer to create a paratextual wordlist for her readership, and reintroduced experiments in literary WE phonetic respelling. However, linguistic echoes of the past Stage Welshness were still present, best evidenced in Prichard, Dillwyn and Raine all using the Elizabethan linguistic stereotype 'look you', demonstrating that despite their dialectological inquiries, particular language stereotypes had solidified.

\subsection{Early $20^{\text {th }}$ century novels and 'The First Flowering'}

The second significant period to feature literary dialects informed by WE emerged following the publication of the controversial Caradoc Evans' My People in 1915: a period dubbed the 'First Flowering' by literary critics. Caradoc first displayed what could be achieved with Welsh heritage by way of $20^{\text {th }}$ century user of English (Mathias, 1987:81). Inheriting the 'Welsh concern with the word' and its sounds and forms, this was a period in which Anglo-Welsh writers used their fascination with poetic language to search for a linguistic medium 'with which to express their 'Welshness"' (Williams, 1970:42-43).

\subsubsection{Caradoc Evans's My People (1915)}

Caradoc Evans' (b. 1878) contribution to Welsh writing in English, and the representation of a WE literary dialect, were momentous. Although Evans was brought up in rural Rhydlewis, Cardiganshire, within the Cymraeg-speaking heartland, he attended an English medium school; this was during a time following educational reforms and the 1889 Education Act (Knight, 2004:32). Like Prichard a century earlier, Evans moved to London becoming an editor and journalist. Annually, Evans would vacation in Wales, and it was in listening to workers' conversations that he formed the idea to write short stories (Harris, 1987,8). Described by Mathias (1987:81) as being a 'maverick [Cymraeg] speaker', Evans' writing was fuelled by his resentment at his immediate family's fall in reputation. Choosing a writing style 
that was savagely biblical and focusing on greed, lust and hypocrisy, Evans was determined to sell to a London readership a view of Wales as 'Neanderthal' (p.81).

My People (1915) was Evans' first notorious output. It focused on the western Welsh society of the $19^{\text {th }}$ century, in particular its Nonconformity. It was met with such fervour by Welsh people that it was reportedly banned and burned upon publication (Harris, 1987:8), an observance that, although surprised Evans, did not displease him (Mathias, 1987:82). Critics such as D. Tecwyn Lloyd believed Evans had shamefully contributed to a literary tradition of Welsh parody by using 'cheap English verbal tricks' to characterise Cymraeg modes of speech (Thomas, 1988), and Mathias (1987) concurs: 'no other Anglo-Welsh prose writer [...] displayed such ill-will to Wales or to the Welsh people' (p.81). Unlike other Anglo-Welsh works, the chief criticism many had with My People was its style of writing. Narration was restrained, formal and reminiscent of biblical language, whilst its speech was 'heavily, abrogatingly, marked by Welshness' (Knight, 2004:33). When published, confused English critics wondered whether the WE speech was 'authentic', whilst discontented Welsh critics believed Evans' literal translations of Welsh idiomatic speech into stilted, 'grotesque' English was an attempt to mock native Welsh culture (Williams, 1970:39-40). Later critics and scholars have refuted both assumptions; it was not intended to be authentic, nor was it directly translated from Cymraeg. Bilingual critic, novelist, and writer Glyn Jones states that although Evans translates particular concepts between the languages (e.g. 'large money' = 'arian mawr', 'red penny' = 'ceiniog goch'), for the majority of words there are 'no parallels' between them, indeed: 'not even remote ones, in [Cymraeg]' (Jones, 1968:73).

The literary critic who has come closest in describing Evans' literary dialect, is Hopkins (1996:434), who suggests Evans' speech is an 'invented rather than 'actual' variety of English'. Of course, literary dialects are all 'inventions' to some degree, distinct from their real-world counterparts; however, Evans exploits the notion that readers assume that Literary dialect a) should be representative of Speech Community a) by intentionally making his speech unrepresentative for satirical purposes. It is Evans' deliberate intention to subvert the expectation that his readers expect 'authenticity' that is sociolinguistically remarkable. 
Evans' early advocates report that at first he had difficulty choosing a style. Not wanting to write in Standard English, as it would destroy the 'effect' of an uneducated church community, Evans' eventual bible diction and 'grotesque misreadings' were 'excited by their artistic possibilities' to create what Harris has called 'a unique creation' (Harris, 1987:10). This notion of artistic dialect was put forth by Williams (1970) who argues it is entirely Caradoc's own creation; that it was 'for his own artistic purposes'. Hopkins (1996) and Williams (1970) both put emphasis on this artistic quality, indeed, this acknowledgement of literary dialect writers as 'dialect artists' is common in the linguistic literature (see Krapp, 1926).

That is not to say that Evans' literary dialect is a complete fabrication without linguistic merit. Prior to this current research, it is only Williams (1970) who has '[looked] for the source of [Evans'] distortions' (p.40). Without the linguistic terminology, Williams has noted Evans' use of phonetic respelling (p.41), that Evans may have been producing an English variety that was a 'result of a living bilingual culture' (i.e. contact variety) (p.42), perhaps even producing an English that had 'halting' features - something that Knight (2004) echoes in suggesting it's a 'poorly learnt English'. Finally, Williams (1970) identified two lexical trends in Caradoc's writing style, encompassing My People and several other texts (e.g. Capel Sion (1916), My Neighbors (1919), and Taffy (1923). The first being Evans' usage of common attested Cymraeg words used by English speakers (e.g. 'dablen', 'shonk', 'baglor') and English derivations (e.g. 'sombreous', 'slipthrift') (Williams, 1970:44); the second being the use of archaic, poetic, and obscure words (e.g. 'dwale', 'pugil', 'scimia') 'that Caradoc seems to have discovered on his journey through the dictionary' (see Williams, 1970: 45, for a full list). Regarding the first group, Williams (1970) suggests Evans' respellings are 'faithful to the spirit of the compromise' (p.45) that Cymraeg-speakers of English might use. Furthermore, Evans never attempted to produce 'that remarkable tendency [...] to speak both English and Cymraeg within the same sentence' (p.45), to which we can assume Williams is referring to code-switching, a technique Evans might have avoided to prevent reader resistance.

Below are some of the linguistic characteristics that hitherto have not been discussed in the literary literature concerning Evans' My People. Though the focus of this 
thesis' research is from a qualitative standpoint, a text such as My People lends itself to some quantitative analysis. Now available in public domain, key terms are digitally searchable. We can use this method to assess how an author such as Evans has chosen to use a particular linguistic form in their literary dialect that previous commentators have noted. ${ }^{16}$

Lexis

Many of the Cymraeg loanwords that Evans uses in My People are lexical items that can be attested in Parry's SAWD. 'Mam' is used on 7 occasions (e.g. "“Me and your mam are full of years."' (p.27), and the expression of disgust 'ach y fi', first used by Raine (1906), appears in a full form (“"Ach y fi!”, p.123) and a shortened form (““Ach, indeed!”, p.257). The Cymraeg loan that is most frequent is the (fe)male term of endearment "fach/bach. Female examples such as: "Nell fach"' (p.33, 34, 36) occur 48 times in the novel, whilst male examples such as: "'now there's a daft boy, bach" (p.23) and "“Boy bach foolish!" (p.25) occur 146 times throughout. These forms were present in the earlier works of Prichard (1828), Ceredig (1870), and Raine (1906), however, the degree to which Evans used the endearment, and his comfort in doing so, suggests that at the time of writing the term was likely enregistered amongst WE speakers, and certainly recognizable amongst non-WE users (i.e. Londoners) as a marker of 'Welshness'.

Several other lexical items that were associated with Welsh English speakers are noteworthy. The phrase 'Indeed to goodness', that occurs sparsely in Prichard's (1828), is present throughout My People occurring 16 times. Its inclusion likely indicating Evans' own awareness of its stereotypical connotations among WE speakers, reinforcing the satirisation within his literary variety. The presence of the well-attested Shakespearean WE 'look you' (p.31) affirms that Caradoc was familiar with this stereotypical lexis and how its enregisterment was used in the construction of the stock Welshman.

That being said, Caradoc also used one term that in the later $20^{\text {th }}$ century did become

\footnotetext{
${ }^{16}$ Methods such as this show the potential for future research that can be conducted for each author from a quantitative perspective.
} 
a common and attested enregistered form in WE, suggesting that Caradoc, when vacationing, was indeed 'listening' to the varieties of English being used around him (Harris, 1987). Making its literary dialectal debut in My People, 'tidy' used as an adjective with the sense of 'decent' rather than solely 'neat' was later recorded by the Parry's $S A W D$ throughout the borders and southern Welsh valleys. In the text, Caradoc uses it largely in reference to the goodness of women, for example "If you could find a thrifty tidy female"" (p.26); and "'Is she a tidy wench?" (p.32), although also for approval of men: 'Nansi said these words in praise of Jos "“Old Jos is very tidy"' (p.217).

Glyn Jones' statement regarding Caradoc's mock translations, that suggest translation yet contain no parallels with Cymraeg, are perhaps best illustrated in his range of English language synonyms for the verb 'to say/'siarad'. These synonyms (see Table 6) are contextually infrequent, coming across as stilted and suggestive of second language learning of English. Such Caradocisms include '[to] voice', '[to] mouth', '[to] speech', and '[to] sound'. Whereas 'to voice' and 'to sound' are both verb forms in Standard English, the senses 'to mouth' and 'to speech' are both formed from their respective nouns via conversion (i.e. zero derivation) into verbs.

Table 7.6: Mock translations for 'to say' in My People (1915)

\begin{tabular}{|c|c|c|}
\hline Word & Example quotation & \\
\hline '[to] voice' & $\begin{array}{l}\text { "How voice you then about Gwen the widow of Noah?" } \\
\text { "Did you voice to Beca about the matter?" }\end{array}$ & $\begin{array}{l}(\mathrm{p} .26) \\
(\mathrm{p} .55)\end{array}$ \\
\hline ‘[to] mouth’ & $\begin{array}{l}\text { "Mouth you now about the houses" } \\
\text { "Mouth you to no one your mission." }\end{array}$ & $\begin{array}{l}(\mathrm{p} .36) \\
(\mathrm{p} .155)\end{array}$ \\
\hline '[to] speech' & $\begin{array}{l}\text { "Wise would be to speech to the male bach." } \\
\text { "Speech you not that." }\end{array}$ & $\begin{array}{l}(\mathrm{p} .54) \\
(\mathrm{p} .126)\end{array}$ \\
\hline '[to] sound'. & "Sound the figures now" & (p.58) \\
\hline
\end{tabular}

Other Caradoc coinages include a word for God, 'Big Man' ('all powerful Big Man', p.5), which occurs 90 times in the text and derives from the Welsh Bod Mawr, translating more literally as 'Great Being', as well as 'talkist' (“"What a talkist you 
are!"', p.125) that features the application of alternative suffixes in place of regular usages, in this case using the -ist agentive suffix rather than -er for 'talker'.

And yet there are some items Evans used that are puzzling. Whereas Caradoc uses an obsolete form of 'hither to' with 'hie' (“"back you hie, you brazen slut”, p.176), a form not recorded in Wales, perhaps the most puzzling is the exclamation 'jasto' (“"Jasto, now.”, p.41; ““Jasto!” he cried.', p.129; “"Bad jasto!””, p.220). Jasto does not occur in the $S A W D$, nor in either the $E D D$ or $O E D$, to which we can surmise one of several things. Although it might be a complete coinage on Evans' behalf, we cannot rule out that, potentially, Evans discovered 'jasto' in a rare dictionary unknown to $O E D$ editors, or amongst the speech of manual laborers he was recording. If the latter is true, then Evans' literary dialect contains linguistic evidence hitherto unrecorded.

\section{Grammar}

Evans' grammatical structures can be divided into three groups: biblical structures, non-attested Cymraeg grammatical loans, and attested Cymraeg grammatical loans. The first group was Caradoc's attempt to reproduce the English variety as it exists in the Early modern English text of the King James Bible - itself dating to 1611. The language consists of inverted speech, much of which would have sounded archaic even to $20^{\text {th }}$ century readers, for example "“Heard you all my prayer?"” (p.7) and “"Heard you not of his doings?"” (p.127). The second group consists of structures which we can surmise are meant to be representative of second language English learners, although these do not necessarily match frequent structures formed by Cymraeg interference. Take for example "I am come for a wife"” (p.31) and "I am come after little Elijah"” (p.148). Here the past participle to form a perfect verb 'to have' is replaced with first person to be verb 'am'. Caradoc might have been translating the past participle 'to have' from the Welsh $d w i$ wedi (I [am] have), except has kept its component present first person to be rather than the past participle. For example, 'Dw [i] wedi cyrraedd', literally: I [am] have come.

The final group consists of forms that are attested in the $S A W D$, most notably Demonstrative There (e.g. "There's lovely, it was.", p.7). Caradoc uses Demonstrative There 39 times in the text, making it one of the most frequent attested 
structures (see Table 7.7). Most interesting is that Evans constructs 32 (82\%) using a tag element that resembles another common grammatical structure of WE: focus fronting. For example: "There's sad it is" (p.200). With the demonstrative absent, 'sad it is', would also be common amongst WE speakers. Caradoc's Demonstrative There usage is split almost evenly between its subject complement taking an predicative adjective (51\%) and taking a predicative nominal (49\%) e.g. 'There's dense' (AdjP) / 'There's a nasty wench' (NP).

Table 7.7: Instances of Demonstrative There + adj/NP in My People (1915)

\begin{tabular}{|c|c|c|c|}
\hline Demonstrative There type & $N$ & $\%$ & Example \\
\hline Demonstrative There $\mathrm{w} /$ tag & 32 & 82 & There's rich he is. (p.256) \\
\hline Demonstrative There w/o tag & 7 & 18 & There's a boy bach $\varnothing$ (p.138) \\
\hline Demonstrative There + AdjP & 20 & 51 & There's slow you are man (p.145) \\
\hline Demonstrative There + NP & 19 & 49 & There's wealth for you (p.195) \\
\hline Total Dem. There & 39 & 100 & \\
\hline
\end{tabular}

\section{Pronunciation}

Evans used few markers of WE pronunciation in his text. Like Raine, the phonetic respelling of 'mister' (/mistə/) is rendered as 'mishtir' throughout (often in thirdperson narration too) suggesting a palato-alveolar fricative rather than an alveolar fricative: / $/$ /, for example: 'Mishtir Lloyd' (p.10). Orthographically, Evans chooses to render some English $<y>$ letters as the Welsh orthographic $<\mathrm{i}>(\mathrm{i} . \mathrm{e} . \mathrm{j} /$ ) in cases such as "“why, dear me, did the iob marry such a useless woman?" (p.24). Here 'iob' refers to 'yob', a back-slang term for boy used throughout Britain in the $19^{\text {th }}$ century $(O E D)$. Evans also produces all 54 affirmative yesses as 'iss' as well. Non-attested items include production of 'rubbish' with the /j/ semi-vowel: "Iobish you talk." (p.251).

Caradoc's My People may be one of the popularly noted (and criticized) examples of a ficto-linguistic portrayal of WE. Yet, items such as 'jasto' and grammatical forms such as Demonstrative There's, coupled with Evans' characters' poorly chosen synonyms and suffixes, both being reminiscent of L2 learners of English, suggest that Caradoc's literary dialect, although 'artistic', captured real-world elements of 
this early $20^{\text {th }}$ century west Wales speech community.

\subsubsection{Margiad Evans's Country Dance (1932)}

Following in both the wake of Caradoc Evans' My People and the First World War, Margiad Evans' Country Dance was published in 1932. Born Peggy Whistler (19091958) in Uxbridge, London, and later living in Ross-on-Wye, the author developed a connection to the rural life of the Welsh borders and adopted the penname Margiad Evans out of affinity with Wales (Collier, 2006:4). Margiad is then the first $20^{\text {th }}$ century English-born novelist to be associated with both Welsh writing in English and construction of a WE literary dialect. Margiad, who had Welsh ancestry, often found her Anglo-Welsh identity a struggle (Dearnley, 1982:12), finding it difficult to assert to critics that she was English, but with Welsh interests. A collection of her poems was described as 'essentially Celtic' by one reviewer; whilst another mocked her literary attempts to identify with Welsh peoples with an antiquated Shakespearean stereotype, writing: 'there is hardly a verse of hers but cries, "I am from Wales, look you"” (p.39).

Margiad's Country Dance focuses on the communities living in the midWelsh/English borderland during the mid-19 $9^{\text {th }}$ century. For women, life on the homestead was difficult, a theme Margiad used for her protagonist, Ann, born of a Welsh mother and English father (Collier, 2006). Although it is not known to what degree Margiad's writing was based on personal experience (Mathias, 1987), critics point towards her literary dialect as a strong element - a component that would have necessitated some form of interaction. Biographer Ceridwen Lloyd-Morgan noted that Margiad had an 'appetite' for recording elements of her surroundings for her fiction, wanting to capture the "actual words used by her unconscious "informants" (Thomas, 2013: 100). Thomas (2013) believes it is these features that are the 'marrow of the story', stating Margiad was a 'connoisseur of dialect, of inflection, of the very pace and rhythm, sound and texture, of narrative' (p.100). The narrative rivalry between the Welsh and English cultural forces is something that Powell (2003) states is never a 'drag' to read, largely due to the 'lilting rhythms of the writing and the mass of authentic detail about the processes of [farming] life' (p.100). Here Powell uses a familiar laymans term: 'lilting rhythm' to describe WE speech, as well as championing Margiad's 'authenticity'. From Powell's perspective, Margiad's 
writing has authenticity in the description of farming life, but when it comes to 'authenticity' of language representation, the 'lilting' rhythms are enough and do not 'drag'. For Powell, there is just enough 'authentic' linguistic material to be interesting, but perhaps not too much to cause reader resistance.

\section{Lexis}

The lexical component of Margiad's literary dialect can be divided into four categories: items loaned from Cymraeg, attested WE forms, British English regional forms, and forms of unknown origins. Cymraeg loans such as 'mam' (“"I feel sick, mam!”, p.25), 'bach' (““Ann, bach,”, p.79; “"Go on, Olwen bach”,, p.95), and 'caton pawb' (p.80) all appear in previous authors' literary dialects. Note that the endearment term typically used for males is used for females in Margiad's dialogues, possibly reflecting an error on her behalf. 'Caton pawb', used previously by Allen Raine's Queen of the Rushes, is reproduced here as an exclamation, which Raine glossed as 'save us all', but has not been documented elsewhere; it is possible that Margiad was familiar with Raine's own literary dialect. Margiad introduced several loans to her WE literary dialect. Two forms that today may be considered enregistered in the variety include the endearment 'cariad' for 'love' (p.72) and the nationalistic phrase 'Cymru am byth!' ('Wales forever!'). Margiad also notes two exclamatives associated with the Christian devil: 'diawl' (p.50) and 'cythraul', the former being attested in WE by the $S A W D$ in Carmarthenshire. One final exclamative Margiad uses is 'Brenin Mawr!' (lit. Great King!), which is used by at least three characters (Ann's mother, Miss Evans, and Mrs Pritchard). And yet this does not appear in records of any WE or Cymraeg dictionary, possibly suggesting either an exoticism (or even 'Caradocism') or a borderlands term hitherto unrecorded. The last term in this category is the English translationism: 'fairy's fingers', a term for foxglove, that the $O E D$ suggests might be related to the Cymraeg term for the plant: bysedd yr ellyllon, lit. '(glove) fingers of fairies'.

Lexis derived from English language traditions include interjections such as affirmative 'ay' (p.13), and emphatic denial 'never' (e.g. "NNever. Tell me what has happened to you.", p.27), as well as 'mind', a verbal form attested in the SAWD (Pem. \& Glam.) in the sense 'to remember' (e.g. "Mind now what I am telling you'", p.55) (used previously by Ceredig). 'Loose me', is attested in Weng. in the 
sense 'let go'. 'Affeared', a predicative adjective in the sense 'afraid', is used several times by Olwen, Chrissie and Mrs Somers, for example: "I'm too affeared." (p.13); “"I'm not affeared"' (p.26). The OED notes 'affeared' as Old English in origin, though now 'regional'; the $E D D$ confirms its regional usage, noting distribution throughout England, Scotland and Ireland. 'To tan' is used for 'to strike' in the utterance: "II shall tan him with my shoe"'. This sense of the word (to touch, fondle, or rage) was detected along the Welsh/English border (in Cheshire, Shropshire, Worcestershire and Somerset) by the EDD. Had Joseph Wright surveyed the English varieties used across the Welsh border, the term might have found currency there too.

Country Dance includes several items of uncertain origins. The phrases 'not a mite to be gained' (p.14) and 'what a black rage he is in' (p.17) could be direct Cymraeg translations. 'Saucering' is a zero-derivation coinage, acting as a nonce verb created during the utterance: "'on his hands and knees with a basin and saucer, saucering it up."” (p.50), thus demonstrating the speech community's linguistic malleability. Ann also produces "“switching his tail"' (p.84), to which we are perhaps to infer 'swishing' (no record in $S A W D, E D D$, or $O E D$ ).

Margiad Evans' use of phonetic respelling is minimal, although she uses Cymraeg cognates to illustrate potential pronunciation change, although how likely a nonCymraeg-using reader would recognize this is slight. Although Evan uses 'ffarwel', being pronounced /fa:wel/, this spelling more likely is used to mark his Welshness in contrast with the English characters.

\section{Grammar}

A few trends become visible in Margiad's grammatical structures. Margiad often uses nonstandard subject verb agreements in character speech. Ann's speech uses irregular past tense indicative 'we was' rather than 'we were' (e.g. "“Where we was used to catch[ing] trout", p.60), a grammatical feature the SAWD records for much of Mid-Wales and the Welsh borders (Radnorshire, Brecon, Flintshire, Monmouthshire). A very common verb disagreement used is inflected forms for the present tense indicative, for example: 'I says' (p.13), 'I draws' (p.16), 'I bursts out' (p.15), 'I takes the pen' (p.43), and present tense 'tell' is used for the past (“"When he tell me"”, p.79). Forms such as this were used throughout Wales when 
the $S A W D$ was recorded. The $S A W D$ reports that prepositions such as 'to' can replace 'with you', a structure that, although not strictly similar in the following example, suggests prepositional irregularity: "Now pen her up, and come to help me with the others."” (p.31). Evan uses two archaic items in his WE speech, the second person singular pronoun 'thou' and the present tense indicative 'art': "Thou art very saucy for a shepherd's daughter"' (p.29). Use of these archaisms are absent from other speakers such as Ann, suggesting two separate styles of speech. Thou and art were attested in the borders as recently as the 1960s, with the SAWD finding distribution throughout Radnorshire, Flintshire, Monmouthshire and neighbouring Staffordshire, Herefordshire and Somerset. One form that the ewave records for WE is 'degree modifier adverbs [having] the same form as adjectives', a usage I shall dub: 'clipped adverbs', in which the regular adverbial suffix $<-1 y>$ is omitted, yet its syntactic position still implies an adverbial sense. Examples include 'fair' to mean 'fairly' ("'Her father is fair furious.", p.59) and "“Ay, fair furious.", p.88), and both 'terrible' for 'terribly' ("'He is terrible hard on his men", p,93) and 'mortal' for 'mortally' (“"he was mortal ill”, , p.14).

\section{Metalanguage}

The fictive linguistic situation that Margiad Evans portrayed was reminiscent of the very real one along the borders, where the divide between Cymraeg speakers and English speakers formed a cultural border between the Welsh and the English. Therefore, one's cultural (or national) identity might be tied to what language they chose to use, regardless of which side on a arbitrary border you lived. Some characters with Welsh names consider themselves culturally 'English', especially if they speak the English language rather than Cymraeg. For these characters, there is no English variety that could be marked by Welshness: WE does not conceptually exist. Still, Ann notes that her father 'has a Welsh voice that sings in speaking in English' (p.12), Margiad playing upon the layman's observance of the Welsh having 'sing-song' English prosody and intonation. Ann, born of Welsh and English parentage, is linguistically conflicted, and although she speaks the Welsh language she accepts Wales' derogatory associations, stating she hates the Welsh, their 'shifty ways', and recites: 'Taffy is a Welshman, Taffy is a thief' (p.19). A poignant (and poetic) observance of the border's linguistic situation is best encapsulated by Evan, her Welsh suitor states: "“Give me a sight of you to take back to England with me. I 
am not speaking Welsh, though indeed it is on the end of my tongue, cariad"' (p.72).

\subsubsection{Jack Jones's Black Parade (1935)}

Born in Merthyr Tydfil, Jack Jones (b.1884-1970) left school at 12 to become a miner. It was not until after the Second World War that he became a politician, public speaker and writer (Basini, 2009). Jones's writing strove to draw attention to 'the poverty, the deprivation and humiliation of an independent, industrious community in South Wales' (Edwards, 1974:30). He was a first language speaker of Cymraeg, although Edwards (1974) argues there is nothing to suggest he had read widely within Cymraeg literature before the industrial era (p.30).

Black Parade (1935), Jones's second novel, concerns the Merthyr-based family conflicts of the Saran and her husband Glyn between 1905 and 1926. Like his contemporaries discussed above, Jones too wanted to capture the rapid acceleration of Anglicisation in the southern valleys; in particular the production of a 'hybrid culture and [its] peculiar linguistic habits' (Edwards, 1974:20). According to Edwards, Jones would 'without explanation or apology' insert literal Cymraeg idiomatic translations to 'accentuate the Welsh tone of his work' (p.20). A literary technique arguably like that of Caradoc Evans. Literary critic Knight (2004) stated that 'Jones's [characters] speak in broad, even erroneous, south Welsh English,' with Saran always producing the form 'threeatre' (p.77) (whether Knight means erroneous by Jones's characters' standards or his is unclear).

\section{Lexis}

Like his contemporaries, Jones used well-attested WE forms. For example, affirmative 'ay' (p.4), 'mam' for mother (p.50), the phrase 'indeed to God' (p.19), the endearment term 'bach' for both males and females (e.g. "'Dai bach”, p.108; “"Saran bach", p.223), as well as 'tidy' as an adjective for good (e.g. "'he's not behaving tidy when he goes on guzzling"') and in the first instance as an adverb (e.g. “"if I'd been asked tidy I might have"').

Jones introduces several new terms to WE literary dialect. One is 'cardies', a term defined in-text as Cardiganshire-born migrants (p.13). 'Fly-me' is used on two 
occasions ("“That's all you know, fly-me,", p.18; and "Now listen Mr. Fly-me", p.122), although its sense is uncertain, the OED suggests 'wild, audacious, impertinent; brash' for 'fly'. 'Mooched' is used in the sense 'to steal' ('"the food you've mooched"', p.199), likely from 'moocher', one that robs drunk people $(E D D)$. 'Puff-puff' for locomotive is used sarcastically ("catch the puff-puff back to dear old Merthyr"), which the $O E D$ notes was used for the register of children's language. 'Jack' a mining term for drinking vessel is variably used as 'drinking-jack' (p.143) and 'tea-jack' (p.144) and was attested in the EDD as 'drinking vessel of leather' or can, occurring in Shropshire, Scotland, Hampshire and Yorkshire. The adjective 'bad' in the sense 'very ill', an attested WE form today (TT) is first-used in literary dialect by Jones here (noted in the $E D D$ throughout the country). 'Melt' a nominal for idiot ("“You bloody melt"”, p.85), does not appear in any records.

\section{Grammar}

Jones uses Focus Fronting minimally in his literary dialect, one notable example within the third-person narration rather than the dialogue being: 'Really funny, he was' (p.337). Nonstandard subject verb agreements that Jones makes use of include the inflected present tense indicative such as: "I draws [draw] the line"” (p.108) as well as the unstressed forms of the past tense indicative: "He's not so daft as you was [were]"', (p.246).

Jones alludes to other nonstandard grammatical usages common throughout the British Isles, such as using 'them' for a demonstrative determiner: 'them [those/these] doctors' (p.19). He also makes use of infixes such as the following: “"Look after your bloody self."”. Jones uses attested SAWD forms too, for example the present participle $<\mathrm{a}$ '[verb/prep./adverb] $>$ is used twice as prepositions: “"as though I'd never been anear 'em"' (p.66) and "You're not going anear the brickyard"' (p.129). This form, native to Monmouthshire and Radnorshire, was previously used by Dillwyn in The Rebecca Rioter. Jones uses the discourse marker 'see': "I know damned well it is, see" (p.111) and the confirmatory interrogative tag: 'is it/isn't it?': “Time for your mother back, isn't it?" (p.151), which is widespread throughout Wales, likely a Cymraeg loaned structure from 'd'ydw fe' that functions similarly $(S A W D)$. One final structure attested previously by Dillwyn is the use of 'as' as a relative pronoun in substitution for 'that', for example: “"They'll be saying as I'm stuck up.”, (p.94) and “"There's beer for all as wants it."” 
(p.247).

\section{Pronunciation}

A surprising feature of Jones's literary dialect is the reoccurrence of fricativisation of affricates, for example the phonetic respelling of 'children' as $<$ shildren $>$ (p.87) and 'Jenkin' as <shenkin $>$ (p.33), that produce $/ \mathrm{g} /$ rather than $/ \mathrm{t} \mathrm{f} /$. This feature was popularised by the theatrical dialects of Shakespeare and contemporaries, utilised in their Elizabethan plays. Perhaps this indicates Jones was familiar with these forms, believing they were representative of early $20^{\text {th }}$ century WE.

Jones consistently uses 'gel' for 'girl' (e.g. “"There's more than one, gel”, p.21), thus suggesting a shortened vowel sound which could be /e/ or /a/ rather than /3:/ although this is difficult to ascertain with just Jones's orthography. It is used in dialogue and third-person narration, therefore suggesting some form of enregisterment: Jones believing it to have wide usage.

A chief component in Jones' WE literary dialect is his usage of clipped allegro speech. Indeed, Jones is one of the first Anglo-Welsh authors (Raine being the initiator) to implement extensive use of these phonetic respellings. Many of these allegro clippings would be common in everyday English speech (regardless of one's variety/style); here, they are used to index a sense of 'dialectness'. There are three trends to note. The first are Jones's use of merged syllables: 's'long' (p.7), 'more'n' (p.9), 'p'raps' (p.10), 'b’longings' (p.93), 'p'licemen' (p.175), 'op'ra' (p.268), 's'pose' (p.278) and 'c'lect' (p.323). The second are omission of coda consonants: "movin" (p.9), “jokin" (p.11), "schoolin" (p.197). And the third are omission of initial consonants/syllables: 'lastic sides' (p.5), ' 'im' (p.21), '’et' (let) (p.21), ' 'ell' (p.38), 'em' (p.82), “'cept' (p.109), 'gainst' (p.227), ''lotment (i.e. allotment) (p.278), 'cruiting meetings' (i.e. recruiting) (p.290). Many of these are selfexplanatory, as they are designed to be familiar to the reader, however some less common forms might produce reader resistance such as 'cruiting meetings' and '’lotments.

\section{Metalanguage}

Knight (2004) rightfully observes that unlike Allen Raine, Jones does not make it 
clear whether his characters spoke Cymraeg to one another, with their dialogue being translated for an English readership. Knight suggests they were Cymraeg speakers because it is explicitly stated that their children went to an English language school. What is evident, however, is that at some point within the novel's narrative of several decades, all generations have shifted to using English more often. The following quote about Saran's children indicates her children used English more than Cymraeg:

[the new generation] thought differently, and talked differently, in the English tongue. And they read books and papers - couldn't live without the Merthyr Express and The Echo - and shouting themselves hoarse and in English at the football matches on Saturday afternoons. (Jones, 1935: 205)

And even Saran also used English more readily:

she ran out into the passage to meet her two sons and her English daughter-in-law. All over them she was, and talking good Welsh and so-so English alternately. "you'll 'scuse me talking Welsh to the boys, my gel," she said to her English daughter-inlaw. (Jones, 1935: 390)

Although literary critics commend Jones' writing's linguistic dimension, Black Parade offers little that had not already been introduced by previous literary dialect writers. Of this material, occurrence of literary dialect and its frequency within the text are minimal. Many characters use Standard English, whether or not they speak English or 'direct-translation' Cymraeg, with the matriarch Saran and her husband Glyn using the most dialectal (and allegro) forms. We can conclude that this was likely to suggest that Saran and Glyn used an older variety of WE, one encapsulated as a contact variety or second language, rather than a 'nativised' variety', a variety their children, being bilingual yet with preference for English, were using.

\subsubsection{Geraint Goodwin's The Heyday in the Blood (1936)}

Born in Newton, Montgomeryshire in 1903, Goodwin grew up along the anglicised Mid-Wales borderland. His aim in his writing career was to present a distinctly 'Welsh' fiction (Gramich, 2008b). Following his work as a London journalist (Mathias, 1987:93), Goodwin moved to Hertfordshire to write. Although remote from other Welsh writers of English, and although not a speaker of Cymraeg, he identified with (and defended vigorously) Welsh culture, having studied Welsh history extensively (Adams, 1975:72; Knight, 2004:44). 
The Heyday in the Blood was written as a contemporary piece that aimed to capture the Welsh and English cultural identities in the 1920s-1930s border country village of Tanygraig (likely Montgomeryshire) (Gramich, 2008b). Its title was taken from Shakespeare's Hamlet, and Goodwin's novel was written in less than two months (Adams, 1975:41). Biographer Adams (1975) argues that a significant achievement of Goodwin's writing was his ability to descriptively capture 'the sights, sounds and odours of a believable countryside' (p.53), and that his 'fine, naturalistic dialogue' demonstrated Goodwin's 'keen ear [...] for the nuances of the Welsh voice' (p.54). This notion is backed up by critic Mathias (1987) stating: 'he had an almost faultless ear for conversation' (p.94), although Mathias also notes 'undoubtedly he was writing for London [readership] and for that reason [...] his Welsh characters sometimes have a strange elusive quality' (p.94). Knight (2004) touches furthermore upon this point: 'the language of the book strains so hard to be authentic it becomes alien' (p.46).

It is assumed that characters' speech is rendered not in Cymraeg and then translated for readers into WE (like Jones and Raine above) but WE, indeed mirroring greatly what we know from the $S A W D$ for this region of Wales. Cymraeg phrases are used, however, and presented in-situ without translation. Goodwin supposedly took great care to render them correctly against English publishers (Knight, 2004). Some examples include: 'arglwydd mawr' [great lord] (p.66), 'cau dy geg' [shut your mouth] (p.69), 'y ngeneth' [the girl] (p.84), 'uffern dan' [fires of hell!] (p.73) and 'fy nghariad' [my love] (p.228). There is one scene where a Cymraeg passage is translated into English. This occurs when Evan is leaving for London, and seeks spiritual help from his pastor. The pastor's final prayer begins: 'He began in [Cymraeg]' to indicate to readers of the language shift, and follows: "'Let us pray...' [...] O God, the Great One who movest in the light beyond the great stars. Dear Jesus, thou friend of the lowly [etc.]"' It is worth noting that the pastor's style of speech parallels English religious biblical style.

A feature that has not been acknowledged by literary critics is that Goodwin is one of the only Anglo-Welsh authors to utilise several varieties of English in one text. Goodwin penned three distinct varieties of English, all regionally distinct. The 
majority of speakers of Tanygraig use North Welsh-Borders English, which, to some extent is dichotomized between younger and older speakers and is marked largely by its Cymraeg loanwords and loaned syntactic structures. Inhabitants of Tanygraig occasionally meet Englishmen across the border, who speak a North English-Borders English, for example the Foxhunter/Old Whip that Llew is friends with. Features include grammatical archaisms such as 'thee' and 'you'm', that reflects the speech recorded by the $S A W D, S E D$, and $E D D$ as belonging to the Welsh borders, as well as Cheshire and Shropshire across the border. Finally, Goodwin represents South Welsh English, the language of the 'shonihoi' characters, from the southern coalfield; split again into a dichotomy of an elderly and younger speakers, and also marked by Cymraeg loans - these loans are often rendered marginally different to the speakers of Tanygraig.

Below is a discussion of the lexis, grammar and pronunciation of the chief dialect of Tanygraig, with the other varieties discussed thereafter.

Lexis

Goodwin uses several Cymraeg loans that other English writers from Wales were using, for example, 'mam' (p.2), 'cwrw' [beer] (p.76), and 'hiraeth' [longing] (p.83). Goodwin also uses both variants of devil as an interjection: 'diawl' that Margiad Evans had used the year before him, and adds another variant 'diawch'. The currency of several of these items across texts indicate these are enregistered forms characteristic of this early $20^{\text {th }}$ century variety of WE and that authors were intertextually lifting vocabulary from one another's texts. That said Goodwin does add several new Cymraeg items (below).

Cymraeg loans new to WE literary dialect include interjections such as the mild oath 'daro' (p.5) that the GPC equivalates with the English 'dash it!', and 'iesu mawr' (p.11) (lit. Great Jesus!). The vocative endearment 'gwas' for lad (GPC) is used: “"Count on me, gwas"' (p.201), as is 'hwyl', a term for high spirits or gusto (GPC, Weng.): 'His voice went up in the hwyl' (p.216). Other nouns include person nouns such as 'cochyn' (p.35), that GPC defines as a red-haired person, the slang derogative 'shonihoi' (p.46) (lit. Johnny-o!) that is used to refer to south-Walian colliers; note too that in-text shonihoi is used with English plural suffix -s. Particular 
fishing terms are used, such as: 'coch-y-bonddu' (p.50) an artificial fly that in English is more readily corrupted as 'cock-a-bundy' $(O E D)$ and 'penhwyad' (p.126), the Welsh word for pike. The Welsh dish 'tatws llaeth' (p.68) (lit. milky potatoes), is mentioned, as are Welsh cultural lexis such as 'englyn' (p.219), a type of stanza in Cymraeg poetry; 'tylwyth teg, a term for fairies (lit. 'fair tribe'); and the Englishderived attributive adjective 'eisteddfodic', used to describe chairs and poems (e.g. 'sat on one of the Eisteddfodic chairs as on a throne') (p.219). Paratexually, Goodwin's writing often lacks the italicism convention for foreignisms (e.g. hiraeth, penhwyad, and tylwyth teg are unitalicized), again, reinforcing the idea that these Cymraeg loans were largely part of everyday WE border variety.

Familiar WE lexis Goodwin uses includes affirmative 'ay' (p.3), the emphatic denial 'never' (e.g. "'Never," said Wati in admiration') (p.66) and 'loose it go' for 'let it go' (p.138). These are both English-language derived forms that were also used by Margiad Evans' Country Dance, also set on the Welsh-English borderland. There are six WE forms used for the first time. Some are distinct amongst the border varieties. The noun 'moucher' (p.34) for truant is a variation of the regionally frequent 'mitcher' ( $S A W D$ records 'miche' in west Glamorganshire, and Dyfed; EDD records this in English border counties Herefordshire and Gloucestershire). This variation pronunciation $\left(/ \operatorname{mavt} \int \mathrm{a} /\right)$ was attested in a 2013 survey undertaken by the current author in Gwent (see Jones, 2016a). The verb 'tamping' is used in the sense of quick movement (e.g. "'He's tamping to the left fast", p.109); this sense was recorded in the $S A W D$ as being prevalent in Monmouthshire and Breconshire especially. Two more borders terms are 'gammy' for 'crooked' or 'bent' (e.g. 'patting his gammy leg', p.216) - recorded in Glamorganshire and Monmouthshire, and 'glat' for 'hedge gaps' (e.g. 'Fumbled for a glat in the hedge', p.227), recorded by the SAWD throughout Monmouthshire, Radnorshire, Breconshire, and Montgomeryshire, and by the $E D D$ in adjacent Shropshire, Worcestershire, and Herefordshire.

Slang usages from the early $20^{\text {th }}$ century's British English are also commonly used such as 'pap' (liquid food) (p.131), 'toff' (p.65) (derogatory term for a wealthy person), 'whiffs' (OED: small cigar) (p.10), 'charabanc/chary-bonk (two variations) (p.46, p.246) for motor-coaches, 'death-hunter' (p.141) for someone whose work profits from death $(O E D)$, and the phrase 'you arr a wan' (p.12) for a 
remarkable person $(O E D)$. Perhaps more remarkable is the usage of slang from American Englishes, such as 'siesta' (p.50) for afternoon-break, and 'swank' (p.58) for 'fancy', indicating some cross-Atlantic levelling. Lexis from other British varieties also occur, for example: 'wik on grass' (p.138) for 'quaking grass' used in Hampshire, Wiltshire, Dorset and Somerset (EDD); and 'robin-run-the-hedge' (p.166) a common term (though not appearing in dialectological records) for the cleaver plant (Galium aparine) (Devlin, 2017). The peculiarity of robin-run-thehedge is highlighted by a pastor character as he runs off two similarly syntactic coinages such as 'Whift-of-cowslip' and 'dandelion's-daughter', neither of which are present in any record. Indeed, there are several other items of uncertain origin, matching no records, these include the phrase 'like [bloody] bees in a storm' (p.104) that mimics other bee idioms (e.g. 'make a bee-line', 'like bees to honey'), 'jennyring' defined in-text as 'the old method of power used for kibbling, pulping and cutting fodder' (p.85), a predicate adjectival phrase 'to be monkey-up-the-stick' (p.79) and 'elder-bloom' (p.30) which may be a plant.

\section{Grammar}

Goodwin's grammar usage matches other writers. He includes both Focus Fronting (e.g. "“too soft, I been"”, p.10; “"joking, you are"”, p.12); and Demonstrative There with focus-fronting tag elements similar to Caradoc Evans (e.g. "“There's a poet he is", p.8; “"There's early, you are",, p.11). He uses discourse marker 'see': "'Gwenno is doing the work of two, she is"” (p.25) and "“A real toff, see" (p.65). Goodwin uses 'as' for a relative pronoun "'that's a ploody gippo as comes with pegs" (p.43) and the present participle <a'[verb/prep./adverb] $>$ in 'there's ladies a'comin', both features recorded in the $S A W D$, and both previously used before by Dillwyn and Jack Jones. Nonstandard subject verb agreement occurs for the present tense indicative in "Betty do as she wants" (p.53). Goodwin does pick up on a grammatical form no other writer had incorporated, one that was later recorded in the $S A W D$ : 'for to' for the sense 'in order to', for example: "II have not come for to run errands"' (p.60). Finally, Goodwin uses a clipped adverb 'proper' as adverbial: “"I couldn't hear proper"' (p.245).

\section{Pronunciation}

The phonological dimension to Goodwin's literary dialect can be divided into three 
areas: typical phonetic respellings, phonetic respellings common to Shakespearean stock characters, a new phonetic respelling form I shall dub: intonation hyphenation, and finally eye-dialect. To begin, changes in orthography suggest changes in phonology, but these cannot be strictly ascertained. For example, Goodwin alters some vowel pronunciation; he spells 'up' as 'app' ('shutapp', p.6; 'app', p.46) which suggests near-open front vowel (/æp/) rather than an open-mid back vowel (/ $/ \mathrm{p} /)$; and spells 'once' and 'one' as 'wance' (p.6) and 'wan' (p.9) which suggests a near-open front vowel (/wæns/) rather than an open back vowel (/wons/). Diphthongs and long vowels are also reduced to shorter vowels in spellings such as 'posscards' [postcards] (p.15) (/pouska:dz/ to /ppska:dz/) and 'shin bif' [shin beef] (p.32) (/bi:f/ to /bif/), whilst some shorter vowels are lengthened, for example 'feesants' [pheasants] (p.154) suggesting a closed-mid front vowel (/e/) becoming a closed front vowel /i:/. Goodwin may have suggested rhoticity in spellings such as 'farr' [far] (p.107) and 'arr' [are] containing additional $<\mathrm{r}>$ graphemes, a feature that according to the $S E D$ and $S A W D$ would have been common in the borders. Finally, 'head' is spelt 'yead' (p.138), this matches the SAWD's record that initial voiceless glottal fricative may have an intrusive voiceless palatal approximant $/ \mathrm{j} /$ in South Wales.

Goodwin uses some phonetic respellings that have appeared prior in Shakespearean/Elizabethan stock Welshmen. Bearing in mind Goodwin was wellacquainted with Shakespeare, having taken the novel's title from Shakespearean material; it is not surprising that Goodwin uses many of the phonetic respellings that Shakespeare used for similar words. Goodwin's usages can be divided into forms that were still in use when the $S A W D$ was undertaken and those that were not recorded. Of the forms that still have large currency, Goodwin uses devoiced final /d/ in words such as 'tamn' [damn] (p.3); devoiced /z/ in words like 'iss' [is], 'hass' [haz], 'hiss' [hiz] (p.3); and omission of initial /w/ in 'orld' [world] (p.221). Devoiced /v/ was also used in 'haf' [have] (p.3) and 'foreffer' (p.6), though SAWD notes it had minimal currency.

Goodwin uses devoicing of $/ \mathrm{b} /$ and devoicing of $/ \mathrm{g} /$, both of which did not occur in $S A W D$, although may have been used in the speech community during Goodwin's writing and even still during Parry's survey. Devoiced $/ \mathrm{b} /$ to $/ \mathrm{p} /$ examples include: 
'ploody' for 'bloody' (p.3) and 'phut' for 'but' (p.5), a phonetically opaque form that suggests initial /f/ yet is meant to suggest devoicing + aspirated $/ \mathrm{h} /$. Devoiced $/ \mathrm{g} /$ to /k/ examples include: 'Cod' for 'God' (p.227). Considering Goodwin went to such length to render many other attested forms of the 1920s-1930s era into his literary dialect, the question remains as to what purpose does this additional 'Fluellenised' speech serve? Is it an intertextual attempt to render an 'archaic' form of WE? A version of WE that Goodwin knows was used by older dialect observers like Shakespeare and his contemporaries? Some of the above respellings do suggest eyedialect (e.g. pheasants spelt with an initial $<\mathrm{f}>$ ), although it is more evident in respellings such as 'jentlemens' [gentlemen] (p.4) which is used in $3^{\text {rd }}$ person narration.

The chief literary dialectal 'invention' Goodwin developed in Heyday is 'intonation hyphenation', an orthographic effect that appears to index the intonation of speech, in this case WE and its well-attested rise and rise-fall tones ${ }^{17}$. As previously seen with Margiad Evans, this term is often highlighted by laymen as 'sing-song' and Goodwin also metalinguistically comments upon this: 'Evan went on in a sing-song, his voice rising in ecstasy' (p.240). In dialogue, Goodwin achieves this by separating two-syllable words using a hyphen, to indicate the rise and stop of one prosodic part and signal the beginning of another, likely falling tone. The following is a list of such renderings: 'wa-at' [what?] (p.9), 'min-nit' (p.10), 'ska-tair' [scatter] (p.15), 'torrants' (p.39), 'li-aar' (p.42), 'ke-eatt' [cat] (p.57), 'com-ik' (p.78), 'men-shun' (p.107), 'work-ahs' (p.109), 'ven-jance' [vengeance] (p.111), 'assh-ure' [assure] (p.116), 'spontan-tantiety' [spontaneity] (p.163), 'vick-tory' (p.216), 'quest-yan' (p.220), 'eck-splore' (p.220), and 'po-ets' (p.221). Evidently, there is also an eyedialectal element to these respellings, e.g. Goodwin respells vengeance as ven-jance. Is this necessary? Might reader resistance have occurred had the spelling been vengeance?

\section{Shonihois and English Border dialects}

This final section addresses the other minor varieties Goodwin utilised. The first is

\footnotetext{
${ }^{17}$ It bears similarity with Malin (1965)'s discovery of Al Capp's hyphenated polysyllabic stress in the Li'l Abner comics (see 3.4.)
} 
the variety of the pessimistic 'Shonihoi' colliers. Although their speech is similar to Tanygraig on-page, it is implied it differs: 'their ways, their talk, their dress were all different. "Down South" was another world' (p.107). Whereas Tanygraig inhabitants are represented using the phonetic respelling: 'pugair' (see above), the Shonihois distinctly use 'pugah' (and 'murdah'), suggesting the vowel final in 'bugger' - /ə/ rather than the diphthong /ea/ ('pugah' is then effectively eye-dialect). Initial glottal fricative $/ \mathrm{h} /$ is also dropped in 'home' and they do not use voiceless consonants for /d/ - producing 'damn' rather than 'tamn.' Lexically, they also use the first usage of the vocative expression 'mun' in WE literary dialect: "Thirty-three years of it, mun", a feature no 'Tanygraigians' use, opting for 'man' instead. The SAWD notes this usage is common throughout south Glamorgan and Gwent.

Meanwhile, the Foxhunter character Ned Jarman is described as a 'border character', Goodwin meaning from 'the English' side of the border, and speaks distinctly from other characters. Jarman uses 'thee' for the possessive pronoun 'your' as well as second person singular 'you', as well as its contraction 'thee art/thee' $t$ ': 'Haud thee breath. Thee't a damned sight less need of it, though, than that thing thee't on' (p.138). 'Thee' and 'thee art' both occur in Radnorshire according to the $S A W D$, but only as second person singular (i.e. you), with 'thy' in place of the possessive 'your'. Jarman also uses present tense negative 'inna' and 'dunna' for 'I'm not' and 'I don't' (e.g. "“I inna roamin' into six shot for thee or thee betters"”, p.152; “"Them folk dunna like that sort o' welcome",, p.153), both match similar forms recorded in the SAWD for Radnorshire: 'have not': 'hanna' (also for auxiliary verbs, e.g. can't, 'canna'; mustn't, 'munna'). Jarman also uses 'you'm' for 'you had': ‘“'you'm best leave well alone. (p.153), a similar form appears for Radnorshire in the SAWD: 'you'm' and 'they'm', although these relate to 'I am/be' rather than 'had'. Lexically, Jarman uses 'pissabeds' (p.176), a quintessential borders term for 'ants' common in Monmouthshire, Glamorganshire, Cheshire and Shropshire. It should be stressed that Jarman also shares features in common with speakers from Tanygraig such as emphatic denial (“Well I never", p.174) and loss of initial /w/ in 'woman' (“"Where's the 'ooman?", p.174), thereby suggesting that features of both varieties of English borrowed elements from one another. In all, Goodwin provides a varied description of the several WE varieties throughout the borders. 


\subsubsection{Lewis Jones's Cwmardy (1937)}

Lewis Jones (b.1897-1939) was born in the mining community of Clydach Vale, Rhondda. Jones was known to challenge political conventions; he attended the Central Labour College, where he joined the Communist Party in 1923, and was the leader of numerous hunger marches. However, Jones was jailed for three months in 1926 Great British General strike for rallying strikers in Nottinghamshire. After, he returned to South Wales and held several leadership posts within the South Wales Miners Federation (Knight, 2004:85; Francis, 2010). Smith (1982) argues that it was his experiences at the mines that led him to writing fiction, as it helped Jones make sense of his community's being (p.23).

Jones set out to write 'short-realist stories' about colliers with Cwmardy (1937) (Knight, 2004:85), it was the first of Jones's two novels, and concerned the political events surrounding Tonypandy from 1900 until the mid-1930s mining strikes. Although the protagonist Len Roberts is a man too physically weak for mining, he has a studious drive (Knight, 2003: 70-71). Despite being considered a 'leftist classic' (Knight, 2003:71), the text was not well-received by all, with Mathias (1987) describing it as a 'wooden [attempt] to depict working-class history' (p.88) and literary critic Frank Kermode described it as 'naïve and clumsy' (Knight, 2003:71). Jones's Cwmardy signals the end of literary depictions of the early $20^{\text {th }}$ century mining and rural communities, indeed with the 'first-flowering' concluding with the advent of the Second World War.

Lexis

Lewis Jones used a number of familiar Cymraeg loans as his contemporaries, for example: 'mam' (p.6), endearments 'bach' and 'fach' (p.4,p.15), 'ach' (p.22), 'nghariad/cariad' (p.52) and 'eisteddfods' ${ }^{18}$ (p.259). The text also features some Cymraeg loans that had not been used since Raine's 1902 writing such as: 'cawl'[soup] (p.6), an exclamative for 'god!') 'duw' (p.10), and 'crot of a boy' (p.21).

New Cymraeg loan additions comprise of an exclamative 'muniferni' (p.7) [for

${ }^{18}$ Notice its hybridised English suffix ending. 
god's judgement]; the adjective 'twp' [foolish] (e.g. "“I might look a bit twp to you beggars"', p.19), attested in SAWD in Dyfed and West-Glamorgan; 'fenyw' [GPC: woman] (p.42) used vocatively; and 'dyn jawl' [devil man] (p.226) comprised of dyn [man] and 'jawl' a phonetic respelling of 'diawl' (according to Weng., alveolar plosive /d/ may in South Wales become an palate-alveolar affricate /dz/). Complete Cymraeg dialogue is used in Jones's work as well, much the same as it was in Goodwin. Some have been featured before in previous WE literary dialects, for example: 'arglwydd mawr' ['Great lord'] (p.21) that appeared in Goodwin's work, and 'nos da' [good night] (p.12), 'merch-i' (p.120), and 'uffern dan' [fiery hell] (p.307) that all appeared in the work of Raine. New additions are 'shoni cap-du' [Black cap Shoni] (p.112), and 'duw's annwl y byd' [God's beloved world] (p.213)

Jones's non-Cymraeg derived lexis features previously attested forms such as vocative 'mun' (p.18), the wide-ranging 'mitching' [truanting] (p.30) (see Goodwin above), 'whiff' [cigarettes] (p.120) (also Goodwin), and a variation of 'indeed to goodness': 'sure to goodness' (p.264).

Newer forms can be divided into two categories: forms that are attested in records and forms that do not appear. The three forms that were attested in the $S A W D$ are 'butty' [workmate] (p.7), common throughout South Wales and English borders, possibly from 'to play booty', i.e. sharing plunder with friends; 'tommy' (p.149) for meal taken to work (Radnorshire and Monmouthshire); and 'black pat' (p.389), a noun for the domestic beetle, used in Dyfed, Powys and mid-Glamorgan. 'Poor dab' (p.114), is an attested phrase in Weng. to signify pity or sympathy for a person (i.e. dab). Three terms matched EDD records. 'Babby' [baby] (p.66), was present throughout northern English dialects and adjacent Herefordshire, Gloucester, Devon and Cornwall. Furthermore, two mining terms: 'gobs' (p.115) for a part of a mine from which coal has been removed; and 'collars' (p.306) that was defined intratextually as 'cross-timber'.

Another in-text mining term, attested in $O E D$, is 'shots' for holes bored in the rock for blasting-charges. In the text, Jones uses it alongside 'rippings' which is intratextually defined as the 'clear-cut roof' (p.143), though this second term does not appear in records. Other colloquial terms the $O E D$ illuminates are 'to stop' for 
'visit' (e.g. 'stop at home', p.337) which is supposedly borrowed from U.S. English; 'fair play' (p.94) a British phrase for appreciation or respect; the shortening 'bacca' [tobacco] (p.153), and 'jack-booted' (p.344), a strong boot with the top reaching above the knee.

There are six lexical items that do not appear in surveys. The verb 'to lose' is used for truanting: "I cannot understand why Len loses school to often"' (p.29), which suggests some synonymy with 'to miss'. There is also the adjectival compound 'bigeating' (e.g. 'a big-eating man', p.91) for greedy, demonstrating gerund formation; and a verbal compound 'deal special' (p.44) for 'to give special treatment': “'do you 'spect the deacons will deal special with you?"'. They share characteristics of Caradoc Evans' usages, possibly suggesting unique forms being used by an L2 English speech community. Bear in mind also that these forms occur early in the novel (which spans several decades) during the language shift from Cymraeg to English. Coupled with the word, 'pewmonia' [pneumonia] (p.113), which gives the impression that the speaker has misread the word, it is possible that Jones was representing speakers' idiolectal usage of English, and the above forms never had large currency. Chronologically later 'unknowns' such as 'swank' (p.381), a verb for 'gossip' (cf. Goodwin's use of 'swank' to mean fanciful), and 'barry' (p.381) a diminutive genericism like 'a john' or 'a joe' (these are more rooted in English language tradition).

\section{Grammar}

Like authors before him, Jones uses nonstandard subject verb agreements for present tense indicative, such as copula 'be' for 'am/are': “"What be you waiting for, dad?" (p.4), that although occurs largely on the borders, has been recorded in the South. He also uses a common British English demonstrative determiner 'them' rather than 'those', similar to Jack Jones: "“Them were the days"' (p.42). Jones also uses the first person plural object (i.e. 'us') in the position of the subject (similar to Dillwyn): "“If us all tell the truth"' (p.115).

Cwmardy introduces several new forms to WE literary dialect, many which will be familiar even to today's speakers of the variety. 'Habitual do' (a feature of Glamorgan, Monmouthshire, Montgomeryshire and Radnorshire: SAWD) where the 
auxiliary 'do' is used to express habitual or continued action, makes its first appearance. For example, “Mam do make it good" (p.6), "I do make supper for you"' (p.15). Another feature which arguably has a degree of enregisterment today ${ }^{19}$, and one that the $S A W D$ noted was widespread throughout South Wales, is the adverbial phrase 'by there' for 'there', for example: "'all the colours in the world by there, dad" (p.8). Another common element introduced is treating past-tense irregular verbs with regular inflectional suffixation, a feature widespread throughout Monmouthshire, Montgomeryshrie, Breconshire, Pembrokeshire, Radnorshire and Glamorganshire. For example, 'I knowed' [knew] (p.35), 'I broked' [broke] (p.144). The discourse marker 'like' is also used (specified in Weng.), e.g. "“Shut your eyes quick, like"".

\section{Pronunciation}

Much like Jack Jones, Lewis Jones also incorporates numerous clippings, several of which shares qualities of allegro speech. Here are several: ' $m e m b e r '$ [remember] (p.5), 'in't' [isn't] (p.6), '’uns' [ones] (p.9), 'spose' [suppose] (p.9), ''bout [about] (p.9), 'specting [expecting] (p.12), 'sylum [asylum] (p.21), and 'scursion' [excursion] (p.41).

Other familiar phonetic respellings are the omission of initial approximate /w/ (e.g. ''ooman' [woman], p.15; and ''on't [won't]), rendering medial vowel /3:/ as /e/ (e.g. 'gel' for 'girl', p.21), replacing word initial voiced palato-alveolars with voiceless palato-alveolar fricatives (e.g. Jenkin as 'Shenkin'; Germans as 'shermans'), and mimicking Caradoc Evans's usage of using voiceless alveolar fricatives as voiceless palato-alveolar fricatives (e.g. 'mister' as 'mishter', 'his majesty' as 'hish majeshty'). Phonetic respelling first-attested with Jones include the medial insertion of a bilabial plosive in 'famblies' [families] (p.94), using a voiceless labiodental fricative /f/ in place of a voiceless dental fricative / $\theta$ / in 'fief' [thief] (p.226), and the omission of voiceless alveolar approximate /1/ in 'sodgers' [soldiers] (p.264). Although the first two forms are not attested in $S A W D$, lack of /1/ medially were recorded in words like 'shoulder' and 'colt'. Finally, Jones employed minor eye-

\footnotetext{
${ }^{19}$ John Edwards's first edition of Talk Tidy features a satirical cover featuring a cross-roads signpost with several directions all pointing towards a variation of 'by there'.
} 
dialect for both 'agen' [again] and 'federashon' [federation], both of which suggest a similar phonetic rendering as Standard English.

\subsubsection{Lynette Roberts's Village Dialect with Seven Stories (1944)}

Like Margiad Evans before her, Lynette Roberts was not brought up in Wales. However, she came to appreciate its culture, its people, and its linguistic dimensions in a way few other creative writers had. Born (1909-1995) in Buenos Aires, Argentina, of Welsh-Australian descent, she married the Welsh poet Keidrych Rhys and moved to Llanybri, west Wales (McGuiness, 2009:1). Roberts lived in Wales for fifteen years, with those years coinciding with her literary career, choosing not to follow it further after the 1950s (p.3). For such reasons, some literacy critics have wrestled with the notion of Roberts being classified as an 'Anglo-Welsh' writer at all (Davies, 2003:152).

Although Roberts's most-famous work was the epic poem, Gods with Stainless Ears (1955), she evidently had wide-ranging interests beyond poetry. She wrote essays on renaissance art, modern farming, Welsh architecture, the history of coracles, and, central to this thesis, the WE dialect (McGuiness: 2009:1). Her short pamphlet Village Dialect with Seven Stories is both a historical treatise on historical WE users of the past, as well as a collection of then-contemporary short-stories that incorporated dialectal material she recognised from speakers around her. For a literary writer, Roberts's metalinguistic awareness of the dialect was acute (a trait following authors will share). Unfortunately, her contributions to WE studies have been largely forgotten.

The contents of Roberts's essay are its own matter, certainly distinct from this thesis' scope, however some points shall be noted. She acknowledged that many surveyors of English literature had largely ignored Welsh contributions to English writing; and that the impact that writers' L1 Cymraeg had had upon English translations may be evident in their writing (she cites Bishop Asser, and writer Layamon as examples) (Roberts, 1944:5). This trend continues. She argues furthermore that Elizabethan prose written by Welshmen had noticeable 'syntax or idioms' that were similar to WE of her day (p.12). Although Roberts's does indeed match some forms with forms that cropped up in Parry's $S A W D$, such as Demonstrative There and Indefinite article 
in mass nouns, there is much that Roberts believes is WE, yet either does not match records (suggesting idiolectal usage) or is attested over a larger area than she believes. Nevertheless, Roberts's work is a pivotal example of independent research of the dialect and its application within the literary sphere. The contents of the latter to be discussed below.

Roberts included seven stories in her collection, all of which function to illustrate application of WE dialect. Each story focuses on a different domain of Welsh life, and therefore provides us with different speech communities. The stories are titled Fox, Tiles, Steer, Graveyard, Pub, Swansea Raid, and Fisherman.

\section{Lexis}

The community that is marked most distinctly are the all-male speakers in the story Pub, who use the endearment term 'bach' (p.22) numerously, coupled with the vocative expression 'mun' (p.23). Roberts uses 'whist' which may be a variation of 'heisht' a non-lexical directive similar to 'sh' or 'hush', previously noted by Dillwyn (1880): “"Whist, I expect the young ones could do it"” (p.17). A variation of 'merch-i' for daughter is used in 'merchan fach', i.e. 'little lady': “'Here merchan fach, this is for you"' (p.18). Roberts also uses some new Cymraeg loans. 'Cwtch' a verb and noun for 'cuddle' (SAWD: widespread throughout mid and south Wales), which, although certainly a very enregistered WE form today, makes its debut inwriting in Roberts's Fox. It is used in reference to fox-cubs nestling with their mother; a sense that is also attested as being used for other canines such as domesticated dogs. Teulu, Cymraeg for family (GPC), is also used (p.20), as well as a dual-language compound: 'Ty-bach buckets' (p.23), where the English language head is modified by the nominal Welsh Ty-bach [outhouse] (lit. Little-house), already a Cymraeg compound.

English origin words include the familiar affirmative 'ay' (p.20), and several new usages. 'Pele' (with italics) is used but with an uncertain sense. Take for example, in Tiles: 'plastering the grate right up to the top with pele' (p.18) and in Steer: 'the bowl of pele rested on her hip' (p.19). The sense appears to be a paste or substance that can be pasted or stored in a bowl. Neither $S A W D, E D D$, or $O E D$ offer possible senses, although the term could be related to an older orthographic form of 'peel', as in rind 
and juice. The idiomatic phrase: 'the earth has a good heart to care for' (p.20), likely meaning the earth consumes animal, or human, cadavers, is also absent from record. Finally, Roberts uses 'rise' in the sense 'raise' or 'take away' in: "'I'll rise the ashes"' (p.19). This precise syntax is attested in Weng. and GOW; Lewis (Weng.) notes it is a translation from Y Ddyfedeg dialect of Cymraeg: 'cwnnu'r llutu'.

\section{Grammar}

The one striking grammatical element Roberts uses is the female personal pronoun for a ungendered English noun, a feature attested in the SAWD (and one Shakespeare and contemporaries used often). Note the following: "'She doesn't look very well the broccoli, I mean"' (p.19). The SAWD records third person singular object 'her' as being the form, here we have the objective usage.

\subsubsection{Summary}

The First Flowering was a period in which WE literary dialect advanced in many forms. Caradoc Evans fueled controversy in taking the notion of 'dialect artist' to a new level - deliberately creating a satirical 'inauthentic' portrayal of the variety, whilst Margiad Evans was the first English-born writer to represent the WE dialect of the border regions, capturing a region where linguistic loyalties were a complex matter. Similarly, Goodwin's work conveyed this linguistic complexity further, rendering several local varieties of Border English in one novel. Further south, coalfield authors such as Jack Jones and Lewis Jones created literary dialects that offered the first insights into the speech of Valleys mining communities and the language shift from Cymraeg to English. Finally, Lynette Roberts, another nonWelsh writer, considered herself a dialectologist, and illustrated west Welsh linguistic forms through a collection of short stories.

\subsection{Late $20^{\text {th }}$ and early $21^{\text {st }}$ century novels and 'The Second Movement'}

The most-recent period of Welsh writing in English has been termed by critics as 'The Second Movement', as well as the 'Integration era' (Knight, 2004:119). Subject matter moves on from an Industrial Wales to a post-Industrial viewpoint, that encompasses themes from throughout Wales's population, history, and connection with the Fantastic or Mythic. Characters are often reflective and texts are often first- 
person narrations. Thus, authors provide readers with more 1PN metalinguistic observations of the Wales their characters live in. There are fewer attempts by authors to represent dialect as it exists in the real-world, often limiting literary dialect to vocabulary. That is not to say what is represented does not 'match' records', rather that the narrative domains in which authors choose to use WE literary dialect are minimalised.

\subsubsection{Dylan Thomas's Under Milk Wood (1954)}

Without doubt, Dylan Thomas (1914-1953) may well be the most-recognised Welsh writer of English. Born in 1914 in Swansea, he grew up speaking English, knowing little Cymraeg. Despite both parents being Cymraeg-speakers hailing from west Wales, Thomas was educated in English. His father was a grammar school English master and there is reason to believe he 'suppressed' his son's native tongue, so much so that he also erased 'the bogey of a Welsh accent' from Thomas's English dialect through elocution lessons (Davies, 1972:4). It has also been argued that the unsuccessful career of Dylan's Cymraeg-speaking poet uncle, spurred him into writing exclusively in English (p.5). Mathias (1987) even suggests that Dylan's writing reveals Thomas had 'a completely English field of literary reference' and that he obtained 'a dislike, even a hatred, of Cymraeg-speaking Wales and his ancestry in it', choosing London (and later NYC), the land of his literary heroes, over Wales (p.84).

That said, Thomas, favouring small coastal towns, spent much time in the coastal Welsh village of Laugharne both before World War II and after. It was here that he wrote his most-famous work, Under Milk Wood (1954); it took over ten years to refine, completing it just a month before his death (Jones, D., 1992:vii). The work ${ }^{20}$ is set in the fictive (almost comically mythical) Welsh town of Llareggub. The townname, a reversism of 'buggerall', plays on the Welsh orthography of double $<\mathrm{L}>$. D. Jones (1992) describes its people as being 'eccentrics strong in their individuality

${ }^{20}$ Under Milk Wood is the only Welsh written English theatrical play analysed in this thesis (Chapter 6 addressing English written Welsh themed plays). Its inclusion here is on account of D. Thomas's international renown for the work, which has been published since 1950s. 
and freedom,' and 'sane [people] who sacrifice everything to some notion of conformity' (p.vii). Llareggub's world has been described as an 'elegiac cartoon of Welsh life' (Davies, 1972:2), and with Thomas '[putting] a premium on word and phrase intricacy and inventiveness at the possible expense of overall meaning and message' (Mathias, 1987:83).

Because of Under Milk Wood's universal popularity, it should come as little surprise that the linguistics of Thomas's writing have been partially addressed in varying means by scholars, and this thesis follows suit in addressing Thomas's literary dialect, although Thomas is largely unremarkable in these terms. D. Jones (1992)'s preface (first-written in 1974) provides insight into the literary critics' perceptions of language usage in Thomas's work. He first writes that should 'Under Milk Wood fall into the hands of a Welsh philologist ${ }^{21}$, it must be made clear that the language used in Anglo-Welsh' (p.x). D. Jones's acknowledgement of Thomas's use of WE variety is encouraging, even if a great many other writers had achieved this accolade before Dylan Thomas. Furthermore, D. Jones's observance of this dialect prompted him to construct a paratextual guide for readers unfamiliar with Cymraeg and 'AngloWelsh' phonetics which can be found in the edition's appendix. This 'note on pronunciation' is typical of layman's attempts of describe language processes. Rightfully, it does contain some of the phonemes prevalent in WE (e.g. Cymraegderived phonemes), however, the list also includes lexical items. Nothing is mentioned of Dylan Thomas' use of grammar. This interpretation of 'AngloWelsh'/Welsh English as simply the 'Welsh accent' seems absolute. There is no 'dialect' of WE, simply a Welsh accent.

Contrast this with biographer W. Davies's analysis. Earlier in his career W. Davies (1972), asked whether, within Anglo-Welsh works like Dylan Thomas's, there still existed a 'radically Welsh mode of thought or sensibility' [...] 'beyond the Anglicisation of a second generation' (p.8). In a 2000 edition of Under Milk Wood, W. Davies wrote its preface and appendix. Although the appendix does not answer W. Davies's arguably philosophical question, it does contain more linguistic analysis

\footnotetext{
${ }^{21}$ What D. Jones means by 'philologist' is uncertain. Jones appears to conflate the sub-field of philology with the field of linguistics, therefore we can assume he means the sense of linguist (if not sociolinguist or dialectologist).
} 
of some of the Anglo-Welsh lexis that Thomas used, some of which will be replicated and/or discussed below.

\section{Lexis}

Cymraeg loan lexis that had been used formerly by Dylan Thomas's predecessors include the expression of disgust 'ach y fi' (p.8) (and the shortening 'ach', p.56), 'cawl' (p.63), and endearment term 'fach' (p.88). The phrase 'playing mwchins' (p.13) in the sense of 'messing around' has some contestation. D. Jones (1992) suggests in the play's appendix that it is 'a compromise between the English "mooching" and the Welsh dialect word "mitching", playing truant' (p.91). By Welsh dialect word, Jones is likely referring to a 'Welsh English' word, because 'mitching' is not of Cymraeg origin; furthermore both 'mitch' and 'mooch' share common lexical etymologies, being variants of 'to lurk' or 'to be absent' $(O E D)$. We can at least confirm that the sense would match $S A W D$ records throughout South Wales. However, W. Davies in his edition's appendices argues that the word is from Cymraeg $^{22}$, and that the sense is more explicitly: 'playing dirty', with the connotation of naughty sexual games' (p.69). W. Davies also argues that it is from the Welsh 'mochyn' [pig]. Two traditional Welsh musical instruments are introduced in Under Milk Wood, the 'crwth', a fiddle (OED), and the 'pibgorn', a hornpipe (OED), alongside the term: 'parchs' (p.22), that Jones paratextually defines as 'clergymen' (p.91) and that the $O E D$ verifies.

W. Davies makes the point that one phrase is a Swansea dialect 'corruption': 'no my never' for 'no I never' (p.4), although this matches no record. W. Davies also attributes the substitution of 'of' for 'have' in 'never should of married' as a Swansea colloquialism. This is arguably a common orthographic substitution throughout the Anglophone world. Thomas introduces an attested SAWD feature 'learn' for 'teach', e.g. 'Learn him with a slipper on his b.t.m. (p.13), common throughout Monmouthshire, Glamorgan, Powys, Clwyd, and Gwynedd, as well as being recorded throughout England in the SED. Thomas introduces a number of Englishderived lexis, for example the compound 'six-penny hops' (p.8) that W. Davies

\footnotetext{
${ }^{22} \mathrm{~W}$. Davies alters the orthography to 'moochins' to suggest a held vowel (/u:/) rather than a layman reader's potential semi-vowel /w/
} 
defines as 'weekend dances in village halls', the phrase 'singing in the w.' (p.11) defined as 'singing in the w.c.', and a shortening 'peke' (p.16) for a Pekinese dogbreed. Finally, Thomas refers to 'gnat-rain' (e.g. 'it settles on the pie in a thin gnatrain' (p.66). Although this could be an example of Thomas's notorious poetic compounding $^{23}$, the lexeme gnat and sense rain were recently discovered in the present author's 2013 survey of Gwent English as 'gnats' piss' in reference to light rain (Jones, 2013).

\section{Grammar and pronunciation}

There is little to report regarding grammar, and pronunciation. Thomas includes the attested Demonstrative There: “"There's a husband, for you.” (p.10), and “"There's a lovely morning"' (p.31). He also makes a metalinguistic reference to the attested initial glottal fricative omission, or 'H-dropping', which occurs in dialects of South Wales. For example, Gossamer Beynon stating: "II want to gobble him up. I don't care if he does drop his aitches" (p.64). Indeed, textual characteristics like commentating upon language usage will be a feature of this period.

\subsubsection{Glyn Jones's Island of Apples (1965)}

Glyn Jones was born in Merthyr Tydfil (1905-1995), to a Cymraeg-speaking family. In his early years, G. Jones's was a Cymraeg user, however, the pressures of Anglicisation within the speech community, from both English, Scottish, Irish and Spanish immigrants, as well attendance at an English language Grammar School, resulted in a loss of 'the ability and the desire to speak [it]' (Norris, 1973:1). Although G. Jones would return to speaking his native tongue in his twenties (Hooker, 2001:8), he left Wales to train in England as a teacher, before then moving back to the southern Welsh valleys (Norris, 1973:3).

Like Caradoc Evans, G. Jones has been described as a 'word-man', having a passion for lexical history and formation. However, Jones's writing was characteristic of a post-Caradoc age in that his themes, although 'industrial, were more 'supernatural' (Mathias, 1987:83). G. Jones has also been described as the forebear of the third

${ }^{23}$ Farringdon (1982) discovered an impressive 204 hyphenated compounds and 47 unhyphenated compounds in Under Milk Wood. 
stage of Welsh writing in English, a literary movement that focussed on 'integration' of Welsh life: advocating writing in both Cymraeg and English (Knight, 2004:120). G. Jones was inspired by both Charlotte Guest's translation of the Welsh mythic canon known as the Mabinogion, and the tales of King Arthur (Humfrey, 1992:vii). His life as a schoolteacher gave him direct access to the world of children's imagination and their language usage (p.xii). His most-known novel, Island of Apples, encompassed many of these themes; and was set in the time following the Industrial Revolution, but before the exodus of the 1930s that saw valley communities crumble (p.xii). The novel focuses on the adolescent Dewi Davies and his fascination with an exotic European stranger, Karl Anthony, who although exists in reality, is fabricated into a mythic hero by Dewi's wild imagination (Norris, 1973:53-54).

Regarding G. Jones's language use, Norris writes:

In the Wales of Glyn Jones's vision, the language of the town is always English, a vigorous and colloquial English may be, and sometimes enriched by an exotic [Cymraeg] word or construction, but English. Apart from the energy and invention of the writer's own ebullient style, it is recognisably the language of the Taff valley. Norris, 1973 (p.8)

From the 1992 edition onwards, G. Jones provides readers with a paratextual glossary in the preface. There are 35 paratextually-defined forms divided between italicised and unitalicized words. Most of the italicised words are Cymraeg loans, therefore suggesting they may be uncommon to non-Welsh readers, whilst the nonitalicised are of English language origin (see Table 8). Despite this, much like Raine's glossary attempt, there are several in-text Cymraeg loan words that do not appear in Jones's paratext glossary e.g. bach, fach, mamgu, hwyl and duw. This may be because previous Anglo-Welsh authors had used these lexes so often that they had a sense of enregisterment for readers. That said, the unparatexted cariad annwyl seems like an outlier to this possibility. There are also several unfamiliar AngloWelsh dialect words that were not listed in the paratext too such as: rodneys, moithering, and wit-wat. We must remember that this was an additional reader-aid provided for a new edition, and despite these missed lexis, G. Jones was an accomplished laymen observer of lexical dimension of the WE variety, as we will see below. Lexis that have been paratextually referenced have attached asterisks $\left(^{*}\right)$ 
followed by Jones's paratextual definition in square-brackets.

Table 7.8: Reproduction of Glyn Jones 's paratext (Jones, 1992:xxxiii-xxxiv)

\begin{tabular}{|c|c|c|}
\hline \multicolumn{3}{|c|}{$\begin{array}{c}\text { Glossary of Welsh words and phrases and Anglo-Welsh dialect forms appearing in } \\
\text { the text } \\
\text { (supplied by Glyn Jones) }\end{array}$} \\
\hline 8 & gwli & a narrow passage between buildings \\
\hline 9 & clecking on & telling tales about \\
\hline 12 & $\operatorname{ach} y f i$ & an expression of disgust \\
\hline 13 & niff & an offensive smell \\
\hline 16 & gambo & a two-wheeled farm cart \\
\hline 21 & drovers & woollen long johns for men \\
\hline 23 & cwtch & nurse, hug \\
\hline 32 & sash & $\begin{array}{l}\text { a cummerbund sometimes worn by } \\
\text { young colliers with their afternoon } \\
\text { suits }\end{array}$ \\
\hline 36 & sâm & liquid fat \\
\hline 38 & $w f f t$ & $\begin{array}{l}\text { an expression of impatience and } \\
\text { contempt }\end{array}$ \\
\hline 38 & ganzy & a jersey or pullover \\
\hline 42 & gammy & imperfect \\
\hline 66 & dubs/dubliws & privies \\
\hline 66 & bobbyslops & policemen \\
\hline 69 & mingier & meaner \\
\hline 70 & tuppences & penises \\
\hline 76 & stife & kitchen smoke \\
\hline 80 & $\begin{array}{l}\text { cambrian dash and the welsh } \\
\text { powderhall }\end{array}$ & then famous foot-races, sprints \\
\hline 86 & dukes & fists \\
\hline 104 & bell-oil & beating \\
\hline 113 & bosh & kitchen sink \\
\hline 117 & dix-stones & five stones \\
\hline 118 & not $\mathrm{s}$ & not satisfactory \\
\hline 119 & bobby-greencoat & school attendance officer \\
\hline 137 & ystrydebol & pedestrian \\
\hline 140 & clodges & turves \\
\hline 146 & talu-pump & $\begin{array}{l}\text { bomberino, a team game played by } \\
\text { schoolchildren }\end{array}$ \\
\hline 147 & cochyn & ginger, red-head \\
\hline 148 & oes gafr eto & $\begin{array}{l}\text { title of a welsh folk-song usually } \\
\text { translated as 'counting the goats' }\end{array}$ \\
\hline 157 & yr hen fochyn & the old pig \\
\hline 161 & jibbons & spring onions \\
\hline 162 & cymanfa & a hymn-singing festival \\
\hline 179 & jontomus & pizzle \\
\hline 180 & didoreth & feckless \\
\hline 240 & yorks & $\begin{array}{l}\text { leather straps worn by workmen } \\
\text { below the knees }\end{array}$ \\
\hline 251 & tir na n'og & (irish) the land of the young ones \\
\hline
\end{tabular}


Lexis

Cymraeg loan words that are incorporated into Jones's literary dialect, and had previously been attested by prior authors, include: 'mam' (p.11); 'ach-y-fi'* [*Expression of disgust] (p.12); 'cwtch'* [*nurse, hug] (p.23); the endearment terms 'bach' and 'fach' (p54, 139); exclamative for God, 'duw' (p60); and the terms for good-spirits ' $\boldsymbol{h w y l}$ ' (p.66); and 'cochyn'* [*red-head] (p.147). Both the latter terms have previously appeared in just Goodwin's Heyday (1936).

Jones included a large number of loans that had not previously been used in WE literary dialect. The lexis that match $S A W D$ records follow. 'Gwli'* [*narrow passageway between buildings] (p.8) is attested in the $S A W D$ (mid-Glamorgan) as 'gully' a 'dry-stone enclosure', in the $E D D$ as 'deep ravine' or 'ditch', in the GPC specifically as a 'narrow-passgeway'. The form was also present in the present author's 2013 survey of Gwent (Jones, 2016) for 'alleyway'. 'Sâm’* [*liquid fat] (p.36) was recorded in Dyfed with the similar sense: 'scraps left behind after rendering pigs lard'. 'Bwbach' (p.95), a Cymraeg word for scarecrow, was confirmed throughout west and south Glamorgan, as well as Dyfed. Finally, 'mamgu' [child's term for grandmother] (p.155) was also verified in Dyfed.

Loaned Cymraeg lexis that were not present in the $S A W D$ follow. The interjection

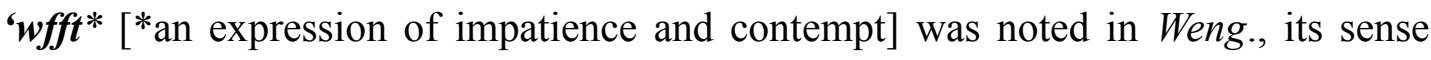
being 'for shame' and noting it is 'from [Cymraeg]'; when cross-referenced with the $G P C$, we find the analogous sense: 'reproach' or 'disapproval'. Predicative adjective 'ystrydebol'* [*pedestrian] (p.137) (e.g. in the synonymic chain: 'so ordinary and common and ystrydebol) should parse readers with a synonym for 'common', even if Jones's paratextual definition 'pedestrian' is not semantically transparent, with the $G P C$ defining the term as 'stereotypical, cliché-ridden'. The attributive adjective 'Didoreth'* [*feckless] (p.180) (e.g. I found her a pretty didoreth housekeeper'), was noted in Weng. as having the characteristics of 'slovenly in household duties' and that it is no longer common; it is defined in the GPC as someone who is 'unmethodical' or 'shiftless'. Then, cymanfa* [*a hymn singing festival] (p.162) is noted in Weng. as 'a [Cymraeg] hymn-singing festival' and in GPC as a 'congregation'. 
The remaining Cymraeg loans are not attested in any Anglo-Welsh dialect report, though can be deduced from the Geiriadur Prifysgol Cymru. Talu-pump* [*bomberino, a team game played by schoolchildren] is derived from the Cymraeg 'to repay five'. Jones's term 'bomberino', meant to validate this Welsh version of the childhood game, also does not match any lexicographic records. Fully Cymraeg syntactic structures, that suggest perhaps elements of code-switching rather than loaned phrases, include: 'oes gafr eto' ${ }^{\text {** }}$ [*title of a [Cymraeg] folk-song usually translated as 'counting the goats'] (p.148), 'yr hen fochyn'* [*the old pig] (p.157), 'croeso, croeso 'nghyfellion i' (welcome, welcome my friends), and the endearment term 'cariad annwyl' (p.194) (dear love). Jones also include an Irish Gaelic term for the underworld, 'Tir na n'og' [*Irish, the land of the Young Ones] (p.251), in italics.

G. Jones uses several anglicised lexis that other authors have used previously. Jones chooses to define one of these terms: 'gammy'* [*imperfect] (p.42), a term previously used by Goodwin in the sense 'crooked' or 'bent' throughout Monmouthshire and Glamorgan. Others include familiarities such as 'tidy', e.g. "“I never smelt anything that tidy to eat there"' (p.10); the phrase 'fair play' (p.24) and the plural noun 'butties' [friends] (both used before in Lewis Jones's Cwmardy); affirmative 'aye' (p.60); vocative use of 'mun' (p.60); and interjection 'fly-me' (p.78) used previously by Jack Jones in Black Parade. At this point in the history of WE literary dialect, we can see how G. Jones's work validates many of the other usages, perhaps suggesting enregisterment for particular forms.

There is, however, a wealth of lexical material that G. Jones introduces; and, of the twenty-one new terms, he paratexually defines nine for the reader (listed below). 'Cellar-niff'* [*an offensive smell] (p.13) contains the head 'niff' which is a colloquial British term for 'disagreeable smell' (OED). 'Gambo'* (p.16) is defined by Jones as a [*two-wheeled cart], this indeed matches several senses obtained by $S A W D$, including: a 'cart without wheels' (in Gwynedd, Powys, west and mid Glamorganshire, and Gwent), and a 'farm wagon' (in Powys, Dyfed, west Glamorganshire and Gwent). Note that it is also italicised by G. Jones, suggesting either he thought the term to be of Cymraeg origin, or was significantly infrequent to the majority of British English readers. The OED notes that it is an especial WE 
regional word, being found in adjacent Herefordshire too, however its etymology remains unknown. 'Ganzy'* [*a jersey or pullover] (p.38) was attested in the SAWD in Dyfed and west Glamorgan as 'gansey', a thick jersey, possibly from 'guernsey'. 'Stife'* [*kitchen smoke] (p.76) was recorded as 'suffocating heat' in Glamorgan by the $S A W D$, and defined as 'suffocating vapour, esp. fumes' by the $E D D$ in Pembrokeshire and north England. 'Bosh'* [*kitchen sink] (p.113) was recorded in the $S A W D$ as 'wash-basin', and present throughout Glamorganshire and Powys, whilst 'jibbons'* [*spring onions] (p.161) was recorded throughout Dyfed, Glamorganshire and Gwent. 'Yorks'* [*leather straps worn by workmen below the knees] (p.240) is common throughout north Wales, west Wales, Glamorganshire and Gwent, with the $S E D$ reporting usage throughout mid and north England. 'Clodges'* [*turves] (p.140) is also attested in mid Glamorgan: 'cut pieces of grass' or turf $(S A W D)$. 'Dukes' [*fists] is a slang term for the hand or fist $(O E D)$. Also, 'Cambrian Dash and the Welsh Powderhall'* [*then famous foot-races, sprints] were attested social events in the valleys (see, Howell \& Baber, 1990: p.326).

Finally, there are three Anglicised Cymraeg terms that Jones defines that do not suggest their etymological history: clecking* and drovers*. These forms are unitalicised, suggesting Jones was unaware of their origins. 'Clecking'* [*telling tales about] (p.9) is reported in Weng. as an intransitive verb 'to gossip', and is derived from the Cymraeg 'clecs' meaning 'talebearer' $(G P C)$. 'Drovers'* [*woollen long johns for men] (p.21) again is attested in Weng. as 'long underwear', Lewis noting it derives from the Welsh 'drafers', defined in the GPC as 'drawers'. In this sense then, drovers has been borrowed into Cymraeg, and reborrowed back into WE. Although not paratextually defined, 'wit-wat' (p.149) shares similarities with the last two entries in that it likely derives from the Cymraeg 'chit-chwat' (Weng.) for undependable or 'fickle $(G P C)$.

Following are the terms that were not paratextually-defined by G. Jones. 'Rodneys' (p.134), recorded by $S A W D$ in Gwent as a 'rumbustious' fellow and by the $O E D$ as a derogative for an idler in south Wales, Yorkshire and west Midlands. 'Simpled' (p.83) is used for 'bested' (e.g. '[she] had simpled him'), the SAWD recognises 'simple' as an adjective for 'poor, physical health', though the EDD more accurately notes 'to have been fooled' used in various senses throughout England and 
Radnorshire. 'Dai-cap' (p.44) is used for a colloquial term for 'flat-cap'. 'Mingier' (p.69) is used for comparative adjective 'meaner' (e.g. 'she was mingier than ever'); the $O E D$ notes 'mingy' is a noun for a mean person. 'Cribbing' (p.71) is used for the transitive verb 'to plagiarise', which the $O E D$ notes is colloquial, the $E D D$ specifying usage in across England from Cornwall to Yorkshire. 'Ragging' (p.94) is defined as 'to tease' in the $O E D$, with the $E D D$ noting usage throughout southern and northern England, and Scotland. 'Fair-dooz', a British colloquialism $(O E D)$, is phonetically respelled possibly to indicate vowel length, a phonological feature that may not be reader-apparent with the standard spelling's apostrophe usage: e.g. 'fair do's'. 'Jib' (p.11), defined by $O E D$ as dialectal for a 'under lip' or the action of 'hanging the jib' is used thus: "II only asked", he mimicked me, making a jib'. The continuous verb 'moithering' (p.41) for 'to pester' is noted by the $O E D$ as belonging to Irish, Manx, and north and mid-English Englishes, though not Welsh English; although the $O E D$ editors do speculate that it may derive from Irish Gaelic modartha or the Cymraeg mwydro.

The last lexical category then concerns forms that are not attested in any record and may be previously unattested form. The first set following are terms paratextuallydefined by Jones: noun 'sash' ${ }^{*}$ [* a cummerbund sometimes worn by young colliers] (p.32); noun 'tuppences'* [*penises] (p.181), likely euphemistic; noun 'bell-oil'* [*beating] (p.104) (e.g. 'a fat lot we cared about him and his bell-oil and his laces'); noun 'jontomus' ${ }^{*}\left[{ }^{*}\right.$ pizzle] (p.179) (i.e. animal penis), noun 'dix-stones'* [five stones] (p.117), contextually a children's game; adjective 'not s.'* [*not satisfactory] (p.118); and both coinages 'bobby-greencoat'* [*school attendance officer] and 'bobbyslops'* [*policeman] (p.66) contain 'bobby', a British colloquialism for policeman, as modifier, with 'greencoat' being attested as a signifying 'militarism' $(O E D)$. 'Dubliw'* [*privies], finally, is a phonetic respelling and shortening of 'double-you', i.e. a w.c., or water-closet, using the Welsh orthography $<$ iw $>$ to signify the $S A W D$-attested Welsh diphthong: /ru/.

The second set of words match no records, and are not defined by G. Jones, although in several cases the syntactic structure provides some contextual information: 'tea and titty' (p.58) might denote 'tea with milk'; 'crawn' (p.89) could be another phonetic-respelling of 'crone' (e.g. 'the cunning old crawn') suggesting a 
phonological change from /əv/ to /av/; 'tommy-shanto' (e.g. a Scotchy's tommyshanto on her head', p.160) might be a dialectal corruption of the Scottish bonnet: Tam o' Shanter; 'horse-tods' (e.g. 'asleep among the horse-tods in the middle of the road', p.51) could be referring to horse dung, 'tods' being a regional word for 'load of hay' $(O E D)$; whilst the modifier in 'caca-hawk' (p.39) might be onomatopoeic, or might be in reference to 'cack' - excrement $(O E D)$, although neither help us identify its species.

\section{Grammar}

It is no surprising that by the 1960s many of the grammatical structures that G. Jones uses in his work had been previously used by other Welsh writers of English. For example, G. Jones uses Demonstrative There (e.g. “"There's ungrateful, Mr. Davies", p.30) and Focus Fronting (e.g. "“Fell off the roof, must have"”, p.60 and "“Home-made, the wine was, he said", p.85). Habitual do is used too: "CComplete stranger everybody do say"' (p.61); as are discourse markers common to WE such as 'like': "Find him we did, like"' (p.60); and use of first person plural object 'us' in the subject position rather than 'we' (used by Dillwyn, and Lewis Jones too): “"Too true we have. Haven't us, Davy?"' (p.60).

Newly attested grammatical features, both attested in the $S A W D$, include double negativity: "Nobody don't know him"” (p.61) common throughout Wales, and auxiliary have present tense indicative 'he have': “Funny bloke, he've got earrings, aye"' (p.79).

\section{Metalanguage}

Much of the novel is stylised in a way that leaves 'dialectal dialogue' absent, the majority of lexical items coming from the protagonist Dewi Davies's first-person narration (1PN). It is also through Dewi that perceptions on language use are provided. Dewi states that the schoolboys in 5b were 'big show-offs' (p.125), and knowingly used in-group language using terms such as the Spanish loan 'Adios!' [goodbye] and 'kickers' for 'football', G. Jones thereby suggesting a classroom sociolect. In fact, some of the lexis in the unattested category mentioned above, such as the euphemistic 'tuppences', 'bell-oil', 'jontomus', and the variants of 'bobbyslops' and 'bobby-greencoat', could be unattested because they may all be 
sociolectal language of childhood used in the Merthyr of G. Jones's youth.

Without question, G. Jones's literary dialect provides us with much linguistic evidence from the Merthyr speech communities. Though chiefly lexical, G. Jones's contributions and passion for dialect inquiry are unparalleled, not only within Welsh writing in English movement, but in WE literary dialect study overall.

\subsubsection{Ron Berry's So Long Hector Bebb (1970)}

Ron Berry (1920-1997) was born a miner's son in the Rhondda. He left school when 14, working in the mines himself until the outbreak of the Second World War. Following service in the army, Berry took up writing after attending an adult student course (Stephens, 1997). So Long Hector Bebb, a tale of a boxer from Cymmer on the run from manslaughter, was written in the 1960s, and reflects Berry's own stint in the boxing sport. Berry's writing has been described as having both 'verbal power' and 'ironic realism', sustaining the vision of a hardy people through 'the muscular drive of his own language and imagination' (Knight, 2004:178). This is done through Berry dividing the narrative between the first-person accounts of no less than fourteen different characters (Griffiths, 2006:xi). Like Glyn Jones's suggestion of different childhood sociolects of WE and Geraint Goodwin's several border varieties before him, Berry's literary device provides readers with fourteen different idiolects, the majority of those reflecting the foundational variety of south Wales's WE. Indeed, Berry's dialect artistry has been commended by literary critics and writers. Pikoulis (1996) alleges that, with Berry's 'epigrammatic rhythms', rarely had 'the valley subculture [...] received such impressive linguistic demonstration' (p.11). Regarding Berry's sense of authenticity, novelist Niall Griffiths said that he was astounded that a novel was capable of conveying dialogue so faithful to nonstandard speech communities; that their 'rhythms and elisions, their slang, [and] their ungrammatical but identifying linguistics tics' that are so important to a community could be captured with such 'communicative power' (Griffiths, 2010: para 3).

Like, Glyn Jones, Berry is fascinated with the lexical element of his literary dialect. Unlike writers of WE dialect before him, Berry's writing features fewer Cymraeg loans, showing some retracted usage by the 1960s's south Welsh communities. There 
are new loans, for example: 'crachach' (p.180), a pejorative noun that has been used for the Welsh-speaking Elite (Weng.) or 'petty gentry' $(G P C)$; the hybridised 'shwmau there' (p.139) [how're you?] (Weng.); and 'brawd' (p.139) ['brother'] $(G P C)$. However, the majority of Cymraeg loans Berry uses are common to other writers - stabilised loanwords and to some extent enregistered parts of WE dialect. Berry uses exclamative 'duw' [god] (p.52), 'cwtch' [hug] (p.40), expression of disgust 'ach y fi' (p.44), 'hwyl' [good spirits] (p.48), and 'mochyn' [pig] (p.130). Berry also provides variations on the adjective 'twp' for 'stupid' (used before by Jack Jones). The first, 'twpsin' (p.126), is attested in the SAWD in Gwynedd (as 'twpsyn'), whilst the second is unattested: 'twp-witted' [dull-witted] (p.85), a new hybridised compound that uses twp as a modifier.

Other familiar lexis used by Berry, of non-Cymraeg derivation, include: affirmative 'aye' (p.6), 'butty' [friend] (p.14), 'black-pat' [domestic beetle] (p.165), 'to learn' for 'to teach' (e.g. "I'll learn you to drive", p.25), and vocative expression 'mun' (p.210). 'Tamping', used previously by Goodwin in the verb sense 'quick moving', is used adjectivally in: 'Tamping left-handers blurring his vision' (p.14).

Three words of non-Cymraeg derivation can be traced to usages recorded by the SAWD. They are: 'chopsing' (p.15), a verb reported in Gwent for gossiping, from 'chops' i.e. 'mouth'; 'diddicai' (p.25), a term for gypsy, which was reported as both 'diddikies' and 'diddikots' throughout south Wales; and 'coalcwch' (p.127), the 'cwch' sharing etymology with the sense of hug, in this case a storage space (this was widely reported across Powys, Dyfed, Gwent, and Glamorgan). Berry also uses new non-Welsh lexis that align with usages throughout the British Englishes that can be attested in the $O E D$. 'The Missis' (p.210), as a colloquialism for one's wife (OED), is used for the first time; as are 'togs' (p.7), a colloquialism for clothes $(O E D)$; 'old dutch' (p.10), a slang compound noun for a costermonger's wife; 'kummel' (e.g. 'more kummel between her legs than in their fists', p.23), a rare term defined in the $O E D$ as being a type of German liqueur; 'southpaws' (p.83), boxing jargon for boxers that lead with their right hand and block with their left $(O E D)$; 'batchy' (e.g “"Don't talk so bloody batchy", .p.159), slang for peculiar; and 'shitten luck' (p.168), the past participle of 'to shit' i.e. 'defiled with excrement' noted in the $O E D$ as both regional and archaic. The $O E D$ also states that the term of address, 'boyo' 
(p.259), is particular to Ireland and Wales, although it has not come up in neither the $S A W D$ nor lay glossaries (indeed, today it is often used to signify a Welsh stereotypical character). The OED suggests that the adjective 'silurian' (Sammy: 'my silurian Venus', p.18), is commonly used in reference to the pre-Roman Celtic tribe of the Silures and artefacts from that region, i.e. Gwent. Here it is used to as a reference to Sammy's wife's origins.

There are two unattested terms that do not appear in records, 'fizz powders' and 'Chinese bends', both of which, it could be argued, are characteristic of the modern era. 'Fizz powders' (e.g. "“Fetch me some fizz-powders from the chemist around the corner. My stomach's upset."' p.42) contextually suggests that Berry is using a colloquialism for antacids, that 'fizz' when added to water; whilst 'chinese bends' (e.g. "“Chinese bends every lunch-hour to keep her figure.", p.53), suggests a colloquialism for an aerobic activity originating from Asia, possibly Tai Chi or Yoga.

\section{Grammar}

Previously attested grammatical structures used here by Berry include: the inflected forms of the present tense indicative: 'I says,' (p.28), 'I makes' (p.30); 'like' and 'see' as discourse markers (p.69), (p.31); Focus Fronting ('Pretty to watch, Sammy was', p.7) and semi-emphatic focus fronting with copular verb omission ('Daft prick, you', p.5, 'Solid as gold, his wife Sue', p.7); and first person plural object (i.e. 'us') being utilised in the position of the subject (e.g. 'us pair', p.125). Berry does introduce at least one new structure: the use of a reflexive pronoun (e.g. 'fancy theirselves [themselves]', p.12; 'Can he behave hisself [himself]', p.13). Both forms are widely attested in the $E D D$ throughout England and Scotland, although no mention is made in the $S A W D$.

\section{Pronunciation}

Arguably, the WE phonology of the Rhondda was a linguistic element that interested Berry significantly, and Berry's many phonetic respellings are designed in such a way to give the sense of variation even within the English speech of the Rhondda valley.

Berry's phonetic respellings match previous writers' observations. For instance, the 
medial vowel /3:/ as /e/ in girl (e.g.'gel', p.15), used in works by Jack Jones and Lewis Jones; as well as devoicing interdental plosives such as the /d/ in 'killed' (e.g. “"He kill’t him!"”); and the phonetic rendering of the Cymraeg loaned diphthong: /Iu/ as 'ew', for example in the hyphenated 'Sam-ew-el!' (p.51). Berry furthermore uses initial glottal fricative omission, or 'H-dropping' (Dylan Thomas metalinguistically alluded to this) in: "left him in the "ouse"' (p.46). The SAWD notes that h-drop is a varied feature throughout Wales; and that a word such as 'here' (/hiə/) might be pronounced with /h/-drop (/rə/), or with palatal approximate intrusion (/hj3:/), or a mixture of both intrusion and drop /j3:/. In the following structure, note that Berry includes both h-drop and h-drop + palatal-approximate in the same sentence: “"'ere's a little fairy in yere"' (p.15). Berry suggests that in sentence initial position, a speaker will use the h-drop, but following an alveolar nasal later in the utterance will produce the palatal approximate. Berry's example provides us with linguistic evidence that the $S A W D$ does not comment upon.

Another variation between words' pronunciations include the phonetic respelling of 'alright'. Unlike the aforementioned variation of 'here' within the same interlocuter, Berry highlights variation between two protagonists - Hector, who consistently uses the form: 'al'right' (p.4), and Tommy who consistently uses 'awright' (p.210). The first contains all graphemes as they would appear in Standard English, with the inclusion of an apostrophe, maybe to indicate rise-fall intonation. The second replaces $<1>$ with $<\mathrm{w}>$, suggesting omission of the lateral approximant /1/: / :rait/.

Berry also uses various shortening and allegro clippings throughout the novel to give the impression of rapid speech to particular speakers. A gender bias exists, for many of these forms are only produced by the male characters: Abe, Sammy, Hector, Tommy and Len, when in reality usage would be present by these characters' wives as well. Abe uses 'ssociated' (p.4) and 'g'wan' (p.12); Hector uses 'pers'nal' (p.15), 'ent' (p.16), 'surg'ry' (p.62), 'op'rations' (p.62); Tommy uses 'gerrout' (p.81), 'ave', 'an', 'fuckin', 'stan'up' and 'on'y' (p.210); and Sammy uses 'whassamatter' (p.31) and two variations of 'shut up': 'shurrup' and 'shaa-rup!' (p.31), the latter hyphenated version being uttered as an isolated utterance and with force. Len uses shortenings like 'setra' [etc.], 'ast' [ask], and 'lectric', however a large portion of his monologue is heavy with what appears to be eye-dialect. A quick 
sample includes: 'fust' [first], 'fetcht' [fetched], 'agenst' [against], 'honnest' [honest], 'bluddy', 'aie' [aye], 'faaqen' [fucking], 'pitchures' [pictures], 'intire' [entire], 'questshuns', and 'dijestshun'. Most of these are phonetically transparent for the reader, although why Berry chooses to respell Len's speech is unclear. As they are first-person narrations, we might deduce that they are respelled to reflect Len's poor literacy, rather than to simply function as 'dialectal' speech; by the time readers reach Len's monologues they would be aware that characters were all speaking a variety of English native to the Rhondda. Also, the fact that Berry's Len monologues are limited to two very short chapters suggests Berry was aware of how reader resistance might impact his narrative.

\section{Metalanguage}

Despite the variation in English that Berry presents, he comments little on language usage overall. Two discussions at least are of note. The first observance concerns Hector's comment upon Tommy, a boxer he had not seen in years. He states that upon rehearing Tommy, 'his voice sounds the same, loud and fast, the way they gab up the valleys' (p.29). In-text Tommy does use more clipped speech, especially clipped final consonants like "fuckin" and 'an" (see above), however it is marginal compared to the other male voices.

The second observance is a stylistic shift between WE and the older Cymraeg usage. In Berry's narrative, few people allude to speaking Cymraeg and unlike other WE literary dialects, no sustained Cymraeg dialogue is used. What is 'defined' by Berry is the common shift from English to Cymraeg for the performance of expletive exclamation. When Sammy uses profanity in response to Abe's statement - “"Iesu Crist Almighty!" - the thoughts in his monologue parenthesisly add that he was 'deliberately Cymru-cursing', and that his 'Welsh Baptist ancestors' were like 'oily emery on [his] conscience' (p.13). To Sammy, Cymraeg is reserved for little more than stylistic swearing; the co-existence of Cymraeg and WE, by the 1960s, no longer existed in the speech communities of south Wales. A stark contrast to many of the earlier writers of literary WE dialect. 


\subsubsection{Joe Dunthorne's Submarine (2008)}

Joe Dunthorne was born in 1982 in Swansea. Dunthorne undertook an MA creative writing course at the University of East Anglia; beginning to write his first novel Submarine whilst on the course. The novel was published to critical acclaim and was described by critic Nicholas Tucker as 'the sharpest, funniest, rudest account of a periodically troubled male teenager's coming-of-age since [Salinger]'s The Catcher in the Rye '(Tucker, 2008: para 1), and Williams (2016: para 6) arguing that was 'deservedly one of Wales' best novels'.

Set somewhere between Swansea and Port Talbot during the late 1990s, the story focuses on Oliver Tate, a fifteen-year-old concerned with both his own love-life and that of his troubled parents. Described as being 'in love with his own cleverness', Tate's 'tremendous moral self-righteousness about adult failings' is typical of teenagers not just in Wales, but around the western world (Adams, 2008: para 2). Tate's obsession with these 'half-facts' (Adams, 2008), which he records in his dairy, forms a narrator who is likened to 'an anthropologist writing up a previously unknown tribe' (Tucker, 2008: para 1). And yet Submarine has been described as an 'inherently Welsh' novel because of its teenager-cum-anthropologist narrator (Williams, 2016: para 3). Williams (2016) writes that we see Swansea from the Tate's teenage perspective and that a large part of the novel's naturalness comes from Dunthorne's incorporation of linguistic 'colloquialisms'.

Tate's anthropological eye creates a character who offers the most metalinguistic commentary of any other character in Welsh writing in English; and, despite its confidence, the bulk of such commentary is sifted through teenage inexperience, creating a layman's prescriptivistic account.

\section{Lexis and grammar}

Previously used lexis that Dunthorne uses include: 'bad' for 'ill' (“"Are you bad?"” / “"I don't feel well," he confirmed', p.95); and 'cwtch' (p.167), the loan verb's nucleus being italicised whilst its present continuous form being hybridised to leave the -ing morpheme unitalicised ('cwtching', p.170). Also used are, 'tamping' ("'I'd be furious, I'd be tamping”, p.225); the vocative expression 'boy bach' (p.129); and 
the vocative use of 'butt' (“'I'm good, butt”, p.129) whereas earlier authors had used it as a noun for 'work-friend'. Tate, whose mother is from England, metalinguistically notes that unlike his school-friends, he unknowingly uses forms such as 'mum' rather than 'mam' and 'grandpa' rather than 'bamps' (p.53) (a shortening of the corruption of English grandpa to bamper, $S A W D$ : Glamorgan), and thus is called 'posh' - thereby giving readers insight into the speech community's sociolinguistic perceptions of regional lexis. Dunthorne also includes the usage of Demonstrative There spoken by a Welsh surfer: “"There's manners"” (p.187).

New lexis includes: the slang adjective 'minging' (p. 48) for 'unpleasant', which originates from Scotland c.1970s (OED) and used interjectively in-text; 'scram' (e.g. 'Jordana itches her forearm, scramming it red', p.28), a verb for a 'scratching with claws', likely derived from the Flemish 'schrammen' from the Welsh Marches early medieval multilingual population finding usage throughout Powys, Glamorganshire and Gwent (SAWD); 'babs' (p.195), which although unattested in any record, is likely a corruption of the U.S. colloquial endearment term 'babe/babes' ${ }^{24}$; and 'mush', a British slang form of address for 'bloke' that derives either from Angloromani, or from Welsh Romani mūršs (OED). Dunthorne also alludes to a modern south Welsh dish known as 'half ' $n$ half' that consists of curry with a portion of half rice/half chips: 'I visualize her asking for half chips, half rice (p.128).

\section{Pronunciation}

Taking linguistic cues from prior Second Movement Welsh writers of English such as Glyn Jones and Ron Berry, Dunthorne varies a selection of phonetic respelling forms of WE to create the sense of sub-groups and speech communities known to Swansea of the 1990s. Tate and his girlfriend Jordana are often represented using standard orthographic forms (despite Jordana's obvious Swansea accent, see below), however, several scenes that portray minor characters are rendered in nonstandard phonetic respelling; these are: Fairground goers (p.104-5), the Swansea surfing community (p.187-195), Tate's father's friend Geraint (p.129-131), and his girlfriend's mother (p.182).

\footnotetext{
${ }^{24}$ The present author can verify its usage in rural Monmouthshire
} 
The Fairground goers that Tate shares a fairground ride with are described as wearing athletic clothing and speaking in 'a sing-song'.

a. "'Ckin' 'ell' the one with the Nike earrings says." (p.104)

b. '“Fuckin' 'ell slow down.' (p.105)

Here Dunthorne attributes clipped allegro speech such as initial glottal fricative omission ('h-drops') and substitution of the final velar nasal with alveolar nasal (' $\mathrm{g}$ drops') with the 'sing-song' speakers, despite such phonetic features being common with many varieties of English. Not all WE users in the novel are rendered in this manner, despite the likelihood that that they too would use these features. Here, Dunthorne has chosen to mark these characters out with eye-dialect to constitute what to Oliver Tate might be considered an undesirable class of WE speakers. Similarly, characters that are a part of the Swansea surfing community are also looked upon poorly by Tate and are stylistically marked in a similar manner. Grammatically, they also use Demonstrative There, and clipped adverb ('talk happy [happily]'), and lexically use 'babs', but phonetically they use a combination of eyedialect, 'H-drops', 'g-drops', and phonetic respellings. For example,

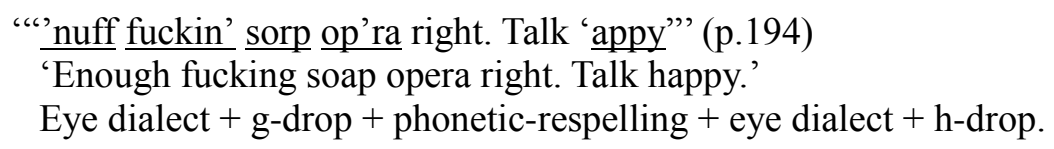

The above utterance displays all four traits: eye-dialect (nuff, op'ra), g-drop (fuckin'), phonetic respelling (sorp: suggesting long vowel /o:/ in place of diphthong /əø/) and 'h-drop' ('appy).

Geraint, Tate's father's friend, is highlighted as being distinct from the previous speech groups, yet all the same marked separately from Tate's own speech. Geraint lexically uses 'butt', 'boy bach' and 'mush' (see above), although it is his accent that is of interest to Tate. Tate describes Geraint as having an accent that is 'melodic, mellifluous, and deep' (p.129), suggesting familiar Welsh linguistic stereotypes of 'sing-song'-ness, and alluding to the rise-fall intonation of WE. This is phonetically represented by intonation hyphenation (see Geraint Goodwin above) in the 
following: 'ow-er you' ['how're you'] and 'ow-zoo' ['how's you/your']. Because this feature is absent from the other younger WE interlocutors; Dunthorne could be suggesting it is a feature he believes to be diminishing. For Geraint, 'you' is also represented as 'yew', the orthography <ew> suggesting the Cymraeg diphthong/ru/ (a phonetic respelling used also by Glyn Jones and Ron Berry). Indeed, Tate metalinguistically comments upon this pronunciation later in the text whilst hiding behind a yew tree, stating that 'in South Wales, people say 'yew' instead of you' (p.149). Geraint does omit his initial $/ \mathrm{h} /$ phonemes, a feature that Tate comments upon during Geraint's discourse with his father. Tate says: 'after a weekend spent with Geraint, my dad's 'h's disappear. Like me, he knows how important it is to sound the same as everybody else' (p.130). Most fascinating here is Dunthorne providing a layman's explanation of Howard Giles's sociolinguistic theory of accommodation theory: in particular, that Tate's father is converging with Geraint's accent. Tate elaborates: 'Dad only sounds properly Welsh when he's been drinking I, when I am trying to impress someone' (p.131).

Finally, Dunthorne uses several phonetic respellings for Jordana's mother. For example: the Cymraeg diphthong /Iu/ for 'yew'; h-drop for 'ello'; and then exclamative 'woh' [whoa] (suggesting a short vowel /wp/ rather than diphthong /wəv/), contraction won't as 'wunt' (again suggesting shorter vowel than a

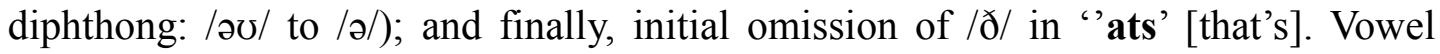
shortening is recorded throughout Wales in the $S A W D$, although omission of voiced interdental fricatives is not.

Because many of the above phonetic respellings are presented in-text as a diary, we can surmise that Tate is the one rendering the speech of other Swansea residents. Tate, whose parents lived in England (including his Welsh-born father), acknowledges that his accent does not match others around him, even if the lexis he uses are similar. An underlying theme is that Tate is fixated with people viewing him as 'posh' because of his English English accent, and that he is seen as an Other, despite having been raised in Swansea. It is not explicitly stated how Tate is perceived as being posh, although the variety that impacts his speech is likely Received Pronunciation (RP). We are first made aware of this in Tate's pamphlet on how to avoid being bullied, in 'Advice 7: Only being yourself inside your head' Tate 
states: 'After they called me 'posh' in primary school, I changed my accent to sound more poor; I cut out the vowels like Marks and Spencer's labels from my shirts.' Tate's accommodation to his peers' speech started in primary school, and that he associates a more pronounced Welsh accent of English to be aligned with connotations of 'poorness'. By 'cutting out the vowels', we can assume Tate is referring to elision and reducing syllables.

Nevertheless, despite Tate's best efforts, Tate cannot eradicate his accent. Tate's girlfriend, Jordana, in fact highlights it to mock him: "Warmer, warmer," she says in a posh voice that is supposed to be an impression of me' (p.68). It is clear Tate does not believe his accent to be as 'posh' (or RP) as the one that Jordana produces, Jordana showing some deliberate use of overaccommodation. Jordana continues to mock Tate by then accent-shifting into a contrived Cockney English accent: "“Cor Blimey, sir' she says in the voice of a Victorian orphan' (p.68), highlighting that to Jordana, Tate's accent may as well belong to any number of English varieties.

Later in the novel, despite his failings with Jordana, Tate continues to attempt phonological accommodation of WE (as it is likely he has done throughout his childhood). In a scene he shares with Jordana's mother, Tate states via monologue: 'if you are trying to impress someone, copy their speech habits. A subtle form of flattery.' He then proceeds to mimic Jordana's mother's shortening of 'tara' [goodbye]: 't'ra' (p.183).

Despite Jordana's teasing, Tate appears to perceive Jordana's accent as unaligned with other WE speakers most of the time. During an emotional scene, Jordana states: 'I'm saw [so] sorry. I've bin [been] nowhere' (p.167). Dunthorne's use of 'saw' to once again suggest shortened vowel and the allegro vowel shortening use of the past tense 'been' are not consistent with Jordana's other pronunciations. This change is coupled with Tate's sense of surprise, where he exclaims: 'she sounds more Welshy today.'

\subsubsection{Summary}

Welsh post-industrial writing of the later $20^{\text {th }}$ century situated WE literary dialect in 
unfamiliar domains. Dylan Thomas and Glyn Jones both created absurd and mystical versions of Wales, yet their representation of dialects was grounded in earlier tradition. Like Raine, Jones's readership had access to a paratextual glossary, an aid useful considering the volume of WE lexis Jones used in his work. Ron Berry was interested in the variations between individual speakers, rendering fourteen distinct idiolects within Valleys WE; similarly, Joe Dunthorne was interested in how individuals perceived varieties of speech around Swansea. Unlike other periods, domains of literary dialect such as phonology and grammar were subordinated, with authors' interest focusing on lexis and dialectal attitudes.

\subsection{The use of Welsh English in late $20^{\text {th }}$ century fantasy novels}

Before this chapter is concluded, it seems fitting to mention a literary trend that begun to gain traction alongside the third era of Welsh writing in English. Novels that featured Wales or Welsh tropes were beginning to be written by fantasy writers, and several of which exhibited characters that spoke with WE varieties. All three authors within this section are non-Welsh and did not live within Wales; their understanding of the Welsh variety of English as a literary dialect therefore comes from the foundations set forth by earlier Welsh writers of English, or from other media sources such as film. The impact of using a Welsh accent to denote 'fantasy' becomes apparent during Chapter 8's focus on film, and Chapter 9's focus on videogames, yet its impetus may be traced to these authors: Alan Garner, Dianna Wynne Jones, and Terry Pratchett.

\subsubsection{Alan Garner's The Owl Service (1967)}

Alan Garner (1934-present) was raised in Cheshire, later attending Oxford before undertaking a career in children's fantasy literature. During early childhood Garner was scolded by teachers for speaking in his Cheshire variety of English, and adopted RP thereafter. His fascination with language usage and words was sated by the numerous books he read whilst confined to his childhood sickbed (Garth, 2013). Garner would use his linguistic observances in The Owl Service, and after its publication, Red Shift - a novel that incorporated his native dialect (Philip, 1981:16).

Published just two years after Glyn Jones's Island of Apples, Garner's The Owl 
Service (1967) also takes inspiration from British/Welsh mythology by situating ancient myths alongside contemporary children and their adventures. In Garner's novel, these stories hail from the Welsh Mabinogi, where, following an English family's vacation in a secluded Welsh valley, mystical events arise.

The novel's Welsh characters, schoolboy Gwyn and the groundskeeper Huw Halfbacon (revealed to be a descendent of the immortal Lleu), offer the English family (and by extension: non-Welsh readers) exposition about Wales's connections with magic and fantasy, indeed, fulfilling age-old stereotypes associated with Wales (see Parker, 2007). Garner writes these characters with Welsh accents, thereby associating the Welsh variety of English with a sense of the 'Fantastic'. Gwyn and his mother use several lexical items and grammatical structures familiar to Welsh writers of English such as: 'mam' (p.50), Demonstrative There (“"There's axiomatic"”, p.58), and discourse markers such as 'like' (p.115), and confirmatory interrogative tags (“'You don't want this rubbish here, isn't it?"'. However, whereas Gwyn is bilingual in English and Cymraeg, Huw Halfbacon is an L1 Cymraeg speaker who knows little English, performing stifled utterances that use the present tense to refer to the past: "'He is killing Gronw without anger ... he is hurt too much by the woman and the spear"' (p.72); and subject verb disagreement for plurality: 'None of them is [are] all to blame' (p.73).

WE phonology is only briefly represented in a metalinguistic exchange that sees one of the English children, Alison, unable to pronounce the voiceless lateral fricative / 1 / (orthographically: $<11>$ ).

Alison: $\quad$ There was this wizard, or something, I forget his name, and he made a woman out of flowers, and she married this Clue Claw Somebody.

Gwyn: $\quad$ Lleu Llaw Gyffes

Alison: $\quad$ Yes: well then she fell in love with a man called Gronw: Gronw Pebyr. And he decided to kill Clue.'

Gwyn: $\quad$ Lleu

Alison: $\quad$ Clue

Gwyn: $\quad$ Never mind. Go on.

(p. 61)

Alison's inability to hear the Cymraeg phoneme mirrors many English mishearings of the phoneme (e.g. Shakespeare's rendering of Llewelyn/Fluellen), and Gwyn's 
dismissal of the linguistic subject is likely to be humorous familiarity to those with a grasp of Cymraeg of WE.

Garner excels at providing metalinguistic commentary, giving us insights into Gwyn's perceptions of language. When Gwyn's mother omits 'auxiliary have' from an utterance ('I got one of my heads'), Gwyn censures her speech, shouting: "II have got," said Gwyn. "I have got one of my heads. It's uncouth to omit the auxiliary verb" (p.80). Gwyn's correction of his mother's grammar usage and his perception of his own WE is expanded upon when Alison discovers Gwyn is using elocution lessons to learn RP.

Gwyn: $\quad$ These records. They teach you to speak properly. That's what matters.

Alison: There's nothing wrong with the way you speak, except when you're putting it on to annoy people.

Gwyn: $\quad$ But I'm a Taff, aren't I?

Alison: $\quad$ It doesn't matter [...] I like it. It's you, and not ten thousand other people. It doesn't matter Gwyn!

Gwyn: It doesn't matter - as long as you haven't got it!

Here, Gwyn's self-perception of his Welsh accent is negative, and he believes it will hold him back should he leave Wales, regardless of what his friend Alison positively thinks of his pronunciation. Alison's comment about Gwyn 'putting it on to annoy people' references an earlier scene where Gwyn, fully aware of the Welsh linguistic stereotypes that the English have constructed of the Welsh, teases Alison's culturallybelittling step-brother Roger with a mock WE utterance: “ 'Master Roger. [...] There's asking for a poke in the gob, you are, indeed to goodness, look you"” (p.115). Here, Garner satirically uses Demonstrative There, the slang lexis 'gob', focus fronting, as well as two WE linguistic stereotypes to convey Gwyn's metalinguistic awareness of how the English perceive WE speakers to speak.

\subsubsection{Dianna Wynne Jones's Howl's Moving Castle (1986)}

Dianna Wynne Jones (1934-2011) was raised in London, but was born to Welsh parents and spent time in Wales during the Second World War child evacuations. Like Garner, Wynne Jones also attended Oxford University where she was taught by fantasy writers J.R.R. Tolkien and C.S. Lewis. Although largely obscure during her writing career, today she is considered one of the best-known children's authors of 
British fantasy (Priest, 2011).

Wynne Jones's most prominent novel to feature Welsh themes was Howl's Moving Castle. The story takes place in the fictional kingdom of Ingary, revolving around wizard Howl Pendragon, his demon-familiar Calcifer, an apprentice, and a new recruit Sophie, a teenaged hatter cursed with old age. Gradually through their adventures, Sophie begins to unearth Howl's non-Ingary origins. She first spots Calcifer singing a 'flickering little song' about saucepans in a language Sophie does not recognise (p.48), likely to be the Cymraeg folk song: Sosban Fach. Then, in chapter eleven, the troupe head into a magical portal, arriving in a land that nobody but Howl recognises. As Howl greets his niece with: 'How are you, cariad?' (a Cymraeg endearment term), it is then made apparent through a sociolinguistic variety shift that Howl originally hails from the south Welsh valleys. He then shifts immediately from English into ‘another language' (Cymraeg); Wynne Jones writing: '[Sophie] wondered about the language. It sounded the same as Calcifer's silly saucepan song, but it was hard to be sure.' Other WE voices are heard too. Focus fronting is used (e.g. "'Looking everywhere for it, he was", p.157) as well as 'see' as discourse marker (e.g. "“He's got this new English teacher, see"”, p.157).

Howl is a bilingual speaker of WE and Cymraeg, capable of shifting parts of his language usage when necessary. And, although Wynne Jones cleverly masks Howl's Welsh identity for most of the novel, the linguistic and identity reveal is downplayed; its effects probably most prominent for Welsh readers. In Howl, who is later revealed to be born Howell Jenkins, Wynne Jones created a wizarding character who, much like Garner's Huw Halfbacon, is linguistically attached to the character stereotype of the 'Fantastical Welsh'.

\subsubsection{Terry Pratchett's Soul Music (1995)}

Terry Pratchett was brought up in Buckinghamshire (1948-2015). Coming to prominence during the $1980 \mathrm{~s}$, and by the 1990s was the best-selling novelist in the U.K. Pratchett wrote fiction that could best be described as 'comic fantasy'; although Pratchett wrote over seventy books, the majority of which were situated in the same fantasy world of Discworld, a mythic world that parodies fantasy tropes (Telegraph, 
Soul Music, Pratchett's sixteenth Discworld story, focuses on the misadventures of the harpist Imp Y Celyn (later taking the stagename Buddy) and his rise to fame as a rock ' $\mathrm{n}$ roll guitarist in the capital city. Buddy's home nation is Llamedos, its orthography indexing Welsh toponymy. On closer inspection, Pratchett uses the same 'reversism' that Dylan Thomas used for Under Milk Wood's Llareggub/buggerall), therefore: Llamedos reverses to Sod 'em All. What is evidentially apparent here is that Pratchett was intertextually aware of the works of Wales's best-known Welsh writer of English. Whereas other elements of Pratchett's stories parody fantasy, Llamedos fulfils many of the stereotypes associated with Wales and by extension Wales's connection with being Fantastical. Llamedos's chief export is mined rainwater, its inhabitants practice druidism, and are all renowned poets and musicians who are deadly with the harp (they even have annual Eisteddfods) (Pratchett \& Briggs, 2004:156).

Speakers of Llamedos evidentially also speak a sort of WE. In an early exchange, a guard identifies Buddy by his 'musical' (i.e. sing-song) accent, which is redolent of descriptions of WE's often rise-fall intonation, and another guard then stating that the accent 'sounds like garglin' with gravel' to him (p.27), likely indexing some of Cymraeg's harder to pronounce phonemes such as $/ \mathrm{X} /$ and /1/. Pratchett employs several grammatical structures to render his Welsh variety such as the occasional discourse marker 'see', for example: "“but the harp is the queen of instruments, see"' (p.31) and Focus Fronting, for example: "“Sioni Bod da, it was” (p.326) (note that 'Sioni Bod da' is a humorous word-for-word Cymraeg translation of 'Johnny Be Good').

Pratchett's most consistent linguistic contributions to the Llamedos dialect are phonological features that act as Welsh phonological puns by way of orthography. The first plays on the homophonic pairing of 'cwm' (valley, in Cymraeg) and the English verb 'to come'. Although they are not strict homophones in standard English, cwm being pronounced $/ \mathrm{ku}: \mathrm{m} /$ and come being pronounced $/ \mathrm{k} \Lambda \mathrm{m} /$, Pratchett substitutes the former for the latter in: "Just once? Cwm on?" (p.330). The SAWD notes that WE speakers in areas throughout mid and south Wales might pronounce 
medial $/ \Lambda /$ as $/ \mathrm{u}$ :/ in particular words. The second phonological pun however is less grounded. Whenever Buddy's speech encounters the grapheme $<\mathrm{l}>$, it is doubled to $<1 \mathrm{l}>$. Pratchett's obvious reasoning being that double $\mathrm{L}$ is commonplace in Cymraeg as the phoneme: $/ 1 /$, thus it works to index 'Welshness'. However, although WE speakers are likely able to produce alveolar lateral fricatives in loanwords and placenames (regardless of aptitude in Cymraeg), they do not substitute them in place of alveolar lateral approximants like $/ 1 /$. As a result, Pratchett features double L in word initial, medial and final positions, respectively: 'llicense' (p. 27), 'actualllly' (p.27), and 'wellll' (p.39). As seen, wherever there's two $<1>$ graphemes already present in the English word, Pratchett doubles those too. Unlike, Garner and Wynne Jones, for his Discworld, Pratchett uses both Cymraeg and WE languages as a source of humour, as well as indexers of a sense of 'Fantasy'.

\subsubsection{Summary}

The latter half of the $20^{\text {th }}$ century also saw several English novelists use a WE dialect as inherent parts of their Fantasy stories to index character stereotypes that the Welsh are Fantastical. Alan Garner, having written dialect before, perhaps creates a version of literary WE most like Welsh-born writers' versions that is present throughout his narrative. Dianna Wynne Jones uses it briefly for a chapter in which her bi-dialectal protagonist adopts his old WE voice. Whilst Terry Pratchett uses WE (and other Welsh tropes) to fully index humour and mysticism in a world very far removed from Wales.

\subsection{Conclusion}

This chapter has investigated the depiction of Welsh English in literary dialect, analyzing seventeen fictive-written pieces from 1828 until 2008. There were trends in dialect-writing across this era in lexical, grammatical, and phonological representation. For these forms to appear frequently between texts, we therefore have evidence that they were likely considered to be enregistered within WE speech communities and for the dialect writers in question.

Of the seventeen texts analysed, all texts included Cymraeg loan words in their literary dialect, even the Fantasy novels written by non-Welsh authors, suggesting 
that Cymraeg is a vital component of fictive WE dialect. The most common items, in chronological order of their appearance, and with parenthesized number of appearances, were: endearment term 'bach/fach' (11/17 texts), expression of disgust 'ach-y-fi/ach' (6/17), 'cwrw' [beer] (4/17) (only early period), 'cawl' [ soup] (3/17), 'mam' [mother] (8/17), endearment term 'cariad' (4/17), 'diawl' [devil] (3/17), 'eisteddfod' (4/17), exclamative 'duw' (4/17), 'twp' [foolish] (2/12) (recent), and 'cwtch' [storage place or cuddle] (4/17) (recent). However, there are many recurring lexical items derived from the English language tradition. Again, in chronological order with appearance tallies, these were: vocative 'mun/man' (6/17 texts), affirmative 'aye/ay' (8/17), variations of 'indeed to goodness' (7/17), tag 'look you' (5/17), 'tidy' [decent] (3/17), emphatic denial 'never' (4/17), verb 'mitch/mouch/mwch' [truant] (3/17), 'tamping' [raging] (3/17), vocative 'butt' \& 'butties' [friend] (4/17).

There were also several reoccurring grammatical features throughout this era and narrative medium, suggesting levels of enregisterment. By far the most common syntactic structure was Demonstrative There $+\mathbf{a d j} / \mathbf{N P}(11 / 17$ texts), and Focus fronting $(8 / 17)$; both were present in the very earliest text, whilst Demonstrative There was also present in the most recent. Other grammatical structures arranged chronologically include: 'as' as a relative pronoun (3/17), inflected presented tense indicative (3/17), discourse marker 'see' (5/17), 'us' as plural subject pronoun (4/17), and discourse marker 'like' (4/17).

Regarding phonetic respelling, there were several tactics fictive-writers used. Many texts analyzed used allegro clippings (6/17 texts), or eye dialect (5/17) to index 'dialectness'. Regarding respelling phonemes, common are RP diphthong /əv/ being rendered as monophthong /p/ or / $/$ :/ (3/17), /3:/ as /e/ especially in 'girl' (3/17), intrusive palatal approximants $/ \mathrm{j} /(2 / 17)$, glottal fricative drops $/ \mathrm{h} /(3 / 17)$ and attempts at rendering the Cymraeg loaned diphthong/ru/ as 'ew' or 'iw' (3/17). Two texts use intonation hyphenisation, to transcribe the rise-fall intonation of WE. There were four texts that used phonetic respelling previously used by Elizabethan playwrights to render /s/ as / $\mathbf{j} /$ (C. Evans), /t $\mathbf{j} /$ as $/ \mathbf{f} /$ (J. Jones), devoicing of plosives such as /b/, /v/, /z/ (Goodwin), and initial /w/ drops (Goodwin); some of these are 
attested in the $S A W D$, others are not - it is therefore possible that some authors took inspiration from Shakespearean theatre's linguistic stereotypes.

Though there were linguistic usages not shared amongst authors, many examples were nevertheless attested in dialectological surveys, thereby suggesting authors were making their own informed dialect inquiries into their speech communities. Some forms used by novelists in their literary dialect did not match any record; this suggests that WE literary dialect provided notable 'linguistic evidence' that future sociolinguists/dialectologists may rely on. Prichard, M. Evans, Goodwin, and G. Jones were especially prolific in this regard, contributing several items per text. Prichard used 'rusties' [drunkards], 'weazon-faced' [wheezed-face], and 'gruffy' [gruff-person]. Evans added 'fairy's fingers' [foxglove], phrase 'not a mite to be gained', 'black-rage', 'saucering' [lapping] and 'switching' [swishing]. Goodwin added 'robin-run-the-hedge' [cleaver plant], 'jenny-ring' [farming method], 'monkey-up-the-stick' [unknown], and 'elder-bloom' [unknown plant]. G. Jones added thirteen unrecorded terms, five examples being: 'sash' [mining cummerbund], 'dix-stones' [children's game], 'bobby-greencoat' [school attendance officer], 'horse-tods' [horse dung], and 'caca-hawk' [bird species].

In the texts analysed, there is no obvious difference in the representation of WE literary dialect written by Englishmen and Welshmen, and writers like M. Evans and Roberts were keen inquirers into Borders WE and West Wales WE respectively, as much as G. Jones was for Valleys English. Unlike Welsh writers, however, English writers such as Garner, D.W. Jones, and Pratchett began to use the WE variety to index a sense of 'Fantasy' stereotyping towards the end of the $20^{\text {th }}$ century.

Some authors added metalinguistic observances about the variety into their texts, the process gaining popularity in the late $20^{\text {th }}$ century. Prichard was an early observer of dialect prejudice, whilst M. Evans recognized complex linguistic loyalty along the border, and J. Jones commented on the effects of language shift generationally. Later, G. Jones highlighted Welsh schoolyard sociolects, and Berry's characters observed, first that there are multiple Welsh Englishes, and second, that language may shift for profanity. Dunthorne's protagonist comments upon discriminatory linguicism; as does Garner's, who worries about how his Welsh accent is perceived by others. And, 
finally, several authors metalinguistically identify particular WE phonemes too. Goodwin observes the 'sing-song' intonation of WE, Dylan Thomas notes ' $h$ dropping', and Dunthorne highlights the diphthong /ru/.

Overall, this chapter has uncovered a wealth of linguistic material and attitudinal observances about literary WE, thus setting strong foundations for future work on WE literary dialect. In the next chapter, our attention will turn to the manner in which WE has been represented in the audio-visual textual genre of film (WE filmic dialect). 


\section{Chapter 8 Representation of Welsh English in $20^{\text {th }}$ century}

\section{$\underline{\text { film }}$}

\subsection{Introduction}

An obvious advantage that film has over written material of previous chapters is the method in which accent and dialect can be tied to the text. Filmmakers can simply set up microphones and record speech, Hodson (2013) argues that it might be because of this fact that dialect in film has received so little dialectological/sociolinguistic analysis: it is 'too easy and too obvious' (p.15). By treating filmic texts similarly to literary texts, it is possible to analyse the representation of dialect in film because films use dialect in 'highly artificial and purposeful ways' like literature (Hodson, 2013:15). Film analysts are prone to putting focus primarily on various artistic styles of a film ${ }^{25}$, from the mise-en-scène (placement of props, lighting) and cinematography (how the scenes are shot), to editing (sequencing of shots), and sound (non-verbal noise, extra-diegetic music). Rarely is the focus on 'artistic' dialogue. One reason why film dialogue is rarely given the linguistic exposure it deserves might be because film began, and continues in many respects, to primarily be a visual medium (Kozloff: 2000:4).

Kozloff (2000) notes that film has a history of using accent as a characterising tool for providing a character's background, that 'recognisable, clichéd dialects are used on-screen to sketch a character's past [,] cultural heritage, [...] financial standing, education level, geographical background, or ethnic group' (p.82). Hodson (2013) argues that as viewers, we are accustomed to seeing this, for they act as characterising 'shortcuts' for viewers (p.11). Kozloff (2000) quite rightly asserts that film dialogue is fundamentally different to real-world speech: 'in narrative films, dialogue may strive mightily to imitate natural conversation, but it is always an imitation. It has been scripted, written and rewritten, censored, polished, rehearsed, and performed' (p.18). Kozloff warns that linguists who might use film dialogue for case studies of genuine everyday conversation are operating on 'mistaken assumptions' (p.19).

\footnotetext{
${ }^{25}$ For a breakdown of analytic approaches, see Bordwell and Thompson (2001)'s section "Part 4: Styles" p.136-350.
} 
This chapter addresses sixteen fictive filmic texts that contain Welsh English dialect. As noted in the literature review (Chapter 3.3.), the question of dialectal 'authenticity' in film is complex for viewers. For analysts studying WE in film, it is easy and simple to cross-reference features with the SAWD and thereby assess how a filmic dialectal representation compares to its real-world variety. We must take into consideration, however that films are often limited by 'production restraints': in this way filmic dialect, like literary dialect, functions as a 'language variety parasite' deriving its form from a real-world variety.

One salient production restraint of film is that producers often cast star actors that are not users of the variety in question in roles. This results in 'contrived' attempts at a target accent. Although actors' aptitudes for learning varieties' phonologies will always vary, for viewers, questions of 'authenticity' of the filmic accent may arise from performances. Although questions of 'authenticity' may be predominately associated with contrived performances, we must also consider that some 'native' users may overemphasise particular enregistered phonemes thereby rendering a WE that feels 'inauthentic' or 'stereotyped' to viewers.

Commentary about actors' biographies (especially birth locations/residences) are taken often from cited material, or from online databases like the internet movie database (hereafter imdb). In doing so, as a rule of thumb we can glean whether particular actors' are or are not native WE users when addressing their representation of WE, especially southern 'valleys' variety, which was the most common. That said, being raised in Wales does not strictly guarantee a southern WE accent, as there are more varieties of WE than just this one, therefore even an actor who was born in Wales and identify with being Welsh may use a 'contrived' WE variety in a film.

\subsection{History of Wales on film}

Writing in 1999, Steve Blandford acknowledges that international recognition of the Welsh film industry had only just begun and that many solid achievements remained relatively small before 1997's success of box-office hit Twin Town (Allen, 1997) and 
arthouse success House of America (Evans, 1997) (Blandford, 2000a:11). At the time, there was a clear attempt by filmmakers to eschew past stereotypes associated with the Welsh and create a new identity in film and cinema (p.16), however, despite being a formative era in British film industry, Wales was still largely underfunded; to the producers, films about Wales were either risky or potentially showed unpopular subjects (p.14). Regarding Wales' film industry before the late 1990s, screenwriter Ed Thomas writes: 'for years we [Welsh film industry] were internationally a laughing stock because we had no strategy for films' (Blandford, 2000b:75). That there was a reluctance to produce Welsh dramas by London drama circles has been suggested by some to display inherent prejudice against Welsh people (Berry, 2000: 137). Welsh director and ex-HTV Wales drama head, Alan Crayton, stated that there's a 'marked lack of self-belief in Welsh writing and directing talent both in Wales and London', with Wales being perceived as not being 'sexy' enough for London audiences (p. 137). Furthermore, director and producer, Karl Francis, has also noted that English production companies have been known to snub Welsh actors for box-office English alternatives (Berry, 2000:133).

One of Wales' filmic contributions prior to the $21^{\text {st }}$ century was that of its animation industry. Shows such as Super Ted (Edwards, 1983-1986) were dubbed into 17 languages worldwide in 45 countries, and Shakespeare: The Animated Tales (Edwards, 1992-1994) being screened in 50 countries (Robins \& Webster, 2000:110). However, despite their success, due to the animation industry's often homogenised quality, which utilise many international talents, it was hard to identify such productions as 'distinctly Welsh', argue Robins \& Webster (2000).

\section{Table 8.1: Welsh film period descriptors}

\begin{tabular}{ll}
\hline Time period & Title used \\
\hline $1930 \mathrm{~s}-1940 \mathrm{~s}$ & Early $20^{\text {th }}$ century films \\
$1950 \mathrm{~s}-1960 \mathrm{~s}$ & Mid $20^{\text {th }}$ century films \\
$1980 \mathrm{~s}-1990 \mathrm{~s}$ & Late $20^{\text {th }}$ century films \\
$2000 \mathrm{~s}-2010 \mathrm{~s}$ & Early $21^{\text {st }}$ century films \\
\hline
\end{tabular}

A chief question concerning Welsh film has been one of linguistic representation: whether to place emphasis on Welsh language or English language film? With the creation of Cymraeg channel S4C in the 1980s, the language had exclusive televisual 
presentation for the first time, even if Cymraeg material is, to this day, largely ignored by London-based distributors, possibly due to a lack of confidence in marketing subtitled film (Berry, 2000:128).

The predominance of Wales' Cymraeg S4C has found its critics, however. A common argument contends that funding bias has resulted in fewer opportunities for Welsh filmmakers to create films in the English language (Blandford, 2000a:13). John (2000), a monolingual WE speaker from South Wales, believed 'English language Welsh writers' were ignored, that 'the communities, the stories, the authentic language of contemporary English speaking Wales [...] are barely represented on our screens' (John, 2000:50). To John (2000), Welshness is 'elastic and complex', citing the fact that Wales has rarely been united, having always a fragmented quality, not just geographically and culturally, but also linguistically (p.53). Others have stated that this kind of bias has '[retarded] English language writing - and crucially [affected] confidence and self-esteem in Wales' (Berry, 2000:128). Berry (2000) even specifically highlights the representation of WE onscreen, stating that there is '[a] lack of opportunities for monolingual (or AngloWelsh) writers and directors' (emphasis mine) (p.128), especially when contrasted with earlier post-war films and 1960s-1970s television serials (p.132).

For bilingual writers and directors, choosing English over Cymraeg was often pragmatic. For example, writer Marc Evans has commented about creating English language films from Wales:

We started creating a culture, sort of in our own backyard because by definition the [Cymraeg] products don't naturally have such a wide audience as things in the English language. Eventually some of us started making things in English, not because we didn't want to work in [Cymraeg]. (Blandford, 2000b:75).

Furthermore, Ed Thomas specified that he wrote in English because his Cymraeg was weaker, although had no 'cultural' preference to either language (Blandford, 2000b:84). There has also been a trend to shoot productions in both Cymraeg and English, for example the film Silent Village (Jennings, 1943) (Blandford, 2000b:86), and more recently Hinterland/Y Gwyll (Thomas, 2013-present), a tactic that on the surface makes use of actors' bilingualism, 'appeases' both speech communities, and 
also secures funding from a variety of sources (e.g. BBC and S4C). Ed Thomas is adamant that modern Welshness is 'culturally rich' and is more than just a rivalry between two speech communities:

There are two languages. If you speak Urdu and live on the south side of Cardiff, you have three languages. All this is to be celebrated, not to be defended. We have been in danger of defending and politicising ourselves out of creative existence. (Blandford, 2000b:87)

Thomas' reference to multilingualism is striking, especially considering that Urdu loanwords have been attested in Parry's Survey of Anglo-Welsh dialects (one example is head-sherang deriving from şerang, meaning boatswain).

The chapter surveys a range 76 years, from Wales' initial foray into cinema before the second world war, until 2014. Many texts are film-readings that highlight representation of the WE variety. The chapter's structure is split into four periods, beginning with the Second World War era (1930s-1940s), then the Post-War era (1950s-1960s) and late $20^{\text {th }}$ century era (1980s-1990s), and concluding with early $21^{\text {st }}$ century films (2000s-present).

Table 8.2: List of film texts analysed

\begin{tabular}{|c|c|c|c|}
\hline Director/Writer(s) & Year & Film text & Film studio \\
\hline $\begin{array}{l}\text { King Vidor / } \\
\text { Ian Dalrymple } \\
\text { Frank Wead } \\
\text { Elizabeth Hill } \\
\text { Emlyn Williams }\end{array}$ & 1938 & The Citadel & $\begin{array}{l}\text { Metro-Goldwyn- } \\
\text { Mayer }\end{array}$ \\
\hline $\begin{array}{l}\text { Pen Tennyson/ } \\
\text { Fredda Brilliant } \\
\text { Louis Golding } \\
\text { Herbert Marshall }\end{array}$ & 1940 & The Proud Valley & Ealing studios \\
\hline $\begin{array}{l}\text { John Ford/ } \\
\text { Philip Dunne }\end{array}$ & 1941 & How Green Was My Valley & 20th Century Fox \\
\hline $\begin{array}{l}\text { Basil Dearden/ } \\
\text { Angus MacPhail, } \\
\text { Diana Morgan }\end{array}$ & 1944 & Halfway House & Ealing Studios \\
\hline $\begin{array}{l}\text { Charles Frend/ } \\
\text { Clifford Evans }\end{array}$ & 1949 & A Run For Your Money & Ealing Studios \\
\hline
\end{tabular}




\begin{tabular}{|c|c|c|c|}
\hline $\begin{array}{l}\text { Richard Hughes } \\
\text { Leslie Norman } \\
\text { Charles Frend } \\
\text { Diana Morgan }\end{array}$ & & & \\
\hline $\begin{array}{l}\text { J. Lee Thompson/ } \\
\text { John Hawkesworth } \\
\text { Shelley Smith }\end{array}$ & 1959 & Tiger Bay & $\begin{array}{l}\text { The Rank } \\
\text { Organisation }\end{array}$ \\
\hline $\begin{array}{l}\text { Sidney Gilliat/ } \\
\text { Bryan Forbes }\end{array}$ & 1962 & Only Two Can Play & British Lion Films \\
\hline Andrew Grieve & 1987 & On The Black Hill & $\begin{array}{l}\text { British Film } \\
\text { institute }\end{array}$ \\
\hline Christopher Monger & 1995 & $\begin{array}{l}\text { The Englishman Who went Up a } \\
\text { Hill and Came Down a Mountain }\end{array}$ & Miramax \\
\hline $\begin{array}{l}\text { Kevin Allen/ } \\
\text { Kevin Allen } \\
\text { Paul Durden }\end{array}$ & 1997 & Twin Town & $\begin{array}{l}\text { Agenda, Aimimage } \\
\text { Productions; \& } \\
\text { Figment Films }\end{array}$ \\
\hline $\begin{array}{l}\text { Marc Evans/ } \\
\text { Ed Thomas }\end{array}$ & 1997 & House of America & $\begin{array}{l}\text { Egmond Film \& } \\
\text { Television }\end{array}$ \\
\hline Justin Kerrigan & 1999 & Human Traffic & $\begin{array}{l}\text { Irish screen and } \\
\text { fruit salad films }\end{array}$ \\
\hline Paul Howard Allen & 2009 & Big Font. Large Spacing & $\begin{array}{l}\text { 33Story } \\
\text { productions }\end{array}$ \\
\hline $\begin{array}{l}\text { Marc Evans/ } \\
\text { Laurence Coriat }\end{array}$ & 2011 & Hunky Dory & $\begin{array}{l}\text { Mulligan and } \\
\text { Nesbitt } \\
\text { Productions }\end{array}$ \\
\hline Peter Jackson & $\begin{array}{l}2012- \\
2014\end{array}$ & The Hobbit trilogy & Newline cinema \\
\hline $\begin{array}{l}\text { Matthew Warchus/ } \\
\text { Stephen Beresford }\end{array}$ & 2014 & Pride & Pathe \\
\hline
\end{tabular}

\subsection{Welsh film around the early $20^{\text {th }}$ century: $1938-1949$}

The first era in which WE varieties gained prominence in film was during the years approaching the onset of the Second World War, with characteristics of the era continuing throughout the 1940s. Welsh film historian Dave Berry rightfully proclaims that "no worthwhile study of films about Wales can afford to skimp in exploring [the films] which emerged in the 1938-1949 period' (Berry, 1994:160). Many of these early productions were feature-length mining stories set in Wales, thereby aligning themselves thematically (and stylistically) with Anglo-Welsh 
literature's 'First Movement' Industrial stories (see Chapter 7). That said, few production studios risked filming outside London, meaning authentic images of Wales were rare (Berry, 1994:148). Filmmakers' attempts to create an 'authentic' Welsh embodiment to a motion-picture were therefore executed often in the casting of Welsh people. With such casting, comes the presence of the Welsh variety of English.

\subsubsection{The Citadel (1938), Dir. King Vidor}

The Citadel, a drama directed by the American filmmaker King Vidor, was the first of many mining films that were created to 'fix, indelibly, the image of South Wales in the minds of audiences throughout the world' (Berry, 1994:148). The film was based on a novel by A.J. Cronin, and shot not in Wales, but in England's Denham studio. King Vidor reportedly saw Wales through a highly-romanticised lens, and reacted to mining conditions with astonishment (p.151).

The film revolves around the fictional town of Blaenelly, that Scottish doctor Andrew Manson visits to better understand miners' lung diseases. The first half of the film is set in Wales, before then moving on to London. The Citadel was also one of the first films to portray a large cast of WE speakers. The film utilises a composite of native Welsh accented speakers, and speakers who have been cast to produce a Welsh accent. For example, Mrs Page a doctor's wife (played by Dilys Davies), Old Thomas the Drive (D.J. Williams), and Mr. Owen head of the Aberalaw medical aid society for miners (Emlyn Williams) were all Welsh actors with native Welsh accents. The script was written by Ian Dalrymple, Frank Wead, and Elizabeth Hill; and the Welsh playwright Emlyn Williams (1905-1987), who plays Mr. Owen, was also consulted for 'additional dialogue'. Williams, who was born in Flintshire, was a Cymraeg speaker, writing exclusively in English (indeed his first literary fascination being the works of Allen Raine (see Chapter 7)) finding fame as a London-based dramatist, actor and screenwriter (Dale-Jones, 1979:2). We can surmise that Williams may have been King Vidor's consultant for the writing or managing of the 
representation of WE in his film, for he had some experience in using it in $20^{\text {th }}$ century plays (for example, see The Druid's Rest, Williams, $1944^{26}$ ).

Understandably, the variety of English that appears in The Citadel mirrors the literary dialect present in 'First Flowering', or Industrial settlement, novels from the Welsh writing in English literary movement (Chapter 7.3).

\section{Lexis}

One lexical feature used in The Citadel is the 'clipped adverb', where an adverbial quantifier takes the form of an adjective, usually omitting the <-ly> suffix yet still functioning as an adverbial. Two utterances follow this pattern: "I've got to have red meat and a drop of stout regular for the blood" and "Do you work proper?". The feature is attested in the eWave and was common to the era, previously used by Anglo-Welsh writers Margiad Evans's Country Dance (1932) and Geraint Goodwin's Heyday in the Blood (1936). Another attested feature is the adjectival use of 'bad' for the sense 'unwell' which the $E D D$ records throughout Wales and England. "I feel bad doctor" a patient says from their bedside ('bad in bed' is a common phrasal variant of this); it was used in Jack Jones's Black Parade (1935). Another attested feature is Mrs. Page's use of iechyd da, which in Cymraeg is a toast to good health $(G P C)$.

A medical colloquial phrase is also used: 'trouble with my tubes'. When the new doctor Manson questions the miners' coughs, Mr. Owen metalinguistically replies: “Ahh yes, I've heard it all my life. 'I've got trouble with my tubes', the number of times I've heard that expression!" The phrase is not attested in any record, although is likely a shortening of the specialised medical vocabulary: bronchial tubes. Old Thomas, 'The Drive', is a title that refers to Old Thomas's occupation as 'driver'. Again, this term does not match records (OED nor $S A W D$ ), however, today finds

\footnotetext{
${ }^{26}$ Unfortunately, with the exception of Dylan Thomas's Under Milk Wood, the analysis of WE in $20^{\text {th }}$ century plays (indeed anything but the Elizabethan era) is beyond the scope of this thesis.
} 
currency in south Wales and south-west England; ${ }^{27}$ The Citadel being one of the earliest instances it has been recorded.

\section{Grammar}

Several common WE grammatical usages derived from Cymraeg and English language contact are used in the film. The confirmatory interrogative tag (or 'invariant discord tag', eWAVE) 'is it/isn't it' is used: "Time for your mother back, isn't it.", a tag widespread throughout Wales ( $S A W D)$, likely loaned from Cymraeg's ' $d$ 'ydw fe' or 'onid $y d y w$ ' (is it/isn't it). It also was featured in Jack Jones's 1935 Black Parade. Mrs Page uses 'There' as a demonstrative pronoun, or Demonstrative There's $+\mathbf{a d j} / \mathbf{N P}$, in this instance using a noun phrase, in "there's a love". This is a structure borrowed from Cymraeg, where 'dyna' can act somewhere between a demonstrative pronoun or demonstrative adverbial being both 'that is' and 'there is', and commonplace throughout Wales $(S A W D)$. Finally, "chilling terrible, she was" demonstrates use of focus fronting, a structure developed from Cymraeg's sentenceinitial emphasis, and is common in south Wales (SAWD). The Citadel also exhibits the treatment of past-tense irregular verbs with regular inflectional suffixation, with Old Thomas stating that he 'knewed it' (Lewis Jones used this a year prior in Cwmardy).

\section{Pronunciation}

In the film, Mrs Page and Mr Owen both exhibit energetic expressions, in a manner that might be called exaggerative, and in some cases comical. That being said, the composure of the phonology does match what we know from SAWD's records. Mrs Page's pronunciation of 'your', 'poor', and 'sure', all use the phonemic vowel nucleus: / $\mathbf{u} \mathbf{u} \mathbf{w} \partial /$, which places medial emphasis on a semi-vowel /w/, creating two

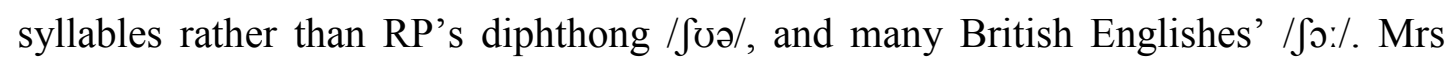
Page also omits the semivowel /j/ medially in 'regular', thereby producing: /regələ/ rather than /regjələ/; this lack of medial /j/ following consonants occurs in all regions of WE (SAWD; Parry, 2015:26). Finally, pronunciation of trilled-/r/ (a.k.a. rolled-/r/) is present, again, $S A W D$ attests both tapped and trilled /r/ largely in north Wales, although it does occur in southern dialects too.

\footnotetext{
${ }^{27}$ Present author's observations
} 
Many of the child actors of Blaenelly, noticeably speak in RP (25:00), this likely reflects the environment of the British film industry, in that child actors from Wales were scarce during these earlier years. Several minor characters, such as colliers, that were cast both exhibit genuine accents and contrived ones, again likely reflecting the casting director's lack of genuine WE speakers.

\section{Metalanguage}

There is some metalinguistic commentary about Welsh accents provided by one of the English doctors, Mr. Denny. In his practice, Denny does a mocking impression of $\mathrm{WE}$, attempting to enunciate the rise-fall intonation common to the variety. The character (and therefore actor, Ralph Richardson) achieves this by breaking his utterance into segments, illustrated here with hyphens: “Doctor Whibley's - gone to Swansea - on important - business' (09:50).

\subsubsection{The Proud Valley (1940). Dir. Pen Tennyson.}

The Proud Valley was directed by London-based Pen Tennyson and written by Fredda Brilliant, Louis Golding, and Herbert Marshall. The drama film is set in a nondescript mining valley in the 1930s, where David Goliath (played by singer, Paul Robeson), a Black American, arrives in Wales to work in the mines, and being musically-inclined, wins the hearts of the local Welsh community. Robeson, who would later state this was the most important film-role of his career, moved to Wales to shoot, reportedly impressed by the authenticity involved in the motion-picture (Hoyt, 1967:94). The casting of Robeson was exceptional. Not only was Robeson one of the only Black actors to be cast in a British film during the 1930s-1940s, but he played the film's sympathetic protagonist (Berry, 1994:166). Equally significant, however, was the casting of Rachel Thomas as the 'Welsh mam' character. Throughout much of Welsh film's history, Ryan (2000) argues that strangely Welsh women were largely absent, with films about Wales often using English, Irish, or American actors to play Welsh women (p.39). The Proud Valley was the first exception. From here, Thomas would go on to play several archetypical Welsh miners' mothers, and although occasionally pandering to certain cultural stereotypes, became a symbol of Welsh womanhood in part due to the authenticity of her acting and native accent. 
An eagerness for authenticity was important to director Pen Tennyson. Before the film was released, Western Mail reported that, much like The Citadel, two Welsh dialogue writers had been employed: Clifford Evans and Jack Jones (the latter having written Black Parade in 1935) writing: 'the dialogue will be the real thing, not an Englishman's music-hall idea of how a Welshman speaks' (cited in Berry, 1994:169). However, following release a reviewer for The Observer had reservations about the final product: 'I should like to have seen this film made entirely in Wales with a Welsh director, [and] a wholly Welsh cast' (cited in Berry, 1994:169). These comments suggest that despite anticipation, the film had failed the test of 'authenticity'. Here, between an early non-native filmmaker, native novelists who wrote in-dialect, and film critics, we can see how the concept of an 'authentic' WE within film was being discursively constructed. Whilst one pre-release publication (Western Mail) believed that some Welsh voices and input from Welsh screenwriters would validate the dialogue's 'realism', a reviewer from The Observer thought the input was not Welsh enough.

\section{Lexis}

Like The Citadel, the lexical dimension of the film's filmic dialect shares commonalities with the literature of the era. Items present include affirmative 'aye' ( common in Northern English, Scottish English and Irish English too, OED); the borrowed Cymraeg endearment term 'bach' (GPC: small); vocative expression 'man' (or 'mun'), that the SAWD notes usage in south Glamorgan and Gwent; and 'butty', a term for workmate known throughout south Wales and the Welsh borders $(S A W D)$. 'Bad' for 'ill' is used in its full phrasal form as well as Dilys Parry states someone is 'bad in bed'. Other lexical usages that are not attested in records include colloquial terms that might be common throughout the British isles, such as 'right-o' (OED: affirmative interjection) and 'to be sure', a adverbial affirmative phrase that the $O E D$ states is 'associative' of Irish English (linguistically stereotypical) today.

\section{Pronunciation}

From a phonological level, at times, it is difficult to tell whether a character is meant to be using the WE dialect or not; an early scene depicting miners coming up from a mineshaft features a variety of fast, argumentative voices that colour discourse, some 
Welsh, others clearly not. In the film's contextual defence, of course, we must consider that Welsh mines did attract English speakers from throughout the British isles (and in Robeson's case, America!), so this may be a non-issue.

As for the main leads, Dilys Davies returns from The Citadel to play Catrin Owen, who once again exaggeratedly enunciates much of her speech. The character of Gwen Owen, played by Janet Johnson, noticeably speaks in RP, however, does manage to produce some phonemes typical of WE, for example the $S A W D$-attested diphthong /ru/ (represented orthographically as $<\mathrm{iw}>$ ) in her pronunciation of 'you' [41:00]. Similarly, Emlyn Parry, played by Simon Lack, has an inconsistent accent varying between RP and WE, but masters the long vowel /o:/ in 'let me go!' (rather than the RP diphthong/əv/) [27:20]. Although Englishman Edward Chapman, playing Dick Parry the choirmaster, uses the attested /j3:/ pronunciation rather than the RP /jiə/ for 'year' (SAWD), he mistakenly pronounces 'eisteddfod' with a voiceless fricative /f/ rather than voiced /v/ in the word's coda; which considering his wife's perfect pronunciation, and the fact he is a choirmaster, is amusingly inexcusable. Although the child Dillys Parry, played by Dilys Thomas, is a user of WE, many of the children again speak RP, one even pronouncing 'eisteddfod"s medial voiced interdental fricative as it is orthographically represented: a voiced alveolar plosive /d/.

From a phonological perspective, it is clear to see why The Observer's reviewer was so disappointed with the poor quality of accents within the film, especially when it is apparent that actors had read from the script using English language conventions rather than Cymraeg (as is the case with Eisteddfod), and could have easily have been avoided by the guidance of the WE users on-set. An argument could be made that a director who had more knowledge, or had been a user, of WE might not have made this error. In all, the inconsistent representation of WE phonology in The Proud Valley pales in comparison to the infamous representation of WE that premiered just one year later. 


\subsubsection{How Green Was My Valley (1941). Dir. John Ford.}

In 1941, Hollywood stalwart John Ford, known best for his westerns, directed How Green Was My Valley, a drama set in the Welsh mining valleys during the $19^{\text {th }}$ century and tells the story of the Morgans, a mining family, during the valley's heavy industrialisation. Taking the Oscars for Best Picture, Supporting Actor, Cinematography and Art Direction, it did exceptionally well with American critics and audiences in part due to its rose-coloured view of an old Celtic nation, a theme much-needed following the outbreak of the war (Carradice, 2014). Until 1997's Twin Town (see below), How Green Was My Valley was the most successful film that had focused on Wales (Perrins, 2000:152). Although Ford initially wanted to shoot his film in Wales, the second world war prevented it, he therefore created a Welsh town on a 3000 acre filmset in California (Carradice, 2014). The inauthenticity of the Hollywood set, however, was the least of the authenticity problems associated with the motion-picture.

In $H G W M V$, Ford produced a highly-romanticised vision of Wales, much of his directing informed, bizarrely, by the sentiment he had for his Irish ancestry (Berry, 1994:160), wanting little more than to represent an idea of 'American Celticism' by creating a simplistic Good Celt/Bad Saxon dichotomy (Perrins, 2000:164). Ford never visited Wales, and was indifferent about the distinctions between Celtic nationalities, in the film mixing Irish pastimes with his representation of Wales (e.g. Irish jigs) and populating his film with Irish, American, and Canadian actors who more often spoke in Irish English or RP rather than WE (Carradice, 2014). Ford's blatant disregard for any sort of linguistic (and cultural) authenticity is perhaps best illustrated in Ford's own response to this criticism, where he stated: '[Wales] is a Celtic country, isn't it? They're all micks, aren't they?' (Berry, 1994:161). Although the only Welshman Ford casted was Rhys Williams, who played Dai Bando, Carradice (2014) argues that despite its poor representation of Welsh life, it introduced the Welsh nation to American audiences: 'This film, sentimental and stereotyping as it was, at the very least brought Wales to the forefront of [American] imaginations. And for that it deserves to be remembered' (Carradice, 2014: para 16). 
The screenplay was written by Philip Dunne, and was adapted from Richard Llewellyn's romanticised 1939 novel of the same name, although it too has been criticised of pseudo-Celticism. Coincidentally, upon the novelist's death, it was revealed Llewelyn was in fact an Englishman, and wrote under the pretence of being Welsh, having little experience of the nation other than time he spent with his grandfather as a child (McVeigh, 1999).

\section{Pronunciation}

The fundamental question of how inauthentic $H G W M V$ is is problematic. Objectively, the filmic dialect does not match WE, especially in its representation of phonology. With the presence of Irish English and Received Pronunciation accents throughout, it would be surprising if any WE users identified strongly with the film on grounds of its linguistic realism, today or back in the 1940s. This can be bestillustrated with the pronunciation of a proper personal noun: Meillyn. Unlikely to be mispronounced by WE speakers, despite deriving from Cymraeg and containing Cymraeg phonemes, Meillyn is pronounced by Irish actor Arthur Shields as /marklin/ rather than /merin/[52:00]. The voiceless alveolar lateral fricative is represented with a consonant cluster of velar plosive + alveolar lateral approximant. As this phoneme is rarely part of English phonology, it is commonly misheard or mispronounced by actors and writers, for example Shakespeare rendering Llewelyn as Fluellen in Henry $V$ (see Chapter 6). Gwilym Morgan (played by Donald Crisp), Beth Morgan (Sarak Allgood) and their son Huw Morgan (Roddy McDowall) waver between their native varieties and a Welsh accent, suggesting they had some dialect coaching. The same cannot be said for characters such as Mr. Gruffydd (Walter Pidgeon) Bronwyn (Anna Lee), and Angharad Morgan (Maureen O'Hara). Nevertheless, the blame for the inaccuracy of WE phonological representation falls upon the apathy of director John Ford, rather than the actors, who evidently did the most they could with his direction.

That being said, the fact that John Ford (or his production team) went out of the way to use Cymraeg in the film's jovial singing scenes (e.g. Calon Lân) (which seem likely to have been added in post-production) suggests some thought was put into the film's use of language. However, the Cymraeg-singing is still played for laughs with one character finishing his verse with a held alveolar trill (rolled-r), a linguistically stereotyped feature, more common in northern WE than southern (SAWD). The 
English-sung folk songs in comparison are not only accented in Irish English, but have no recorded historical tradition in Wales, the fact that the Gwilym Morgan's drunk-ditty at [14:40] references one 'Peter O'Pea' strongly suggests it was written into the screenplay by Dunne through input from the Irish actors. It also demonstrates that the American filmmakers' knowledge of language usage in Wales comprised of knowing only about Cymraeg, ultimately not recognising any presence of a Welsh variety of English (or folk-song tradition); a fact that seems peculiar considering both The Citadel and Proud Valley had premiered years earlier.

\section{Lexis and grammar}

Presence of WE lexis in the film is minimal. Present is the interjection 'indeed to goodness!', which at this point in WE literary dialect had become enregistered if not becoming associated with WE linguistic stereotyping [42:20]. There is no record of the 'dada' [8:00] and 'momma' [47:30] being used as a children's endearment term for their parents. A quick glance through Richard Llewelyn's novel reveals that both are used heavily, Llewelyn's limited time in Wales suggests he may have heard it in passing, and believed it had wide frequency.

The nonstandard grammatical structures that do appear in $H G W M V$ match records, all of which are frequent. Demonstrative There is used (e.g. 'There's lovely, you are' [9:30]) by Mrs. Morgan, one of the few characters to consistently use the structure. Often, however, she uses it in an 'uncontracted' form, for example: 'There is good' [1:20:22]. This does not match usage in the $S A W D$, indeed, this film is the sole usage in all sampled WE literary/filmic dialects. What it does match, once again, is usage from Llewelyn's novel (e.g. 'There is silly you are', p.16), thus demonstrating how much dialogue must have been lifted from Llewelyn's work for this adaptation. Focus fronting exists too, in instances such as Mr. Parry's: 'only asking a civil question, I was' [36:30] and the postman's 'From Windsor Castle, it is!' [44:00], as does confirmatory interrogative tag 'is it?' in 'It will be he that's giving the beating, is it?' $[1: 10: 30]$.

Despite $H G W M V$ 's pseudo-Welshness (it represents grammatical structures well), the film is important to the study of Welsh fictive English. It stands as an example of how artists/directors may be chastised for not attempting to discursively construct the 
notion of a fictive dialect's authenticity. Ford was shooting films in the US for American audiences; audiences who were predominately unfamiliar with WE. The viewers who would come judge the 'authenticity' of his film's dialect were absent until well after the film's premiere.

The concept of a Welsh 'authenticity' of dialect was of little matter to Ford; he had no qualms about substituting another variety in place of the expected fictive dialect derivative. There is barely an 'authenticity parasite' here. Like, Caradoc Evans' work, Ford's fictive WE is something almost wholly removed from its source by using Irish English (a readily available accent in Hollywood) to index a sense of Celticness, and only then, by extension, Welshness.

\subsubsection{Halfway House (1944). Dir. Basil Dearden.}

Directed by Englishman Basil Dearden and written by both the London-born Angus MacPhail and the Welsh screenwriter Diana Morgan, Halfway House is the second prominent Ealing Studios motion-picture to feature Wales. The premise concerns a group of holidaymakers converging at The Halfway House, a hotel within the remote Welsh countryside, during WW2. The hoteliers, a welcoming Welsh father Rhys (Mervyn Johns) and his daughter Gwyneth (Glynis Johns), seem sincere, however, the holidaymakers begin noticing both their strange attributes (lack of shadows) and their inn's (radio broadcasts and newspapers are dated a year old). The ultimate reveal is mystical: the hoteliers are ghosts; their hotel a figment of the past, having been bombed a year prior.

Berry (1994) writes that the film is very much set 'in a Wales of the imagination', Ealing Studios providing 'wish fulfilment comedies and fantasies' during WW2 (p.223). The film, like others before it, was not shot in Wales, but upon the Devon/Somerset border. To Berry, the final result was insensitive. Presence of Welsh folk-songs such as Sospan fach, and silly conversations aboard the train portrayed several of the Welsh elements as little more than comical farce (Berry, 1994:223).

\section{Pronunciation}


Perhaps the best examples of using a sense of Welshness farcically is in the presence of the train passengers and railway porters (Jack Jones and Moses Jones) in the beginning scenes, whose accents, though are non-contrived, are exaggerated and their actions fatuous. For example, the train passenger that offers Margaret (Philippa Hiatt) a welshcake, performs a very long, perhaps over-trilled, trilled /r/ when she pronounces 'real butter', which seems only to be included to index the 'comical' difference of Welsh accented speech compared to RP, Margaret being visibly uncomfortably bewildered by the 'foreign' interlocuters during the scene.

Meanwhile, the two Welsh-accented hosts ultimately fulfil the stereotype of the Welsh as the Fantastic. Nobody else with regional accents, non-native accents, or RP-speakers exhibit traits of being comical or being mystical. The only other character with a non-contrived Welsh accent is Mrs Morgan, played by the wellrespect Welsh actress Rachel Morgan, a minor hotelier at the beginning of the film.

Of the three main Welsh characters (Rhys, Gwyneth, David Davies), it is only Mervyn Johns' host character Rhys that uses an native Welsh accent. His accent is a commanding force in the film, and when it is used, it draws the attention and obedience of the other characters. Glynis Johns' hostess character is both the inuniverse and real-world daughter of Mervyn Johns. Glynis, born in S. Africa, and not raised with the accent, uses her best attempt, contrived as it is, being likely dialectcoached by her father. David Davies, a well-renowned conductor, though Welsh born and speaking limited Cymraeg, notably uses an RP accent, subtly indicating that he has in some manner eradicated the accent from his language usage.

\section{Lexis and grammar}

The film does not break new ground in attempting to represent the lexis or grammar of WE. The railways porters use vocative 'mun', and Rhys uses the endearment term 'fach' for Gwyneth ('Show David his room, Gwyneth fach'). Gwyneth peppers her speech with Cymraeg loans such as 'bore da' and 'eisteddfod' to index her Welshness where her accent wavers. Gwyneth also refers to her father as 'dada' [30:00], which matches usage used in How Green Was My Valley (see above) and does not match dialectal records, possibly being a fabrication by the author of film's source material. Its inclusion here as well could be hinting towards unrecorded usage 
during the 1940s, however, more likely is that its prominence in $H G W M V$ influenced Halfway House's screenwriters to use it as a intertextual point of reference for filmgoers (the writers of course have no reason to believe it was not genuine). Finally, Demonstrative There and focus fronting are both used by Mrs. Morgan, e.g. 'A sailor on a farm, there's daft, it is' [11:00] as well as passengers on the train, as is the interrogative tag 'is it'.

\subsubsection{A Run for Your Money (1949) Dir. Charles Frend}

A Run for Your Money was directed by Charles Frend and its screenplay was written by Frend, Clifford Evans and Richard Hughes, with Diana Morgan providing 'additional dialogue'. The comedy revolves around the misadventures of two south Welsh colliers who win tickets to visit London and watch a rugby match, however, they quickly lose each other when they arrive. The two miners David 'Dai Number 9' Jones and Twm Jones are played by Welshmen Donald Houston and Meredith Edwards respectively, and are later accompanied by their fellow townsman Huw, a harpist (Hugh Griffiths).

Much like Halfway House and other motion-pictures based on Wales or the Welsh during the 1940s -1950s, A Run for Your Money is a simple genre film, exhibiting simple escapist suspense and catering to stereotypical characters (Berry, 1994:215). Berry argues that from the first scene, Frend presents the Welshmen as more simpleminded than guileless' (p.217). The film's critical reception is testament to this. Although Ealing Studios intended the film to be the Welsh equivalent to the Scottish comedy Whisky Galore (1949) (it was nominated for the BAFTA for Best Film that year (imdb, n.d:a)), Welsh audiences reportedly found it too simplistic, and at worst patronising (Stephens, 1999).

It should be stressed, however much the Welsh public disliked the film, that ARfYM marks several Welsh film firsts. It is the one of first big budget films with a Welsh theme to a) feature protagonists who are Welsh b) have said protagonists played by actors from Wales and speaking native WE and c) have a writing team that comprised of two Welsh writers: Hughes and Morgan, the latter also receiving a writing credit for Halfway House. Morgan was reportedly brought in to help write 
the dialogue for scenes involving Dai and Twm, but only receiving the credit: 'additional dialogue', a credit she spoke out about, stating: 'I was put on the film when they were in a mess. I re-wrote the script more or less. The dialogue needed putting into shape' (cited in Berry, 1949:218). Morgan's comments are interesting in that the speech represented in the film holds true to what we know of the WE of the late 1940s, adding nuanced qualities hitherto absent, and avoiding linguistic stereotypes. Arguably, Diana Morgan's input contributes to the most accurate representation of WE in film during this early era, indeed, the film might have been worse off without her doctoring.

That is not to say that linguistic stereotypes were not used for comedic effect, only that Twm and Dai's speech does not reflect such usage; Twm and Dai are comical characters, but it is chiefly through their actions, rather than their dialect, that drive the comedy (even if their tone when marvelling at London can seem exaggerated). Regarding the linguistic stereotypes, the film uses Cymraeg orthography coupled with stereotypical toponymy for comedic effect. The town Twm and Dai come from has the lengthy title: Hafoduwchbenceubwllymarchogcoch. The name is a comedic reference to Wales' longest placename: Llanfairpwllgwyngyllgogerychwyrndrobwllllantysiliogogogoch, and much like Llanfairpwllgwyn, which has pop-cultural currency as much today as it did in the 1940s, plays off the fact that non-Welsh readers will find Cymraeg/WE orthography bemusing, or comical, when parsing graphemes to their understanding of phonemes.

\section{Lexis}

The writers have stuck to several well-attested lexical items that their contemporary filmmakers had also utilised. This suggests intertextuality, and perhaps a sense of WE enregisterment within the British filmmaking zeitgeist. The writers use vocative 'mun' (e.g. 'I haven't done nothing, mun'); clipped adverb usage for 'proper' (e.g. 'See it proper'); Cymraeg loan 'iechyd da' as an interjective; and affirmative 'aye'. They also use variations such as the compound 'boy bach' (Weng), used vocatively ('Where are you, boy bach?') and formed using the diminutive endearment term, and the compound 'pit-butties' in the sense 'mining workmates'. 'Butt', a shortening of 'butties' and common today as a vocative in south Wales, makes its first appearance in WE fictive dialect ('You've only got tuppence, so far, butt'). 
There are nine new lexical items that are incorporated into WE filmic dialect that have parallels in the adjacent WE literary dialect movement. Several of these may stem from Diana Morgan's input and editorial changes to the script. The one English-derived lexical item, 'tidy', as an adjective for 'decent' common to the Welsh borders and Glamorgan (SAWD), had been popularised by Caradoc Evans (1915) and Jack Jones (1935), but makes its filmic dialect debut here. The other eight additions are Cymraeg loanwords. For example: 'duw' [god!], an interjection that can be dated to Allen Raine's writing (1906); 'twp' [foolish] ('Don't be so twp'), an adjective appearing in Lewis Jones' Cwmardy (1937) with the SAWD recording usage in Gwynedd and south Glamorgan; 'ych-y-fi', an expression of disgust common throughout south Wales, and popularised in writing by both Raine (1906) and Caradoc Evans (1915) as 'ach y fi'; and finally interjective 'daro' [dash it] $(G P C)$, used in Geraint Goodwin's Heyday (1936). There is some Cymraeg which is unsubtitled, such as 'da iawn' [well done] $(G P C)$.

Most interesting, however, are the three variants of interjections that semantically derive from Cymraeg words for the Christian devil: 'diawch', 'diawl' and 'cythrawl'. 'Diawch' had formerly appeared in Goodwin's writing (1936), whilst 'diawl' (attested in Gwynedd, SAWD) and its variant 'jawl' had appeared in Margiad Evans' Country Dance (1932) and Lewis Jones's Cwmardy (1937). Whereas writers such as Margiad Evans had more opportunities to incorporate lexical items and variants thereof into their work, it seems noteworthy that ARfYM achieved this display of variants with only a feature-length running time (although, it could be argued its frequency might index the stereotype of Welsh religiosity).

\section{Pronunciation}

Two common phonological forms are used by the Welsh characters: 'Huw' is pronounced /hıu/ not /hju:/, producing the Cymraeg diphthong and dropping the semi-vowel common to other regional varieties; and 'yours' is pronounced with two syllables: /ju:wəz / instead of /jo:z/ or /juəz/ in other varieties. Furthermore, 'girl' is pronounced /gel/ rather than /gs:1/, an open-mid front vowel /e/ replacing open-mid 
central vowel /3:/. ${ }^{28}$ 'Train' is pronounced as /tre:n/ rather than /treIn/, therefore a close-mid front vowel /e:/ replacing a diphthong/ei/. This is attested throughout Wales by the $S A W D$.

\section{Grammar}

Grammatically, ARfYM matches much of what we know from records. Demonstrative There ('There's lovely, you look, Dai') and focus fronting ('shouting, he is!') are both present and within combination too (similar to Caradoc Evans's literary dialect) in: 'There's careless, you are'. Represented also is nonstandard verb agreement in 'do it?' for 'does it'? in 'Not exactly take your breath away, do it?'. ARfYM is the first text to depict WE discourse markers on film, featuring both 'like' and 'see' in: 'If it's after the match, we'll meet at Paddington, under the clock, see' and 'this is more refined, like' respectively.

\section{Metalanguage}

The metalinguistic observance of the miners' accents by another character, con-artist Jo, drives the story forward when Twm and Dai arrive in London. Jo recognises the two Welshmen immediately by their accents, identifying their 'foreignness' thereby making them easy marks for conning. Jo bites off more than she can chew, however, when she asks: 'Is this your first visit to London?'. The miners reply: 'Aye, it's our first visit to England'. Jo furrows her brow in confusion: "But.. Wales is a part of England." This conversational exchange ends with Dai and Twm sniggering at the well-known English assumption and responding: 'It's easy to see you've never been to Wales, miss'. Later, Jo, who has been 'courting' Dai, exasperatedly utters a prejudiced remark in referring to Dai by the derogative, 'taffy': "Just like a Taffy, never open-handed until the shops are shut."

\subsubsection{Summary}

To summarise this section on early WE filmic dialect, the era began with the popularity of numerous mining movies like The Citadel, Proud Valley, and How

\footnotetext{
${ }^{28}$ In WE literary dialect this is often written <gel> (arguably a phonetic respelling), for the sake of its phonological form, it is listed in this section under Pronunciation.
} 
Green Was My valley. They offered simplistic examples of mining speech communities, mirroring several linguistic forms being used in literature.

There was some early indexing of the WE variety with ideas of 'fantasy' with Halfway House, as well as portraying Welshmen as comical in A Run for Your Money. Attested grammatical features such as confirmatory interrogative tags, demonstrative there, and focus fronting were present from the beginning of WE filmic dialect, and films like A Run for Your Money were well-rounded with attested lexical, phonological, and grammatical representation. The least 'authentic' was How Green Was My Valley, a film that to this day is still chastised by viewers for its poor representation, especially in the phonological domain.

\subsection{Welsh film around the mid-20 ${ }^{\text {th }}$ century: 1959-1967}

Following A Run for Your Money (1949), there was a notable dearth of films that tackled Welsh themes and films in which WE dialect would be represented. It was not until ten years later that a notable Welsh-related film was produced. Within this next ten-year period, there are two films that are of interest. Very much reminiscent of the films that came before them, Tiger Bay (1959) and Only Two Can Play (1962) are situated in Wales and do their best to source Welsh actors and strive to represent their versions of Welsh fictive English.

\subsubsection{Tiger Bay (1959), Dir. J. Lee Thompson}

Directed by Englishman J. Lee Thompson and written by Londoner John Hawkesworth, the BAFTA award-winning Tiger Bay (1959) is a crime thriller set in the old eponymous Cardiff docklands. Berry (1994) writes that it 'ranks among the finest British suspense thrillers of the fifties and is even more eloquent as a study of childhood' (p.233). Hayley Mills was cast as the child protagonist Gillie, a former Londoner and outcast in the multi-ethnic bay, and performs her scenes in a naturally childlike manner, especially in the first scenes alongside numerous local dockland children, many of whom had no acting experience.

The film has had a lasting effect in the Cardiff community, being 'most loved by the local inhabitants [...] for its scenery and the memory it evokes' (Sinclair, 2003:43). 
Following the film's production, Tiger Bay's multicultural port community was largely dismantled by the local council. Although this community nostalgia is strong, it has been argued that Tiger Bay has a notable absence of Welsh thematic quality, with Berry writing: 'the Welsh people in the film - the local inhabitants, the actors in cameo roles - are never quite distinctive enough to leave an enduring impression' (Berry, 1994:234). Berry may be alluding to Welsh characters' screen presence, or possibly their character representation.

\section{Pronunciation and lexis}

Although true that the protagonists are indeed non-Welsh and are unconcerned with Welsh life: Gillie, a speaker of London English, and her criminal friend Korchinksy (Horst Buchholz), speaking in a filmic Polish English, the representations of the Welsh characters and their speech are not contrived. Gillie lives with her aunt Mrs Phillips (played by Englishwoman Megs Jenkins), who wavers between speaking with a Welsh accent and RP, and shares the apartment block with several native users of WE who would have been familiar faces in the British film industry such as Mrs Parry (Rachel Thomas from Proud Valley) ${ }^{29}$ and P.C. Williams (Meredith Edwards from A Run for Your Money). There are also day-trippers that Gillie meets halfway into the narrative [1:06:56], who are indexed as belonging to a different community than Gillie is used to (i.e. 'valleys' rather than urban Cardiff). One might view their performances as slightly contrived, though their linguistic traits they exhibit match records such as pronouncing 'no' accurately with the vowel /p:/ rather than RP's diphthong /əo/; the alveolar tap /r/ in 'right'; the pronunciation of 'you' with the diphthong/Iu/; and pronouncing 'hurt' with an omitted initial/h/. Lexically, they are marked as distinct in their use of affirmative 'aye'.

Much like the day-trippers, Gillie's neighbour characters' Welsh Englishes are clearly valleys accents, rather than representative of the urban variety of Cardiff English. In fact, the only character to use a native Cardiffian accent is a child that Gillie attempts to play with. Played by Neil Sinclair (today a local historian) of AfroWelsh heritage, the boy shouts: 'Go on Gillie, go back to London, scram!' [7:40] in

\footnotetext{
${ }^{29}$ Coincidentally, this is the second 'Mrs Parry' role Rachel Thomas has played, the first being Proud Valley.
} 
an unmistakably WE accent. Drama student Sinclair was chosen by director Thompson for the role (Sinclair, 2003:43). Regarding the Cardiff variety of English, Sinclair has affirmed that his voice was the only Cardiff accent in the film (Sinclair, n.d.). Sinclair was not only one of the first actors to use a Cardiff accent in film, however. Sinclair also takes the accolade for being one of the first child actors to use WE on film, breaking the tendency for filmmakers to utilise RP-speaking children (a evident production restraint). Equally impressive however, is that with Thompson's film-direction, Tiger Bay encapsulates not just the district's urban aesthetic, but also the very real cultural and sociolinguistic situation of Tiger Bay - with its many ethnicities and English varieties represented. Indeed, with Tiger Bay, Neil Sinclair might be the first Black WE speaker on film.

Another striking linguistic element to the film surrounds another child actor. When a lost Korchinsky, who clutches a note with his destination upon it, asks a child (Michael Anderson Jr.) if they know where a 'Llanwis court', the child is confused. However, upon reading the note the youth understands and exclaims: 'Oh clan-wis court' (this is verified by the film's subtitles, see Figure 8.1). Here, the young character (perhaps even the actor) who speaks an English English (Anderson was from Middlesex) understands that the phoneme is not an alveolar lateral approximant /1/ like Korchinsky pronounces, knowing that there is a clear difference to the correct phoneme - a Cymraeg voiceless lateral fricative /1/ (graphemically <LL>) - however can only approximate a velar plosive coupled with an alveolar lateral approximant /kl/ himself. Once again this commonly misheard phoneme manifests itself in fiction. Nevertheless, this scene, demonstrates what may linguistically have been a common scene within Tiger Bay: the actor representing one of many portside children accommodating between their native variety of speech and the WE of the Cardiff urban area used by children around him (such as his friend played by Neil Sinclair). 


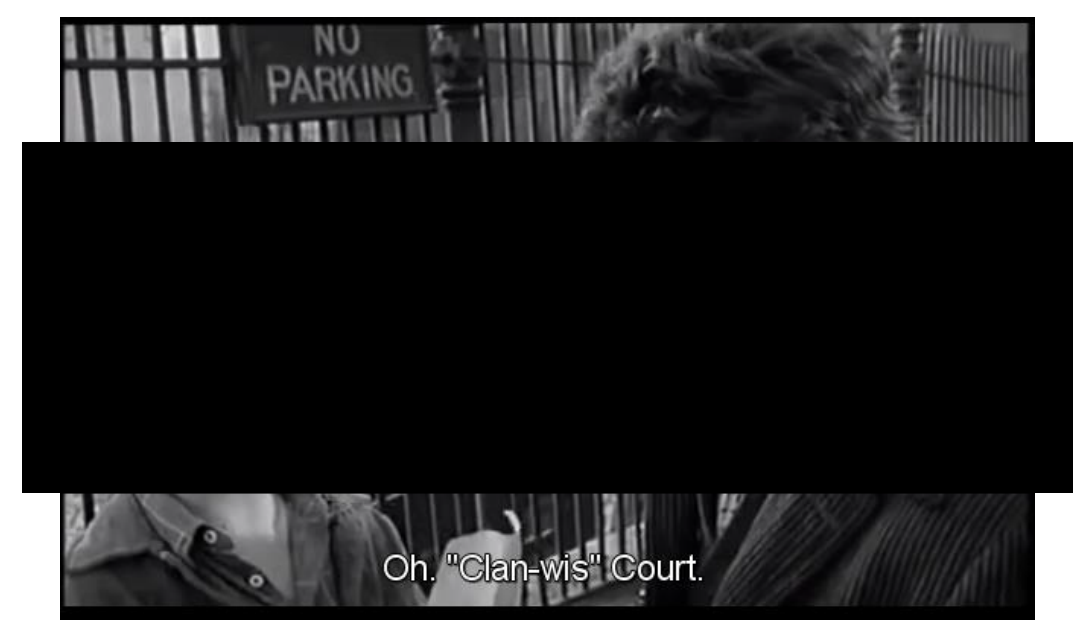

Figure 8.1: Screenshot of Tiger Bay. Llanwis or Clanwis?

\subsubsection{Only Two Can Play (1962), Dir. Sidney Gilliat}

Adapted from Kingsley Amis's novel That Uncertain Feeling (1955), Only Two Can Play's screenplay was written and directed by Englishmen Bryan Forbes and Sidney Gilliat. The comedy film was filmed around Swansea, is set in the fictional Aberdarcy, and follows librarian John Lewis (Peter Sellers) who finds his marital commitments to his wife Jean (Virginia Maskell) hard to adhere to when he meets the wife of a local councillor, Elizabeth Gruffydd-Williams (Mai Zetterling).

Film historian Berry said it was 'the funniest of all Welsh screen comedies', adding that the text 'retains many of the novel's provocative qualities, for instance [treating] the Welsh language and the minority cultural scene with almost cavalier disdain' (Berry, 1994:237).

However, Kingsley Amis, who had lived in Swansea and lectured at its university, was disenchanted with the film, stating it was 'crawling' with 'Welsh eccentrics' thereby contributed to a 'contrived Welshness' (Berry, 1994:239-240). Reportedly, Amis's intention with his novel was to bring out the deviousness of the Welsh who he believed, compared to the English, were 'more cheerful, hospitable, and [had] great sense of irony'. Although Amis's comments do suggest some generalising and association with the Welsh stereotype of The Comical, his purpose was to write a novel that was not full of Welsh stage mannerisms - qualities he believed were 
inherent in the work of his contemporary Dylan Thomas; Amis stating Under Milk Wood was an insult to his own Welsh countrymen.

\section{Pronunciation}

Amis was also disappointed that the main parts went to English or non-Welsh actors (Berry, 1994:240). Amis's disappointment may have been connected to questions of 'authenticity'. This may have been due to Welsh actors often being overlooked in the British film industry, or it may have been to do with the performance of the accents, something Peter Sellers comments on below. The accents that characters use are a melange, in part due to casting English actors who knew little of the WE dialect. The poorest and most contrived accents come from both Jean (Virginia Maskell), whose wavering pronunciation and intonation makes it hard to pinpoint its inaccuracies, and Gareth L. Probert (Richard Attenborough), whose exaggerative Welsh accent makes it difficult to believe the character has any reported fluency in Cymraeg, especially with his over-trilled alveolar taps. Elizabeth Gruffudd-Williams (Mai Zetterling), a Welsh socialite who speaks in RP, was according to Amis, only partially correct, Amis stating: '[although] [Elizabeth] has a veneer of sophistication and Anglicisation, [...] at heart, she was a nice little Welsh girl' (Berry, 1994:240). Ieuan Jenkins, John's friend played by Kenneth Griffith, also has a slightly exaggerated accent reminiscent of the southern valleys. Griffith was born in west Wales, Pembrokeshire, and in interviews (e.g Tenby Poisoner trailer, n.d.) can be heard speaking in both a western WE and RP, suggesting the actor was, to some level, bidialectal.

That is not to say that there are no Welsh actors using non-contrived accents in the film. Mrs Davies (Maudie Edwards), John Lewis's landlady, speaks with her genuine southern WE accent, and notably elides her initial glottal fricatives, e.g. 'handsome' as /ænds $\Lambda \mathrm{m} /$; and yod-drops the palatal approximant in the collocation 'will you?', /wil ju:/ becoming /wilıu/. This process of initial /j/ occasionally being dropped in word-initial form if followed by a close back vowel, or the Cymraeg/ru/ diphthong, is attested in $S A W D$. 
John Lewis's young daughter Gwyneth (Meg Wynn Owen) was the second prominent character to use genuine WE; Owen's performance vying for one of the first performances of WE by a child (see Tiger Bay's Neil Sinclair above).

One could argue that the most 'authentic' non-native accent in the film is performed by Peter Sellers' protagonist character John Lewis. Perhaps one of the better examples of a Welsh accent being used by a non-native user of WE, Sellers, who was well-known for imitating different varieties' phonologies, took the imitation of accent very seriously. Regarding Sellers' accent, director Gilliat reported that Sellers worked 'assiduously to perfect a Welsh accent', so much so that he was worried about his co-star Maskell's ability to 'handle the voice requirements'. After just one scene Sellers wanted Maskell fired from production, a demand that was partially remedied through Maudie Edwards (Mrs Davies in the film) acting as voice-coach to Maskell (Berry, 1994:240). Despite Sellers taking his imitation, and the imitation of others, seriously, on-set he reportedly still had insecurities about voicing the part of John (p.240). Examples of Sellers' pronunciation that match records include his pronunciation of 'you' with the Cymraeg diphthong / jıu/ rather than the RP standard: /ju:/; only lightly alveolar tapping the /r/ phoneme in word medial positions (e.g. 'worried teenager' and 'three layers'); as well as correctly identifying where the stress often lies in WE pronunciations, for example the second from last syllable (a form loaned from Cymraeg) in a word such as 'creative urges' (/kri:'ertıv/) that often accounts for the 'rise-fall' intonation in WE. Sellers' pronunciation only rarely falters, for example in producing 'beauty' with the initial consonantal cluster of bilabial plosive and palatal approximant $(/ \mathrm{bj} /)$ which is often elided in WE (yoddropping).

\section{Grammar}

Although, like many texts both literary and filmic before it, Only Two Can Play uses the attested focus fronting (e.g. Ieuan's 'A laughing stock, I am' [1:18:00]), the principal and most frequent linguistic features that the writers used to index 'Welshness' were discourse markers and tag questions. This rarely feels contrived, and creates a sense of realistic discourse that was rare in Welsh film prior to this film. These can be divided into discourse markers, common tag questions, and WE's own confirmatory interrogative tags. Discourse markers include 'you see' 
('Megan keeps going on about it, you see' [16:00]), 'see' ('I lowered the front of it, see'). Tag questions are common throughout, for example: ranging from the less repetitive 'he's one of those, is he?' to full repetition in 'Did you do something with it, did you?' One example of the confirmatory interrogative tag common in WE is 'isn't it' in the structure: 'It gives an extra touch of flair to the bottle of HP sauce on the mantelpiece, isn't it?' [30:00]

\section{Lexis}

Well-attested vocative usages are used, for example 'mun' ('I'm not going to jump for it, mun' [15:10]), endearment term 'bach' ('Come on now, Sammy bach'), as well as new additions such as 'boy' (e.g. 'Fine, boy') and its variation 'boyo' ('You're going to get it in a moment, Boyo') used by John when angered. Arguably this second usage is often stereotyped as a marker of 'Welshness', with little to no record in dialect surveys. The affirmative 'right-o' [16:55], used prior in the film The Citadel, is used, as are Cymraeg loans uttered by Gwyneth Lewis and John Lewis, such as 'mam' [8:00], 'duw' [25:25] and the phrase 'nos da' [good night] [1:03:50].

\section{Metalanguage}

John Lewis also expresses knowledge of a varied vocabulary in deliberately using language to mock others. John asks where the 'thunderbox' is, a slang term for lavatory dating between the 1930s-1950s (OED) [41:50] at a well-to-do party, to the bemusement of an aristocratic gentleman. Second, John uses the colloquial verb 'muffed', when conversing with Liz about how he 'muffed' [messed-up] the interview. When the aristocratic Liz expresses confusion for the term, John humorously offers a deliberately mock linguistic explanation: 'I muffed it, you know. From the old Welsh word: to muff from a great height'. Here, John Lewis' character uses Liz's ignorance of Cymraeg, as well as its derivative WE and its corresponding Cymraeg language loans, and indeed all 'lowerclass' colloquial or slang speech, to sardonically humour both himself and the viewers (who would ideally have knowledge of the terms) with metalinguistic wordplay.

John understands both the confusion and fascination caused by unknown words, using it to his own comical ends. Another linguistic dimension to mention is his 
ability to mock others by imitating their accents (bear in mind Peter Sellers often imitated accents for comic effect). John's main targets are the Welsh socialites.

John's 'thunderbox' comment is delivered in a mock RP, creating a distinct juxtaposition between the slang vocabulary and an accent perceptually associated with the upper-class. When the gentleman is confused, he repairs his utterance with 'where does one go to wash one's hands?' [41:50]. When conversing with writer Gareth Probert (who he excuses of stealing his wife, Jean), John begins with a sarcastic tone before fully shifting into his mock RP to index a sense of the intelligentsia when he attempts to pronounce 'nourished' as three syllables rather than two (/nırIft/ /nırIfed/), a trait John associates with well-to-do circles. The conversation is replicated below with bold font indicating John's dialect shift into mock RP [40:00].

John Lewis: I was ploughing through your novel again the other day, Nourished is the Grass. Or, should I say: 'Nouri-shed is the Grass.' We have an unsigned first edition. I believe they are the rare ones, aren't they?

5 Gareth Probert: [Ignores John Lewis, talks to Jean] Are you coming to the first night of my play, Jean?

Jean Lewis: Oh, we'd like to very much, but a bit difficult for me, you see. But John'll be coming, won't you, love?

10

John Lewis: Oh. Yes, yes. Well of course, I get in free you, you know. What's it called?

15

Gareth Probert: 'Bowen Thomas, Tailor of Llandeilo.'

John Lewis: What a fabulous title. I wonder why nobody's used it before. Is it a comedy, is it?

In the final utterance (line 16-17), John reverts to his WE accent, to emphasise this shift, the writers (or possible Sellers through improvisation) add WE grammatical flair with a tag question, a marker of WE grammar that the film has largely established prior. In this scene, and others in which John attempts an exaggerated RP, parts of John's Welsh accent surface. Effectively, Sellers is performing a WE variety, and then upon this phonological layer adopts an RP accent: constructing an ever more complex series of portrayals for any dialect actor to perform. 
However, it is not just RP that John shifts into, he also shifts into a secondary WE. At 47:35 John mockingly imitates the accent of his elderly landlady (Maudie Edwards) when her dog Sammy starts barking. Unlike his own pronunciation of John, Sellers distinctly imitates a different WE: his rise-fall intonation is exaggerated with longer length between syllables, and he pronounces 'here' as / hj3:/, a trait he does not produce usually (attested in $S A W D$ variably throughout Wales). The shift represents a change that John perceives to be distinct from his own: perhaps this is an imitation of him doing a variety of WE spoken by an older generation, perhaps it is a decision to imitate the other sex's use of WE, or perhaps he is distinguishing a geographic difference between his own accent and that of his landlady. Whatever the reason for the shift, the line is delivered by Sellers in this manner for comedic effect no different from his mock RP, its delivery is framed in such a manner that the audience should be able to hear the difference between two varieties of WE within a single scene. For Sellers and the filmmakers, this is an impressive feat, on both a pragmatic level and a sociolinguistic one.

\subsubsection{Summary}

Tiger Bay and Only Two Can Play were mid-century films distinct from earlier portrayals in that, although they were similarly urban and comedic respectively, the filmmakers were aiming for realism. And, in doing so, to make the most 'authentic' filmic WE that they could. Tiger Bay saw the first Cardiff English on-screen, whilst Only Two Can Play demonstrated that unlike A Run for Your Money, a comedic performance did not necessitate the actors playing the nonstandard 'comic clown'. Indeed, Peter Sellers's Welsh accent in ARFYM became the exemplification of a well-performed, yet contrived, accent. This may have been due to Sellers' emphasis on aiming for achieving an 'authentic' Welsh accent.

\subsection{Welsh film around the late-20 $0^{\text {th }}$ century: 1987-1999}

Only Two Can Play (1962) marked the beginnings of a second scarcity of internationally renowned Welsh film production, mirroring the chronological gap that occurred between the first filmic period and the second (1949-1959). However, unlike the previous hiatus, this one lasted for almost a quarter of a century. The few films that were made during this time are today out of circulation. 
Arguably, the most respected audio-visual Welsh productions made during this era often focused on television (See Berry, 1994: Section 4: Television and a Welsh film Mini-boom), which included popular animation serials, for example, award-winning productions such as Super Ted (Edwards, 1983-1986) and Fireman Sam (Jones, 1987-1994), rather than film (Robins \& Webster, 2000: 112). ${ }^{30}$ The 1990s were also notable for the boom in Cymraeg films, several of which were produced by the Welsh language channel S4C, were internationally screened and awarded at film festivals. For example Paul Turner's Hedd Wyn (1992) was the first Cymraeg film to be nominated for the Best Foreign Language Film Oscar, and won numerous BAFTA awards (imdb, n.d.:b), with Endaf Emlyn's Gadael Lenin (1995) securing several BAFTAs (imdb, n.d.:c). Whereas the films of previous eras were written and directed often by non-Welsh creators, a characteristic of this period was its prominence of Welsh-born creators, such as Andrew Grieve, Kevin Allen, and Marc Evans. Films like Twin Town (1997), and House of America (1997), dared to present a sordid view of Wales that was far from male voice choirs and rugby (Blandford, 2000a:17). That said, it was an era of international collaboration, especially in terms of film funding; such funding being pivotal in helping elevate Welsh film to international audiences once more. Writing of this Welsh boom, however, there was still much doubt in the industry about Welsh film's future, Berry stating:

The fierce pride in tradition, and the social and/or cultural legacy, were issues increasingly dear to the film-makers in the early nineties as they considered a future of growing reliance on multinational co-productions and international financing. Berry (1994:420).

It was during this era that Wales's 'best known' English language film of the modern era was produced, Twin Town, a film that was mocked by some critics at the time, but has achieved lasting impression as a cult-film today.

\footnotetext{
${ }^{30}$ Televisual productions and their representation of WE is not area of this thesis, although deserve their own linguistic analysis in future.
} 


\subsubsection{On the Black Hill (1987). Dir. Andrew Grieve.}

The first film of note from that this era that uses aspects of WE dialect is Andrew Grieve's On The Black Hill. Developed from the novel of the same name and screenwritten by both Welsh-born Grieve and the original author Englishman Bruce Chatwin, and made for a modest $£ 600,000$ with help from the British Film Institute, the film addresses an eighty-year relationship between twin brothers beginning at the end of the $19^{\text {th }}$ century (Berry, 1994:416). The twins, Benjamin and Lewis Jones (portrayed as adults by real-life brothers Mike Gwilym and Robert Gwilym respectively), are born to a farming family upon the Welsh-English border of midWales; and, the film addresses several sociological developments that occur between the resident Welsh and English communities along this hinterland. This is expertly established visually in the cinematography of the initial establishing shot, that features a flyover scene that subtitles 'Wales', before seamlessly replacing the subtitle with 'England' as the shot continues across the hills.

Like Margiad Evans' Country Dance (1932) and Geraint Goodwin's Heyday in the Blood (1936) (see Chapter 7), the film uses the Welsh dialect of English native to the Borders, a dialect that incorporates elements of the English spoken in Shropshire, Gloucestershire, and Herefordshire, with influences from Cymraeg.

\section{Lexis}

From a lexical standpoint there is little to mark a sense of Welshness that is any different from the predominately south Welsh valleys dialect, despite its rural Borders location. For example, 'tidy' for the sense 'decent' (e.g. 'As nice and tidy a person as has meant no harm'- Grandpa Sam); 'mam' for mother (e.g. 'take that for your mam' [28:20]); and affirmative 'aye'. Topographically, Grandpa Sam specifies several local names for hills whilst on a walk: The Whimble, the Black Mixen, The Bach, and the lesser-known Smatcher.

\section{Pronunciation}

Pronunciation in many parts of the film is marked in a way that the Welsh are accented Welsh, and the English distinctly RP or West country, although there is some variation as we would expect along the border. The twins both speak in a WE 
accent, likely the actors' original voices, using monophthong rather than diphthong vowel in 'no' (i.e. /nw:/ rather than / nəo/). Pronunciation of 'sure' matches WE

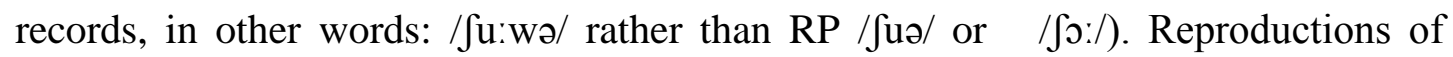
'here' also match records pronounced with initially inserted palatal approximant /hj3:/ (Parry, 1999:42). Amos blends rhotic phonemes from WE with those from the west English borders. He uses alveolar taps /r/ (common in WE) but also wordmedial rhoticity, as in 'farm' at [12:25]. Using both phonemes is rare throughout Welsh Englishes, although may have distribution along the border counties (SAWD).

\section{Grammar}

The area that appears to have received the most attention is the grammatical representation of WE; arguably more so in this film than in other up until this point. ${ }^{31}$ Granted, the film reuses structures that were commonly known not only to the public at this point, but to this historical period, yet introduces Borders structures that viewers may have been unfamiliar with.

Familiar grammatical usages include focus fronting (e.g. 'face down in a pool, he was'; 'over there, we'll go'), confirmatory interrogative tag 'is it/isn't it (e.g. 'Let's give her a little present, is it?'); and as 'like' as discourse marker, which is used interjectively and interrogatively (e.g. 'says he might get lost in the fog, like'; 'how can we have two souls, like'). 'Mind', recorded in SAWD as a verb 'to remember' in Dyfed and west Glamorgan, is used in: 'I've always loved Benjamin, mind', however, functions more like a discourse marker in this sense (a 'colloquialism for 'taking note' according to the $O E D$ ).

Grammatical features that have prior been represented in literature of the Welsh borders make their debuts in film within Grieve's film. The usage of habitual do (e.g. 'It do belong to the estate'), is common throughout Glamorgan, and border counties such as Monmouthshire, Montgomeryshire, and Radnorshire (SAWD). The adverbial 'by there' (e.g. 'Get away from by there' [33:50]), a feature the $S A W D$ reports is widespread throughout border counties such as Monmouthshire,

\footnotetext{
${ }^{31}$ The focus on grammar may have been material lifted from Chatwin's novel, which was not analysed for this study.
} 
Montgomeryshrie, Breconshire, and Radnorshire. Another, 'as' as a relative pronoun is used (e.g. 'as nice and tidy a person as [that] has meant no harm'; 'I have a map as can prove it' [33:55]), a feature confined largely to Mid-Wales (SAWD). Finally, the first person plural subject 'we', in the position of a plural object in: 'This land belongs to we' [34:50]. This is more common in the English midland counties such as Herefordshire and Gloucestershire, but also in Monmouthshire.

Use of 'be' for the third person singular present rather than 'is' is also present, for example in the interrogative 'be it a boy?' [24:45], declarative 'there it be!' [12:50], and even indicatively coupled with the common WE focus fronting in: 'Bitter cold, it be' [19:25]. This is not a feature recorded in WE of the $S A W D$, however, the SED records significant usage in the English border counties of Gloucester and in the Welsh county of Monmouthshire for the present tense indicative, and Shropshire, Herefordshire, Gloucestershire, and Monmouthshire for the interrogative usage.

In all, the film is to be commended for putting to screen the dialectological complexities present along the Welsh borders community, a feat previously put to paper by Geraint Goodwin and Margiad Evans within writing (Chapter 7).

\subsubsection{The Englishman Who Went Up a Hill and Came Down a Mountain (1995). Dir. Christopher Monger}

Similar to the adaptation of Up The Black Hill, where its script was co-written by the novelist who had written the original story, Welsh novelist Christopher Monger was also the screenwriter for the 1995 The Englishman Who Went up a Hill and Came Down a Mountain. A significant difference here was that Monger also chose to direct the film. In all, it is a rarity that a writer has had control over so many on-set elements within a Welsh film. The comedy is set in a rural Welsh village during the First World War, the plot being driven by two English cartographers who have come to measure the village's 'mountain', only to discover it fails the arbitrary $1000 \mathrm{ft}$. requirement and is therefore a 'hill'. The offended villagers then take it upon themselves to 'add' to its height with manual labour and much hilarity ensues. 
A testament to how a director or writer may be constrained by the film industry's 'supply' and availability of actors and their aptitude for acquiring dialects' phonologies is demonstrated well with Monger's film. During the mid-1990s, several Hollywood films were experimenting with asking big name actors to learn accents, usually for British historical pieces. For example, both Liam Neeson and Mel Gibson learnt Scottish English for their respective films Rob Roy (Canton-Jones, 1995) and Braveheart (Gibson, 1995). Miramax wanted to provide the same treatment for a film set in Wales starring Hugh Grant (Lyall, 1995). Though Hugh Grant does not render a WE accent, being the eponymous Englishman, several of his actors he shares the screen with do.

Monger wanted the accents to be as authentic as possible, hoping to avoid what he perceived to be past indiscretions for WE dialect filmic representations. Describing its plot, in an interview Monger stated that 'the film is about two outsiders coming into a village, and in a sense that's what the audience does, too. I thought there should be a distinct difference in the language. And I also want to be able to hold my head up high when I go back to Wales and not do what John Ford did ${ }^{32}$, (Lyall, 1995).

\section{Pronunciation}

Despite Monger's vision, several non-Welsh actors did find it very difficult to approximate the south Welsh accent of English he required, at least according to dialect coach Penny Dyer. Dyer was instructed to help Irish actor Colm Meaney (playing Morgan the Goat) and English actors Tara Fitzgerald (playing Elizabeth) and Ian Hart (playing Johnny Shellshocked), master the phonology. Although Dyer asserts her own success, the result is in places mixed. It is uncertain how helpful the coaching was, considering Dyer's own comments about the accent appear subjectively non-professional, stating Welsh accents are 'hard to master, in part because of [their] musical quality, which requires it to be sung more than spoken' (Lyall, 1995: para 7).

\footnotetext{
${ }^{32}$ Monger is referring here to How Green Was my Valley (1941).
} 
Several of the main characters are non-native users of WE. Whereas Fitzgerald (Elizabeth) overexaggerates her rise-fall intonation in many of the scenes that she is in, Meaney invariably stumbles back into his native Irish English in some conversations. Liverpudlian Ian Hart's Johnny, whose character's lines are few due to conflict PTSD, delivers perhaps the most accurate of these contrived accents.

That is not to say that there are no native users of WE as main characters. Kenneth Griffiths plays Reverend Jones, Ieuan Rhys plays Sgt. Thomas, Robert Pughs plays Williams the Petroleum, Lisa Palfrey plays Blod Jones, and Tudor and Hugh Vaughan play the elderly Thomas Twp twins; in all, these actors offer a myriad of different varieties of WE that span both time and place. Take for example, Griffiths's (previously discussed above in Only Two Can Play) speech that is reminiscent of his upbringing in Pembrokeshire. His version of Reverend Jones pronounces 'here' [11:50] distinct from other Welsh characters (who pronounce the word /hj3:/ or /j3:/, for example Palfrey's Blod), pronouncing the initial glottal fricative and the RP centring diphthong thus: /hı//. Griffiths does however yod-drop the approximant in 'educated' with /edu:keitıd/, as well as pronouncing alveolar taps, attested features of Glamorganshire (SAWD). Ieuan Rhys's speech is reminiscent of Glamorganshire, dropping his initial glottal fricatives (e.g. 'I hate the summer' [6:20]) and pronouncing 'sure' with two syllables: / Ju:wə/ [6:40], a feature Fitzgerald's contrived Elizabeth cannot reproduce at [49:57] with /Juə/.

Lexis

Monger's screenwriting sticks largely to lexical forms that by this time in WE's literary history would be known widely. Characters are prone to using vocative 'mun' (e.g. 'Ffynnon Garw, mun!' [7:05], as well as exclamative 'duw' [god] (e.g. Reverend Jones's: 'Duw! I thought you were an educated man. Duw, duw!' [12:40]); affirmative 'aye' and its doubling 'aye-aye' [30:50]; the endearment term 'bach' (e.g. 'Yes we have, bach' [46:08]), and the Cymraeg loan phrase 'da iawn' [very good] [1:18:00]. One lexical item is repeatedly used throughout the script as a source of humour, the Cymraeg loan 'twp' for 'dim-witted' (featured first in ARFYM above). Not only is twp italicised in the film's DVD subtitles to show its 'foreignness', but it is treated in-film as a term few audience members would recognise, at least compared to the items listed above, and incorporates a part of two 
characters' names. When the English surveyors realise they are being followed by two men, one (Hugh Grant) asks who they are to Morgan. Morgan replies that they are Thomas Twp and Thomas Twp, Too. He goes on to say: 'They're not quite with it. Touched. Stupid. Twp!' [15:55]. Stringing together these unintellectual synonyms shows that Morgan attempts to teach to Grant's character (and by extension the audience) the definition of the WE lexis. Feeling this may not be sufficient, Morgan then points to his head with his finger using a paralinguistic gesture to suggest there is something wrong with their brains (Fig. 8.2).

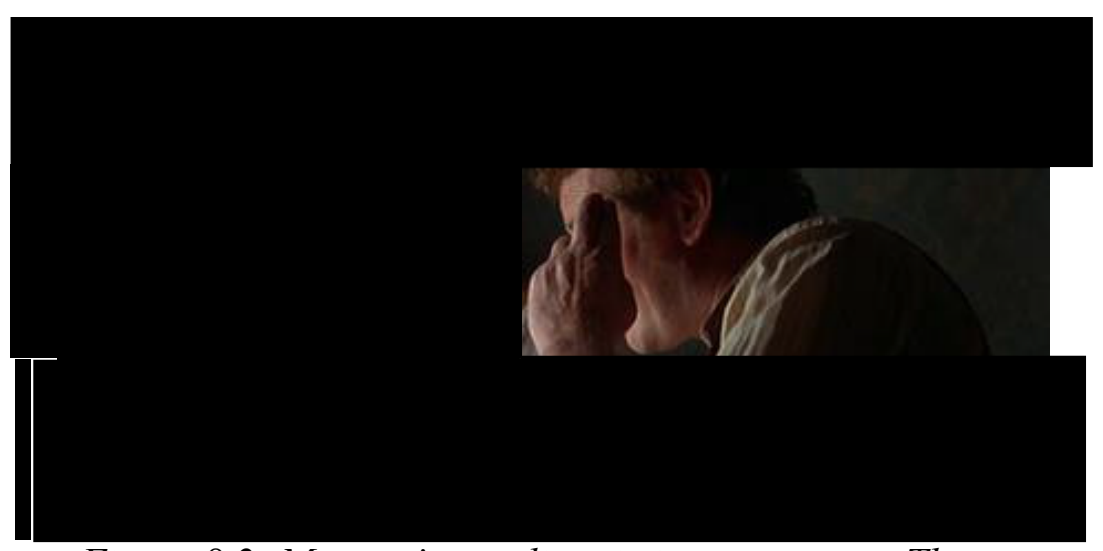

Figure 8.2: Morgan's paralinguistic twp gesture. The Englishman Who Went up a Hill... (1995)

One English language lexical item that made its introduction to WE filmic dialect is 'tump', a noun for 'mound' or 'hill' (e.g. 'A twenty-foot tump' [27:24]). Previously appearing in Prichard's 1828 novel Twm Shon Catty (Chapter 7), it was recorded by the SAWD in Powys and Glamorgan, in the SED in West midland counties of Wiltshire and Worcester; whilst the EDD reporting usage as far afield as Scotland, Ireland, and Yorkshire. Indeed, considering the film's subject matter, it would have been a wasted opportunity for Monger to have not used the word. Another word to make an introduction in WE fictive representation is a Cymraeg loan: 'bradwr' [traitor] $(G P C)$, although this is only spoken to affirm a character's 'Welshness' in response to a second character's supposed perceptually Anglicised behaviour and therefore may not constitute a loan word, but rather a deliberate language shift.

There is a clever linguistic joke in the film that works for those with proficiency in Cymraeg or WE. When Williams surreptitiously plants a mechanical object in the surveyors' car to prohibit them leaving the village, he replies upon 'discovering' it 
with: 'Well, I don't know the English word, but in Welsh we call it a bethangalw.' Bethangalw, however, is a placeholder name used in Cymraeg - similar to English's 'whatsitcalled' or 'thingymajig' (GPC). To the English surveyors (arguably even the non-Welsh audience), who just moments before stated aloud that they knew nothing of mechanics, they believe Williams to be genuinely describing a mechanical apparatus they are unfamiliar with. Bethangalw has recently been found in some south-east varieties of WE, not just Cymraeg (Jones, 2016a). Considering that Williams the Petroleum uses English throughout the film, it seems doubtful that he would not have known the English word for 'whatitscalled' (especially because it has a similar root: beth being what in Welsh), which affirms he uses the placeholder term to hoodwink the English surveyors. It works, for one surveyor even attempts to repronounce the item to memorise it for future.

\section{Grammar}

Finally, there are few examples of WE grammar in the film. Perhaps most notable is the use of focus fronting, which for the first time in fiction, is played for laughs in a manner not dissimilar from this film's usage of 'twp'. The English cartographers at numerous points in the film are metalinguistically assessed by inhabitants of Ffynnon Garw after hearing their RP voices with the phrase: 'English, are you?', which becomes a running joke for viewers, much to the frustration of the characters. Morgan asks this at [4:30], the Sergeant at [6:30], and by the mid-point of the film, when the trainmaster does at [44:20], the cartographers are visibly frustrated by the phrasing.

\subsubsection{Twin Town (1997). Dir. Kevin Allen}

Written by Kevin Allen and Paul Durden, and directed by Allen, Twin Town is a comedy revenge story set in Swansea and tells of the exploits of the eponymous Lewis twins, Jeremy and Julian (Rhys Ifans and Llyr Evans). The film features car thefts, joyrides, excessive drug usage, and countless expletives. Understandably, both critical and local reception was mixed, despite doing better at the Box Office than any previous Welsh film, both domestically and globally (Blandford, 2000a:11,17). Perrins (2000:155) argues that viewers' initial response to the film mirrored the backlash that Caradoc Evans' received for his 1915 novel My People (see Chapter 7). 
Blandford writes: '[The film] has 'elusive confidence $[\ldots]$ to either ignore the obvious ways to 'be welsh' or to laugh at them from within. Its reported reception with Welsh audiences suggest that for younger people at least it is a confidence that is beginning to be shared' (Blandford, 2000a:18). Twenty years later, there is no doubt that Twin Town has become one of Wales's best-loved films, enjoying 'cult status in the pantheon of Welsh cinema' (Prior, 2017: para 1).

Both Blandford and Perry argue that the film's success is in part due to its appeal to younger viewers, and a large component of this appeal, according to Perrins (2000), is its use of language - not simply its profanity ${ }^{33}$, but characters' usage of monolingual English, i.e. WE dialect. He writes that Twin Town's Swansea is 'an environment where bilingualism has passed on to an educated middle-class together with a rump of the older working class population' (Perrins, 2000:162). Older characters speak Cymraeg, such as detective Greyo (Dorien Thomas), and the twins' parents - their mother (Di Botcher) resorting to using it just with the family dog.

Unlike other commentators, Perrins (2000) directly alludes to WE in a film, via the concept of 'Wenglish' that John Edwards coined and Robert Lewis (and other SouthWalians) employ: '[The film]'s "Wenglish" is further elaborated upon [...] by the employment of an array of 'words' that only appear in [Cymraeg]' (p.163). To Perrins, '[W]english' appears to be the 'employment of an array of 'words ${ }^{34}$; i.e. the lexical dimension, rather than being synonymous with 'WE dialect' and thus incorporating grammar and phonology too. Whereas the Twins' peers characters use 'Wenglish', Perrins argues that the Twins do not, that they 'sever this link by not entering into [...] sentimental linguistic privileging of '[W]english' (p.163). The Twins use phonological and grammatical components of WE, therefore Perrins must again be referring to lexical usage. In fact, what Perrins is likely suggesting is that the Twins choose not to use particular lexical forms known within the speech community as markers of 'Wenglish': in other words, they refuse to use 'enregistered' forms to distance themselves from other speakers. There is certainly

\footnotetext{
${ }^{33}$ Supposedly 318 expletives in a 99 minute run-time at an average of 1 expletive per 19 seconds according to Prior (2017)

${ }^{34}$ Lexis that Perrins highlights as 'wenglish' include: 'mam', 'cwtch', and 'hobbles'
} 
evidence of this throughout the film, neither Twin uses any Cymraeg lexical loans in their English, for example, however they do use 'mam' (e.g. 'You burned my mam and dad' [1:20:50]), largely attributed to Cymraeg influence.

\section{Lexis}

Familiar lexis from previous filmic dialect include: 'mam' for mother, 'tidy' for decent, vocative 'mun', and affirmative 'aye'. The endearment term 'boy bach' [1:03:10] is used by the humourous farmer character Emrys (Keith Allen). Emrys is one of the few characters to have a contrived Welsh accent in the film, and the usage of the archaic 'boy bach', used archaically even in A Run for Your Money (1949), suggests his language usage is not meant to be taken seriously. New to WE filmic representation is 'cwtch', a verb and noun for 'cuddle' that is attested throughout mid and south Wales (often for 'squashed' or 'to lay in place' from Middle English 'couch', SAWD), and which by Twin Town's release had been used in at least two previous fictive texts - Lynette Roberts' Village Dialect (1944) and Glyn Jones's Island of Apples (1965). The term takes the focus of one comically morbid scene involving burial rights. During a funeral that sees the burial of three of the Twins' close relatives, Chip Roberts (Morgan Hopkins) insensitively questions why the family did not opt for a mass-grave to keep one another company, much to Dai Reese's (Brian Hibbard) disbelief (see reproduction below and Figure 8.3) [1:06:26]

$\begin{array}{ll}\text { Chip Roberts: } & \text { Why don't they put them all in one grave, Dai? } \\ \text { Dai Reese: } & \text { What? } \\ \text { Chip Roberts: } & \text { One on top of another. Like a triple-decker. [Gestures } \\ & \text { placement] } \\ \text { Dai Reese: } & \text { Triple-fucking-decker?! } \\ \text { Chip Roberts: } & \text { They were all related. They could cwtch up? } \\ \text { Dai Reese: } & \text { Cwtch up?! How do you mean 'cwtch up'?! } \\ \text { Chip Roberts: } & \text { Cwtch up. [Gestures 'cwtching']. They could keep each } \\ & \text { other company. Cwtch up; the three of them. } \\ \text { Dai Reese: } & \text { Chip, they are fucking dead, mun. } \\ \text { Chip Roberts: } & \text { I know that... } \\ \text { Dai Reese: } & \text { Well, shut up then! }\end{array}$




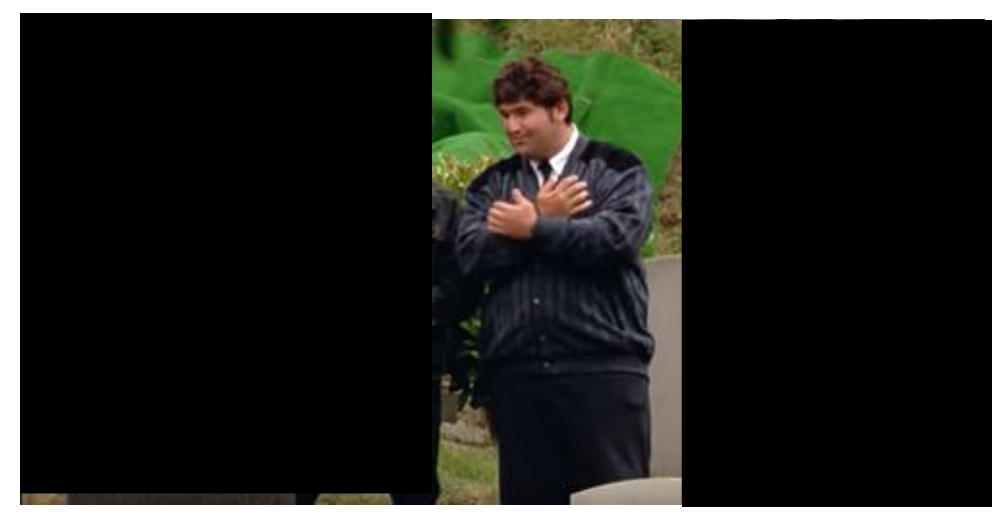

Figure 8.3: Chip's paralinguistic cwtch gesture (Twin

Town, 1997)

Like Morgan's 'twp definition' in The Englishman Who Went Up a Hill... (1995), Chip's paralinguistic gesture provides viewers who may not be familiar with the term a 'visual definition', a unique in-text defining that only the visual arts allows for literary/filmic dialects. When Dai questions Chip, Chip does not explicitly state that a cwtch is a hug, but signals it. Dai Reese's questioning of what a cwtch is should not be mistaken for his own ignorance of the term, but rather his disbelief that Chip would suggest such an idea. Whether the audience knows what cwtches are, Chips's bizarre proposal still warrants further explanation. Today, this term is widespread throughout Wales (and perhaps recognised beyond its borders) arguably being an enregistered Welsh English term, had the film been shot today, Chip's 'visual definition' may not have been needed for British audiences, although even in 2000 Perrins highlights 'cwtch' as being a 'good example of wenglish' (p.163) suggesting it had thorough frequency at that point.

The film uses 'chopsy' as an adjective for talkative (e.g.' Chopsy little shite' [20:29]). Recorded by the $S A W D$ as a verb to idly chat or gossip in Gwent (likely from chops as in one's jaws), its continuous verb form 'chopsing' was used by author Ron Berry in So Long Hector Bebb (1970). What is interesting is that the term is not used by a WE speaker, but by corrupt policeman Terry, who speaks a Scottish English though has lived in Swansea for some time. Several things may be linguistically occurring. Terry may be 'accommodating' his speech (see Giles \& Powesland, 1975), overtly shifting his vocabulary usage whilst in the presence of his work colleague Greyo, who does use WE, to reduce social distance. The alternative 
is that Terry has picked up the WE lexis unknowingly during his time in Swansea and added it to his vocabulary covertly. However, thirdly, we cannot rule out that its usage was externally written into the film by its writers unknowingly - assuming that the term has wider usage in British English than it does. This would make Terry's usage of 'chopsy' a production error.

Writer Allen also uses 'clever' in the script in reference to the poor guttering on a roof: 'not looking too clever' [17:50] to mean 'decent'. The $O E D$ notes that this is a dialectal usage of satisfaction or liking. He also uses 'hobbles', a term for illicit work $(T T)$ to describe the work Fatty Lewis was performing at the beginning of the film.

\section{Pronunciation}

More so than any other film analysed, Twin Town has the largest cast of real-life WE users to create its fictive WE dialect, the majority of the cast being native speakers of the variety (an exceptions being Emrys, as mentioned above). For example, 'here' is pronounced /j3:/ [3:00] with initial palatal approximant; initial position alveolar taps /r/ are especially used by older residents such as Mr. and Mrs Mott's pronunciation of 'relief'; initial glottal fricatives are dropped in 'hammock'/æm $\wedge$ / [23:20]; most characters pronounce 'you' with the Cymraeg diphthong/Iu/; and the twins omit their palatal approximants (yod-drops) in their coalescence of 'had you' in their much-loved phrase: 'fucking had you'/'æd, ru/.

\section{Grammar}

Twin Town relies once more on established grammatical forms such as focus fronting in phrases such as: 'A sick bay, they have' [22:40], however, expands upon WE filmic dialect's arsenal with inflected forms of the first-person present tense indicative, for example: 'I knows that, but the kids likes it with their cider'; 'I fucking loves it' [15:56]. This feature was commonly reported throughout Wales by the $S A W D$. Indeed, it is surprising that it was not used in a film until 1997, in many ways demonstrating the attention to detail that Kevin Allen put into the authenticity of the film's language.

\section{Metalanguage}


Characters in Twin Town also demonstrate some implicit knowledge of language usage within the community. During the film's opening, Dodgy (David Hayman), a drug-peddler from South-east England who is well-versed in Welsh stereotypes, sarcastically remarks upon entering Swansea and greeting the corrupt policemen: 'Won't keep you from a coal mine lads. The Welsh got shoes on their fucking feet. Not a rugby ball in sight!' This visibly riles up Welshman policeman Greyo. Greyo interrupts Dodgy's conversational turn, taking the floor by sarcastically facilitating another Welsh stereotype, adding the vocative expression: 'yeah, and I've been picking leeks all morning, boyo!' Here Greyo's usage of 'boyo' demonstrates his own awareness of Welsh linguistic stereotypes, 'boyo' being an expression that by the late 1990s had fallen out of common usage, perhaps as a deregistered term, possibly due to its stereotypical derogatory connotations. It should be noted that Dodgy similarly refers to Greyo as 'taff', a derogative term for a Welshman. Whether Dodgy recognises that Greyo uses a sarcastic linguistic stereotype in his rebuttal is unclear.

Ultimately, Twin Town was a film that took every opportunity to incorporate Swansea WE into its script, and despite its features being attested, and its writers avoiding linguistic stereotypes, in some scenes fulfils little more than fulfilling a 'comic' delivery.

\subsubsection{House of America (1997) Dir. Marc Evans}

House of America was directed by Marc Evans and was adapted from Ed Thomas's play of the same name from 1988 (Thomas, 1988: 2013) with Thomas reworking his play into a screenplay. Of the three Welsh films released in the late 1990s (Twin Town, see above; and Human Traffic, see below), House of America had more 'art house leanings' doing well critically, though achieved little fanfare internationally (Blandford, 2000a). Indeed, Berry (2000) highlighted the film as the call for Wales to begin to 'develop or invent its own contemporary [filmic] mythology' (p.137). Blandford (2000b) largely agrees, stating that it is 'central to any account of an emerging Welsh film industry' (Blandford, 2000b:66). 
The film focuses upon the cultural Americanisation of Wales with characters promoting the American dream and having wonderment with America's cultural heroes. These are then juxtaposed against Wales's economic collapse following the closure of the mines and its lack of indigenous stars. Sid (Steven Mackintosh) and his sister Gwenny (Lisa Palfrey) want to join their father in the U.S., however, Boyo (Mathew Rhys) is suspicious about their mam's (Siân Phillips) explanation of where their father is, and, equally so, his siblings' lack of interest in Wales and Welsh identity.

From the beginning of production, the director's vision was for an all-Welsh cast, and one familiar with the WE dialect. Marc Evans states: 'just for practical terms the strategy for the casting was originally to cast as many Welsh actors as possible, partly because the vernacular is so Welsh' (Blandford, 2000b:79). Although this suggests that authenticity was a primary focus for Evans; he wanted the right 'performance' over complete accuracy of language usage, thereby acknowledging that dialect in film serves a different function than in reality. Evans states: 'Everybody who was interested I said to them don't sit there and try and do a Welsh accent' (p.81). Eventually, they did cast an English actor, Steve Mackintosh, as Sid, who, despite the many Welsh actors who auditioned, performed the character in a manner they wanted: 'at the end of the day you have to keep your mind open and his accent and attitude were just right for the Sid character in the film' (p.80).

Lexis

The script for House of America does not stray too far from established lexical norms for WE. Much like Twin Town, items that may be considered enregistered such as 'mam', and 'mun' are generously applied to dialogue, with Boyo especially using it in many of his utterances. Regarding Boyo's name, whereas Gwenny and Sid have what could be argued given names, Boyo is the only character whose name is likely a nickname, deriving from the eponymous enregistered and attested term.

The film introduces 'leave [ProN] go', possibly a variant of 'loose go' for 'let go', which is attested by Weng., for example: 'Leave me go' [19:50] and 'leave him go' [29:30] (note that Margiad Evans's also used 'loose me' in Country Dance, 1932). It also uses 'gwas' vocatively, a Cymraeg loan synonymous with vocative usage of 
'lad' (GPC); used prior in a WE fictive sense by novelist Geraint Goodwin (1936). Gwas's shortening 'wus' is used covertly in Ed Thomas's 1988 play during in discourse between Sid and Boyo (p.37), but is overtly chosen metalinguistically as an indexer of Welshness during the film by Sid who mockingly imagines what would happen if American songwriter Lou Reed came to live in Wales, stating sarcastically: 'Can you imagine Lou Reed walking around Banwen? “Alright Lou, how's it going, gwas?" Walk on the Wild Side?" He's probably never heard of Wales' [6:05]. Here use of the WE dialect is derided as a subject of humour by the American-fantasist Sid.

Like the films The Citadel (1938) and A Run for Your Money (1949) and the writing of Goodwin (1936) and Margiad Evans (1932), the film (and play) make use also of 'clipped adverbs', where an adverb premodifies an adjective but without the norm of a -ly suffix. Here the choice of word is 'bastard', used by Sid and Boyo respectively: 'Typical, that is, bastard typical' [10:05]; 'It's bastard obvious, mun' [1:00:30]. Arguably, bastardly is an infrequent adverbial modifier, perhaps Ed Thomas used the term to semantically suggest profanity in place of the more English English 'bloody' or high-profane 'fucking'. Either way, though the morphology matches attested usage, lexical choice of 'bastard' matches no record.

The final word that does not match any WE record is 'Mickeymouse' (e.g. 'It's all mickeymouse anyway' - Sid [11:10]; 'It's a mickeymouse address, Gwenny' Boyo). The term is a colloquial usage for 'nonsense', an eponym deriving from the Disney character of the same name, gaining currency after the 1950s in the U.S. particularly $(O E D)$. There's a sense of 'linguistic irony' in use of this US colloquialism, for although Sid wants to go to America and be American, his brother Boyo is against the idea, and yet Boyo covertly uses lexis derived from American pop-culture. Ultimately, it is a fictive indicator of the contemporary levelling effect of American English upon Welsh English; regardless whether Sid goes to America, America's filtering into Wales.

\section{Pronunciation}

Characters such as Gwenny and Boyo use more of the phonological markers of WE such as alveolar taps in 'round' [36:35] and 'road' [37:05]; initial glottal fricative 
omission in 'who's' (/u:z/) [12:14]; yod-dropping on 'news' (/nu:z/) [8:40]; and use of initial palatal approximants and vowel backness in 'here' (/j3:/) [8:00]. Mackintosh's accent for Sid does not match his siblings' accents, but perhaps no more so than idiolects may differ between brothers. In fact, Mackintosh's performance matches attested phonology, for instance dropping his $/ \mathrm{h} / \mathrm{s}$ in 'her side' [47:50], although it is speculatively the rise-fall intonation of WE that the actor matches best (something not studied in the $S A W D$ ). A testament to Mackintosh's ability to mimic intonation is given at [48:20] when he tells fabricated stories of his father. Here, he approximates an 'American English' accent primarily in its intonation, sticking to the WE phonology. Much like the way that Peter Sellers layers an RP accent on top of a Welsh accent in Only Two Can Play (see above), here Steven Mackintosh similarly adds an American English cadence to his already fabricated Welsh accent.

\section{Grammar}

Grammatically, there are a few markers typical of WE. Most characters use the discourse marker 'see' (e.g. 'He's living in New York now, see' - Sid [7:00]), as well as focus fronting (e.g. 'Typical, that is' - Sid [10:00]; 'Nice, is she?' - Boyo [41:45]). There is also one example of Demonstrative There in 'There's a coincidence now' [11:10].

\subsubsection{Human Traffic (1999) Dir. Justin Kerrigan}

Justin Kerrigan wrote and directed Human Traffic based upon his own experiences of the 1990s clubbing and drug culture (Kerrigan, 2002). Set across a drug-induced weekend in Cardiff, Human Traffic represents a very different representation of Cardiff than the other Cardiff-based film analysed in this thesis, Tiger Bay (1959). The film lacks a distinctly 'Welsh' theme, instead taking a more cosmopolitan tone, with much of the main cast's characters having emigrated from elsewhere (e.g. North of England, Ireland, and London), and thereby bringing their native varieties of English with them to the film.

\section{Pronunciation}


Nina (Nicola Reynolds) is the only member of the main cast to use a WE variety notably rendering 'you' with /Iu/, as does her brother Lee (Dean Davies), a minor character who pronounces 'here' with the palatal approximant (/j3:/. Many of the minor characters are voiced with Cardiff English or Welsh valleys accents. For example, Jip's mother (Helen Griffin) uses a WE not native to Cardiff, and Nina's sex-pest manager (Giles Thomas). The film utilises one notable 'drug explanation' scene in which real-life cannabis smuggler Howard Marks from Bridgend uses his Valleys variant of WE to deliver the comical: 'Spliff Politics' segment [1:10:10].

Cardiff English is heard less often. It is explicitly stated that the film's main character Jip (John Simm) moved to the area when younger. For Jip, John Simm notably pronounces the closed back vowel /a:/ with a more open front position, thus rendering 'Cardiff' more like /ka:dif/; this is an enregistered (and stigmatised) feature of Cardiff English (Collins \& Mees, 1990:96), and may be representative of Justin Kerrigan direction, to represent that Jip, having lived in Cardiff since childhood, has accommodated some of the dialect's phonology. Valleys accented Inca (Roger Evans), introduced as a clubber on a high [44:30], varies his pronunciation of vocative 'mun' as $/ \mathrm{m} \Lambda \mathrm{n} /$ and $/ \mathrm{mæn} /$. Later during a paranoid conversation with one of the only Cardiff English users to have sustained dialogue - Casey [1:01:00], Inca exclusively pronounces the vocative as /mæn/, aligned with Casey's own usage. This may constitute a profound shift in pronunciation of the vocative item 'mun' from a back vowel sound to a front vowel, that was perhaps occurring during the late 1990s in south Wales with Inca (indeed his actor too) caught 'between' both pronunciations (see Big Font. Large Spacing below too).

\section{Lexis}

The lexical component of Human Traffic is grounded more in the 1990s slang usages of young people. Human Traffic is perhaps the only film to document that the 1990s British slang common throughout English urban centres had distribution in Welsh centres such as Cardiff too. Several of these items still have some frequency today, however, several due to their 'slang' characteristics may now be considered 'dated'. The adjective 'safe' in the sense 'excellent' is used several times [23:35]. Although the $O E D$ suggests an origin from 1970s S.Africa, alternatively, it may derive from the phrasal 'safe as houses' ['secure'], which dates back to the mid-19 ${ }^{\text {th }}$ century. A 
similar form of this phrase is used in Human Traffic: 'safe as fuck' [45:05] taking the syntax: '[Adj] as [NP]'. The initial adjective can be interchanged from 'safe' to any number of similar 'decency' adjectives, and the final noun-phrase can be omitted, for example: 'Sweet as [Ø]' [25:40]. The noun phrase 'a mission and a half' in the sense a 'tough task' is used [38:20], likely clipped from the 1980s slang prepositional phrase 'on a mission' denoting a 'task' or 'goal' and compounded with 'and a half' a colloquialism denoting 'extra effort' dating to as far back as the 1600s (OED). Several drug-related slang terms are shown. For example, the noun 'spliff', for a cannabis cigarette (originating in the 1930s West Indies, OED); the verb 'drop' for the consumption of illegal pills (OED: slang, 1960s); the noun 'blinder' for a 'fantastic time' (originating from 1950s British sports language); and 'mullered' for 'intoxicated' (OED: British slang, 1990s). Most surprising is the usage of the attributive adjective 'minxing' in 'minxing slapper' to denote 'sexually forward' and is used by Jip in a scene where he approximates the Welsh valleys dialect [1:17:30]. The $O E D$ records that it is a regional English term that had currency in 1760 s, but was last recorded in 1883. It is possible that the term still has some currency in urban centres, with the writer/director Kerrigan having heard the term in use during his upbringing in Cardiff.

Although the usage of 1990s youth language encompasses the majority of this fictive dialect's lexical dimension, that is not to say that WE items were not present, as mentioned above, vocative 'man' is used by Inca and Casey, it is also used exaggeratively and played for laughs in a scene depicting two drug-addled Star Wars fans, one of which Andy (Richard Coyle) uses at least 12 instances of 'man' in under a minute, after all his utterances. This resembles a discourse marker rather than vocative usage [1:03:10]. 'Butt', a shortening of 'butty' for work-mate, is also used vocatively [44:30], having been used prior in A Run For Your Money (1949). Vocative usage such as this lies below the usage of new forms within these speech communities.

\section{Grammar}

Grammatically there are few items of note. Casey, as we've established above is one of the only Cardiff English speakers, uses inflected forms of the first-person present tense indicative in: 'I grows my own' and 'I knows Millsy' [1:11:45], which is an 
attested form in south Wales $(S A W D)$. The only other WE grammatical structure referenced is the interrogative tag 'is it', being used for comical effect; evidentially, Kerrigan recognises it as a well-known WE item - indeed, enregistered. Its use as a joke mirrors the usage of 'twp' in Englishman Who Went Up a Hill... several years before. In one scene, a customer in Koop's record store [8:40] approximates an East Coast African-American Vernacular as a means of accommodating to Koop and the East coast music scene, however upon finding out the record is more than he is willing to pay, shifts inadvertently back into his native WE, finishing his utterance with 'is it?'. [10:05]. The second notable scene occurs towards the film's end [1:17:07]. Jip and his friends are intoxicated, and they fall into imitating various accents; they metalinguistically assess an unknown WE user they know, and Jip, Koop (London English), and Lulu (Irish English) fall into a repetitive loop of 'is it' tag questions. Nina and Lee, both WE users, find their contrived representations of WE to be hilarious.

\subsubsection{Summary}

The later $20^{\text {th }}$ century featured a variety of WE representations. Historical representations featured in On the Black Hill, a film that first featured Welsh Borders English, and in The Englishman Who Went up a Hill..., that though demonstrated actors' varying aptitudes for acquiring a WE accent, showed viewers early $20^{\text {th }}$ century south Welsh life. Contemporary visions were supplied for Swansea, the Valleys, and Cardiff. Twin Town premiered the best-known example of WE on film, depicting a contemporary Swansea English, that although supplied native talent and attested features, were slightly exaggerated for consumer appeal. House of America highlighted the dilapidated mining towns and the Americanisation of Wales and influence of American Englishes upon WE. Finally, Human Traffic portrayed the second example of Cardiff English, set amongst the slang sociolects of the 1990s clubbing scene.

\subsection{Welsh film from the millennium until present: 2005-2014}

Although the creative surge of Welsh film production during the 1990s began to peter off after the millennium, several new movements sprung up. Low budget 
independent films such as Big Font Large Spacing and Hunky Dory continued to tell stories of comedic drama. Not only this, but both Hunky Dory and PRIDE focused on period pieces telling stories of a historical Wales of the 1970s and 1980s; by the close of this period Welsh themes began to be picked up once again by non-Welsh filmmakers with Hunky Dory, PRIDE and even The Hobbit trilogy with lead characters once more using contrived Welsh accents.

\subsubsection{Big Font. Large Spacing (2009) Dir. Paul Howard Allen}

Written and directed by psychology lecturer Paul Howard Allen with script editing by Quirine Robbins (Price, 2010; Allen, 2011), Big Font. Large Spacing is Wales' first university comedy film. Taking place in the space of one night, two psychology students who have forgotten to write their course assignments, desperately strive to meet the wordcount.

Although Big Font. Large Spacing is the third film analysed in this thesis to portray Cardiff on-screen (after Tiger Bay (1959) and Human Traffic (1999)), a Cardiff variety of English is not used by any of the characters. Of a cast of just four characters, two actors are non-native WE users - Kimberley Wintle (playing Debbie) and James Kristian (playing Tom), and two use Welsh valleys English - Gareth Aldon (playing Steve) and Amy Morgan (playing Sarah). Unlike the Welsh films that follow BF.LS, the film's representation of WE is performed in an in-situ and naturalistic state; though a script existed, emphasis was placed upon performing lines naturally, as if 'real' talk (Allen, 2009). This is similar to American Independent 'mumblecore' films, like Mutual Appreciation (Bujalski, 2005), that gained popularity mid-decade (Wood, 2009:150). Therefore, the representation of Steve and Sarah's WE in many ways embodies the variety's form as it exists in the early $21 \mathrm{st}$ century and as spoken by young users.

\section{Pronunciation}

Steve and Sarah's phonology match what we know from the SAWD. For 'Tuesday', Steve yod-drops the initial palatal approximant (e.g. /tu:zdeI/) [3:17] and medially in 'ridiculous' (e.g. / ridıkıləs/); they omit initial glottal fricatives as in 'describe her' [4:00] (e.g. /3:/) and 'heads' (e.g. /edz/) [11:50]; and render 'here' with an initial 
palatal approximant (e.g. /j3:/) [4:12]. Steve also omits his palatal approximants (yod-drops) in the coalescence of 'would you', thereby pronouncing it: / wodiu/, with the final diphthong / $\mathrm{ru} /$ unique to WE. This parallels the use of 'had you' (e.g. /'æd, Iu/) in Twin Town.

\section{Grammar and Lexis}

Steve uses the confirmatory interrogative tag 'is it' (e.g. 'Let's try and get a bit of perspective, is it?'), however he also uses a negative form of the confirmatory interrogative tag 'is it' several times, however, in a contracted form of 'isn't it': 'innit' (e.g. 'It's kinda sitting in our laps, innit?' [12:35]). This is the first text in the analysis that uses this form, indeed it is a contemporary form of the tag that today is widespread throughout not just Wales, but the several British varieties of English $(O E D)$. Interestingly, the film's subtitles render the form as <isn't it $>$, suggesting perhaps that actor Gareth Aldon ad-libbed from the 'loose script' his more naturalistic response. Contrarily, the subtitles may have been created in postproduction; thereby, not derived from a script, but by a transcriber writing in standardised speech.

It should also be brought to the forefront that the use of the vocative 'mun' may have completely shifted to 'man' within younger speech communities. Whilst in Human Traffic Cardiff English users used 'man', speakers from the valleys used man/mun interchangeably, however by 2011 , if we are to take the film as 'linguistic evidence', the 'man/mun' phonemic shift is complete, as Steve is not a Cardiff English user, but a Valleys English user. Actor Aldon does not make any ad-libbed attempt to pronounce the vocative as $/ \mathrm{m} \Lambda \mathrm{n} /$, as he does grammatically with the decision to voice 'isn't it' as 'innit' (above).

\subsubsection{Hunky Dory (2011) Dir. Marc Evans}

Directed by Marc Evans and written by French screenwriter Laurence Coriat, Hunky Dory is Wales's first high school musical film, and certainly the first to be penned by a French national. Set in the freak heat-wave of 1976 in Swansea, the film tackles the many trials of adolescence, as drama teacher Miss Mae (Minnie Driver) attempts to 
put on a musical that combines Shakespeare's Tempest with music from the early 1970s.

Hunky Dory is Marc Evans's second filmic text to be analysed in this thesis for its WE content. Being set in 1976, an observer might expect the variety of WE to be reminiscent of this period. However, the script is fairly conservative in its lexical and grammatical dimensions, opting rather for just phonological representation; in this way it avoids the possibility of anachronistic criticism in its representation of language.

\section{Pronunciation}

Regarding the film's phonology, the pupil characters who make up the bulk of the cast and indeed WE accent representation of the film were from local schools and colleges (Evans, 2011). The outlier was Minnie Driver's Miss Mae. Although the director knew her accent, being non-native, was going to be contrived, he was not aware Driver's father was from Swansea and she was familiar with the accent, which he believes gave her an advantage (Evans, 2011). Coaches that helped her perfect the accent were Matthew Rees (from House of America) and dialect coach William Conacher. Largely, Driver's accent matches attested forms and the forms that other WE speakers use. For example, in terms of phonology, Driver yod-drops the initial palatal approximant in 'music', thereby rendering /mu:sik/ not /mju:sık/ [41:00] and in 'opportunity' following the medial / $t$ / does not render medial approximant $/ \mathrm{j} /$ nor palato-alveolar affricate /t $\mathrm{f} /$, both common to RP, but opts for /ppotu:niti:/ [20:10]. These are traits that the children also use, however they are absent from many teachers, who are approximating an RP accent (e.g. headmaster and Miss Valentine do not yod-drop). Driver also omits the initial glottal fricative in 'happen' [40:30]; and renders 'here' as /hj3:/, with inserted palatal approximant. Only occasionally does Driver's accent falter, for example in the production of 'go' in 'right there you go' [1:06:00] where she produces the diphthong /əo/, rather than /p:/, more commonly used in south Wales.

Lexis 
Familiar lexis include affirmative 'aye' [2:50]; 'mam' for mother [6:00]; vocative use of 'mun' [33:15] ${ }^{35}$; and the use of clipped adverbial suffix for 'proper' in 'Lovely story, catchy tune; proper' [20:30]. The film features both 'ta-ta' and 'ta-ra' for 'goodbye' [10:30], used on the first turn by Davy's nan and then by Davy (Aneurin Barnard) on the next turn. The variation in these two interjections suggests there is an age difference between these two uses of WE. This is a term used colloquially in other British English varieties (OED), however, has been noted to be used in south Wales (Weng.); its introduction during a 2011 film is indeed surprising and perhaps long overdue.

Like Human Traffic, several lexical items of a slang register are used; the majority of which are of a sexual nature. Unlike Human Traffic, their usage in Hunky Dory does not necessitate authentic WE usage, either from the period, or necessarily contemporarily. Whether any of these terms are anachronistic for this period in WE's history is debatable, however, the characters that use the terms, Angus and Kenny, are portrayed as delinquents in the film, thus associating slang register with a particular speech community. Several are derogatory terms for homosexuals, for example: 'poof' [11:30], a term in usage since 1833 (OED); and 'bummer' (e.g. 'he's such a bummer' [11:45]), which is not attested in the $O E D$, although is likely derived from 'bum-boy' (c.1930s, OED). Other slang usages are derogatory terms for sexually active women. The first, at 34:10, is 'bike' used by Angus (e.g. 'Everyone knows she's the school bike'); here 'bike' is derogatory slang for a promiscuous woman deriving, from Australian English of the 1940s (OED). The second instance is 'prick-tease', a shortening of 'prick-teaser' (c.1930s, OED), a woman giving the impression of being sexually available but evades intercourse. The OED notes that this shortening was first accounted for in 1974, just two years from when the film is set.

\section{Grammar}

The film uses a select few attested WE grammatical forms. Discourse marker 'see' is used ('You've gotta find the bubbles, see.' [9:00]), as is the use of 'auxiliary have present tense unstressed' in 'Your nan haven't been around, have she?' substituting 'has' for 'have', attested throughout Glamorganshire and Monmouthshire (SAWD).

\footnotetext{
${ }^{35}$ The subtitles render this orthographically as <man>
} 
'Isn't it', the confirmatory interrogative tag, has several forms in this film. Its pure form is used at 1:19:31: 'It couldn't have been him that started that fire, isn't it?', however a form exists that marks for gender: 'He's my brother, in't'he' [15:20], and finally the contraction of 'isn't it':, innit is used (e.g. 'That's just the taste of disappointment, innit?' [8:20]). 'Innit' as a tag is today widespread throughout not just Wales, but the several British varieties of English (OED), although it is debatable whether it has currency in 1976 alongside the dominant form: 'is it/isn't it'.

\subsubsection{PRIDE (2014) Dir. Matthew Warchus}

PRIDE, directed by Matthew Warchus, is, like Hunky Dory, another period drama piece set in Wales, this time in the mining strikes of the 1980s. The film was written by Stephen Beresford, an English writer who was inspired by the real-life events of the LGSM's (Lesbians and Gays Support the Miners) support for striking miners. The film won the BAFTA for Beresford and producer David Livingstone for 'outstanding debut' and was a sleeper hit, making $£ 4,000,000$ at the UK box office (Lee, 2015).

Although one of the most recent 'Welsh' films analysed, and one that aims to represent the authenticity of minority groups' struggles on-film, one may recognise the irony in the fact that the entirety of PRIDE's highest billed main cast was voiced with non-native users using contrived WE accents. Cliff (Bill Nighy), Dai (Paddy Considine), Hefina (Imedla Staunton), Gethin (Andrew Scott) and Gail (Nia Gwynne) were all cast as inhabitants of the Welsh village of Dulais. Of course, when it comes to authenticity of dialect representation on-film, we must not forget that occasionally viable actors are not available in preproduction, however, as seen prior in this chapter, authentic Welsh actors using Welsh varieties are often cast in films to do with Wales; the fact no WE actors made it into the film's main Welsh roles suggests the producers preferred to cast big-name actors for their mainstream production to draw in audiences. Authenticity of accent is heard best, however, in one antagonistic character and the minor characters. Maureen (Lisa Palfrey) plays the antagonistic role, and is a native WE speaker, as are Martin (Rhodri Meilir), Gwen (Menna Trussler), Lee (Dyfan Dwyfor), Carl (Kyle Rees). Bearing this in mind, 
producer David Livingstone reports that when shown the film, the people that the characters were based on were 'so moved and so happy' with their representations (Livingstone, 2014). This suggests that in a biopic, the authenticity of linguistic variety was not a predominant concern, at least in comparison to the depiction of real-events.

Much like Hunky Dory, there is little to suggest that the Welsh variety of English used in the film is intended to correspond directly with the variety as it existed during the time period; nor was it the intention of the filmmakers to make that parallel; the contrived accents that are used are informed by contemporary usage.

\section{Pronunciation}

This phonological analytic section for PRIDE is concerned more with the accuracy of the contrived accents than the native speaking minor characters. As is to be expected, the aptitude in acquiring the accent varies between actors, and is made all the more prominent in a film where the majority of speakers are using contrived accents. Imelda Staunton's Hefina and Paddy Considine's Dai never find the balance in the intonation, with Staunton overcompensating the rise-fall stress, whilst Considine often coming across monotonal. That said, all representations are heard using genuine phonemes from WE. Andrew Scott's Gethin is heard consistently using palatal approximant initial insertion coupled with the open-mid central vowel /3:/ replacing what in RP would be a centring diphthong/Iə/ in 'here' and 'years', thus: /hj3:/ [9:40] and /j3:z/ [13:40]. Considine's Dai similarly puts stress upon this vowel change in his pronunciation of 'here' [18:40], and also renders the Cymraeg diphthong /ru/ in place of the /u:/ in 'thank you' [17:15]. And Nighy's Cliff similarly uses /hj3:/ for 'here'. Staunton's Hefina accurately drops her initial glottal fricatives in 'hell' [39:10], and unlike other characters, alveolar taps most word initial /r/, however occasionally overcompensates into a long trill at times, a feature lesser-used in south Wales, though often stereotyped (e.g. 'oh right, because you're so bloody irresistible' [39:20].

\section{Grammar and lexis}

The only lexical item that is attested is the use of vocative 'mun' [1:27:30]. It is not surprising to find that the domains of a variety's grammar and lexis are paid less 
attention when the filmmakers' (especially the writer) familiarity with the variety is less certain. Items they believe are familiar may also be used in their scripts, as is likely the case with the usage of the verb 'het up' [41:30]. 'Het' is peculiar in that it is used by one of the minor characters - one of the Welsh colliers, it is a term not recorded in $S A W D$ or other WE dialect dictionaries, with the $O E D$ noting its usage as 'to heat up' as finding chiefly Northern English and Scots English distribution. Grammatically, there has been some effort to adhere to known grammatical usages. The filmscript uses confirmatory tag 'is it' as a filler (e.g. 'It's you lot, is it, the gays?' [36:50]); clipped adverbials (e.g. 'absolute terrifying' [22:05]); the discourse markers 'like', 'mind' and 'see' (respectively: 'You live together, like' [37:40]; 'This is a Welsh castle, mind' [31:50]; 'The maiden Sabrina came here, see' [32:00]), and focus fronting (e.g. 'Lily of the valley, I use'). From PRIDE's production, it is clear that, these grammatical features have become markers of WE grammar within film, aiding non-native writers in their construction of the grammatical domain of WE.

\section{Metalanguage}

There is one scene in the film that alludes metalinguistically to the 'Welsh accent'. Hefina asks of the gay activist Gethin over the phone: 'Is that a Welsh accent I can hear?'. Gethin, who has lived in London for sixteen years, has disowned his sense of Welshness yet still is depicted as using his native variety's phonology. Gethin sheepishly replies with a nervous smile: 'Uh, oh, maybe', before repairing his utterance affirmatively: 'The remnants [of one]. I haven't been home in a long time, so...' Hefina finishes her conversation with Gethin by saying: 'Nadolig Llawen to you my love' (Cymraeg: Merry Christmas), to which he repeats with a smile. The inference by Hefina (or the screenwriters) is that somebody who speaks with a Welsh variety of English is likely to be familiar with the Cymraeg phrase for Merry Christmas.

\subsubsection{Peter Jackson's The Hobbit (2014)}

Peter Jackson's The Hobbit trilogy is the follow-up fantasy film series to his awardwinning Lord of the Rings (LOTR) trilogy adaptation (2001-2003). Adapted from J.R.R. Tolkien's The Hobbit, several writers were involved in the films' screenplays, 
including Jackson, Fran Walsh, Philippa Boyens, and Guillermo del Toro, a feat that stretched a small novel into three feature-length pictures. The series follows the journey of a party of dwarves and a hobbit across Middle-earth to the dwarves' ancestral mountain-home so they can reclaim its ownership from a tyrannous dragon; the story culminating in a grand battle between numerous fantasy races. Much like the prior LOTR series, the series features on ensemble cast, and was nominated for multiple BAFTAs and Oscars.

\section{Varieties of 'Common Tongue' in The Hobbit}

The Hobbit series is the only filmic text in this thesis to address the use of a Welsh variety of English in a fantasy filmic setting and is of significant interest due to the wealth of production details surrounding its usage.

The English of the film (and indeed Tolkien's original book) represents a 'stand-in' language, the actual language being 'Common Tongue'. In essence, it is 'translated' into English for the purpose of the reader/viewer. In this fantasy world, various races speak it, from Hobbits of the Shire to Dwarves of Misty Mountain, to the Men depicted in the film's Laketown, who are ancestors from nearby Dale. For the film, unlike average dialectal coachwork, Roisin Carty arguably had an expanded role within The Hobbit's production. As there were often at least thirteen dwarf characters on screen at any one time, she was tasked with applying different real-world accents to specific families of both dwarves and men for the means of quick characterization for viewers (Sibley, 2013:26). The idea was to fulfil a semblance of a language diaspora - that, following the dragon's capture of the dwarven homeland, the dwarves had 'dispersed to various parts of Middle-earth where they developed different accents' (p.26).

The process for accenting the dwarven characters started with a basis upon particular actors' native voices with certain central dwarven actors providing the 'accent model' for more minor characters amongst their kin. For example, Richard Armitage provided his Leicestershire English accent for lead character, Thorin, with Dean O'Gorman and Aidan Turner, playing Thorin's nephews by imitating Armitage's native accent. This is an interesting approach for tackling diversity of dialect within a 
fictional film narrative, and does not rely so heavily upon contrived or approximated accents.

It is in the accent chosen for Bard the Bowman (of the race of men) that is of most interest to this discussion, the actor Luke Evans being a native WE speaker. Prior to The Hobbit Evans had not, despite starring in many high-grossing Hollywood films, been asked to use his native variety of English (Turner, 2013). Evans has spoken out about several of elements of his casting in interviews, and it gives us some further indication of how Evans' casting was marginally different when compared to the dwarven characters. In an interview with Robin Turner from Wales Online, Evans stated:

I had a chat with Philippa Boyens [co-screenwriter and producer] on the phone the night before my audition, and she said, 'we want you to go in and do it in your Welsh accent'. And I was like: 'really? I've never done a Welsh accent ever in anything'. Even though it's my accent, most people want to stamp it out. And she said, 'No, we like it. We really like it'.

- Luke Evans, (Wales Online)

It is possible that Bard's accent may have already been chosen by the production team, Evans having potentially being chosen for his accent. From Philippa Boyens's comments it is evident that the New Zealand-based producers attitudinally positioned WE, and its usage in the film, within a positive rather than negative or trivially mocking domain. Indeed, the WE speaking Bard is portrayed as the most competent character, being friendly yet firm; handy as a bargeman, fisher, archer, and being a single-parent of three children - a far cry from the comical nature of several past WE filmic portrayals such as A Run for Your Money, Only Two Can Play, and Twin Town. In an interview with Press Association, Evans comments how he believes that WE works for Bard:

What's lovely is that Bard's ancestors now all have a Welsh accent, and anybody in Lake Town whose ancestors are from Dale (the same as Bard's), have a Welsh accent. So, we employed a lot of Welsh-accented people in New Zealand because of this movie' - (Press Association, 2013).

One example of a background Welsh accent occurs at 1:19:55 where an old man says: 'It's the prophecy, Durin's folk'. Use of dialect in this way enriches a sense of 
believability in a living fantasy world. Regarding Bard's children, like the dwarf characters, Evans acted as a 'dialect model' for other actors in the production. Bard's daughters in the movie Sigrid and Tilda are portrayed by Northern Irish actresses Peggy and Mary Nesbitt, have WE accents in the film, as does his son Bain.

What is less clear is why WE was explicitly chosen, and whether it was to index particular stereotypical attributes associated with WE users. It is possible that the production had run the gauntlet of regional British accents to use on Men after all twelve Dwarves. Alternatively, WE may have been chosen for Bard for the connection with certain Cymric stereotypical imagery. The first connection concerns itself with the orthography and pronunciation of Bard's name, for it shares a homophonic connection with the Celtic/Welsh word for professional poet. Secondly, it seems equally likely that considering Bard is the sole character to do battle with the dragon and kill it, a Welsh accented Bard was chosen to attach imagery of a Welsh accented English, with Welsh imagery of 'the dragon', a long-held visual motif in Wales. If so, the filmmakers use WE to index the Fantastic Welsh stereotype, thus associating the Welsh and their culture with Fantasy through equating dragons to Wales and WE accented people. Bear in mind similar indexical strategies were previously used contemporarily by novelists (see Chapter 7), and will be a focal point of WE videogame characters (Chapter 9).

\section{Phonology, Grammar, and Lexis}

What elements of WE are found in Evans' portrayal of Bard, and by extension within the Common Tongue of Dale/Laketown as seen within Peter Jackson's Tolkienian adaptation series? First, Bard's accent is reminiscent of WE, but lacks much of the rise-fall intonation within the sentence stress of his speech, although this is perhaps due to Luke Evans's own idiolect. This is in contrast to his children Bain (John Bell), Tilda (Mary Nesbitt), and Sigrid (Peggy Nesbitt). Their contrived accents have more pronounced rise-fall intonation heard perhaps best in Sigrid's 'Why are there dwarves coming out our toilet?' [1:12:00]. Attested phonemes are present in all characters, one example being the use of the Cymraeg diphthong/ru/ in place of the /u:/ in 'you' [1:01:00]. Grammatically, there is an example of 'focus fronting' usage by Bard when asked to explain a type of weapon, to which he replies: 'A crowbill, we call it' [1:16:50] demonstrating how either Luke Evans or the writers had 
considered aspects of WE other than phonology. This may be apparent in the lexis too, for Bard uses affirmative 'aye' several times [1:01:20], although this could have been an indexer of 'archaic' English rather than a nod to WE regional usage. Most confusing is the usage of 'da' as a vocative for 'father', used by Bard's children. ' $\mathrm{Da}$ ' is not attested in the $S A W D$ nor any layman glossary, with the $O E D$ suggesting it is a shortening of 'dada', which has colloquial and regional usage amongst speakers of Scottish English and Irish English. In this scenario, it is likely then that the influence stems from the children's native Irish English, this along with Evans's focus fronting might suggest the script and atmosphere on-set was more 'dynamic' rather than 'static'.

Despite using language varieties to induce the believability of realistic speech communities, dialect coach Carty noted that the production team were wary about using placeholder varieties because they did not want the audience to 'accent-spot' whilst watching a Tolkienian fantasy. (Sibley, 2013:p.28). Therefore, it was paramount that the team devised a method to distinguish these unique varieties of Common Tongue from their real-world English varieties, for Middle-Earth is 'a realm that is very different to our own yet possesses similarities that we recognize' (p.28). The phrase 'accents of otherwhere' was created by the team, with the sole purpose of helping them to construct dialogue that felt familiar, but not immediately locatable within a certain Anglophonic region, dialogue which was 'not too modern, not too much of our time' (p.28). The fact that the use of 'da' for father is used by the children, and even Bard defining the 'crowbill', disassociates a direct parallel with WE, even if the phonology and grammar match WE, lexical usage suggests an 'otherwhere' characteristic.

\subsubsection{Summary}

In summary, small independent films like Big Font. Large Spacing captured ad-hoc Welsh English through casting non-actors. Again, WE featured in several 'historical' dramas like 1970s Hunky Dory, and 1980s PRIDE, the latter of which however like Englishman before it, cast many non-WE users in lead-roles. The end of this period also saw the WE variety being used in the fantasy Hobbit films, in doing so indexing 
qualities of Fantasy with the variety for international audiences, a trend carried across from literature (and prominent in Videogames, chapter 9).

\subsection{Conclusion}

This chapter has investigated the depiction of Welsh English in filmic dialects, analysing sixteen texts from 1938 until 2014. Texts shared familiarity in dialect depiction throughout this period with particular forms appearing to be 'enregistered' for filmmakers' as representative markers of the dialect.

Like literary dialect, filmic dialect includes a Cymraeg-loan dimension - with both the endearment term 'bach/fach' (6/16 texts) and 'mam' [mother] (5/16) similarly occurring most-frequently, and exclamative 'duw' occurring in three texts. 'Iechyd da' [good health] occurred in two early filmic texts but dropped out of usage. Dialectal lexis from English were more frequent in these texts. In chronological order of appearance and tallies, these were: 'clipped adverbials' (5/16), affirmative 'aye' (7/16), vocative 'mun/man' (11/16), noun and vocative 'butt/butty' (3/16), adjective 'tidy' [decent] (3/16), and vocative 'boyo' (3/16) (however identified twice as a linguistic stereotype).

There were also reoccurring grammatical features throughout. The most common feature was focus fronting (11/16 texts) used in the earliest analysed film (1938) and the last (2014). Following this in chronological order, confirmatory interrogative tags like 'is it?' (9/16), demonstrative There (5/16), discourse marker 'see' $(5 / 16)$, and discourse marker 'like' (4/16). For phonology, we must consider that both native users of WE and non-native WE users used a WE filmic dialect. Though this may hamper treatment of filmic-phonology as linguistic evidence, we can nevertheless get an idea of phonemes that were perceived to index a WE filmic dialect. The most common was the rolled or tapped /r/ (10/16 texts), present from 1938 until 2014. Then in chronological order of appearance: omission of medial palatal approximant /j/ (yod-dropping) (7/16 texts), RP diphthong /oə/ (or /o:/) as /u:wə/ (4/16), closed back vowel /u:/ as diphthong /Iu/ (8/16), and RP diphthong /ıə/ or /hı/ as /3:/ or /j3:/ (9/16). Omission of initial glottal fricative /h/ (8/16), though present in half the sample, began appearing after the 1950s. Production restraints also 
saw trends: early films like The Citadel and Proud Valley saw children represented with RP accents; by the 1950s native WE users were being sourced. The representation of lexico-grammatical features did diminish further into the $21^{\text {st }}$ century with phonology (accent) being the key linguistic domain. This could be representative of dialect levelling present in contemporary WE, yet is more likely a production restraint or directorial choice, possibly to avoid a sense of dialectal 'viewer resistance'.

Regarding new 'linguistic evidence', there are few undiscovered linguistic features debuting in filmic-dialect except for The Citadel's mining phrase 'trouble with my tubes'. Why there are fewer undiscovered features found in films is uncertain, though, again, it could be to avoid dialectal resistance from viewers. Unlike a 'crosssectional' dialect study, we can however use the sample films in a 'longitudinal' manner to assess chronologically some features. Focus fronting's presence throughout this period shows it is a pervasive feature; mentioned only briefly in the $S A W D$, one could argue that the linguistic evidence this sample provides is that focus fronting is one the grounded markers of WE. Indeed, the SAWD may not have picked this feature up due to a methodological failure wherein grammatical features were not directly sought in the questionnaire format. Even if this is not true of the equivalent real-world variety, it is clear that it is enregistered, with writers perceiving it to be a strong marker of WE.

Furthermore, from observing recorded filmic dialect, this chapter identified that a distinct phonological change may have occurred since the 1940s as vocative 'mun/man' shifted from a mid-central vowel $/ \Lambda /$ to an open front vowel /æ/. Actors speaking Cardiff English (Human Traffic) were using vocative /mæn/ in the late 1990s; by 2010s young users from the Valleys were also recorded using this feature.

Addressing the question regarding differences between Welsh and non-Welsh filmmakers, without doubt, How Green Was My Valley is a chief example of a nonWelsh producer choosing not to utilize any sense of authenticity of variety in a film. Though early Welsh cinema was made by non-Welsh producers/directors, Welsh actors often starred in productions, thereby utilizing native WE varieties. Contemporarily, apart from Twin Town's Kevin Allen, few Welsh producers end up 
casting WE users in films. Grieve, Monger, and Marc Evans all use 'well-known' non-Welsh actors using contrived accents likely for audience familiarity: a salient production restraint. Understandably, aptitude for acquiring a WE variety is mixed, and few actors came as close to Peter Sellers' production in Only Two Can Play (1962). Despite producers' best intentions to cast an 'authentic' accent, the final product may fail to match attested forms, this is evident in Grieve's Englishman, and Tennyson's Proud Valley.

Metalinguistic awareness and linguistic/character stereotyping varies. WE is used to connote humour by A Run For Your Money, and Only Two Can Play, whilst Twin Town, and Halfway House and the Hobbit pair WE varieties with indexical Fantasticism. Films like The Citadel and Human Traffic portray characters imitating the accent for humour, and $A R F y M$ and Twin Town highlight derogatory terms for Welsh people. 


\section{Chapter 9 Representation of Welsh English in $21^{\text {st }}$ century videogames}

\subsection{Introduction}

Previous chapters, for example Chapter 7: Novels and Chapter 8: Film, have addressed historical periods and literary/filmic texts in which the representation of Welsh English had been largely authored/produced by both speakers of the variety or those familiar with it. This chapter however focuses upon seven $21^{\text {st }}$ century period's videogame narratives, and although similar to audio-visual media such as film, in many ways, shares creative similarity with the approaches used by Tudor and Stuart playwrights in Elizabethan plays (see Chapter 6: Plays). This era saw numerous English playwrights attempting to use the WE of its era to quickly index stereotypical 'comic' Welshness, a trend that has come full-circle in the $21^{\text {st }}$ century during the emergence of videogames as a narrative medium.

In most cases, the chapter sees the production, writing, and direction of fictive texts being undertaken by those without an immediate connection to WE. Much like the previous chapter on film, the dialect's delivery through actors (in videogames' case: voice-actors) varies between affirmed speakers of the variety, and contrived speakers.

Many of the texts (see Table 9.1.) featuring WE are situated in narrative genres that are distinct from the real-world literary worlds of Wales or Welsh diaspora, leaning more towards fantasy and science fiction, similar to the analyses of Chapter 7 and Chapter 8's The Owl Service (Garner), Howl's Moving Castle (Jones), Soul Music (Pratchett), and Hobbit trilogy (Jackson). Therefore, this chapter will investigate WE-using characters who may not inherently be 'Welsh', but may have been given a WE variety to index stereotypes, or denote 'otherness'. A unique question this chapter answers is why has the WE accent been used for such characterisation in videogame narratives? 
Table 9.1: List of videogame texts analysed

\begin{tabular}{lll}
\hline Developer & Year & Text \\
\hline Free Radical Design & Mar 2005 & Timesplitters: Future Perfect \\
Rockstar San Diego & May, 2010 & Red Dead Redemption \\
Lionhead Studios & Oct, 2010 & Fable III \\
BioWare & Mar, 2011 & Dragon Age II \\
BioWare & Dec, 2011 & Star Wars: The Old Republic \\
Studio Ghibli & Jan, 2013 & Ni no Kuni: Wrath of the White \\
Ubisoft Montreal & Witch \\
\hline
\end{tabular}

Key. Red: narrative set in the 'real-world'. Green: narrative set in a 'fictive-world'

\subsection{Videogames as narrative media}

So far, this thesis has presumed that consumers of fiction acknowledge that plays, novels, and film are all fictive narrative modes and that dialects can be represented in all three modes. A case must now be made for the contemporary narrative genre of the videogame; in other words, for the 'videoludic' fictive text.

In the first decade of the $21^{\text {st }}$ century, the videogame industry had begun to dominate the creative industries throughout the United States, Europe, and Japan. At the close of the first decade, the Entertainment Software Association reported that games had sold \$10.5 billion in 2009 alone, and that 67\% of American households owned gaming hardware (Ensslin, 2012:1-2). In 2011, revenues for the industry (\$55.5 billion) surpassed the music industry ( $\$ 23.4$ billion), though still lagged behind the film industry ( $\$ 86.2$ billion), although unlike film's 5.9\% annual increase, the game industry receives around 8.2\% per year (Egenfeldt-Nielsen, Smith, \& Tosca, 2013). A result of this is that the academic study of videogames has also seen considerable growth, encompassing both fields of ludology (studying gameplay) and narratology (studying games as art and narratives) (Ensslin, 2012:2).

What comprises a 'videogame' can be, contemporarily, a heated discussion. Game theorist Jesper Juul, who leans more towards analysing videogames by their ludic 
(i.e. gameplay) properties, defines a game as:

a rule-based formal system with a variable and quantifiable outcome, where different outcomes are assigned different values, the player exerts effort in order to influence the outcome, the player feels attached to the outcome, and the consequences of the activity are optional and negotiable. (Juul, 2003: section 4).

Other scholars, such as Henry Jenkins, argue that modern videogames are first and foremost cultural artefacts. Videogames are, like cinema before it, new forms of popular art:

Games represent a new lively art, one as appropriate for the digital age as those earlier media were for the machine age. They open up new aesthetic experiences and transform the computer screen into a realm of experimentation and innovation that is broadly accessible. And a public that has otherwise been unimpressed by much of what passes for digital art has embraced games. (Jenkins, 2005:177)

The debate surrounding whether videogames should be primarily analysed by their gameplay elements or their story-telling elements has dominated videogame studies in recent years, especially since literary critics have begun treating games as texts for textual analysis (Egenfeldt-Nielsen et al 2013, 214-215). Juul and Jenkins believe videogames are first and foremost games, and that that is their formal intrinsic property, whereas literary critics such as Julian Kücklich have attacked the standpoint for simply treating the story elements as 'uninteresting ornaments or gift wrappings' that are positioned on top of a game's rule-based structure (EgenfeldtNielsen et al, 2013:215).

Although the earliest videogames to feature stories were the niche text-based adventures, today a large variety of videogame genres incorporate story elements into their ludic structures. As computer processing power, graphical power, and artificial intelligence became more sophisticated during the 1990s, videogames began to resemble real-world imagery; naturally, story-driven games emerged in correlation with these developments (Egenfeldt-Nielsen et al, 2013: 194).

The definition of narrative provided by Katie Wales's Dictionary of Stylistics (2001) is: 'a story, of happenings or events, either real or imaginary, which the narrator considers interesting or important' (p.264). Such a definition matches many 
contemporary videogames, although unlike conventional narratives such as novels and film, videogames are narrative-framed slightly different. Narratively driven videogame stories often contain beginnings, middles and ends, are situated within time and space, and feature both protagonistic and antagonistic characters (Ensslin, 2012:143). There are, however, some differences in videogame plots. Bates (2001) outlines that a common structure for videogame plots begins with a conflict that the player character acts upon, the middle of the game can vary in length and often comprises of multiple challenges throughout, whilst the end of the story is the final challenge, often requiring the defeat of a 'boss' character, that will offer closure to the narrative. In this way then, ludic elements tailor the stories of videogames (Ensslin, 2012:145).

Many scholars of narratology, such as Ensslin (2012), view videogames not as preconceived, closed stories, but rather open narratives, narratives that often encourage the player to personalise the story (via gameplay); they are texts that offer fictional worlds for players to explore, thus allowing players to generate their own understanding of a text's narrative (p.143-144) (see Nitsche, 2008:230). Ensslin (2012) states: 'videogames aren't narratives in the traditional sense of chrono-logic sequencing. Rather, they are fictional environments which are explored spatiotemporally by players in the shape of their avatars' (Ensslin, 2012:24).

Videogames are not textual in the same way that film, novels and theatre are. They offer a new method of consuming story: players interact with games, they have 'direct cognitive and kinetic participation in the execution of the underlying software code' (Ensslin, 2012: 41, emphasis mine). This execution, or agency, is fundamentally different from passively reading.

Varying degree of interactiveness within game texts can lead players to believe that the gameworld lives, perhaps even when the player is not interacting with the game, creating an illusion of immersion previously unexplored via traditional texts (Egenfeldt-Nielsen et al, 2012: 199). Characters are a large part of such interactiveness. Egenfeldt-Nielsen, Smith, \& Tosca (2013) summarise four key interactive character types that players will encounter and interact with (p.203). The first are stage characters, who are part of the scenario, and move around, but have 
no personality or function in-game. Second, are functional characters, who have minimal functions in-game (as tools). Third are cast characters, who have a large function in the story, and often a personality. Finally, player characters, whose actions are controlled by the player, but whose motivations are decided by the game's story. See Table 9.2. for a breakdown of analysed texts' characters and their videogame character 'types' in this thesis.

Table 9.2: List of videogame characters, their character type/roles \& voice-actors

\begin{tabular}{|c|c|c|c|}
\hline $\begin{array}{l}\text { Character } \\
\text { (Text) }\end{array}$ & $\begin{array}{l}\text { Videogame } \\
\text { character type }\end{array}$ & $\begin{array}{l}\text { Videogame character } \\
\text { role }\end{array}$ & $\begin{array}{l}\text { Voice-actor } \\
\text { Native/Contrived (N/C) }\end{array}$ \\
\hline $\begin{array}{l}\text { Drippy, Lord } \\
\text { Fairy } \\
\text { (Ni No Kuni) }\end{array}$ & Cast character & Companion & Steffan Rhodri, S. Wales (N) \\
\hline $\begin{array}{l}\text { Captain Bryn, } \\
\text { Military } \\
\text { captain } \\
\text { (Star Wars: The } \\
\text { Old Republic) }\end{array}$ & $\begin{array}{l}\text { Functional } \\
\text { character }\end{array}$ & Quest-giver & Unknown (?) \\
\hline $\begin{array}{l}\text { Sabine, King of } \\
\text { Mistpeak } \\
\text { (Fable III) }\end{array}$ & $\begin{array}{l}\text { Functional } \\
\text { character }\end{array}$ & Quest-giver & Ben Kingsley, York (C) \\
\hline $\begin{array}{l}\text { Merrill, First to } \\
\text { the Keeper of } \\
\text { the Sabrae } \\
\text { Clan } \\
\text { (Dragon Age } \\
\text { II) }\end{array}$ & Cast character & $\begin{array}{l}\text { Companion } \\
\text { Romantic interest }\end{array}$ & Eve Myles, Ystradgynlais (N) \\
\hline $\begin{array}{l}\text { Lenny } \\
\text { Oldburn, } \\
\text { Scientist } \\
\text { (Timesplitters } \\
\text { FP) }\end{array}$ & Stage character & Enemy & Unknown (?) \\
\hline $\begin{array}{l}\text { Edward } \\
\text { Kenway, } \\
\text { British } \\
\text { privateer } \\
\text { (Assassins } \\
\text { Creed IV) }\end{array}$ & Player character & Protagonist & Matt Ryan, Swansea (N) \\
\hline $\begin{array}{l}\text { Alwyn Lloyd } \\
\text { ("Welsh") } \\
\text { Career- } \\
\text { criminal } \\
\text { (Red Dead } \\
\text { Redemption) }\end{array}$ & Stage character & Enemy & Paul Mullan, Swansea (N) \\
\hline
\end{tabular}


In some ways, these types (except for the dialogueless stage character) share similarity with Short (1996) and Hodson (2012)'s three core positions in which dialogue, and by extension - dialect, occur in a text, such as: direct speech and thought (which can be first or third person), within a narrative (first and third person), and free indirect speech (mixed) (see 3.1 above). Whereas functional characters and cast characters are character types that the player will talk to (represented as third-person direct speech), player characters talk for the player of the game (similar to first-person direct speech/thought). Unlike a dialectal portrayal in first-person literature, there is dissonance in videogames: whilst a player controls the player character's movements, the player character controls their speech (which is part of the game-script). Regarding this thesis, and future analyses of dialect in videogames, addressing what type of videogame character is using 'dialect' will be of interest in a variety's representation, although future research could interrogate perceptions of player character's varieties in relation to players' own varieties.

As stated above, videogames often follow the familiar three-act structure, and feature plots that players will recognise from literature and film, plots they recognise as readers and viewers of media. This sense of familiarity, or intertextuality, is prevalent in many games and help players make points of reference to well-established tropes, some of which are formed by stereotypes (Ensslin, 2012:55). Both genres and narrative devices are commonly lifted from previously established textual modes. For example, action games borrow visual language from action movies and fantasy games borrow tropes and character-types from literature. Also, a common narrative device that frames narrative in videogames are cutscenes. Cutscenes are short filmic movies that break the flow of gamer agency often to create additional dramatic impact, or depict scenes the gameplay might find difficult to render (Ensslin, 2012:149). In many ways, this indexes a sense of 'cinematicity' to a videogame.

Regarding the aforementioned stereotyping enforced by intertextual references, the use of ethnic othering in videogames and gameworlds is common, with enemies often stereotyped by recognisable features, from skin colour, to clothing and even language varieties (both accents and registers) (Ensslin, 2012:38-39). Ensslin argues that because of videogames' sense of immersion and hyper-attention to gameplay, videogames have a far more potent covert ideological force than other media like 
novels (p.41).To quote Ensslin: 'for the sake of successful gameplay, players prioritise rule implementation and interface interaction over the critical reception of individual representational modes such as [non-player character]'s voices and accents' (p.138). Game developers tend to use conventional and unconventional semantic oppositions to construct binaries of good/bad, subjecting players to usage of language that is encoded into the user interface (p.139). Such othering brings to mind the sort of stereotyping of otherness that is common practice in other 'animated' modes such as animated television and film (see 4.2 above).

Hitherto, there have been few analyses of 'literary dialect' within videogame texts. This chapter attempts to fill this gap by offering several case studies in which the WE dialect has been used in videogame narratives. Regarding 'the few', Ensslin (2012) analysed Lionhead Studios' real-time strategy game, Black and White 2 (2005). In $B \& W 2$, players take the role of either a benevolent god or malevolent god. Both characters are accented to reflect morally good/bad binary. The white, elderly, angelic character speaks with an 'overarticulated [Received Pronunciation] accent and in a formal register', whilst the darker-skinned, demonic character speaks with a 'Standard North American accent mixed with a non-formal register' (p.139).

This chapter treats videogames primarily as texts, or storytelling devices (i.e. narratives). Egenfeldt-Nielsen et al (2013) cautions, however, that videogames are not strictly 'static' texts like drama, novels and film, because the agency and decision-making of the player means that 'no two game sessions will be exactly the same' (p.197). Because this thesis is concerned with the representation of language variety in the scripted dialogue of characters, we can use 'text' in a similar manner to previous modes from previous chapters. However, due to this 'textual dynamism', there is the possibility that Player $\mathrm{X}$ will not necessarily experience all the same representations of dialect on-screen as Player $\mathrm{Y}$ will, especially for interactions which are parts of 'side-missions', rather than along the main narrative trajectory. 


\subsection{Welsh English In Fantasy Videogames}

\subsubsection{The Elven 'Other': Welsh fairies, and Tolkien's 'Elf'}

The 'Fantastical Welsh' stereotype (see 4.6.2.) comes into play within videogame representations to a degree far exceeding any previous medium addressed. As will be shown, both fairy and elven creatures have recently been voiced in videogames with WE accents. Part of this chapter's core question asks why this indexing of WE accents has taken place, and whether, with videogames being intertextual, the stereotype has arisen from past tropes?

Since their mytho-narrative inception, elves and fairies in Norse and Celtic folklore have been used to denote the 'Other' in Northern European folklore: like humans, but with disqualifying features (Bergman, 2011:9). Of interest to our discussion is the Celtic/Welsh elf-fairy. Medieval Cymraeg mythological texts (White Book of Rhydderch, c.1350; Red Book of Hergest, c.1382-1410) noted residents of the Fantastical Annwn, the Otherworld, as 'Othered' beings (Bergman, 2011:28). Welsh fairies, first described as the tylwyth Gwyn (i.e. fair-family) in the poem $Y N i w l$, and then as tylwyth teg by William Salesbury, appeared later during a time when fairy depiction soared (p.35). Here, the diminutive fairy was created, and writers like Chaucer and Shakespeare both used the Fairy/Elf to 'lighten moods' and add comic flair (Bergman, 2011:65). In 1590, Edmund Spenser wrote The Faerie Queen for Queen Elizabeth I, an accolade later critics like Greenlaw (Greenlaw, 1918:120) attributed to the Queen's Tudor/Welsh origins.

The perspective of fairytale elves was significantly reinvented in the $20^{\text {th }}$ century with Lord Dunsany's The King of Elfland's Daughter (1924) and J.R.R. Tolkien's Middle-Earth legendarium. Tolkien's Lord of the Rings (LOTR) solidified in the zeitgeist the elf as 'significant other' reintroducing elves as human-sized, but as creatures that were unaging, fair, wise and nature-loving (Bergman, 2011:99-100). Tolkien's elves were 'sages, warriors and lovers', tropes directly lifted from Sir Orfeo, the Irish Tuatha de Danaan, Welsh Arthurian romances, and specifically tales like Culhwch and Olwen from the Welsh mythic canon, the Mabinogion (Phelpstead, 2011:64-65). One connection between the new Tolkienian Elf and Welsh culture not mentioned by Bergman (2011) was Tolkien's use of language. Tolkien, being a self- 
professed cymricphile, admired Welsh people, their historic struggles, and particularly the language (Phelpstead, 2013:3; Burns, 2006:21). During his lecture English and Welsh in October 1955 Tolkien went as far as saying that the influence of Cymraeg was paramount to the success of LOTR, that 'the names of persons and places in [LOTR] were mainly composed on patterns deliberately modelled on those of [Cymraeg]' (Tolkien, 1983:197). However, it was not just toponymy and names that were influenced by Cymraeg, for Tolkien also created a constructed-language (conlang): the Elven language, Sindarin - linguistically derived from Cymraeg.

Tolkien, being a philologist and scholar of Medieval Cymraeg, had the expertise for constructing a new language (Phelpstead, 2011:12-13); indeed, his creation of Sindarin began as a product of his enjoyment in linguistic experimentation, predating his fictive world, 'Middle-Earth' (Phelpstead, 2011:40-41). Tolkien created detailed histories for Sindarin's speakers, highlighting lexical, grammatical, and phonological changes, with Cymraeg's grammar and phonemes influencing him greatly. He stated that he chose Cymraeg for Sindarin because he found it 'very attractive', and because 'it seemed to fit the rather 'Celtic' type of legends and stories told of [Sindarin's] speakers' (Tolkien, 1981:176). By voicing his elves with a language derived from the phonological and grammatical systems of Cymraeg, Tolkien directly tied the Elven fantasy race with the Celtic/Welsh cultural sphere.

The model of Tolkien's Elf has had profound intertextual impact upon writers' depictions of elves. Bergman (2011) states: 'readers of Tolkien and post-Tolkienian fantasy may now consider elf to be the proper name for a supernatural being of human proportions' (p.158). And, although the High Fantasy literary genre is not solely derived from Tolkien, the 'stereotypical or stock fantasy elf [...] is derived from [Tolkien's] writing' (p.196).

Today, a popular genre to find post-Tolkienian elves is the videogame, with gamers intertextually recognizing connections between various game franchises. Poor (2012) believes that videogame representations of elves often represent a cultural or ethnic/racial 'other', presented as 'almost human but more in tune with nature' (p.376). Poor argues that because Western fantasy often omits non-White humans, texts lack a human 'other'. This slot fits the post-Tolkienian elf, thus mirroring real- 
world cultural tensions and avoiding socially stigmatic, real-world prejudices that might look unfavourable with human analogues (p.391). Post-Tolkienian videogame elves may be enslaved by men, may have had their cultures destroyed, or may have been forced into ghettos (p.378). Occasionally elven characters reflect linguistic stereotyping. World of Warcraft (Pardo, Kaplan, Chilton, 2004) has appropriated several ethnicities by making 'evil' non-human races like trolls speak with Jamaican accents and 'good' human races speak with British and American Englishes (Higgin, 2009:9; Langer, 2008: 89), reflecting the good/bad accent-binary noted by Ensslin (2012) for $B \& W I I$ above.

Although many depictions of elves in fantasy works today use Tolkien's reimagined elven race as a basis (e.g. human-sized, nature affinity), Tolkien's Welsh linguistic dimension appears absent from these depictions. The first part of this chapter demonstrates that two contemporary texts $d o$ incorporate a Welsh linguistic element into their representation, via Welsh accented English.

\subsubsection{Fable III (2010), Lionhead studios}

One of the first examples of the WE used in a fantasy video-game setting comes from the third instalment of the Fable series, which featured a contrived WE accent performed by non-native speaking, Ben Kingsley. It is the first of several similar discussions that will see the videogame medium present portrayals of WE as an 'othering accentual tool' to index quick characterisation.

Fable III is a fantasy game developed by British developers Lionhead Studios, released in 2010 for the Xbox 360. Fable III takes place in what may be viewed as a parallel fantasy version of Britain, known as Albion. With the name Albion itself is a familiar trope-naming stereotype for British culture, it is not surprising that cultural stereotypes find their way into other facets of this ludonarrative. The game narrative sees the player take the role of a tyrannical king's brother, who gradually builds an army to overthrow him. 


\section{Creating Sabine, the 'Welsh' king}

Ben Kingsley was cast for his reputation as a British classically trained actor, several other well-known British actors were cast as characters in the game, such as Simon Pegg, John Cleese and Stephen Fry (Hart, 2010). Kingsley was drawn to taking part in the project after viewing the committed team of developers and the beauty of the fantasy world they were creating (LionheadStudios, 2011). In what was his first videogame voice-acting role, Kingsley voices the human character Sabine, and is the King of a mountainous, misty region called Mist Peak. Most importantly, Kingsley portrays Sabine with a contrived WE accent. Although Sabine is, much like Drippy in Ni No Kuni and Merrill in Dragon Age II, a supporting character in the plot, unlike these later elven characters he acts as a functional character. Sabine is a quest-giver within the game - his role is to present a quest for the player to embark upon. At first it appears there may be little connection between the choice of accent and the character's cultural surroundings, especially considering that Sabine and his tribal community have an aesthetic that is more reminiscent of Eurasian nomads. Being a contrived accent, did Kingsley or Liongate Studios have a motivation for intentionally choosing a WE for Sabine over any other regional variety?

When examining the Mist Peak/Wales connection further it appears that, like Wales, Mist Peak community is at odds with Albion/England, for Albion want to discreetly incorporate the Mist Peak kingdom into Albion's empire, a colonial gesture that mirrors Anglic-Cymric relations of the medieval period. The stereotype of the Welsh ethnic minority seems in place. The choice of setting being mountainous and shrouded in heavy rainfall also mirrors the central geographical nature of Wales.

Yet it was not in Lionhead Studio's conceptual design to have Kingsley voice Sabine with a Welsh voice. According to producer Louise Murray, much to the confusion of other members in the studio, Kingsley 'looked at the character, read it, then played it in a Welsh accent' (Hart, 2010). This suggests that Kingsley may have also seen some mirroring of Mistpeak's struggles and mapped it onto what knowledge he had of Welsh peoples' struggles. This is backed up by what he has to say about the character Sabine in relation to a previous Welsh accented character he played in a film called The Last Legion (2007). He says: 'there is I think some loose connection between a character I played in the film called 'The Last Legion' and Sabine. They're 
both from the same part of the UK; they're both from Wales' (Lionhead Studios, 2011: [video]). Nevertheless, comical stereotypes are present here too, as Sabine is presented as a comical king archetype, laughing and joking in front of the player character.

\section{Pronunciation}

Regarding the authenticity of the portrayal, Sabine's accent emphasies the wellknown rise-fall intonation characteristic of WE to an almost comic level. It is unlikely that Kingsley's intention was mockery, being more likely ignorance and lack of a suitable voice coach. For example, Kingsley places emphasis and pause on each syllable when speaking: 'Ou-wer her-ro re-turns'. Kingsley also taps, and trills, his $/ \mathrm{r} /$ in words such as 'bringing', and, inconsistently, drops his initial glottal fricatives in 'have'. That said, many of the phonemes he uses are more reminiscent of Received Pronunciation than WE, for example his wavering between using the diphthong RP /əo/ in the final vowel of 'hero' and the attested WE / $\mathrm{p}$ :/ in the medial 'folk' and 'so'; whilst his pronunciation of 'castle' also uses an open back vowel /a:/, a phoneme absent from WE, often in place of near-open front vowel /æ/.

There appears to be some sincerity in Kingsley's decision to choose a Welsh accent for Sabine, and in some small way it presents the variety in a relatively positive light, albeit slightly stereotyped: this time the stereotype being that the Welsh peoples and speakers are synonymous with oppressed tribal peoples. But ultimately, we must question whether there is any worth in representing a variety through the means of a non-native speaker, especially one who poorly executed the dialect. Kingsley even admits that choosing a Welsh accent may have been a poor choice on his behalf and jokingly asks for forgiveness from the Welsh players: 'I apologize to any Welsh players of the game for my Welsh accent, but I did have-a-go' (Lionhead Studios, 2011). Lionhead Studios' are not unfamiliar with this kind of stereotypical 'othering' surrounding accent, as mentioned in the introduction to this chapter, Ensslin (2012) found their binary good/bad accent othering in Black and White 2 (2010) to similarly use accent as a tool for quick characterisation based upon established tropes. 
Whether or not Kingsley's 'having-a-go' attitude caused offense to WE users, it may not be coincidence that following this early depiction contrived accents diminished and native WE voice-actors began to be sourced for characters.

\subsubsection{Dragon Age II (2011), Bioware}

Dragon Age II is a fantasy role-playing game developed by Canadian videogame developers, Bioware Corporation, and released in 2011 for the gaming systems: Mac, PC, PlayStation 3 and Xbox 360, and is a sequel to Dragon Age: Origins, released in 2009. The player takes on the role of the human character, Hawke, who is one of the few to survive the destruction of their homeland. The game tasks the player with gathering the deadliest of allies to combat the threat, whilst amassing fame and fortune in the process and 'seal a place in history' (Dragon Age II blurb, 2011). With $D A I I$, the linguistic medium of a WE dialect reconnects the Cymric linguistic association that Tolkien envisioned for his Elven races (section 9.2.1.).

\section{Creating Merill, the 'Welsh' elf.}

It is not the playable character, Hawke, that interests us, but one of the supporting characters: Merrill. In ludonarrative terms Merill is a cast character, that can act as a companion, or helper, to the protagonist (and also love interest should they pursue it). Merill's fantasy species, and connected accent are relevant to this discussion, for Merill is an elf who speaks with a WE accent. Why it is that Bioware actively chose to cast Merrill with a Welsh accent opens much discussion. She exists in a fantasy world, and, in a similar way to Luke Evans' Bard (Chapter 8), has no contact with real-world WE-using people. Compared to Lippi-Green's statistics of Disney characters, she would be classed within the category of those 'illogically' speaking English (Lippi-Green, 1997:87) acting as an 'othering' tool. The official website describes Merrill, and her people - The Dalish - in quite Tolkienian Elven terms, linking further the fictional Elven world with the realistic Cymric world:

The Keepers of the Dalish are the masters of ancient lore and guardians of old secrets. Merrill can recite all of known elven history and navigate the Fade... but has very little experience with the world or even her own people. Now in a foreign land, surrounded by dangers on all sides, Merrill must find help for her clan. Whatever the cost. (Dragonage.bioware.com, n.d.) 
Tropes of the Post-Tolkienian elf are evident: besides the fact that they all humansized, the Dalish are described as 'masters of ancient lore and guardians of old secrets', similar to Tolkienian depictions of The Elf. The website describes the Dalish as nomads, who wander the world seeking to recover, inherit and preserve the elven knowledge lost when two independent elven kingdoms, The Dales and Elvhenan, fell to ruin, following invasion. The Dalish are descended from the ancient inhabitants of Dales, and Merill, who is a Keeper of the Dalish, is descended from the nobility who governed the region.

This historical description draws comparison between the Elvish Dalish of DAII and the real-life history of Cymric or Celtic peoples. Indeed, this trope is also similar to Sabine's Mistpeak Welsh-inspired community being marginalised in Fable III. Poor (2012) elaborates that because the nomadic elves of Dragon Age series have suffered a loss of cultural heritage and are presented in-game as the 'other', they resemble real-world peoples driven to such extremes by invaders, for example the Celts' subjugation by both the Romans and Anglo-Saxons (p.384-385).

Could it be that the creators of DAII indexed a Welsh accent for their elven depiction specifically because of this purpose? It should be noted that the character of Merrill was included in the first game and was voiced with a General American English accent, voiced by Erin Matthews of Portland, Oregon (imdb, n.d.:d). It was only in the development of the second game that the developers, Bioware, decided to change her voice for a Celtic English, with the final characterisation being a WE accented character, voiced by Eve Myles (imdb, n.d.:e). Regarding her involvement in DAII, it appears upon casting Myles had had little knowledge of the videogaming industry (taking the role because of her nephew's familiarity with the series) (Manning, 2014). Subsequently, it seems that Myles might have had little involvement with Merrill's character development, at least in comparison to, for example, Luke Evans' engagement with Bard the Bowman's WE (Chapter 8).

The creation of Myles' character, Merrill, can be attributed to writer David Gaider, her dialogue was then written by co-writer Mary Kirby (Kirby, 2011). During development of the game, Gaider and Kirby were both active within the fan community via online forums. These forums in turn form a valuable resource for this 
current discussion for they reveal a few of the developers' creative processes for Merrill. Regarding the casting of Myles, Gaider commented that the actress was specifically sought after for the role of Merrill, stating that she was 'on the list of "actors I specifically asked for and got on the first try" (Gaider, (2011a [accessed 2016, April 9]). Gaider's decision for choosing Myles to voice Merrill stems first from an affinity with Myles' voice, and by extension her WE. Regarding Myles' voice, Gaider wrote in response to a fan's admiration for Myles that he also loved it, then going on to state that casting Myles as Merrill resulted in 'one of those rare cases where the voice actor takes a character and turns it into something special. I will take Merrill along in my [roleplaying] party just to listen to her talk' (Gaider, 2011 b [accessed 2016, April 9]).

However, it was not just an admiration for the Welsh accented speech of one particular individual that pushed the development team to choose Myles's voice for Merrill. Gaider suggests that it was part of the developers' executive decision to voice all the Dalish elves in the game with Celtic English accents: "we use both Irish and Welsh accents for the Dalish. Honestly, if we stuck to Welsh only we'd have a really small pool to draw from.' (Gaider, 2011c). During the game it appears that it is only Merrill, and an elder elf named Paivel (voiced by Peter Jessop in the first game, but by Mark Lewis Jones (imdb:n.d.:f) in the second), who speak with WE accents; the rest of the Dalish speak with Irish English accents. Gaider's comments directly reveal that the developers' desire to voice more elves with WE varieties did not come to fruition due to the current lack of WE voice-actors for animation; a clear dialect production restraint that resulted in the writer/developers altering their plans.

Either way, without a doubt there is a significant Celtic element involved in casting these voice-actors; although there are more Irish-accented elves in the game than Welsh-accented elves, the fact that Bioware and Gaider chose a Welsh accented elf as one of the main characters, rather than a minor character, elevates the trope of the Welsh fantasy being/elf ever so slightly higher. In all, it seems likely that Bioware's casting of Celtic Englishes in elven roles was due to a stereotypical association that these Englishes have connotations with the fantastical, magical, or mythical aspects of these native speakers' cultures. That said, we cannot rule out the possibility that they were also cast to highlight the parallels between the histories of the Dalish and 
that of the WE and Irish English speakers', namely in their struggles with Anglicisation, and displacement of their traditional culture and people.

\section{Dialectal perceptions}

We shall now briefly investigate the dialectal perceptions derived from Eve Myles's portrayal of Merrill and how the use of a WE accent in her speech relates to her presence as a main character within the narrative. There is evidence from players that Myles's portrayal and use of Welsh accent for the character were perceived positively, rather than a negatively.

Player commentary from the forums help inform us of how the casting of a WE dialect has been received for use in this particular fantasy setting. Many players commented that Eve Myle's voice-acting provided Merrill with an attractive and kind-sounding demeanour. The following comments were written by fans following the official release of the voice-actors, this was prior to the game's release (Bioware forum, 2011). One user, ReallyRue, wrote: 'Eve Myles voices Merrill? Oh, that's fantastic!' Another, AllThatJazz, who identified as Welsh, wrote positively of the casting (although had some disliking for a particular element of WE): 'Eve Myles is one of my favourite actresses at the moment. As a Welsh girl myself, I am delighted to see our (mostly) beautiful accent getting some love. Thankyou, Mr Gaider, and Bioware'. Others like ViSeiRa were fans of her previous work: 'I've been following Torchwood since season one, gotta say Eve Myles + Dragon Age is a dream come true'; whereas one member, Rinji the Bearded, gained knowledge of both the actress and the WE dialect through listening to Eve Myles: 'Okay, I just listened to Eve Myles... Wow. AWESOME casting. Her voice and accent are simply beautiful.'

\section{Pronunciation, lexis, and grammar}

For the most part, Merrill's speech is not exaggerated, there appear to be no usages of WE specific grammar or lexis, thereby confining her representation strictly to the domain of pronunciation. Regarding this pronunciation, Merill's phonology largely matches the casual speech of actress Eve Myles; she uses tapped /r/ in the medial position in 'Merill', pronounces 'you' with the Cymraeg diphthong/ru/, and 'you're' with two syllables: as /ju:wə/ with a lengthened back close vowel and 
medial /w/ approximant. However, there are some phonemes that are closer to RP than WE, especially in her pronunciation of 'so' and 'go' in which she users the RP diphthong / $/$ / rather than / $\mathbf{p}$ / and in 'here' in which she uses the RP diphthong/ı/ rather than the more common /j3:/. Myles's Merrill also uses a rise-fall intonation.

Although true that there is a degree of indexical stereotyping involved in the depiction of Merrill as a Welsh accented speaker (represented most strongly in the stereotype that Celtic peoples, and by extension their speakers, are connected to the magical world (i.e. elves) and subjugated), it would be detrimental to describe Bioware's motives as overly pejorative, especially as it makes a departure from Welsh stereotypes focused upon deriding humour, seen in earlier Shakespearean works or mid $-20^{\text {th }}$ century film.

\subsubsection{Star Wars: The Old Republic (2011), Bioware}

Star Wars: The Old Republic (SW:TOR) is a massive-multiplayer online roleplaying game (MMORPG) set in the science fiction series, Star Wars. The sci-fi series has a storied history of using accents as quick characterization tools. The film Star Wars: The Phantom Menace (1999) was criticized for its numerous accents, from Jar Jar Binks' pseudo-Jamaican accent (Kapell, 2006:168), to the Neimoidian alien-race's Asian English brogue (Williams, 1999). Voicing alien-races, robots, and more with different language varieties to index a sense of 'otherness' has a long history (Kilgore, 2003), Wolmark (1994) arguing that it can be 'appropriate' when employed to 'subvert' real-world subordinations (p.27), however can be a problem when used to reinforce stereotypical or discriminatory tropes, which is what Milojevic \& Inayatullah (2003:51) argue happened in The Phantom Menace, with nonstandard foreign accents accompanying characters' comical antics.

More relevant to this discussion however is the use of RP and other British Englishes to index a sense of 'evil' or 'British Imperialism' to the Star Wars franchise. Viaggiatore (2003) states that it is a linguistic trope Hollywood constructed to quickly characterize 'evilness' in shorter feature length films, formed from American history's viewpoint that the old British empire was historically antagonistic to American interests. One of the strongest examples of this is in the original Star Wars 
trilogy (1979-1985), that sees the antagonistic Galactic Empire's chief figures all speaking RP. This is best-evidenced in Peter Cushing's Grand-Moff Tarkin, meanwhile the heroes of the films speak American Englishes.

Other 'expanded' Star Wars media (television, videogames, literature) continues the 'othering' of varieties. This is often more complex than the films, such as using dialect for differentiating Galactic cultures. It is implied that 'English' (and its varieties) is just a placeholder language (foreign-accent correlator), as in this 'Galaxy far far away' the dominant language is 'Galactic-Basic Standard' (similar to MiddleEarth's Common Tongue in LOTR, chapter 8). Contributors to the Star Wars wikia ${ }^{36}$ (Star Wars wikia, n.d.) even believe they have identified several accents including native varieties like Scottish English, Jamaican English and New Zealand English, as well as foreign L2 varieties like French English, German English, and Russian English.

In $S W: T O R$ the player character is situated in a cold war between a democratic galactic republic associated with the light side of the Force (good/benevolence) and the tyrannical Imperial Sith empire, and chooses one of several classes in either of these allegiances. In turn, this sets the player on one of several storylines (mobygames, n.d.). What is interesting about SW:TOR (2011) is that it is not strictly a Lucasfilms production (producers of Star Wars films), instead the videogame was developed for the PC gaming system by BioWare, the same creators of Dragon Age II (2011). Like DAII, the game was both a roleplaying game, released in 2011, and, most surprisingly, also featured a WE-speaking character. Though only conjecture, it would seem somewhat more than coincidental that two games from the same studio, in the same year had included a Celtic British English variety in their Canadian videogame.

\footnotetext{
${ }^{36}$ As of May 2014, Wookiepedia: the Star Wars wikia is one of the largest, well-researched, well-referenced, community-driven encyclopedic communities on the internet with over 110,200 articles (http://starwars.wikia.com/wiki/Special:Statistics)
} 
The key WE accented character is a human - Captain Bryn, whose accent notably contains numerous attested phonological features of WE dialect. The question arises: in what vein has this character been formed? How does he compare to the previous Star Wars media sources: has the accent been chosen to ridicule and cast stereotype, or has the accent been chosen as a means to aurally distinguish alien races?

Captain Bryn is a brown-haired, freckled human who serves in the Sith Empire in the Imperial special forces on the Sith planet of Dromund Kaas and during the game is stationed inside Lord Grathan's estate, where he is tasked with retrieving secret plans for a weapon. He passes this mission onto the player character in the form of a quest, therefore he is a functional character. One of Bryn's main characteristics in the dialogue seems to be to drive a little humour. Bryn makes jokes directly, for example, in a speech where he lists off a series of serious technological items (such as robots and weapons) that Lord Grathan likes to acquire, he offhandedly lists: 'ergonomic chairs'. It could be argued that Bryn appears to offer a light-hearted divergence to an otherwise quite serious atmosphere of SW:TOR. Whether this character trait coincides in part due to his accent is debateable.

\section{Dialectal perceptions}

There is, however, a positive player reception of Bryn's character and voice. Taken from a sample of comments from a YouTube video (YouTube, 2012), users describe his portrayal as 'brilliant', that the 'ergonomic chairs [was] the best part [of the scene]', and that the presence of a Welsh imperial officer 'made [them] laugh when [they] first met him [and that] he's ace'. Two users directly referred to linguistic elements of Welsh culture, the first commenting that 'Captain Bryn is a fucking boyo', referencing a well-attested, albeit marginally linguistically stereotyped noun in WE, 'boyo' meaning Welsh boy. Another commented: 'I was in stitches when I came across this $>$. $<$ Cymru am byth!', Cymru am byth (lit. 'Wales forever') being a popular Welsh phrase used by Cymraeg speakers and non-Cymraeg speakers alike to affirm a sense of Welsh nationalism. A final comment writes: 'finally, a Welsh character in a video game!'. These last three comments in particular directly reference Welsh sense of identity, and appear to be accepting of Captain Bryn and his 
Welshisms as a positive depiction, rather than a negative, and that videogame characters with WE accents are few, if not perceived to be non-existent.

\section{Bryn's Pronunciation and grammar}

Regarding the Bryn's dialectal features, the dialogue largely uses WE phonology. His cadence is similar to the intonation found in many South WE dialects. Bryn's accent also uses a very slight tapped /r/, notably drops his initial glottal fricatives in 'how' (/av/), pronounces 'my' with a front close vowel /i:/ rather than RP /mai/, and pronounces 'news' with a final voiceless alveolar sibilant fricative. There are some rhotic features in the portrayal in words such as: 'empire' as /emparor/; and Bryn also pronounces 'here' as /hı/, with the RP diphthong, rather than the more common WE mid-close front vowel /3:/, as in /hj3:/. It is phonology such as this that could suggest that if the voice-actor is from South Wales they have been influenced by accents from neighbouring West Country English or RP. Alternatively, the voiceactor might be performing a contrived WE. Unfortunately, there is no record in the credits or cast of the voice-actor who portrays Bryn.

Bryn does use some grammatical features in the form of the discourse marker 'see', but otherwise there is nothing significant, and Bryn uses no WE lexis. That being said, Bryn's name is of some significance, as it is Welsh first-name, taken from Cymraeg for 'hill'. There is also the possibility too that the characterisation of 'Captain' Bryn may indeed be a reference to 'Captain' Fluellen of Henry V, though such a connection seems more coincidental than directly derivative. Either way, it is characterisation such as voicing a character with a Welsh accent and attaching a Welsh personal name to the character that suggests that it is highly likely that the captain was always intended to be 'Welsh' to some degree, rather than any other cultural/regional identity. This possibly could have been for delivering stereotypical humour or light heartedness, but it could equally have been a decision to cast various space-faring races and cultures with distinct accents.

It may also support Viaggiatore's comments that American audiences may not be able to distinguish too clearly between varieties of British Englishes, and in this case the creators have chosen a WE accent to fit the role of an accent closely related to 
RP. There is evidently some intertextuality regarding accent portrayal between this game and other Star Wars media tie-ins and the movies themselves. The presence of a Welsh accent in the game is intertextually aligning itself with what fans already know: that the Galaxy has many accents of Galactic Basic, all of which correlate with familiar real-world accents.

\subsubsection{Ni No Kuni: Wrath of the White Witch (2013), Level-5}

Very much like DAII, Ni No Kuni: Wrath of the White Witch (2013) is also a fantasy role-playing game. It was developed by Japanese videogame developers, Level-5, with animated consultation from award-winning Japanese animation studio, Studio Ghibli. It was released in Japanese territories in 2010 for the 3DS, and later for the PS3 in 2011. The English 'localisation' of the game was later released in American and European territories in 2013. In Ni No Kuni (which is Japanese means: Second Country) the player takes the role of a young boy called Oliver, who has journeyed to a fantasy world which lies parallel to ours, in an attempt to save his mother. The blurb advertises that the players will take part in 'exciting battles combining realtime and turn-based tactical elements', whilst they 'explore a breathtaking world filled with curious creatures and vibrant landscapes.'

The character in question is Drippy, a wise-cracking, Welsh-accented fairy from the 'Other World' (note the parallel with the Welsh 'Annwn', often referred to as Otherworld), who guides and accompanies Oliver throughout his long journey. Like Merrill, ludonarratively, Drippy is a cast character, acting as a companion, to the player. What is most interesting about the characterisation of Drippy is that the characterisation could be viewed as combining the two stereotypes of the Welsh accented stock character - the fantastical and the comic. It should be noted that there is no impetus for Drippy to be voiced with a WE variety: although the game begins in our world (an anonymous mid-western American town to be exact) Drippy is from the magical world Oliver travels to, and therefore has had no contact with WEspeaking peoples. This then raises questions, as it did with Merrill's casting, as to why the developers characterised Drippy with this specific accent?

Studio Ghibli and Wales 
A trend inherent in Japanese comics and animation is the heavy borrowing of Western artistic themes (MacWilliams, 2008:6;11). The game's establishing locale, the Westernised 'Motorville', is indicative of this (Yamanaka, 2008:250). Indeed, Studio Ghibli's co-founder animator-director Hayao Miyazaki has, throughout his career, preferred settings that lacked Japanese national identification by using these Western artistic tropes and settings, one reoccurring theme is Wales. For one of Miyazaki's first films, Laputa: Castle in the Sky (1986), the director's locationscouting took him to Wales during the 1984 mining strike (McCarthy, 2002:94). In a 1999 interview, Miyazaki stated: 'I really admired the way the miners' unions fought to the very end for their jobs and communities, and I wanted to reflect the strength of those communities in my film' (p.94). Much of the Welsh mining aesthetic, from the clothes to the village architecture that the protagonist hails from, made it into the film; and McCarthy argues that 'the Welsh dimension is one of the film's strongest influences' (McCarthy, 2002:95).

Miyazaki's affection for Wales and Celtic culture grew; his studio's next Welshinspired motion-picture was an adaptation of Diana Wynne Jones' Howl's Moving Castle (2004), a novel with many inherent Welsh themes. Once again Miyazaki went location-scouting in Wales, as Jones had used the central Welsh moorlands as inspiration for the book. The studio also visited Cardiff, though in the end Miyazaki chose Alsatian towns for the urban inspiration (Cavallaro, 2006:167). Unlike the novel, that features a chapter where Howl the Wizard travels home to Wales from a Fantasy world he resides in and linguistically shifts to using WE (analysed in 7.5.2.), the final film omits the scene, thereby leaving few explicit Welsh elements but Howl's true-name reveal: Howell Pendragon. Though both Welsh-influenced films had opportunities to utilise WE, neither Ghibli film did, however, nine years later, their involvement with videogame developers Level-5 introduced Ghibli's first Welsh linguistic element.

\section{Creating Drippy, the 'Welsh' fairy}

When Ghibli became involved in Level-5's game, they expected conceptual and animation work to take three months; however the desire to produce a 'theatre-level of quality' for the game's animation dominated their plans (Gifford, 2009). Animation director Yoshiyuki Momose stated that it was the first time their studio 
had been 'deeply involved' in a videogame. Akihiro Hino, Level-5's supervisor of the project, elaborated: "with regards to all aspects of shaping the personality of this work, [Studio Ghibli] helped us think through the development of Ni No Kuni. In addition to that, [...] Momose, who was primarily working on the animation, was involved in very detailed aspects of the staging' (Bandai Namco Games Europe, 2012a). Hino has also stated that, although the original plans were generated by Level-5, 'after the partnership was confirmed we requested that they review the setting, the characters and art design. Studio Ghibli recreated it all in their taste' (Edge Magazine, 2012).

Ghibli used their trademark Westernised elements in the game's animation, but also employed their long-term composer, Joe Hisaishi for the soundtrack. Hisaishi's remarks about the music's atmosphere are of interest, for they reflect Ghibli's known 'Celtic' influences: 'The music [...] was meant to have a certain elegance, based on the traditional folk music of Ireland amongst others. Something nostalgic, but still connected to the future' (Bandai Namco Games Europe, 2012b). However, there is some uncertainty regarding Miyazaki's involvement with the game, Hino explicitly noted in an interview that the work was not the product of just Miyazaki, but the whole animation company (Nutt, 2009), and it is unclear whether the Japanese Cymricphile had involvement in the decision to create the game's fairies with a Welsh dimension, although a Celtic presence is certainly felt throughout.

Drippy's accent has received much coverage. For the initial Japanese language release, Hino explains that Drippy has a 'heavy Osaka accent, but in the international [English] version it's Welsh', and that Level-5/Studio Ghibli had a 'localisation director who [was] very particular with all the minor details' (Edge Magazine, 2012). How 'minor' a detail it was to voice Drippy with a Welsh accent is debatable. Edge Magazine note that: 'in Japan, the Osaka accent has the same, often comedic, yokel connotations as a southern American drawl', and that they were unsure how Welsh players would react to this, thereby suggesting WE was chosen as a 'foreign accent correspondent' - to index similar linguistic/character stereotypes as Osaka Japanese: that both speech communities are perceived as 'comic'. 
In an interview with Steffan Rhodri, the voice of Drippy, Smith (2013: para 1) comments that it is not very often that one would 'hear a distinctive Welsh timbre emanating from a character within a game' asking Rhodri whether he could expand upon his involvement with the game. Like Eve Myles in DAII, Rhodri knew little about videogames, and admitted there was uncertainty about why he was cast, but prepared by watching the Japanese-voiced character's speech mannerisms before creating his WE analogue. In the interview, Rhodri metalinguistically assesses that he believes '[the] Welsh accent often works for comedy. Either the accent itself, or maybe the people, are naturally funny' (Smith, 2013: para 5). Essentially Rhodri is internalising the well-known character stereotype associated with his own speech community: that his speech and others who speak like himself, are inherently amusing.

Regarding his representation of Drippy, Rhodri's portrayal was close to the WE speech of his youth, stating:

Drippy was very close to my real accent, maybe more like my accent when I was a child. It was useful for [voicing] the character to remember myself as a child and several people I knew growing up. I think, in general, the Welsh people from my home town are enthusiastic and straight talking like Drippy! (Smith, 2013: para 5)

However, it is not just WE phonology that Drippy uses, there are also lexical and grammatical components. This is likely accredited to an anonymous screenwriter from north Wales, giving an additional level of screenwritten authenticity than other videogame texts might see (Smith, 2013). Despite the close proximity to WE, Drippy's dialect is representative of the fairy dialect of the 'Other World', despite, as will be evidenced below, the many common (arguably enregistered) linguistic forms (especially lexis) likely being linked in gamers' language perceptions to the realworld dialect.

\section{Pronunciation}

Drippy's accent uses the rise-fall intonation characteristic of WE, but there are also a number of phonemes that this 'fairy accent' uses that are common to WE. It should be noted that Ni No Kuni uses subtitles for when characters are audibly talking, and for when text from the characters is displayed without any audio (similar to a novel's 
dialogue). They are provided at the bottom of the screen. The speech of Drippy both in-audio and non-audio is rendered in a manner that attempts a phonetic respelling of WE; and is similar to the rendering of dialogue that occurs in Welsh writing in English literature (chapter 7). It should also be noted that Oliver's General American accent is rendered in-game with the standard written English, therefore it seems likely that Drippy's non-standard orthography is deliberately designed to first, convey an overall difference in his speech, and second, to distinguish his nonstandard voice from Oliver's. It is an attempt to create a distinct 'otherness' surrounding his character. Also worth noting is that there are other characters who speak with more standardised English accents - one of which is a character who speaks with RP.

In the game's subtitles, 'your' is rendered as <youer>, and 'poor' is rendered as <pooer>. This is an orthographic attempt at rendering the standard /o:/ or /\%ə/ as WE /owa/ and is one of the most common orthographic representations of Drippy/Rhodri's accent within the subtitles of the game. The vocative 'mun' is rendered as 'mun' in -game and voiced $/ \mathrm{m} \Lambda \mathrm{n} /$. 'Here' is orthographically rendered as 'y'ere' and rather than RP /hı/ is accurately pronounced /hj3/. These are all forms that are attested in the $S A W D$. 'Myself' is rendered as 'meself', although phonologically pronounced /məself/ with a central vowel, rather than /mi:self/ with a front close vowel, thus, this is closer to the natural speech of many regional and standard forms, therefore this example leans more towards the script-writing conveying a type of literary eye-dialect. There are other features which are not orthographically distinguished in the game. For example, tapping of $/ \mathbf{r} /$ is common in occasional initial and medial positions. Another is the pronunciation of 'you' with the common Cymraeg-loaned diphthong /ru/ and in the phrase 'in you', there is example of yod-dropping: /Inru/.

\section{Grammar}

There are several grammatical usages that derive from WE. Two very common usages in Drippy's speech, and both attested in the $S A W D$, are: focus fronting, for example: 'take you far, it will' and 'Clean forgot, I did' (which has qualities of habitual 'do' as well), and 'demonstrative there's + adj.' syntax, for example: 'there's nice'. Discourse markers are also a feature of Drippy's speech. Both 'like' (e.g. 'Give you something to work towards, like') and 'see' are used (e.g. 'see, it's 
like this, see'), as are confirmatory interrogative tags (a.k.a. invariant non-concord tags) like 'en't it' and 'is it' (e.g. 'curse lifted, is it?'). Drippy uses the clipped adverbial suffix in 'you look proper sharp', used as early as 1930s in both filmic and literary WE dialects.

Drippy also uses less common, yet attested, grammatical features of WE, of which there are few examples in WE literary dialect. First, he uses the adverbial phrase 'by here' in place of adverb 'here' several times; this is attested in $T T$, although was recorded previously in Lewis Jones's 1937 novel Cwmardy (see Chapter 7) and the film On the Black Hill (1987). Second, Drippy uses present participle $<\mathrm{a}$ '[verb/prep./adv. $>$ in phrases such as 'a'shunting'. The SAWD attributes this feature largely to the Welsh borders; in literary dialect it appears in Goodwin's representation of the borders, but also Dillwyn's representation of west WE, and Jack Jones's representation of southern WE. Finally, infixing of lexis for emphatic purposes is used, for example: 'any-old-where' for 'anywhere', and 'a-whole-nother world' for 'another world'. This is not specifically an attested feature of WE, and may be idiolectal of Rhodri.

\section{Lexis}

Many of the lexical forms that Drippy uses have a basis in WE and as a result its literary and filmic dialects, their inclusion by the writers and voice-actor Rhodri likely intertextually reference such material. These include: the affirmative interjection 'righto' (used in both The Proud Valley, 1940, and Only Two Can Play, 1962); 'butty' for 'friend' (used first in novels such as Cwmardy (1937) and So Long Hector Bebb, 1970); 'tidy' for 'decent' (numerous novels and films starting with Caradoc Evans' My People, 1915 and as recent as Twin Town, 1997); and 'fair do's' for ‘fair enough' (used in Island of Apples, 1965).

Whether there is any doubt that Drippy is supposed to be using WE is cleared up in the several Cymraeg loanwords that the character uses. Not only does he use terms that may be better known amongst players such as 'mam' (several English English dialects use this too), but also terms that may appear more 'opaque' for players such as the vocative usage of 'boy bach' [lit. small boy] (used as early as the novel $M y$ People (1915) and film A Run for your Money (1949)), the exclamative 'duw' 
meaning 'god!' (common to WE literary dialect as early as 1906 with novel Queen of the Rushes).

There are several unattested forms not recorded in WE databases, though frequent colloquialisms. For example, the verbal 'brick it' for 'scared' (OED: derived from 'to shit a brick'), as well as the U.S. English derived 'kicking about in there' (OED: US colloq. for 'unwanted'), and 'spoiling for a fight' (OED: 'eager'). Regarding Drippy's phrases, some of these have grounds in WE trends, others are more general to British Englishes overall, and some are likely to be idiolectal to his character or Rhodri's own speech.

\section{A continuing character stereotype?}

There is still a semblance of the previous character stereotype that Welsh speakers are comical, though it has to some extent been subverted from being a passive comical role, to an active comical role by that of the Comedian.

It would be easy for critics to counter the argument that Drippy's WE is directly connected with cultural stereotypes of the Comic or the Fantastic by perhaps arguing that much of Drippy's linguistic characterisation is simply coincidence. For example, one may argue that it is coincidental that Drippy ended up with a WE accent; Drippy could have ended up with any regional accent, especially as regional British accents, as well as others in Anglo-centric cultures, receive a degree of comic stigmatisation. Second, perhaps the association of a fairy trope with a WE speaker is a one-off coincidence.

This argument would hold more merit if Drippy was the only character voiced with a WE accent in the game. However, Drippy is not the only fairy in-game with a WE accent, nor is he the only fairy-comedian. In fact, all the fairies that the player encounters in the game harbour WE voices, and all have an over-exaggerative comical air about them to varying degrees, from Drippy's stand-up comedy neighbours, to his humourous 'mam'. The trend seems apparent, especially considering such effort was put into the scripting of the dialogue, that Drippy and company were always going to be Welsh-accented in the international version; that the Japanese studio wanted an English nonstandard that could be indexically comical 
- WE long being associated with humour, from Shakespeare's Fluellen up until Giles \& Powesland's early perceptual dialectology surveys. The only element that is disputable is the connection between the Welsh and the game's fairies. Whether Studio Ghibli and Level-5 wanted an English accent associated with fairy/elven cultural connections is uncertain, although with Studio Ghibli's proven connections with Welsh historic-fantasy settings, and with Miyazaki having knowledge of Celtic mythology, we cannot disregard that this was a factor when the world they travel to is the 'Other world' (like the Welsh mythic Annwn).

Ultimately, Drippy, as represented in Ni No Kuni, is a stereotype of WE speakers. His characterisation posits that WE speakers are associated with the Fantastic, and that they are comical characters; indeed, the stereotype is acknowledged and internalised by Drippy's voice-actor. What should not be dismissed, however, is that unlike earlier representations of Comic Welshmen, Drippy and his accent feature in more active comic roles that drive comedy as Comedians rather than the passive Clowns of the Elizabethan Stage Welshmen (Chapter 6).

\subsubsection{Summary}

In summary, WE has been used multiple times in Fantasy videogames. In Fable III, Kingsley chose a WE variety for his depiction of an exiled fantasy king, and in later texts, WE has explicitly been chosen to index Fantasy/elven otherness in both Dragon Age II and Ni No Kuni, both of which starred established Welsh actors Myles and Rhodri. In $S W$ : TOR, an 'Imperial' character had a WE accent, tying WE into the larger scope of othered British Englishes often reserved for RP speakers.

\subsection{Welsh English in real-world videogames}

There has been a significant utilisation of the WE dialect within fantasy videogames in recent years. However, it would be incorrect to suggest that the use of the WE dialect as a characterisation tool was limited to this genre of videogame narrative. Although there are fewer cases than the former fantasy focus, developers making historical fiction videogames set in the real-world have also incorporated a WE dialect into their videogames. With real-world narratives, this eradicates stereotypical tropes that WE users are connected to Fantastic fairy/elf, however, as we shall see, a 
core stereotypical connotation of the WE speaker is still used: that WE speakers act the Comic.

\subsubsection{Timesplitters: Future Perfect (2005), Free-Radical-Design}

It is not only the Fantastical genre that makes use of the WE dialect to create stereotypical characters; it is also a trend that appears in technological fantasy: that of science fiction set in the real-world. Timesplitters: Future Perfect is, chronologically, the first videogame text that utilised a WE dialect in this analysis (possibly the very first videogame overall): five years before both fantasy game Fable III (above), and historical western Red Red Dead Redemption (below).

Timesplitters is a First-Person Shooter series developed by Free Radical Design, a videogame developer from Nottingham, U.K. Unlike many first-person shooters, both the visual look and the narrative tone of Timesplitters games are stylised in a zany, and outwardly silly manner, with character models and locations having a cartoon or comic-book aesthetic. The series incorporates many western pop-cultural references into its games often by means of parody humour; in many ways, $T S$ serves metareferentially as a comedy game, much of its content being flippant or facetious. Timesplitters: Future Perfect was the final instalment in the franchise and was released on PS2, Xbox and Gamecube in 2005.

A product of this comedy is provided by a large selection of eccentric, clichéd characters to play the game with, many of these characters come equipped with stereotypical accents to match their blatantly stereotyped personalities. For example, the character Harry Tipper is a stereotype of 1970s cold-war secret agents, and is voiced with a West Coast American English, and spouting phrases such as 'far out!'. Another character, Captain Ash is a stereotype of a British gentlemanly explorer, and speaks in RP with phrases such as: 'I say, what are you doing out here, old chap?'.

A WE dialect is also used by a mad scientist character Dr. Harvey, a.k.a. Lenny Oldburn. The accent, much like Sabine's in Fable III is a contrived one, though inkeeping with most of the TS games, is intentionally a parody. Lenny Oldburn appears in one level: What Lies Below, which is set in a laboratory beneath an abandoned 
Connecticut mansion in 1994. He acts ludonarratively as a stage character - he is seen feeding human limbs to his monstrous creation, but cannot be interacted with. Rather, the player is invited to listen to his rambling dialogue, although this can be skipped. Oldburn uses some features attested in WE such as tapped /r/, but also some more exaggerated ones, for example he elongates many of his vowels to extreme lengths, applying rise-fall intonation as he does so. This can be orthographically represented briefly with duplicated letters, for example, 'Princ-eeess, I caught some more fo-oo-od', 'ba-aa-ad zombie', and 'baa-ayby'. Numerous phonemes equate to WE, for example use of a back open vowel /p:/ rather than RP diphthong /əo/, however, Oldburn's pronunciation of 'beautiful' (/bju:tifol/) uses an initial palatal approximant $/ \mathrm{j} /$, a feature more likely dropped from WE varieties. Grammatically, the one attested WE feature that Oldburn uses is the discourse marker 'see': 'She hurt her eye, but I'm making it better, see.' The character does not use any WE lexis.

What is strange about Oldburn's use of WE is that in a game that parodies so many character archetypes and stereotypes, it seems out of place that a Welsh accented character like Oldburn bears no resemblance to any cultural Welsh element. Welsh people are not known to have association with mad scientist stereotypes. Of course, Oldburn is a comical character through his zany nature as a mad scientist; yet it is uncertain whether the creators were using the Welsh accent as a stereotype for humour or not; in a game where the majority of characters have deliberately stereotyped and contrived accents, it seems less likely that they chose WE for any comical purpose per se, though we should not dismiss it.

An answer to why WE is used may present itself in the recognition that Lenny Oldburn is in fact a parody of a pop-cultural icon rather than a type of people, such as the aforementioned '70s spies or upperclass English explorers. First and foremost, aesthetically, Lenny is unquestionably a parody of Heavy metal icon Ozzy Osbourne. The character's name also bears resemblence with the real-world counterpart: Ozzy and Lenny, and Oldburn and Osbourne, and both also have an affiliation with Rock music (Lenny Oldburn's catchphrase on the 'Timesplitters gallery' is "Rock ' $\mathrm{n}$ Roll"). It seems quite likely that rather than coincidence, there is a homage present 
here. But then why does Lenny Oldburn have a WE accent rather than Ozzy's native West Midlands English?

In popular culture, Ozzy Osbourne's incomprehensibility is, for viewers, often the source of humour and confusion and a unique marker of his idiolectal speech. Goldberg writes: '[Osbourne] can barely speak. [...] Indeed, he's so unintelligible that various reviews of [TV show The Osbournes] quote the same lines of Osbourne's dialogue differently; not even journalists with a videotape can quite make out what the hell he's saying' (Goldberg, 2002:31). Although Osbourne has suffered years of drug and alcohol abuse, for non-native speakers of his west midlands dialect, his regional accent may also be part of this incomprehension. The connection could be that the writers of Timesplitters wanted an accent for Lenny which appeared similar (perhaps in incomprehension), but not too similar to warrant investigation by Osbourne's copyright and legal estate. WE is, geographically, and to some extent linguistically, quite close to the English midlands English, indeed several authors (Ellis, 1882 \& Coupland \& Thomas, 1990), have noted that WE shares some similarities with West Midlands English, as one would expect to find where two geographic varieties' have close proximity to one another. A similar, regional nonstandard accent, incomprehensible to some, may have been the developers' reason. A second explanation could be that they wanted an accent which stereotypically appeared "bonkers" (a term used by an in-game character to describe Lenny) to a more general audience. If this was the case, which may be so considering Lenny's exaggerated version of WE, casting Lenny with a nonstandard variety may have been a result of stereotypical linguistic prejudice.

\subsubsection{Red Dead Redemption (2010), Rockstar Games}

Red Dead Redemption (2010) is an action-adventure game centred around the Old American West during its final years. Developed by Rockstar San Diego, it tells the story of John Marston, an ex-outlaw who's now a family-man being blackmailed by the federal agents to hunt down his old gang.

There is only one scene in which a Welshman, Alwyn 'Welsh' Lloyd, appears, which is during the beginning of the quest: 'A Frenchman, a Welshman, and an Irishman'. 
What is interesting about $R D R$ is that there is direct metalinguistic commentary upon how WE is perceived to non-native speakers of the variety, such as speakers of American Englishes.

\section{Creating “Welsh", the Welsh cowboy}

Rockstar San Diego's developmental aim was to construct a game with historical accuracy, we have to then ask: to what degree is there authenticity in the inclusion of a Welshman in their frontier videogame? Although a popular image of America to non-Americans may be the 'Wild West', this image often leaves out any mention of Welsh influence in its history. In fact, Carradice (2010) estimates that 250,000 Welsh people emigrated to USA in the $19^{\text {th }}$ century, and although many settled in Pennyslvania, others ventured west, joining wagon trains searching for new territory to farm. In fact, several Welsh people made it into the annals of history, such as: John Rees of Merthyr Tydfil who fought in the war against Mexico in the 1830s; and John T Morris, who became sheriff of Collins Country, Texas in 1870 (Carradice, 2010).

However, for every tale of a Welsh law-abider there was one of the Welsh not following the laws of the land in the Old West. There were numerous reports of Welsh people defying the law, especially in regards to alcohol usage (Meirion, 2007:9). In a Welsh-American newspaper from 1870, Y Drych, a description of the Welsh who settled in Scranton, Pennsylvania indicated that many Welsh people had opened 'grogshops, whisky holes, gin mills, rum cellars', and that it was common to see whole families of Welsh immigrants being 'half-drunk all the time, playing silly games, hanging about and singing in Welsh' (p.10). It concludes with: 'if you want lack of respect on the Sabbath, if you want to hear the language of hell ... from Welsh mouths, go for half an hour along the streets and into the Welsh saloons in Hyde Park' (p.10). Meirion (2007) comments that the characters and the stereotypes of the 'Wild West' we find in books, comics, films and television programmes give 'the impression [...] that all these characters were English' but that in reality 'many Welsh men and women [were] amongst them' (p.10). 
In the game, Alwyn Lloyd appears during a cutscene, acting simply as a stage character within a dialogue. The protagonist character John Marston is verbally abused by Alwyn Lloyd (known as "Welsh" in the script and later revealed as Alwyn Lloyd in the game's newspaper). His next turn in the conversation is retaliation in the form of an attack on the Lloyd's accent, particularly his intonation (i.e. 'Sing-song voice'), before then sarcastically imitating WE vocabulary that Lloyd uses, notably 'boyo'.

Lloyd: $\quad$ Fuck off, boyo. This don't concerns you.

Marston: When a man with a sing-song voice tells me to fuck off, it always concerns me, BOYO

We can gather from this that the character - an American living in the western frontiers perceives the WE accent to be unpleasant. And, possibly by extension, so do the writers, developers or producers of the video-game. Although it is only the protagonist who actively engages in linguistic prejudice, the supporting character in the scene, "Irish" (who later accompanies the player on the mission's journey), utilizes national stereotyping when referring to his once-companion, Welsh. When questioned by John Marston about potentially stealing weaponry, Irish comments that: 'I never stole nothing, sir. Never did nothing all me life. That French cunt is playing with the Welshman's tiny and ineffective mind!'. Marston then proceeds to shoot both French and Welsh down in self-defence, after both characters draw their weapons on him. Irish then comments over Welsh's corpse: 'Don't worry yourself, hell's better than Wales.'

It is also significant that the character "Welsh" is referred to, possibly by way of nickname, by his nationality - a similar method was used in the previous Tudor English portrayals of WE accented stock characters. For all intents and purposes, $R D R$ 's Alwyn "Welsh" Lloyd serves no other purpose than to be that of comical stock, although arguably Rockstar San Diego provide the same comical characterisation treatment for Irish's character throughout the duration of the mission, portraying him as energetic and comical. The intention to portray these British/Celtic accented characters with a comical air potentially derives from the title of the game mission, which takes the syntactic form common in racial or ethnic jokes: ie. 'A [stereotyped ethnicity \#1], a [stereotyped ethnicity \#2], and a [stereotyped ethnicity 
\#3] [walk into a bar]...', in this case the stereotypes are French, Welsh and Irish. It should be noted that the character French, who also is shot in self-defence, is not a Frenchman in anything but ancestry, unlike Welsh and Irish.

\section{Grammar, lexis, and pronunciation}

Regarding "Welsh"'s dialect, there are some grammatical qualities found in WE, such as the nonstandard inflected forms of the first-person present tense indicative in: 'this don't (doesn't) concerns you'. Lexically, he uses 'boyo', though this would likely be an anachronism, the term beginning to appear in literary/filmic WE dialect from the early 1960s (e.g. Only Two Can Play).

"Welsh"'s speech matches attested phonological forms, e.g. / $/ \mathbf{i n}$ place of RP/ov/ in 'boyo', /Iu/ in place of /u:/ in 'you', /owə/ in place of /s:/ or /\%ə/ in 'you're', and h-drops in 'who', as well as the rise-fall intonation of WE.

It appears that Red Dead Redemption is possibly one of the few depictions of a Welshman on the frontier in popular media, and for this alone, this is a positive inclusion, as it does reflect authentic historic events. The depiction of the drunken, Welshman Alwyn Lloyd may not be what Meirion (2007) envisions as the best representation of a Welshman in the West, bearing in mind the clippings from the $19^{\text {th }}$ century, it would be hard to argue that characters such as Alwyn "Welsh" Lloyd were absent from the frontier life. Ultimately, Rockstar evidently did their research on the immigrant groups who left their native countries for the American West, casting Irish and Welsh accents to represent these communities.

\subsubsection{Assassin's Creed IV: Black Flag (2013), Ubisoft-Montreal}

One of the most recent representations of a Welsh accented English speaker in a videogame comes from Assassin's Creed IV: Black Flag (2013). The Assassin's Creed series has sold over 55 million copies prior to the fourth main instalment and has been hailed as a technological triumph of its videogaming genre (Williams, 2013). Black Flag is a third-person action adventure that takes place in the Caribbean during 1715; the game was developed by French-Canadian studio Ubisoft Montreal. The story centres around the rule of 'legendary' pirates, who plundered fortunes and brought 'empires to their knees' during the $18^{\text {th }}$ century. 
Much like Rockstar San Diego's RDR, Ubisoft's Black Flag's developers aimed for historical accuracy in their representation of the pirates of the Caribbean. Therefore, a contingency of pirates in the game were voiced with WE accents, on the account that many pirates and buccaneers in the $18^{\text {th }}$ century were of Welsh origin, for example: Henry Morgan from Llanrhymney, Black Bart (John Roberts) from Pembrokeshire and Hywel Davies from Fishguard (Williams, 2013).

The protagonist of the game, Edward Kenway, is a 'fearless young captain who earns the respect of the pirates'. There are several speakers of WE in the videogame, but the most notorious is the protagonist. This effectively makes Edward Kenway the first protagonist - and therefore the first player character - in videogaming to not only be of Welsh descent, but also the first to use a Welsh variety of English. How the WE variety came to be used in the game is of great interest to this discussion. In an interview, Darby McDevitt (scriptwriter), stated that the original casting was for a pirate character from an English port town, such as Bristol, Portsmouth or Manchester. It was only when Matt Ryan (a WE speaker) auditioned that the producers changed their mind. Ryan initially chose to portray Edward Kenway with a Bristolian English accent when in the casting call, however, when the developers heard Ryan's natural South Welsh accent they asked him to voice Kenway instead with a South-Welsh English accent. McDevitt said: 'we asked him to speak in his own accent - and we loved it and we loved his personality. Then we went back and wrote Edward Kenway's biography' (Williams, 2013: para 10). Remarkably, the story was altered so that Kenway's backstory fit Ryan's WE accent; much like his voice actor, the character's biography states he comes from Swansea, but moved to Bristol when he was in his youth. Kenway's backstory became more influenced by Wales than originally intended, with Ryan and McDevitt writing in several Cymraeg phrases into the narrative as well, which were provided by Matt Ryan's own Cymraeg-speaking father (Williams, 2013).

The authenticity of the language in Black Flag was very important to the developers. McDevitt explains that he was 'excited working on [the] game, coming to the U.K. and getting actors with the proper accents to play the parts' (Williams, 2013: para 18). Regarding the impact that the WE dialect has had on players of the game, 
McDevitt adds: 'We've had kids in the U.S. asking what is, or where is Wales, and then we've got the Welsh gamers excited that the hero is Welsh. Nobody was expecting him to be from Wales. And there's a history lesson in there too' (Williams, 2013: para 24)

Edward's accent is WE, although there isn't anything to suggest that he uses lexical items of Cymraeg origin, nor morpho-syntax. Edward is from Swansea, born to a Welsh mother and English father, however spent his teenage years living in Bristol, England. At the start of the story it is clear that Kenway considers himself to be a Welshman. To help players who may not be familiar with Welsh accented English situate the protagonist, the developers use flashbacks to present Kenway's backstory and earlier life in Wales. Early in the game, Kenway alludes to his Welsh background several times.

A subtle conversation about sociolinguistic identity occurs near the beginning of the game. Before a brawl in a tavern, Kenway has a brief spoken exchange with another Welsh-accented sailor who comments about Kenway's 'Welshness'; the sailor himself clearly identifies with being English rather than Welsh.

Sailor: Fancy meeting a Welshman deep in Dago Country. I'm English meself, Biding my time "til the next War calls me to Service.

Kenway: Lucky King George having a Piss-pot like you flying his Flag.

Sailor: Oy! Skulk! I seen your Face before. You's Mates with them Pirates down in Nassau.

Kenway: Shut your fucking Gob or I fill it with Shot. You hear me?

Sailor: Edward, is it?

The sailor is marked as having a Welsh accent predominately through the length of several of his vowels, such as the vowel in 'time' being /tæ̈Im/ rather than /taIm/, and pronounces 'myself' with a front close vowel /i:/ rather than RP diphthong /mai/. He also has nonstandard grammatical forms such as, 'you's' and 'them pirates' instead of 'those pirates', and uses the confirmatory interrogative tag, 'is it'. Interestingly, these are features that are not found in Kenway's speech, and yet it is Kenway who associates with being Welsh rather than English. Both interlocutors do use colloquial 
speech in this interaction with words such as 'Piss-pot', 'skulk', 'gob', and 'shot' all identifying the speakers as being from non-standard speaking regions of the British Isles.

McDevitt's statement that 'Nobody was expecting [Kenway] to be from Wales' and that 'there's a history lesson in [the casting of Kenway] too', suggests there's a larger historicity concerning Wales' depiction in the game. In a time when Wales and Welsh culture had been consumed by English interests following complete annexation in 1536 (see Acts of Union), the casting of a Welsh-accented character stating he's English parallels with Kenway's Welsh-accented identity of being Welsh. What is perhaps implied by the developers is that speaking with a Welsh 'accent' does not factor in to any concept of Welshness to pirates in the West Indies, despite Kenway asserting continually that he is Welsh because he speaks with a Welsh accent. This is exemplified well following a successful plunder during a conversation with his firstmate Adéwalé, a former Black slave:

Kenway: What will you do with your share of the gold we take from Governor Torres? Return to Africa? A Prince among Men?

Adéwalé: [Laughs] I cannot return to a place I've never been! I was born in Trinidad - a slave from my first breath.

Kenway: Oh. Wouldn't you feel, I dunno, more welcome there?

Adéwalé: [Mockingly] You might feel more welcome in Paris?

Kenway: Fair point...

Adéwalé: With this skin and this voice, where can I go in the world and feel at ease?

Kenway believes that one's accent and one's skin colour should ideally align with a fixed placed in time: specifically, the region from which their ancestors hail. Adéwalé jokingly diffuses this sense of identity by illustrating that a characteristic as widespread as skin colour is not the best indicator of a person's home country, and therefore then suggests that Kenway with his Welsh accent (Adéwalé knows nothing of Wales) and white skin may well have been from France for all he knew, simply based on the assumption that white men come from Europe. Following this conversation with Adéwale, Kenway's discussion of his accent, his ancestral homeland, and his national identity is reduced in the remainder of the narrative. 
Several other characters that Kenway meets in the Caribbean use WE. One foe, Vargas, that Kenway interrogates in Grand Cayman notably speaks with a Welsh accent (as do several NPCs within the town). Vargas' pronunciation of 'lesson' in his line: "her army will teach you a lesson"” is marked with additional stress on the second syllable beginning with /s/, to mimic the rise-fall intonation of WE. When Kenway later befriends the infamous real-life Welsh pirate Bartholomew Roberts, there is no discussion of Kenway's Welshness, via their shared accent or national identity. Roberts is interesting in his own right, being voiced by Englishman Oliver Milburn. Lexically he uses 'aye', and Milburn's pronunciation conforms well with several markers of Valleys Welsh accent, such as the tapping of $/ \mathbf{r} /$ and pronouncing 'here' as /j3:/, dropping initial glottal fricatives, despite some overcompensation of the rise-fall intonation and the fact Bartholomew Roberts was from Pembrokeshire.

There are other subtle discussions about Kenway's Welsh accent throughout game. It should be noted that Kenway is not technically the chief 'protagonist' of Black Flag. The premise of the game is that the protagonist character is in fact a contemporary man/woman who is experiencing the historical, virtual memory of Edward Kenway which has been genetically obtained from one of Kenway's modern-day descendants. The majority of Kenway's story is viewed in a high-tech futuristic apparatus called the Animus, where the viewer/user can control the historical image they are presented with (much like a historical simulator). In the story, the protagonist has been asked to cull interesting genetic memories that best suit their corporation's ideals of providing immersive VR entertainment products. At one point, the Animus user is called to the CEO's office to discuss some of Kenway's memories with the interests of marketing the 'Pirating Experience' for consumers. During the discussion, the CEO suggests to the protagonist that Kenway's voice is not really 'marketable', and that it would be in the company's best interests if the genetic memory's accent was 'altered' to something more pleasing such as a 'James Bond' styled voice.

In one very limited discussion, the $A C$ writers have metalinguistically touched upon the several perceptions that we have seen discussed about the WE accent: that it is not marketable, is relatively unknown around the globe, and that even today 
undergoes discriminatory remarks. In the case of Black Flag, the desired variety is 'James Bond speech', which of course equates to RP; a variety that has historically been the preference for decades already. All of this is executed well by the writers and mirrors their own marketing decisions during the production of the game in an ironic way, for they went to great efforts to make sure that Kenway did not sound familiar, in the pursuit of showcasing English varieties pirates would have genuinely been using, and by doing so doing away with the 'Arr-me-hearty' stock variety that has plagued Golden Age pirate representations for most of film history.

\subsubsection{Summary}

Alongside fantasy depictions, we have seen that WE has also been used in real-world contexts. Although the early text Timesplitters FP used a Welsh accented scientist for a mocking comedic effect, later texts like $R D R$ and Black Flag chose WE to better construct the sense of varied speech communities in historical narratives such as the American frontier and Golden Age of Piracy.

\subsection{Conclusion}

This chapter has investigated WE in videoludic dialects, analysing seven texts from 2005 until 2013. Several linguistic features were shared between texts, much like chapter 7 and chapter 8, suggesting a degree of enregisterment. Like filmic dialect, tapped/trilled /r/ was the commonest phonological feature ( $6 / 7$ texts), followed by glottal fricative omission (3/7), diphthong /əo/ pronounced /p:/ (3/7), RP diphthong/ठə/ (or /o:/) as /u:wə/ (3/7), and closed back vowel/u:/ as diphthong/ru/ (3/7). Grammatically, discourse marker 'see' was common (3/7), and confirmatory interrogative tag 'is it/en't it' (2/7). Bear in mind, however, that only Ni No Kuni and Assassins Creed are reminiscent of earlier literary/filmic dialect samples in that they both contain multiple characters using WE (many of these texts included one character using WE briefly). Ni No Kuni's Drippy used many enregistered lexical, grammatical and phonological WE forms from other fictive dialects, e.g. vocative 'mun', 'mam', 'bach', 'duw' and grammatically both focus fronting and demonstrative there. Regarding a sense of 'linguistic evidence', there is little of note from videoludic dialect. 
A more principal question for this chapter has been why WE has been cast in videogame texts? In many ways, there is an intention to cast a WE accent to connote underlying character stereotypes about Welsh people, chiefly that WE users are inherently connected to a sense of Celtic fantasy, and that, speaking a nonstandard variety, they are inherently 'comic'. Both Merill and Drippy are elven/fairy characters whose accents were used to index fantasy, tropes also present in late $20^{\text {th }}$ century novels (chapter 7) and recent Hobbit films (chapter 8). Drippy's accent was also chosen to represent 'the comic'. Other WE characters like Bryn, Sabine, Oldburn and Alwyn Lloyd, whether intentional or not, are also portrayed as comical, reinforcing prior character stereotypes, beginning with Welsh characters of Elizabethan theatre (like Fluellen), that WE speakers are inherently comical (chapter 6). One trend is clear: when videogame characters are simply stage or functional characters there is less room for dialectal representation: lexical and grammatical domains are subordinate to a phonology/accent that can quickly index character stereotypes; then, when characters are cast or player characters, the range of dialectal representation expands, though this does not necessitate reduction of character stereotypes.

We must bear in mind that at this early stage in videogame history, there are no Welsh-made videogames: games featuring Welsh characters are made by non-Welsh companies. That said, in recent years developers have actively sought 'authenticity' by involving actors in the creative process of creating videoludic dialects. As seen in sections 9.2.3. and 9.2.5 and 9.3.3, WE-speaking actors have become, in a way, 'dialect ambassadors'. Eve Myles, Steffan Rhodri, and Matt Ryan, all WE users, were involved in the creation and promotion of their games' fantasy and real-world characters. Compare this to earlier games like Timesplitters and Fable III and recent films in Chapter 8, that either a) use the Welsh accent for a quick characterization and to index comedy or b) cast 'well-known' non-users to approximate a Welsh accent (often due to production restraints), and what emerges in the videoludic dialect scene is a profound 'awareness' and desire by both companies and actors for the creation of accurate dialect representation. Furthermore, developers are also presenting some metalinguistic observations of dialect perception in their games. $R D R$ shows the protagonist shows linguistic prejudice against a 'sing-song' accent, 
whilst Black Flag elegantly touches upon the fact Kenway's nonstandard WE accent may not 'marketable' in the same way as RP.

Overall, this chapter has provided insights into the way WE has been used in fantasy and real-world videogames, especially the utilization of character stereotypes to index both Fantastical and Comic tropes. 


\section{Chapter 10 Conclusion}

The central question of this thesis has been: how has the Welsh English (WE) dialect been represented in fiction? And, to what extent could a history of WE be constructed through analysing theatrical, literary, filmic, and videoludic dialects? Several questions followed from this. What linguistic features of WE have authors chosen as markers of dialect, and what features are most common (i.e. enregistered) throughout fictive WE? What can fictive WE offer dialectologists and sociolinguists in terms of 'linguistic evidence'? How might representation differ between WE written by, or acted by, native users and non-native users of WE? And, what linguistic or character stereotypes are attached to WE representation?

Prior to this study, only some late medieval and Elizabethan fictive WE had been addressed (German, 2009), therefore, there was ample scope to construct a large historical database of fictive WE. Unlike other literary linguistic studies of the $20^{\text {th }}$ century, this project has also analysed WE in the emerging field of filmic dialect study, and is the first project to address a literary dialect's use in videogame narratives.

\subsection{Key findings}

Phonology was the one of the earliest linguistic domains writers used to convey WE dialect. Phonetic respelling conventions used in late medieval dialect literature poetry became linguistic stereotypes in Elizabethan theatre, like the devoicing of bilabial, alveolar, and velar plosives, alveolar fricatives and labiodental fricatives; as well as the depalatisation of palato-alveolar fricatives to alveolar fricatives. Some of these features were still in use in novels from the 1930s, though this medium introduced new conventions, many used in film and videogames, like RP diphthong/ov/ as monophthongal /p:/ (6 texts), glottal fricative /h/ omissions (14), and the Cymraegloaned diphthong /ru/ (14). Filmic dialect was also able to convey the tapped /r/ (16 texts), and omission of medial palatal approximant (yod-drops) (7). Like other literary dialects some authors used eye-dialectal and allegro-clippings to index a sense of WE 'dialectness', and two authors used hyphenation to index the 'singsong'-ness of WE intonation. 
Use of lexis to mark WE dialect existed in some early late medieval texts, however, it did not become a component of WE fictive dialect until the advent of the novel in the $19^{\text {th }}$ century. Cymraeg loans are found across literary, filmic, and videoludic dialects, the most common being the endearment term 'bach/fach' (18 texts), the expression of disgust 'achyfi' (6), noun 'mam' [mother] (14), and exclamative 'duw' (8). Common forms derived from English language tradition include vocative 'man/mun' (18 texts), affirmative 'aye' (16), and vocative and noun 'butt(y)' [friend] (7). Theatrical and early literary texts also created linguistic stereotypes that were used to index Welshness like 'look you' ( 8 texts) and 'indeed to goodness' (7 texts).

Although six early texts used 'her' as a subject pronoun, markers of WE grammatical representation increased in popularity with the $19^{\text {th }}$ century novel. Here several common forms began appearing across literature, film, and videogames. Most common was Focus Fronting (e.g. 'joking, you are') (20 texts), followed by Demonstrative There (e.g. 'there's [that's] early') (17), then two discourse markers 'see' (13) and 'like' (8); whilst confirmatory interrogatives (e.g. 'is it?/ isn't it?) found increased usage in later audio-visual media (13).

By analysing fictive WE, not only do we now have assessments of linguistic features creators were known to use, but a number of other 'linguistic evidences'. We now know that there was some slight WE depiction prior to ap Hywel Swrdwal's poetry in texts from the 'Katherine Group', and that phonetic respellings of early texts align with what we know of the variety today. We have found that some novelists, like Glyn Jones, were prolific surveyors of the variety, Jones himself utilising thirteen unrecorded words. Also, in reviewing filmic dialect over the course of 76 years, we have found that the vowel in vocative 'mun' has taken a position that is more forward and open (e.g. $/ \mathrm{m} \wedge \mathrm{n} /, / \mathrm{mæn} /$ ).

In some narrative forms there is a difference between WE depiction by known users and non-users of the variety. Early on, Elizabethan playwrights were some of the sole producers of written WE dialect, and the linguistic stereotypes borne of this era formed long-lasting character stereotypes. By the time of Anglo-Welsh novels, authors from non-Welsh backgrounds like M. Evans and L. Roberts were in fact keen inquirers into the language variety, and, although at the end of the $20^{\text {th }}$ century 
several English fantasy authors used literary WE, their representations were similar to native writers. With audio-visual representation, however, How Green Was My Valley was a good example of how poorly dialect could be represented on-screen when a director is unfamiliar with the target variety in question. Indeed, several films and videogames have demonstrated that non-native users had, even with honest intentions, varying degrees of aptitude for acquiring WE phonemes and intonation. More recently, however, in the interests of 'authenticity', videogame developers have liaised with WE-using actors to create videogaming experiences that incorporated videoludic dialect that resembles its real-world equivalent, demonstrating a significant change in attitudes to casting nonstandard-speaking actors. Here 'authenticity' of dialect in games is being discursively constructed between developers and users of the dialect.

Metalinguistic observations about WE were common, especially after the inception of Welsh writing in English. J. Jones commented upon Cymraeg-English language shift, M. Evans wrote about language loyalties on the border, G. Jones observed childhood sociolects of WE whilst Berry attempted to depict idiolects of Valleys WE, and Dunthorne discussed WE language attitudes and discrimination. This thesis has also unearthed attitudinal stereotypes associated with the WE variety, and how they are used in fiction. First, the Elizabethan theatre's linguistic stereotypes were entwined with the character stereotype of using a stage Welshman to fulfil the role of the theatrical Comic. The Comic stereotype would resurface particularly in filmic dialect, such as A Run for Your Money, Only Two Can Play, and Twin Town, and would be present in numerous contemporary videogame texts. The other patent character/linguistic stereotype is one that sees language users from Wales being inherently connected with Fantastic/Mythic. The thesis has discovered that the trope has ancient origins, but began to be used in association with the Welsh variety of English in three late $20^{\text {th }}$ century novels, then two videogame narratives, and one contemporary film, several of which used WE to index the connotations of 'Fantasticism'.

We now have a resource of WE representation in early theatre, the heyday of Welsh written English novels, Welsh film, and the beginnings of videogame narratives. How the WE dialect is continually received throughout visual media such as 
videogames will be of continued interest. The aim for 'authenticity' has underscored many representations of WE, many playwrights, poets, novelists and screenwriters have expressed interest in dialectal representation and achieving accurate examples in their fictive dialect. Some creators, playwrights like Shakespeare, filmmakers like John Ford, and novelists like Caradoc Evans have intentionally subverted this notion to render deliberately inaccurate texts whether for the purpose of stereotyping, noninterest in linguistic accuracy, or satire, respectively. Even with broadening acceptance of regional and nonstandard varieties, the established character stereotype of the Welsh (and WE user) being inherently Comical or Fantastical (whether indexed positively or negatively) will likely continue. Videogames like Dragon Age II, Ni No Kuni, and Assassins Creed: Black Flag suggest that 'inauthentic' WE speech representations could be reduced in lieu of more authentic renditions, as we have seen unprecedented cooperation between WE-using actors and the gamedevelopers, however, the recent treatment of WE in period drama film (PRIDE, Hunky Dory) also suggests there is still the production restraint issue that audiences want to see familiar actors (i.e. non-users using contrived accents) in films.

\subsection{Limitations of the study}

Regarding both the chronology and genres analysed, this study's scope was vast, focusing on four key narrative genres (early texts \& early theatre, novels, films, and videogames) across almost 900 years. Yet, with more time and resources, it would have been advantageous to assess associative genres like film's companion medium, television, or the novel's derivative medium, comic-books. Furthermore, before this study chose to focus exclusively on fictive writing, a small pilot study was constructed to assess whether historical non-fictional material like newspapers, biographic writing, and personal letters would also fit the thesis' scope. Although these media likely provide their own 'linguistic evidences' about WE, this thesis' focus on the abundance of fictive narrative text types was a large enough object of study in its own right.

A noteworthy caveat was that there was no unequivocal method of assessing whether WE literary dialect featured in a text, nor were there definitive lists of texts that might contain WE. Some correspondence helped narrow some results, however, in 
the main most texts had to be independently located, before being accessed multiple times either by reading, viewing, or playing the text in question, so that they could be analysed.

\subsection{Future research}

Prior to this thesis, WE in fiction had received little treatment compared to American English varieties, other British varieties, or Irish varieties. There was no assessment of linguistic forms, discussion on writers' methods, or evaluation of the character stereotypes that are attached to the variety. We now have a strong foundation from which further research can be conducted.

Because of this severe prior lack of study and analysis regarding fictiolinguistic WE, this thesis' method has been rooted in a qualitative historical discussion in order to open the potential for future work to be undertaken. One immediate follow-up project to this one could take a lexicographic approach - a dictionary and grammar of fictive WE, constructed from this thesis' material, similar to publications constructed from surveys like the $S E D$ and $S A W D$. Also, now that texts have been identified, future research would do well to apply quantitative methods to the texts unearthed. For example, a corpus of fictive WE could be constructed by using the written material texts like playscripts and novels that have been sampled here.

The thesis has also assessed the feasibility of constructing a diachronic literarylinguistic view of a fictiolinguistic variety, and similar work for other varieties could follow this framework. Finally, this thesis was the first to assess the use of a literary dialect in videogame texts; as videogames are a new narrative medium, this is not surprising, yet, future fictiolinguistic research must take into consideration not only filmic dialect, but also audiovisual texts like videogames. 


\section{Bibliography}

\section{List of works analysed}

\section{$\underline{1 .}$ Late medieval texts \& Elizabethan plays}

Anonymous (1596). A hundred merry tales. In W.C. Hazlitt (Ed.,1887), A hundred merry tales: the earliest English jest-book (pp.42-98). London, England: J.W. Jarvis \& Son. Retrieved from https://archive.org/details/hundredmerrytale00hazl

Anonymous (1599). Sir John Oldcastle. Retrieved from https://archive.org/details/sirjohnoldcastle01788gut

ap Hywel Swrdwal, I. (1480). Hymn to the virgin. In R. Garlick \& Roland Mathias (Eds. 1984), Anglo-Welsh poetry: 1480-1980 (pp. 45-48). Bridgend, Wales: Poetry Wales Press.

Armin, R. (1609). The history of the two maids of more-clacke. London, England: N.O. for Thomas Archer. Retrieved from http://gateway.proquest.com/openurl?ctx_ver=Z39.882003\&xri:pqil:res_ver $=0.2 \&$ res_id=xri:lion\&rft_id=xri:lion:ft:dr:Z00005129 4:\&rft.accountid=14680

Borde, A. (1547). Fyrst boke of the introduction of knowledge. In M. Barnes \& F. Furnivall (Eds. 1880), The fyrst boke of the introduction of knowledge made by Andrew Borde, of physycke doctor. A compendyous regyment; or, A dyetary of helth made in Mountpyllier. London, England: The Early English Text Society. Retrieved from https://archive.org/details/fyrstbokeintrod01boorgoog

Dekker, T. (1597). The Welsh Embassador. In F. Bowers (Ed. 1961), The dramatic works of Thomas Dekker, Vol. 4. (pp. 301-404). Cambridge, England: Cambridge University Press.

Dekker, T. (1600). The patient Grissill. In F. Bowers (Ed. 1953), The dramatic works of Thomas Dekker Vol. 1. (pp. 207-298). Cambridge, England: Cambridge University Press.

Jonson, B. (1618). For the honor of Wales. London, England: Printed by Richard Bishop, and sold by Andrew Crooke. Retrieved from http://gateway.proquest.com/openurl?ctx_ver=Z39.88- 
2003\&xri:pqil:res_ver=0.2\&res_id=xri:lion\&rft_id=xri:lion:ft:dr:Z00009277

4:\&rft.accountid $=14680$

Middleton, T. (1613). A chaste maid in Cheapside. Retrieved from http://www.tech.org/ cleary/chast.html

Shakespeare, W. (1597). The merry wives of Windsor. Retrieved from http://www.gutenberg.org/cache/epub/1116/pg1116.txt

Shakespeare, W. (1599). Henry $V$. Retrieved from http://www.gutenberg.org/cache/epub/1784/pg1784.txt

$\underline{\text { 2. Novels \& poetry collections. }}$

Berry, R. (2006). So Long Hector Bebb. Cardigan, Wales: Parthian. (Original work published in 1970).

Dillywn, A. (2008). The Rebecca Rioter. South Glamorgan, Wales: Honno Classics. (Original work published 1880)

Ddu, I. (1867). Cambria Upon Two Sticks. Pontypridd, Wales: David J. Hopkin

Dunthorne, J. (2008). Submarine. London: Penguin.

Evans, C. (1987). My People. Bridgend, Wales: Seren. (Original work published 1915).

Evans, M. (2006). Country Dance. Cardigan, Wales: Parthian. (Original work published 1932).

Garner, A. (2007). The Owl Service. London: Harper Collins. (Original work published 1967)

Hall, R. (1850). A Tale of the Past and other poems. Llandovery, Wales: William Rees.

Hughes, T. (1865). Poems by Hughes: [unknown place \& publisher]

Jones, D.W.(1986). Howl's Moving Castle. London, England: Harper Collins (original work published 1986)

Jones, G. (1998). The Island of Apples. Cardiff: University of Wales Press. (Original work published 1965).

Jones, J. (2009). Black Parade. Cardigan, Wales: Parthian. (Original work published 1935). 
Jones, L. (2010). Cwmardy \& We Live. Cardigan, Wales: Parthian. (Original work published $1937 \& 1939)$.

Goodwin, G. (2008). The Heyday in the Blood. Cardigan, Wales: Parthian. (Original work published 1936).

Parry, O. "Ceredig", (1870). Among the mountains, or Life in Wales. Ebbw Vale, Wales: J. Davies \& J. Clarke

Pratchett, T. (1994). Soul Music. London: Corgi Books.

Prichard, T.J.L. (1828). The Adventures and Vagaries of Twm Shon Catti, descriptive of Life in Wales: Enterspersed with Poems. Aberystwyth, Wales: Printed for the author by John Cox. Retrieved from Llyfrau.org (http://bit.ly/1nho5Rn)

Raine, A. (1998). Queen of the rushes: A tale of Welsh revival. South Glamorgan, Wales: Honno Classics. (Original work published 1906).

Roberts, L. (1944). An Introduction to Village Dialect with Seven Stories. London: The Druid Press.

Thomas, D. (1977). Under Milk Wood: A Play For Voices. London: J.M. Dent \& Sons Ltd. (Original work published 1954).

\section{$\underline{\text { 3. Films }}$}

Allen, K. (Director) \& McAleese, P. (Producer) (1997). Twin town. United Kingdom: Agenda, Aimimage Productions, \& Figment Films.

Allen, P.H. (Director) \& Muller-Rommel, V. (Producer) (2009). Big font. Large spacing. United Kingdom: 33Story Productions.

Dearden, B. (Director) \& Balcon, M. (Producer) (1944). The halfway house. United Kingdom: Ealing studios.

Evans, M. (Director), Crown, S. \& de Weers, H. (Producers) (1997). House of America. United Kingdom: Egmond Film \& Television

Evans, M. (Director), Finn, J. \& Lupovitz, D. (Producer) (2011). Hunky dory. United Kingdom: Mulligan and Nesbitt Productions.

Ford, J. (Director) \& Zanuck, D. F. (Producer) (1941). How green was my valley. United States: $20^{\text {th }}$ Century Fox

Frend, C. (Director) \& Balcon, M. \& Norman, L. (Producers) (1949). A Run for your money. United Kingdom: Ealing studios. 
Grieve, A. (Director) \& Howarth, J. (Producer) (1987). On the black hill. United Kingdom: British Film Institute.

Jackson, P. (Director, producer), Cunningham, C., Walshe, F., \& Weiner, Z. (Producers) (2013). The Hobbit: The Desolation of Smaug. New Zealand \& United States: Newline Cinema.

Kerrigan, J. (Director) \& McCourt, E. (Producer) (1999). Human traffic. United Kingdom: Irish screen \& Fruit Salad Films.

Monger, C. (Director) \& Curtis, S. (Producer) (1995). The Englishman that went up a hill and came down a mountain. United Kingdom: Miramax Films.

Sidney, G. (Director) \& Gilliat, L. (Producer) (1962). Only two can play. United Kingdom: British Lion Films.

Tennyson, P. (Director) \& Balcon, M. (Producer) (1940). Proud valley. United Kingdom: Ealing Studios.

Thompson, J. L. (Director) \& Hawkesworth, J. (Producer) (1959). Tiger Bay. United Kingdom: Rank Organisation.

Vidor, K. (Director) \& Saville, V. (Producer) (1938). The Citadel. United Kingdom: Metro-Goldwyn-Mayer.

Warchus, M. (Director) \& Livingstone, D. (Producer) (2014). Pride. United Kingdom: Pathé.

\section{$\underline{\text { 4. Videogames }}$}

Darrah, M. (Director) \& Gaider, D. (Writer) (2011). Dragon Age II. Canada: BioWare.

Doak, D. \& Ellis, S. (Directors) (2005). Timesplitters: Future Perfect. United Kingdom: Free Radical Design.

Ismail, A. \& Guesdon, J. (Directors), Trottier, S. (Producer), \& McDevitt, D. and May, C. (Writers). (2013). Assassin's Creed IV: Black Flag. Canada: Ubisoft Montreal.

Martin, S. \& Kunkler, D. (Producers), \& Houser, D., Unsworth, M. \& Cantamessa, C. (Writers) (2010). Red Dead Redemption. United States: Rockstar San Diego.

Molyneux, P. \& Backer, G.(Producers), Hill, M. \& Bryant, R. (Writers). (2010). Fable III. United Kingdom: Lionhead Studios. 
Motomura, K. (Director), Suzuki, T. (Producer), \& Hino, A. (Writer). (2013). Ni No Kuni: Wrath of the White Witch. Japan: Level-5 \& Studio Ghibli.

Ohlen, J. (Director), Gutheie, B. \& Keating, S. (Producers), \& Erickson, D. (Writer). (2011). Star Wars: The Old Republic. Canada: BioWare. 


\section{Bibliography of works cited}

Adams, S. (1975). Writers of Wales: Geraint Goodwin. Cardiff, Wales: University of Wales Press.

Adams, T. (2008, Feb 17). 'If you snog like a dentist, you're clearly a loser'. Retrieved from https://www.theguardian.com/books/2008/feb/17/fiction.reviews1

Agha, A. (2007). Language and social relations. New York: Cambridge University Press.

Allen, P.H. (2011). Special features: 'Making Of'. In Big Font. Large Spacing. [DVD]. Cardiff, Wales: 33Story Productions.

AllenRaine.com (2015, March 5). Who was Allen Raine? Retrieved from http://allenraine.com/whowas.html

Arashiro, M. (2014). A descriptive study of intonation in Welsh English: preliminary investigation of statements and yes/no questions. Tokyo University of Foreign Studies Journal, 172-192. Retrieved from http://repository.tufs.ac.jp/bitstream/10108/81176/1/lacs020011.pdf

Azevedo, M.M. (2002). Considerations of Literary Dialect in Spanish and Portuguese. Hispania, 85, 505-514

Bae, S. H. (2014). Complexity of language ideologies in transnational movement: Korean jogi yuhak families' ambivalent attitudes towards local varieties of English in Singapore. International Journal of Bilingual Education and Bilingualism, 18, 643-659.

Bartley, J.O. (1954). Teague, Shenkin, and Sawney. Cork, Ireland: Cork University Press.

Basini, M. (2009). Foreword. In J. Jones, Black Parade (pp.ix-xiv). Cardigan, Wales: Parthian.

Bates, B. (2001). Story: Writing skills for game developers. Proceedings from Game Developers Conference San Jose 2001. Retrieved from http://www.gamasutra.com/gdarchive/2001/bates.doc

BBC (2012, November 29). Darklands: Horror film's US release after 10 year fight. Retrieved from http://www.bbc.co.uk/news/uk-wales-20542316

Beal, J.C. (2009). 'Enregisterment, Commodification and historical context: 'Geordie' versus 'Sheffieldish', American Speech, 84 (2), pp.138-156. 
Bergman, J. (2011). The significant other: A literary history of elves (doctoral dissertation). Retrieved from ProQuest (U516593). Cardiff University, Cardiff.

Berry, D. (1994). Wales \& Cinema: The First Hundred Years. Cardiff, Wales: University of Wales Press.

Berry, D. (2000). Unearthing the Present: television drama in Wales. In S. Blandford (Ed.) Wales on Screen (pp. 128-151). Bridgend, Wales: Seren.

Bolinger, D.L (1946). Visual Morphemes. Linguistic Society of America. 22, 333340. Retrieved from http://www.jstor.org/stable/409923 .

Bordwell, D. \& Thompson, K. (2001). Film art: An introduction $\left(6^{\text {th }}\right.$ ed.) New York: McGraw-Hill.

Blake, N.F. (1981). Non-standard language in English literature. London: A. Deutsch.

Blandford, S. (2000a). Introduction. In S. Blandford Wales on Screen (pp. 11-37). Bridgend, Wales: Seren

Blandford, S. (2000b). Making House of America: An interview with Marc Evans and Ed Thomas. In S. Blandford, Wales on Screen (pp. 66-89). Bridgend, Wales Seren.

Blank, P. (1996). Broken English. London, England: Routledge.

Burns, M. (2005). Perilous Realms: Celtic and Norse in Tolkien's Middle-earth. Toronto: University of Toronto Press.

Burton, J. (1992). Don (Juanito) duck and the imperial-patriarchal unconscious: Disney studios, the good neighbor policy, and the packaging of Latin America. In A. Parker, M. Russo, D. Sommer, et al. (eds.), Nationalisms and sexualities (pp.21-41). New York, NY: Routledge.

Butler, S. (1997). Corpus of English in southeast Asia: implications for a regional dictionary. In M.L.S. Bautista (ed.), English is an Asian Language: the Phillippine Context. Manila, Philippines: Macquarie.

Canon, E.B. (2009). 'Language ideology in the United States: Migration, Local Identity, and Discrimination'. Interdisciplinary, 1-9.

Carkeet, D. (1979). The dialects in Huckleberry Finn. American Literature, 51, 315332.

Carradice, P. (2010). Welsh cowboys. Retrieved from http://www.bbc.co.uk/blogs/wales/posts/welsh_cowboys 
Carradice, P. (2014, Mar 26). How Green Was My Valley takes the Oscar. Retrieved from http://www.bbc.co.uk/blogs/wales/entries/758bf13c-3ca5-3ecd-8773$\underline{3 \mathrm{e} 83381169 \mathrm{e} 4}$

Cavallaro, D. (2006). The Anime art of Hayao Miyazaki. Jefferson, NC: McFarland \& Company Inc.

Collier, C. (2006). Foreword. In M. Evans, Country Dance (pp. ix-xiii). Cardigan, Wales: Parthian.

Cook, V. (2016). Eye Dialect in English literature. Retrieved from http://www.viviancook.uk/SpellingNovel/EyeDialect.htm

Cooper, P. (2015). 'Enregisterment' in historical contexts: nineteenth century Yorkshire dialect'. Dialectologia, 14, 1-16.

Cooper, P. (2017). 'Deregisterment' and 'fossil forms': the cases of gan and mun in 'Yorkshire' dialect. English Today, 33 (1), 43-52.

Collins, J. (1849). 'A list of words from the Gower dialect of Glamorganshire'. Philological society proceedings, 4 (87), 222-223.

Collins, B. \& Mees, I.M. (1990). The phonetics of Cardiff English. In N. Coupland (ed.) English in Wales (pp.87-103). Clevedon: Multilingual Matters.

Coupland, N. (ed., A.R. Thomas) (1990). English in Wales: diversity, conflict, and change. Clevedon, England: Multilingual Matters

Coupland, N. \& Thomas, A.R. (1990). Introduction: Social and linguistic perspectives on English in Wales. In N. Coupland (ed. A.R. Thomas) English in Wales (pp. 1-18). Clevedon: Multilingual matters.

Coupland, N. (2007). Style: Language variation and identity. Cambridge, England: Cambridge University Press.

Dahlgreen, W., (2014). "'Brummie" is the least attractive accent'. Retrieved from https://yougov.co.uk/news/2014/12/09/accent-map2/ [accessed 25 January 2015]

Dale-Jones, D. (1979). Emlyn Williams: Writers of Wales. Cardiff, Wales: University of Wales Press.

Davenport, T. (2010). Wales and Welshness in Middle-English romances. In R. Kennedy \& S. Meecham-Jones (Eds.), Authority and subjugation in writing of Medieval Wales (pp.137-158). Basingstoke, England: Palgrave Macmillan.

Davies, J. (2007). A History of Wales (2nd ed.). London, England: Penguin. 
Davies, J.A. (2003). Dylan Thomas and his Welsh contemporaries. In M.W. Thomas (Ed.) (pp.120-164), Welsh Writing in English. Cardiff, Wales: University of Wales Press.

Davies, J.D. (1877-94). A history of west Gower, Glamorganshire Parts I-IV. Swansea: The Cambrian.

Davies, J.H. (1902). Yny lhyvyr hwn a Ban o gyfreith Howel. Bangor, Wales: Jarvis and Foster.

Davies, R.R. (2000). The first English empire: Power and identities in the British Isles 1093-1343. Oxford, England: Oxford University Press.

Davies, T.W. (1920). 'Gowerland: Its People, Speech and Some of its Ways'. Archaeologia Cambrensis, 10, 179-188.

Davies, W. (1972). Writers of Wales: Dylan Thomas. Cardiff, Wales: University of Wales Press

Dearnley, M. (1982). Writers of Wales: Margiad Evans. Cardiff, Wales: University of Wales Press

Devlin, Z. (2017). Information on cleavers. Retrieved from http://www.wildflowersofireland.net/plant_detail.php?id_flower=64

Dobson, E.J. (1976). The origins of Ancrene Wisse. Oxford, England: Clarendon Press.

Dobson, E.J. (1953). Hymn to the Virgin. London, England: Honourable Society of the Commorodorion .

Durham, M. (2014). \#Love or \#Hate the Welsh accent?. Retrieved from http://www.cardiff.ac.uk/news/view/69153-love-or-hate-the-welsh-accent

Eckert, P. (2003). 'Sociolinguistics and authenticity: an elephant in the room', Journal of Sociolinguistics, 7.3, 392-397.

Edwards, J. (1985). Talk Tidy. Cowbridge, Wales: D Brown and Sons.

Edwards, J. (1986). More Talk Tidy. Cowbridge, Wales: D Brown and Sons.

Edwards, K. (1974). Jack Jones: Writers of Wales. Cardiff, Wales: University of Wales Press

Egenfeldt-Nielsen, S., Smith, J.H., \& Tosca, S.P. (2013) Understanding videogames: the essential introduction. Oxon, England: Routledge.

Ellis, A.J. (1882). On the delimitation of the English and Welsh languages. $Y$ Cymmrodor, 4, 173-208. 
Ellis, A.J. (1889). On Early English Pronunciation, With especial reference to Shakespeare and Chaucer. London, England: Trübner and Co.

Ellis, M. (1994). Literary dialect as linguistic evidence: subject-verb concord in nineteenth-century Southern literature. American speech, 69, 128-144.

Ensslin, A. (2012). The Language of Gaming. Basingstoke, England: Palgrave Macmillan

Evans, G. (2008). Wales and the Welsh language in Andrew Borde's fyrst boke of the introduction of knowledge. Studia Celtica, 42, 87-104.

Evans, G. (2010). William Salesbury and Welsh printing in London before 1557. In

R. Kennedy \& S. Meecham-Jones (Eds.), Authority and subjugation in writing of Medieval Wales (pp.251-266). Basingstoke, England: Palgrave Macmillan.

Evans, J. \& Knight, S. (2011). In A.L.Becker \& K. Noone (eds.) Welsh Mythology and folklore in popular culture. Jefferson, N.C.: McFarland \& Company

Evans, M. (2011). Special features: 'Interview with Marc Evans'. In Hunky Dory [DVD]. London, England: Entertainment One.

Farringdon, M.G. (1982). A concordance and word-lists to Dylan Thomas's Under Milk Wood. Swansea, Wales: Ariel House Publications.

Fenno, C.R. (1983). Nineteenth-century Illinois dialect: Robert Casey. American Speech, 50, 244-254.

Ferguson, S. L. (1998). Drawing fictional lines: Dialect and narrative the Victorian novel. Style, 32(1), 1-17. Retrieved from https://search.proquest.com/docview/231161915? accountid=14680

Fine, E. (1983). In defense of literary dialect: a response to Dennis R. Preston. American Folklore society, 96 (381), 323-330

Francis, H. (2010). Foreword. In L. Jones, Cwmardy \& We Live (pp. ix -xiv). Cardigan, Wales: Parthian.

Gaider, D. (2011a, Jan 10). Merill: She's a Keeper. [Page 4]. Message posted to http://forum.bioware.com/topic/161075-merrill-shes-a-keeper/page-4

Gaider, D. (2011b, Feb 22). Voice actors (speculation and discussion). [Page 8]. Message posted to http://forum.bioware.com/topic/168250-voice-actorsspeculation-and-discussion-voice-cast-revealed/page- 8

Gaider, D., (2011c: Feb 9). Voice actors (speculation and discussion: voice cast revealed). [Page 1] http://forum.bioware.com/topic/168250-voice-actors- 
speculation-and-discussion-voice-cast-revealed/\#5977855 [accessed 2016, April 6]

Garlick, R. \& Mathias, R. (1982). Anglo-Welsh poetry: 1480-1990. Bridgend, Wales: Seren.

Garth, J. (22, May, 2013). The Storyteller, Oxford Today. Retrieved from: http://www.oxfordtoday.ox.ac.uk/features/storyteller\#

Garrett, P., Coupland, N., \& Williams, A. (1999). Evaluating dialect in discourse: teachers' and teenagers' responses to young English speakers in Wales. Language in Society, 28, 321-354.

German, G. (2009). Two early examples of Welsh English as a marker of national identity: Ieuan ap Hywel Swrdwal's Hymn to the Virgin and Shakespeare's Fluellen. Pays de Galles: quelle (s) images?= What visibility for Wales?, 2338.

Gifford, K. (2009, May 20). Studio Ghibli discusses NinoKuni project. Retrieved from http://www.1up.com/news/studio-ghibli-discusses-ninokuni-project

Gramich, K. (1998). Introduction. In A. Raine, Queen of the rushes: A tale of Welsh revival (pp. 1-23). South Glamorgan, Wales: Honno Classics.

Gramich, K. (2008a). Introduction. In A. Dillwyn, The Rebecca Rioter (pp. v-xxi). South Glamorgan, Wales: Honno Classics.

Gramich, K. (2008b). Introduction. In G. Goodwin, The Heyday in the Blood (pp. Ix - xv). Cardigan, Wales: Parthian.

Greenlaw, E. (1918). Spenser's Fairy Mythology. Studies in philology, 15 (2), $105-$ 122. Retrieved from http://www.jstor.org/stable/4171728

Griffiths, D. (1969). Talk of My Town. Buckley, Wales: Buckley Young People's Cultural Association.

Griffiths, H. (2010). “O, I am ignorance itself in this!”: Listening to Welsh in Shakespeare and Armin. In W. Maley \& P. Schwyzer (Eds.), Shakespeare and Wales: From the Marches to the Assembly (pp.111-126). Basingstoke, England: Palgrave Macmillan.

Griffiths, N. (2006). Foreword. In R. Berry, So Long Hector Bebb (pp.ix-xiii). Cardigan, Wales: Parthian.

Griffiths, N. (2010). Book of a Lifetime, So Long, Hector Bebb, By Ron Berry. Retrieved from http://www.independent.co.uk/artsentertainment/books/reviews/book-of-a-lifetime-so-long-hector-bebb-by-ronberry-2162262.html 
Giles, H. \& Powesland, P.F. (1975). Speech Style \& Social Evaluation. London: Academic Press Inc. Ltd

Goldberg, J. (2002, Jun 17,). Ozzy without Harriet, National Review, 54, 30-32. Retrieved from https://search-proquest-com.openathensproxy.swan.ac.uk/docview/229713421? accountid=14680

Hadikin, G. (2014). A, an, and the environments in spoken Korean English. Corpora, 9, 1-28.

Hakala, T. (2010). Working dialect: Nonstandard voices in Victorian Literature (unpublished PhD thesis). University of Michigan: Ann Arbor, Michigan.

Hamon, I. (1697). The Old English of West Gower, which is now out of use.MS Carte 108 (Collections for Wales) at the Bodleian Library, Oxford, folios 2130. Reproduced in F.V. Emery (1965), 91-108.

Harris, J. (1987). Introduction. In C. Evans (Ed.), My People (pp. 7-47). Bridgend, Wales: Seren.

Hart, E. (2010, September 7). Q\&A With Fable Producer Louise Murray. Retrieved from http://www.kotaku.com.au/2010/09/qa-with-fable-producer-louisemurray/

Henry, E.S. (2010). Interpretations of 'Chinglish': Native speakers, language learners and the enregisterment of stigmatized code. Language in Society, 39, 669688 .

Herman, L.H., \& Herman, M.S. (1943) Foreign dialects: a manual for actors, directors, and writers. New York, NY: Theatre Arts Books

Hickey, R. (2010a). Varieties of English in writing: the written word as linguistic evidence. Amsterdam: John Benjamins Publishing.

Hickey, R. (2010b). Irish English in early modern drama: The birth of a linguistic stereotype. In R. Hickey (Ed.), Varieties of English in writing: the written word as linguistic evidence (pp. 121-138). Amsterdam: John Benjamins Publishing.

Higgin, T. (2009). Blackless fantasy: The disappearance of race in massively multiplayer online role-playing games. Games and Culture, 4, 3-26.

Hodson, J. (2014). Dialect in film and literature. Gordonsville: Palgrave MacMillan

Hodson, J. \& Broadhand, A. (2013). Developments in literary dialect representation in British fiction 1800-1836, Language and literature, 22, 315-333.

Hooker, J. (2001). Imagining Wales: A View of Modern Welsh Writing in English. Cardiff, Wales: University of Wales Press. 
Hopkins, C. (1996). Translating Caradoc Evans's Welsh English. Style, 30, pp. 433445.

Howell, D.W. \& Baber, C. (1990). Wales. In F. M. L. Thompson The Cambridge Social History of Britain, 1750-1950, Volume 1: Regions (p.281-354). Cambridge: Cambridge University Press.

Hoyt, E.P. (1967). Paul Robeson, the American Othello. Cleveland, OH: World Publishing Company

Humfrey, B. (1992). Introduction. In G. Jones (Ed.) The Island of Apples (pp.viixxxi). Cardiff: University of Wales Press.

Humfrey, B. (2003). Prelude to the twentieth century. In M.W. Thomas, Welsh writing in English (ed.) (pp.7-46). Cardiff, Wales: University of Wales Press

Ives, S. (1950). A theory of literary dialect. Tulane Studies in English, 2, 137-182.

Jenkins, H. (2005). Games: The new lively art. In J.Raessens \& J. Goldstein (eds.), Handbook of computer game studies (pp. 175-192). Cambridge, MA: MIT Press.

John, P. (2000). The Story of a Welsh Screenplay. In S. Blandford (Ed.), Wales on Screen (pp. 50-65). Bridgend, Wales: Seren.

Johnstone, B., Andrus, J., \& Danielson, A.E. (2006). Mobility, Indexicality, and the Enregisterment of "Pittsburghese". Journal of English Linguistics, 34, (2), 77 - 104. doi: $\underline{10.1177 / 0075424206290692}$

Jones, B. (2016a). Gwent English: A comparative investigation of lexical items Tradition Today, 5, 20-34.

Jones, B. (2016b). Welsh English dialect. Sheffield, England: Bradwell Books

Jones, D. (1992). Preface. In D. Thomas, Under Milk Wood: A Play For Voices (pp vii-xiv). London: J.M. Dent \& Sons Ltd

Jones, G. (1968). The dragon has two tongues. London, England: J.M. Dent \& Sons.

Jones, S. (1979). Writers of Wales: Allen Raine. Cardiff, Wales: University of Wales Press

Juul, J. (2003). The game, the player, the world: Looking for a heart of gameness. Retrieved from https://www.jesperjuul.net/text/gameplayerworld/

Kapell, M.W. (2006). Eugenics, Racism and the Jedi gene pool. In M.W. Kapell and J.S. Lawrence, Finding the Force of the Star Wars franchise: Fans, Merchandise \& Critics (pp.159-173). New York, NY: Peter Lang. 
Karshner, R. \& Stern, D.A. (1990). Dialect monologues. Toluca Lake, CA: Dramaline.

Kerrigan, J. (2002). Special Features: Cast interviews. In Human traffic. [DVD]. London, England: Cinema Club

Kilgore, D.D (2003). Astrofuturism: Science, Race, and visions of Utopia in space. Philadelphia: University of Pennsylvania Press

Kirby, M. (2011, Jan 10). Merill: She's a Keeper. [Page 4]. Message posted to http://forum.bioware.com/topic/161075-merrill-shes-a-keeper/page-4 [accessed 2016, April 9]

Kortmann, B \& Lunkenheimer, K (eds.) 2013. The Electronic World Atlas of Varieties of English. Leipzig: Max Planck Institute for Evolutionary Anthropology. Retrieved from http://ewave-atlas.org [Accessed on 2017-03$15]$

Kozloff, S. (2000). Overhearing film dialogue. Berkeley: University of California Press . retrieved from http://hdl.handle.net/2027/heb.08123.0001.001.

Knight, S. (2003). A new enormous music: Industrial fiction in Wales. In M.W. Thomas, Welsh writing in English (ed.) (pp.47-90). Cardiff, Wales: University of Wales Press

Knight, S. (2004). A hundred years of fiction: writing Wales in English. Cardiff: University of Wales Press.

Krapp, G.P. (1925). The English Language in America. 2 vols. New York: Ungar.

Krapp, G.P. (1926). The Psychology of Dialect writing. The Bookman, July 1926, 522-527. Retrieved from: http://www.unz.org/Pub/Bookman-1926jul-00522

Kücklich, J. (2003). Perspectives on computer game philology. Games studies, 3 (1). Retrieved from http://gamestudies.org/0301/kucklich

Labov, W. (1972). Sociolinguistic patterns. Philadelphia: University of Pennsylvania Press.

Lambert, Wallace E., Hodgson, R.C., Gardner, R.C., \& Fillenbaum, S. (1960). Evaluational reactions to spoken languages. Journal of Abnormal and Social Psychology, 60, 44-51.

Langer, J. (2008). The familiar and the foreign: Playing (post) colonialism in World of Warcraft. In H. Corneliussen \& J. Rettberg (Eds.), Digital culture, play, and identity: A World of Warcraft reader (pp. 87-108). Cambridge: MIT Press. 
Lee, B. (2015, March 6). Miners and LGBT activists who inspired hit film Pride reunite. Retrieved from

https:/www.theguardian.com/film/2015/mar/16/miners-lgbt-activists-pridefilm-reunite

Leigh, P.J. (2011). A Game of Confidence: Literary dialect, linguistics, and authenticity (unpublished $\mathrm{PhD}$ thesis). The University of Texas at Austin: Austin, Texas.

Levenston, E.A. (1992). The Stuff of Literature: Physical Aspects of Texts and Their relation to literary meaning (google eBook). Albanu: New York Press.

Lewis, R. (2008). Wenglish: the dialect of the south Wales valleys. Talybont (Cer.), Wales: Y Lolfa.

Lewis. R. (2010). Wenglish, the dialect of the south Wales valleys, as a medium for narrative and performance. Unpublished thesis: University of Glamorgan

Lippi-Green, R. (1997). English with an accent : language, ideology, and discrimination in the United States. London: Routledge.

Livingstone, D. (2014). Special features: Making of featurette. In Pride [DVD]. United Kingdom: Pathé.

Llamzon, T.A. (1983). Essential features of new varieties of English. In R.B. Noss (ed.), Varieties of English in southeast Asia. Singapore:Regional Language Centre, 92-109

Lloyd, M. (2010). Rhymer, Minstrel Lady Mortimer and the power of Welsh words. In W. Maley \& P. Schwyzer (Eds.), Shakespeare and Wales: From the Marches to the Assembly (pp.59-73). Basingstoke, England: Palgrave Macmillan.

Lyall, S. (1995, May 28). The hardest part: Making the actors sound Welsh. Retrieved from: http://www.nytimes.com/1995/05/28/movies/film-thehardest-part-making-the-actors-sound-welsh.html

Macaulay, R.S. (1991). "Coz it izny spelt when they say it”: Displaying dialect in writing. American Speech. 66, 280-291.

MacWilliams, M. (2008). Introduction. In M. MacWilliams (Ed.), Japanese Visual Culture : Explorations in the World of Manga and Anime (pp.3-25). Armonk, NY: M.E Sharpe, Inc.

Maley, W. \& Schwyzer, P. (2010). Shakespeare and Wales: From the Marches to the Assembly. Basingstoke, England: Palgrave Macmillan.

Malin, S.D. (1965). Dialect in “Li'l Abner”. American Speech, 40, 229-232. 
Manning, S. (2014, March 29). Torchwood star Eve Myles keeping crossed for Series 5. Retrieved from https://tv.yahoo.com/news/torchwood-star-eve-myleskeeping-214500401.html

Mathias, R. (1987). Anglo-Welsh Literature. An Illustrated History. Bridgend: Poetry Wales Press.

McCafferty, K. (2005). William Carleton between Irish and English: Using literary dialect to study language contact and change. Language and Literature, 4, 329-362.

McCarthy, H. (2002). Hayao Miyazaki: Master of Japanese animation. Berkeley, CA:Stone Bridge Press.

McGuinness, P. (2009). Introduction to Lynette Roberts. In P. MacCarthy, Welsh Issue: Carpenters of Song, Mayfield, England: Agenda. Retrieved from http://www.agendapoetry.co.uk/documents/PatrickMcGuinnessonLynetteRoberts.pdf

McVeigh, T. (1999, Dec 5). How phoney was my Welsh valley. Retrieved from https://www.theguardian.com/uk/1999/dec/05/tracymcveigh.theobserver

Meecham-Jones, S. (2010). Erasure of Wales in Medieval Culture. In R. Kennedy \& S. Meecham-Jones (Eds.), Authority and subjugation in writing of Medieval Wales (pp.27-55). Basingstoke, England: Palgrave Macmillan.

Melchers, G. (2010). Southern English in writing. In R. Hickey Varieties of English in Writing: The Written word as linguistic evidence (pp. 81-99). Amsterdam: John Benjamins Publishing.

Meirion, D. (2007). It's Wales: Welsh cowboys and outlaws. Y Lolfa: Talybont, Ceredigion.

Mesthrie, R. (2002). Building a new English dialect. In R. Watts \& P. Trudgill (Eds.), Alternative histories of English (p.111 - 133). Oxon: Routledge.

Milojevic, I. \& Inayatullah, S. (2003). Future dreaming outside and on the margins of the western world. Futures. 35, 493-507

Morgan, C.D. (1886). Wanderings in Gower: a perfect guide to the tourist, with all the lays, legends, and customs, and glossary of the dialect $\left(2^{\text {nd }}\right.$ ed.). Swansea: The Cambrian.

Morgan, G. (1966). The Dragon's tongue. Cardiff, Wales: Triskell press.

Norris, N. (1973). Glyn Jones: Writers of Wales. Cardiff, Wales: University of Wales Press. 
Nitsche, M. (2008). Video game spaces: Image, play, and structure in 3D worlds. Cambridge: MIT Press.

Nuessel, F.H. (Jr) (1982). Eye dialect in Spanish: some pedagogical applications. Hispania, 65, 346-351.

Nutt, C. (2009, Mar 25). GDC: Level-5 CEO Akihiro Hino's keys to success. Retrieved from http://gamasutra.com/php-bin/news_index.php?story=22917

Owen, G. D. (1962). Elizabethan Wales: The Social Scene. Cardiff, Wales: University of Wales Press.

Painting, D. (1987). Writers of Wales: Amy Dillwyn. Cardiff, Wales: University of Wales Press.

Parker, M. (2007). Neighbours from Hell?: English attitudes to the Welsh. Y Lolfa: Talybont, Ceredigion.

Parry, D. (1977). The Survey of Anglo-Welsh Dialects, Vol.1, The South-East. Swansea: privately published by the editor.

Parry, D. (1979). The Survey of Anglo-Welsh Dialects. Vol 2, The South-West. Swansea: privately published by the editor.

Parry, D. (1999). A Grammar and Glossary of the Conservative Anglo-Welsh dialects of Rural Wales. Sheffield : National Centre for English Cultural Tradition

Parry, D. (2015). The traditional Anglo-Welsh dialects of rural Wales. (working title of Unpublished typescript).

Paulasto, H. (2014). Conceptions of Welsh English and the factors of time, space, and linguistic identity. [Powerpoint slides]. Retrieved from https://www.academia.edu/14736787/Conceptions_of_Welsh_English_and_t he factors_of time_space_and_linguistic_identity

Penhallurick, R. (1991). The Anglo-Welsh dialects of North Wales : a survey of conservative rural spoken English in the counties of Gwynedd and Clwyd. Frankfurt am Main: Peter Lang.

Penhallurick, R. (1994). Gowerland and its language. Frankfurt am Main: Peter Lang

Penhallurick, R. (2013). 'Welsh English'. In Kortmann, Bernd \& Lunkenheimer, Kerstin (eds.) The Electronic World Atlas of Varieties of English. Leipzig: Max Planck Institute for Evolutionary Anthropology. Available online at http://ewave-atlas.org/languages/5, Accessed on 2016-03-04.

Penhallurick, R. (2018). Studying dialect: Perspectives on the English Language. Basingstoke, England: Palgrave Macmillan. 
Perrins, D. (2000). This town ain't big enough for the both of us. In S. Blandford Wales on Screen (pp. 152-167 ). Bridgend, Wales: Seren

Phelpstead, C. (2011). Tolkien and Wales: language, literature and identity. Cardiff: University of Wales Press.

Philip, N. (1981). A Fine Anger: A Critical Introduction to the Work of Alan Garner. London, England: Collins.

Poor, N. (2012). Digital Elves as a Racial Other in video games: Acknowledgment and Avoidance. Games and Culture, 7 (5), 375-396.

Powell-Ward, J. (2003). Borders and borderline cases. In M.W. Thomas, Welsh writing in English (ed.) (pp. 91-119). Cardiff, Wales: University of Wales Press.

Powers, A.W. (1994). 'Gallia and Gaul, French and Welsh': comic ethnic Slander in the Gallia War. In F. Teague (ed.), Acting Funny: Comic Theory and Practice in Shakespeare's Plays (pp. 109-22). Cranbury, NJ : Associated University Presses.

Pikoulis, J. (Autumn 1996). 'Word of mouth cultures cease in cemeteries'. New Welsh Review, 34.

Pratchett, P. \& Briggs, S. (2004). The New Discworld Companion. London, England: Gollancz.

Preston, D.R. (1982). 'Ritin' fowklower daun 'rong: folklorists' failures in phonology. Journal of American Folklore, 95 (377), 304-326

Preston, D.R. (1983). Mowr Bayud Spellin': A Reply to Fine. Journal of American Folklore, 96 (381), 330-339

Price, K. (2010). Movie Big Font. Large Spacing pays homage to the student way of life. WalesOnline. Retrieved from http://www.walesonline.co.uk/lifestyle/showbiz/movie-big-font-largespacing-1924089

Priest, C. (2011). Diana Wynne Jones obituary. Retrieved from https://www.theguardian.com/books/2011/mar/27/diana-wynne-jonesobituary

Prior, N. (2017, August 3). Twin Town 20 Years on: it belched in people's faces. Retrieved from http://www.bbc.co.uk/news/uk-wales-40800777

Quaino, S. (2011). The intonation of Welsh English - the case of Ceredigion and Gwynedd (unpublished $\mathrm{PhD}$ thesis). Alpen-Adria-Universität Klagenfurt, Klagenfurt. 
Randolph, V. (1927). The Ozark dialect in fiction. American Speech, 2, 283-289.

Randall, D.B.J. (1960). Dialect in the verse of 'The Hoosier Poet'. American Speech, $35,36-50$.

Roberts, S.E. (2010). "By the authority of the devil": The operation of Welsh and English law in medieval Wales. In R. Kennedy \& S. Meecham-Jones (Eds.), Authority and subjugation in writing of Medieval Wales (pp. 85-98).

Basingstoke, England: Palgrave Macmillan.

Robins, T. \& Webster, C. (2000). Between nation and animation: Fear of a Mickey Mouse planet. In S. Blandford Wales on Screen (pp. 110-127). Bridgend, Wales: Seren.

Ryan, M. (2000). A Woman's place: women and film in Wales. In S. Blandford (Ed.) Wales on Screen (pp. 38-49). Bridgend, Wales: Seren.

Seyler, C.A. (1920). “"Stedworlango.” A study of the fee of Penmaen in Gower'. Archaeologia Cambrensis, 10, 134-158.

Short, M. (1996). Exploring the language of poems, plays and prose. London, England: Longman.

Shorrocks, G. (1996). Non-standard dialect literature and popular culture. In Klemola, J., Kyto, M., Rissanen, M. (eds.), Speech: Past and Present, (385411). Frankfurt am Main: Peter lang $\mathrm{GmbH}$.

Shorrocks, G. (2000). Purpose, theory and method in English dialectology: towards a more objective history of the discipline. In R. Penhallurick Debating dialect (84-107). University of Wales Press: Cardiff.

Sibley, B. (2013). The Hobbit, the Desolation of Smaug: Official Movie Guide. USA: Houghton Mifflin Harcourt.

Silverstein, M. (2003). Indexical order and the dialectics of sociolinguistic life. Language and Communication, 23, 193-229.

Smith, D. (1982). Writers of Wales: Lewis Jones. Cardiff, Wales: University of Wales Press.

Smith, S.B. (1987). “A Yorkshire burr": language in Shirley. Studies in English Literature. 1500-1900, 27, 637-645.

Smith, S. (2013, Feb 6). Interview: The Voice of Mr Drippy - Steffan Rhodri. Retrieved from http://www.godisageek.com/2013/02/interview-voice-drippysteffan-rhodri/ 
Stephens, M. (1997, July 23). Obituary: Ron Berry. Retrieved from http://www.independent.co.uk/news/obituaries/obituary-ron-berry$\underline{1252238 . h t m l}$

Stephens, M. (1999, Feb 15). Obituary: Meredith Edwards. Retrieved from https://www.independent.co.uk/arts-entertainment/obituary-meredithedwards-1071003.html

Sternglass, M.S. (1975). Dialect literature: positive reinforce for writing 'In' and 'Out' of Dialect. National Council of Teachers of English, 26, 201-204

Simpson, M.J. (1997). Interview: Julian Richards. Retrieved from http://mjsimpsonfilms.blogspot.co.uk/2014/04/interview-julian-richards-1997.html

Sinclair, N.M.C. (2003). The Tiger Bay Story. Cardiff, Wales: Dragon and Tiger Enterprises

Sinclair, N.M.C. (n.d.). A stroll through Cardiff bay; part 2 of 4 [Video]. Retrieved from https://www.youtube.com/watch?v=tqUirIo0bok

Sullivan, J.P. (1980). The validity of literary dialect: evidence from the theatrical portrayal of Hiberno-English forms. Language in society. 9, 195-219. Retrieved from http://www.jstor.org/stable/4167139

Sullivan, C.W. (1989). Welsh Celtic myth in modern fantasy. New York: Greenwood Press.

Tamasi, S. (2001). Huck doesn't sound like himself: consistency in the literary dialect of Mark Twain. Language and Literature, 10, 129-144.

Thomas, A. (1984). Welsh English. In: P. Trudgill (ed,), Language in the British Isles, Cambridge (pp.178-194). England: Cambridge University Press.

Thomas, E. (2013). House of America. Cardigan, Wales: Parthian. Original work published 1988.

Thomas, M.W. (1988). My People and the revenge of the novel. New Welsh Review, 1. Retrieved from https://www.newwelshreview.com/article.php?id=19

Thomas, M.W. (2003). 'Introduction'. In M.W. Thomas (Ed.), Welsh Writing in English. Cardiff, Wales: University of Wales Press.

Thomas, M.W. (2011). In the Shadow of the Pulpit: Literature and Nonconformist Wales. Cardiff, Wales: University of Wales Press.

Thomas, M. W. (2013). Margiad Evans and Eudora Welty: A Confluence of Imaginations. In K. Bohata \& K. Gramich, Rediscovering Margiad Evans: Marginality, Gender and Illness. Cardiff, Wales: University of Wales Press. 
Tolkien, J.R.R. (1981). Letter 144: To Naomi Mitchison. In H. Carpenter \& C. Tolkien (Eds.) The Letters of J.R.R. Tolkien (pp. 173-181). Hammersmith, England: HarperCollins.

Tolkien, J.R.R. (1983). English and Welsh. In C. Tolkien (Ed.) The essays of J.R.R. Tolkien: The Monsters and the critics, and other essays (pp. 162-197). Hammersmith, England: HarperCollins.

Toolan, M. (1992). 'The significations of representing dialect in writing'. Language and literature, 1 (1), 28-46.

Tucker, H.M. (1950). 'The Dialect speech of Gower'. Gower: Journal of the Gower society, 3, 26-29.

Tucker, H.M. (1951). Gower gleanings. Swansea: The Gower Society.

Tucker, H.M. (1957). My Gower. Neath: Rowlands \& Company.

Tucker, N. (2008, Feb 6). Dive deep into a troubled teenage mind and come up laughing. Retrieved from http://www.independent.co.uk/artsentertainment/books/reviews/submarine-by-joe-dunthorne-778478.html

Turner, R. (2013, July 8). Actor Luke Evans using his Welsh accent on-screen in latest The Hobbit film. Wales Online. Retrieved from http://www.walesonline.co.uk/whats-on/film-tv/actor-luke-evans-usingwelsh-6280625

Viaggiatore, I. (2003). Why villains in movies have English accents. Retrieved from http://news.bbc.co.uk/dna/place-lancashire/plain/A891155

Wales, K. (2001). A dictionary of stylistics ( $2^{\text {nd }}$ ed.). London, England: Longman.

Wales, K. (2010). Northern English in writing. In R. Hickey Varieties of English in Writing: The Written word as linguistic evidence (pp. 61-80). Amsterdam: John Benjamins Publishing.

Walpole, J.R. (1974). Eye dialect in fictional dialogue. College Composition and Communication. 25, 191-196. Retrieved from http://www.jstor.org/stable/357177

Walser, R. (1955). Negro dialect in Eighteenth-century American drama. American Speech, 30, 269-276.

Warner, C.D (1897). The people for whom Shakespeare wrote. Retrieved from https://archive.org/details/forwhomshakespea03124gut 
Welsh Language Act 1993. (c38) (U.K.). Retrieved from http://www.legislation.gov.uk/ukpga/1993/38/pdfs/ukpga_19930038_en.pdf

Welsh Language Measure 2011. (nawm1) (U.K.) Retrieved from http://www.legislation.gov.uk/mwa/2011/1/pdfs/mwa_20110001_en.pdf

Williams, E. (2016, Sept 8). Greatest Welsh Novels Revisited: Submarine. Retrieved from http://www.walesartsreview.org/greatest-welsh-novel-2-submarine-byjoe-dunthorne/

Williams, G. (1987). Recovery, Reorientation and Reformation : Wales c. 14151642. Oxford, England: University of Wales press.

Williams, K. (2013). Shiver me timbers! Pirate hero in new Assassin's Creed is a Welshman!. Retrieved from http://www.walesonline.co.uk/lifestyle/piratehero-new-assassins-creed-6074652

Williams, Q. E. (2012). The enregisterment of English in rap braggadocio: a study from English-Afrikaans bilingualism in Cape Town. English Today 28(2), 5459.

Williams, P.J. (1999). Racial Ventriloquism. Retrieved from http://www.thenation.com/article/racial-ventriloquism

Williams, T.L. (1970). Caradoc Evans. Cardiff, Wales: Welsh Arts Council.

Wolmark, J. (1994). Aliens and others: Science Fiction, Feminism and Postmodernism. Iowa City: University of Iowa Press

Wood, J. (2009). 100 American Independent Films ( $2^{\text {nd }}$ ed.). London, England: Palgrave Macmillan.

Woodbridge, L. (2009). In G. Taylor, \& J. Lavagnino, Thomas Middleton: The collected works (pp. 907-958). Oxford, England: Oxford University Press.

Wright, J. (1898-1905). The English dialect dictionary, Vol 1-6. Oxford: Oxford University Press.

Yamanaka, H. (2008). The Utopian "Power to Live" : The significance of the Miyazaki phenomenon. In M. MacWilliams (Ed.), Japanese Visual Culture : Explorations in the World of Manga and Anime (pp. 237-255). Armonk, NY: M.E Sharpe, Inc.

Zall, P.M. (1963). A hundred merry tales and other jestbooks. Lincoln, NE: University of Nebraska Press.

Zingg, G. (2013). Is there Hiberno-English on them?: Hiberno-English in Modern Irish Literature: The Use of Dialect in Joyce, O'Brien, Shaw and Friel. Bern, Switzerland: Peter Lang AG, International Academic Publishers. 


\section{$\underline{\text { Webography }^{37}}$}

Bandai Namco Games Europe (2012a). Ni No Kuni: Wrath of the White Witch PS3 - The Art of Studio Ghibli-5 (Behind the scene \#2). Retrieved from https://www.youtube.com/watch?v=YjrwfQH-P2c

Bandai Namco Games Europe (2012b). Ni No Kuni: Wrath of the White Witch PS3 - The music of Joe Hisaishi (Behind the scene \#3.) Retrieved from https://www.youtube.com/watch?v=YjrwfQH-P2c

Bioware forum (2011). Voice actors speculation and discussion (voice actors revealed) [Page 9]. Messages posted to http://forum.bioware.com/topic/168250voice-actors-speculation-and-discussion-voice-cast-revealed/page-9

Dragonage.bioware.com, n.d. Dragon Age II: The world, characters, Merill. Retrieved from http://dragonage.bioware.com/da2/world/characters/merrill/ [Accessed 9/5/16]

Edge Magazine, (2012, May 5). Localising Ni No Kuni for the west. Retrieved from http://www.edge-online.com/features/ni-no-kuni-wrath-white-witch/\#null

Facts About Wales, (N.D.) Retrieved from: http://www.wales.com/about-wales/factsabout-wales Accessed 15/2/2016

LionheadStudios (2011, Aug 5). Fable III: Inside Lionhead 3 The Cast. Retrieved from https://www.youtube.com/watch?v=4ynpmblbSN8.

Mobygames, (n.d.). Retrieved from http://www.mobygames.com/game/windows/star-wars-the-old-republic

Press Association (2013, December 13). Evans: I've introduced Welsh Bard. Retrieved from https://www.youtube.com/watch?v=WBptP-lfz0o

imdb, (n.d.:a). A run for your money awards. Retrieved from http://www.imdb.com/title/tt0041831/awards?ref_=tt_awd

imdb, (n.d.:b). Hedd Wyn awards. Retrieved from http://www.imdb.com/title/tt0104403/awards?ref_=tt_awd

imdb, (n.d.:c). Gadael Lenin awards. Retrieved from http://www.imdb.com/title/tt0106984/awards?ref_=tt_awd

imdb, (n.d:d). Erin Matthews. Retrieved from http://www.imdb.com/name/nm0560019/

\footnotetext{
${ }^{37}$ A list of websites referenced without attested authors.
} 
imdb, (n.d.:e). Mark Lewis Jones. Retrieved from http://www.imdb.com/name/nm0428765/

Star Wars wikia, n.d. Galactic Basic Standard. Retrieved from http://starwars.wikia.com/wiki/Galactic_Basic_Standard

StatsWales (2015a). National Level Population Estimates by Year/Age/UK Country https://statswales.wales.gov.uk/Catalogue/Population-andMigration/Population/Estimates/nationallevelpopulationestimates-by-yearage-ukcountry Accessed 15/02/2016

StatsWales, (2015b). Population Density by Local Authority Year https://statswales.wales.gov.uk/Catalogue/Population-andMigration/Population/Density/populationdensity-by-localauthority-year Accessed 15/02/2016

StatsWales, (2015c). Population Estimates by Local Authority Year https://statswales.wales.gov.uk/Catalogue/Population-andMigration/Population/Estimates/Local-Authority/populationestimates-bylocalauthority-year Accessed 15/02/2016.

Telegraph (2015). Sir Terry Pratchett, author - obituary. Retrieved from http://www.telegraph.co.uk/news/obituaries/11467719/Sir-Terry-Pratchettauthor-obituary.html

TimeOut (n.d.) Darklands review. Retrieved from: https://www.timeout.com/london/film/darklands

Youtube (2012). SWTOR: Captain Bryn pt1 (2012). Retrieved from https://www.youtube.com/watch?v=Aa4KRJoxhtQ

YouGov (2014). YouGov Survey Results. Retrieved from http://cdn.yougov.com/cumulus_uploads/document/iwkrmxbxyl/InternalResu lts_141128_accents_Website.pdf

Tenby Poisoner trailer (n.d.) Retrieved from https://www.youtube.com/watch?v=vo5NGOP9jZo 